\title{
ASSESSING SOIL CARBON AND SOIL QUALITY FOR SUSTAINABLE AGRICULTURAL SYSTEMS IN TROPICAL HILLSLOPE SOILS USING SPECTROSCOPIC METHODS
}

\author{
A Dissertation \\ presented to \\ the Faculty of the Graduate School \\ at the University of Missouri-Columbia \\ In Partial Fulfillment \\ of the Requirements for the Degree \\ Doctor of Philosophy \\ by \\ BUNJIRTLUK JINTARIDTH \\ Dr. Peter P. Motavalli, Dissertation Supervisor
}

December 2017 
The undersigned, appointed by the dean of the Graduate School, have examined the dissertation entitled

\section{ASSESSING SOIL CARBON AND SOIL QUALITY FOR SUSTAINABLE AGRICULTURAL SYSTEMS IN TROPICAL HILLSLOPE SOILS USING SPECTROSCOPIC METHODS}

presented by Bunjirtluk Jintaridth, a candidate for the degree of Doctor of Philosophy, and hereby certify that, in their opinion, it is worthy of acceptance.

Dr. Peter Motavalli

Dr. Keith Goyne

Dr. Robert Kremer

Dr. Frieda Eivazi

Dr. Kelly Nelson 


\section{DEDICATION}

This dissertation work is dedicated to my parents, Col. Bumrung and Dr. Ampai

Jintaridth, for their love and support for my decisions throughout my life. I thank my sister, Dr. Pornrut Jintaridth, and my brother, Dr. Suneth Jintaridth, for their love and support during my $\mathrm{PhD}$ degree. 


\section{ACKNOWLEDGEMENTS}

I deeply thank my major professor, Dr. Peter Motavalli, for providing me the opportunity to undertake this project, and for his continuous guidance, encouragement and friendship throughout my years in Columbia, Missouri. My special thanks also go to my graduate committee members, Dr. Keith Goyne, and Dr. Robert Kremer, for their time, advice, patience and critical comments on my research project. Dr. Frieda Eivazi and Dr. Kelly Nelson also provided strong support during my doctoral program.

My sincerest appreciation is also for the Royal Thai Government Scholarship, USAID and Virginia Tech University for its financial support through the Sustainable Agriculture and Natural Resource Management - Collaborative Research Support Program (SANREM CRSP) project, and to the Department of Soil, Environmental and Atmospheric Sciences (SEAS) for giving me the chance to improve my graduate education.

A deep appreciation to all my fellow SEAS graduate students for their kindness and support while taking classes together and working hard in the lab. I am also grateful to the undergraduate students from Bolivia, the Philippines and Indonesia, for helping me to collect valuable field information and for sending me relevant material and information during the course of my research.

My sincere appreciation is also expressed to the C2 Church members for their constant support and friendship and for giving me the opportunity to worship God throughout my years in Columbia. My deep love and gratitude to my dad, mom, brother and sister and also to my host family Shirley, Bob, Rob, and Renu Olson for their constant love and emotional support from United States. 


\section{TABLE OF CONTENTS}

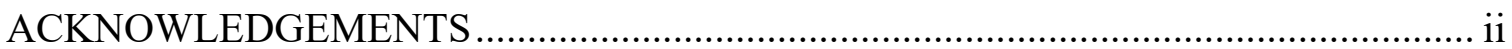

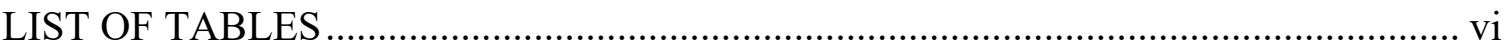

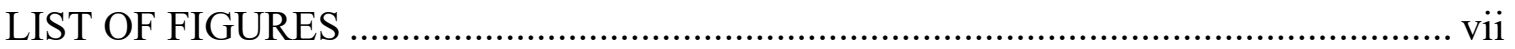

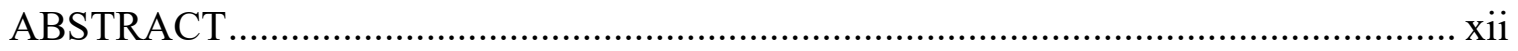

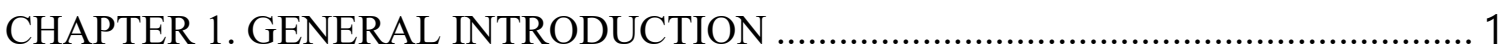

Definition of Soil Quality ………………............................................................

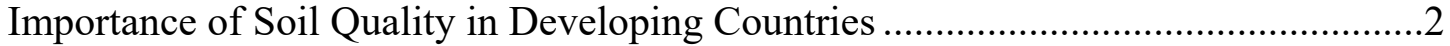

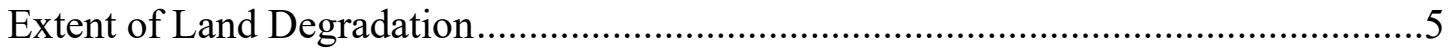

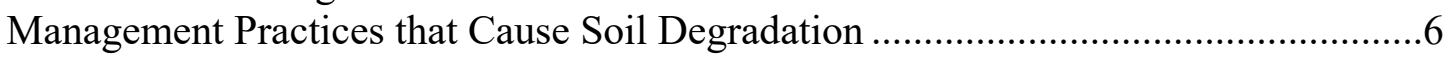

Measurement of Soil Quality ...........................................................................

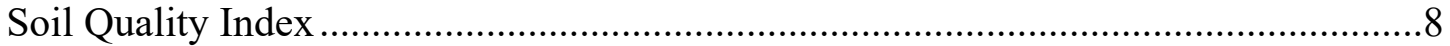

Soil Quality Kits for Field Assessment....................................................................

Problems with Measurement of Soil Quality ...........................................................12

Soil Testing Constraints for Soil Quality in Asia ........................................................14

Importance of Soil Organic Carbon Fractions as the Indicators of

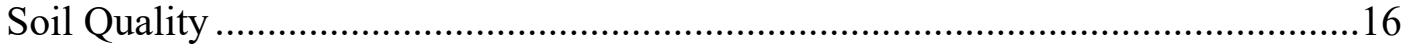

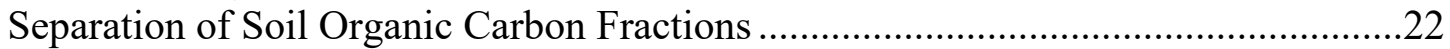

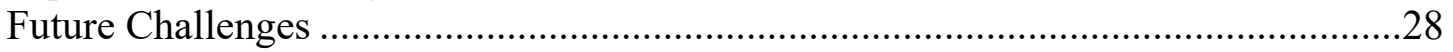

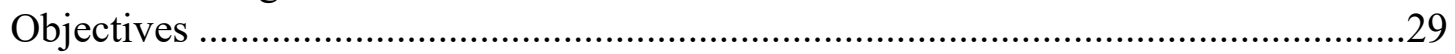

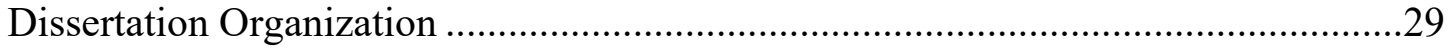

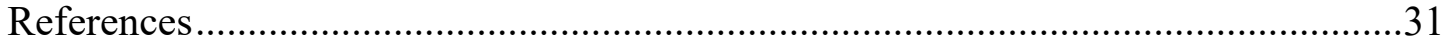

\section{CHAPTER 2. USE OF THE POTASSIUM PERMANGANATE TEST FOR}

DETERMINING ACTIVE SOIL ORGANIC CARBON

IN TROPICAL HILLSLOPE AGROECOSYSTEMS

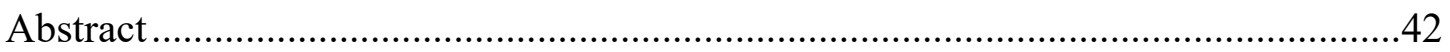

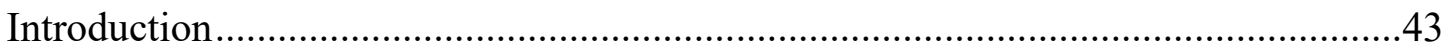

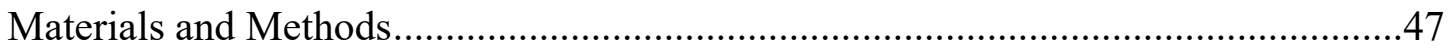

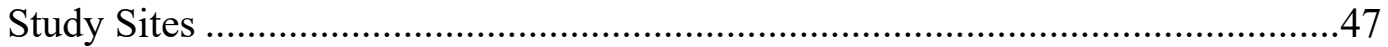

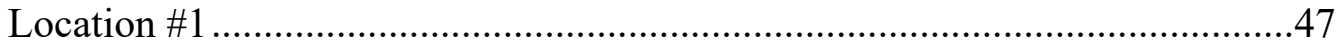

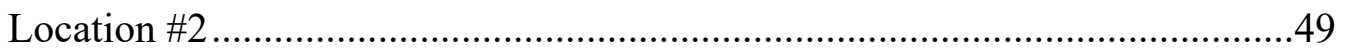

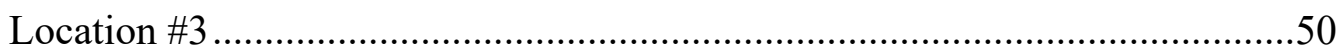

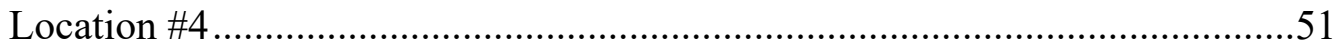

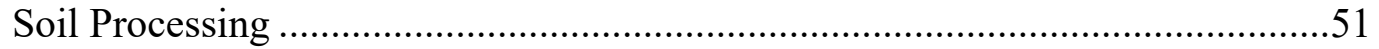

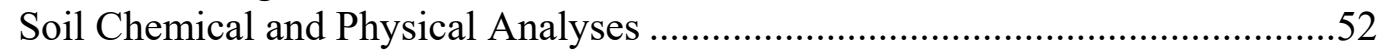

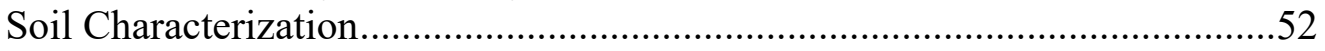

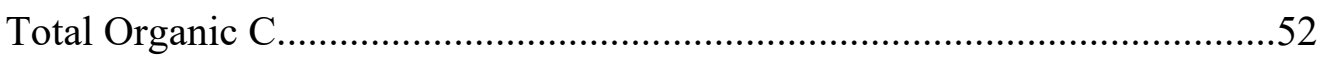




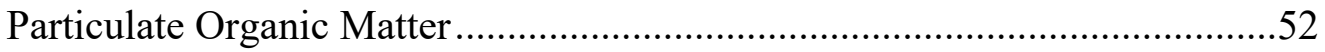

Potassium permanganate active $\mathrm{C}(\mathrm{MnOxC})$ analysis....................................53

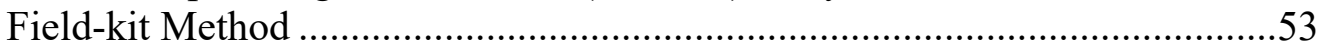

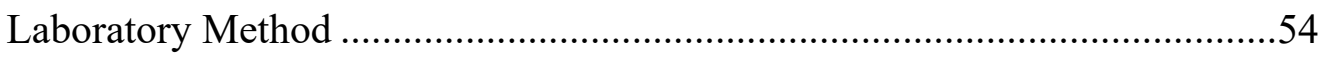

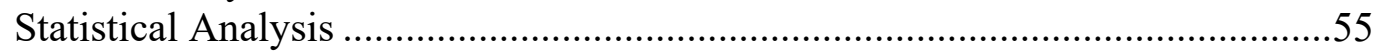

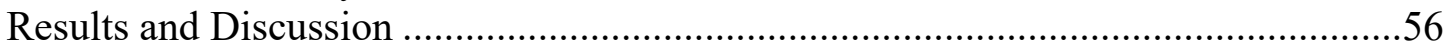

Responsiveness of $\mathrm{KMnO}_{4}$-Oxidizable C Test to Differences in

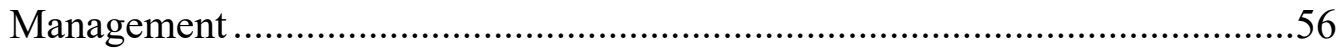

Comparison Between Laboratory and Field MnOxC Methods

Among the Field Locations ................................................................................62

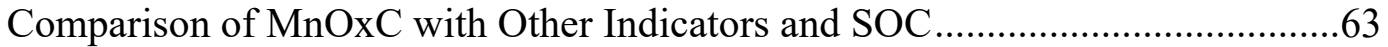

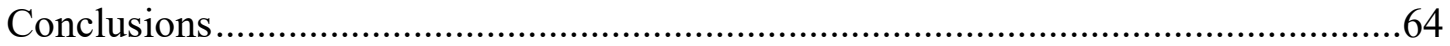

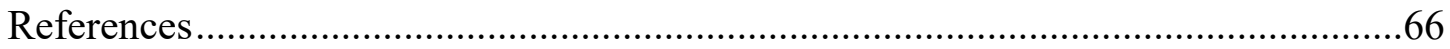

CHAPTER 3. USE OF VISIBLE NEAR INFRARED SPECTROSCOPY TO EVALUATE TOTAL SOIL ORGANIC CARBON AND SOIL CARBON FRACTIONS IN TROPICAL HILLSLOPE AGROECOSYSTEMS ....................................................79

Abstract

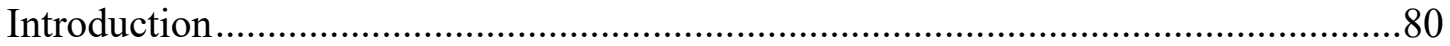

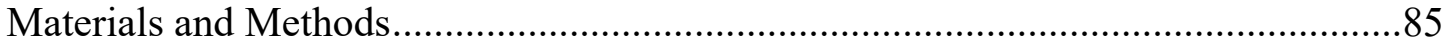

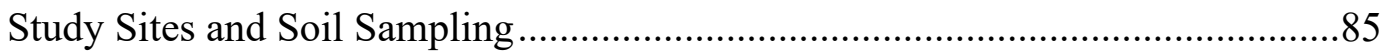

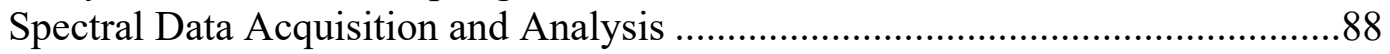

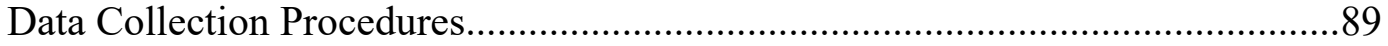

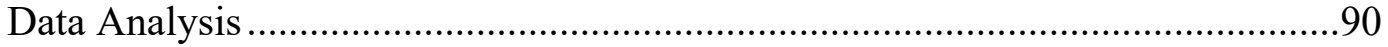

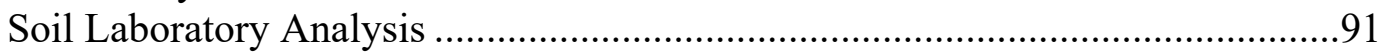

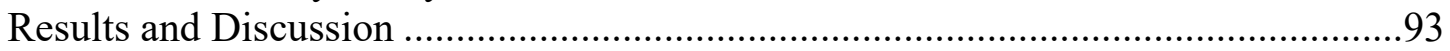

Evaluation of the MnOxC, POM-C, and SOC Analyses ......................................94

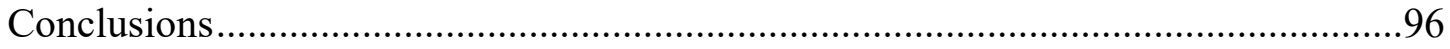

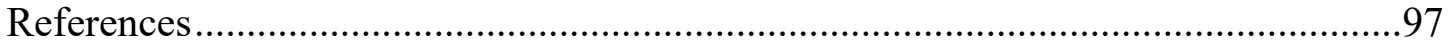

CHAPTER 4. USE OF MID-INFRARED DIFFUSE REFLECTANCE

TO ASSESS THE EFFECTS OF SOIL MANAGEMENT ON SOIL QUALITY IN TROPICAL HILLSLOPE

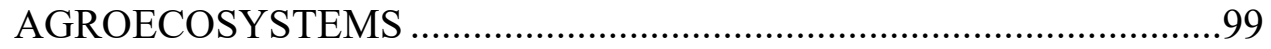

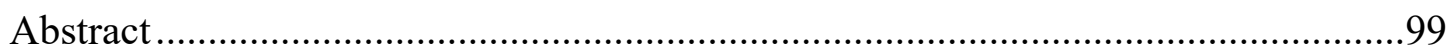

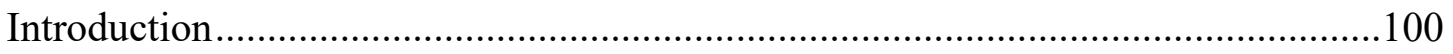

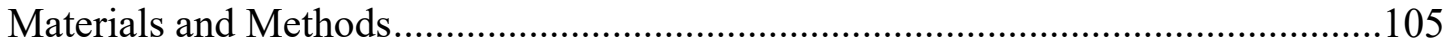

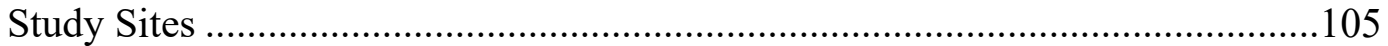

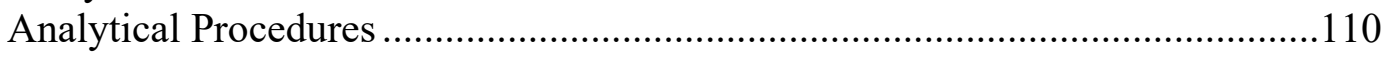

Humic Acid Extraction and Fractionation Procedure.....................................110

Sample Preparation and Analysis for DRIFT ..............................................111

Spectra Data Acquisition and Analysis.......................................................113

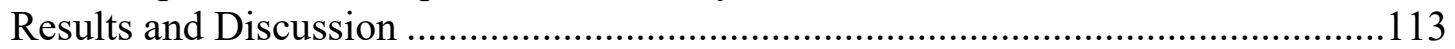


DRIFT Spectra Acquisition

DRIFT Spectroscopy and Comparison of Peak Ratio (O/R ratio) of Humic Acids Across Location....................................................................114

Location \#1 (Umala, Bolivia) .........................................................................114

Location \#2 (Cochabamba, Bolivia) ...............................................................115

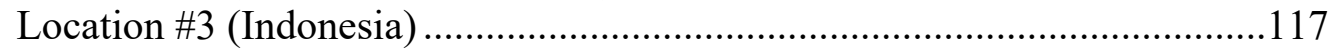

Location \#4 (Philippines)......................................................................120

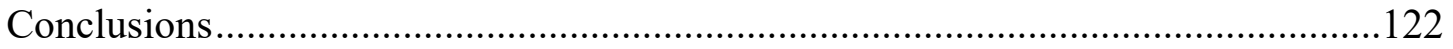

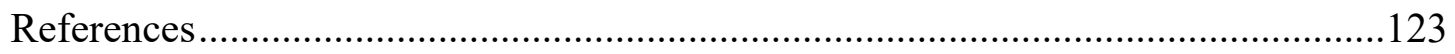

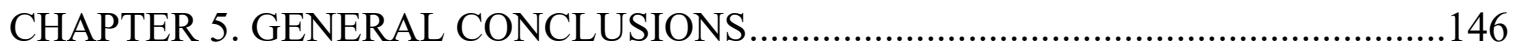

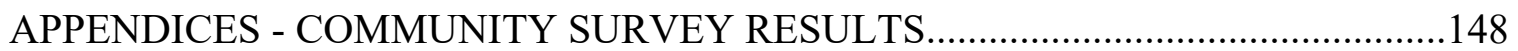

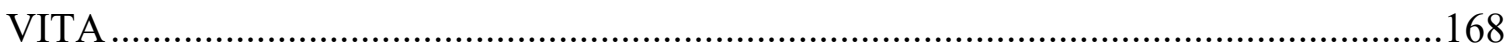




\section{LIST OF TABLES}

Table

Page

2.1 Selected soil properties due to different fallow length in

Umala communities at relatively lower elevation

2.2 Selected soil properties due to different fallow length in

Umala communities at relatively higher elevation

2.3 Linear regressions for soil active carbon $(\mathrm{MnOxC})$ determined

by the laboratory or field method and soil total organic carbon (SOC)

or soil particulate organic matter carbon (POM C) for soils at different

tropical locations.

3.1 Model evaluation statistics for partial least square analysis for predicting soil total organic $\mathrm{C}$ and selected organic $\mathrm{C}$ fractions using VNIR spectroscopy for each study location.

4.1 Approximate DRIFT infrared spectra peak assignments and occurrences in physical and chemical organic matter fractions

4.2 Ratios of peak heights intensity from Diffuse Reflectance Fourier Transform Infrared spectra (DRIFT) of humic acid fractions with different fallow lengths and locations in Location \#1 (Umala, Bolivia) .....129

4.3 Ratios of peak heights intensity from Diffuse Reflectance Fourier Transform Infrared spectra (DRIFT) of humic acid (HA) fractions from communities of different elevation with degraded land in Location \#2 (Cochabamba, Bolivia)

4.4 Ratios of peak heights intensity from Diffuse Reflectance

Fourier Transform Infrared spectra (DRIFT) of humic acid (HA)

fractions from communities of different elevation with non-degraded

land in Location \#2 (Cochabamba, Bolivia)

4.5 Ratio of peak heights (O/R ratio) from Diffuse Reflectance Fourier Transform Infrared spectra of humic acid in agroforestry fields in Location \#3 (Indonesia)

4.6 Ratio of peak heights (O/R ratio) from Diffuse Reflectance Fourier Transform Infrared spectra of humic acid in non-agroforestry fields in Location \#3 (Indonesia) 
4.7 Ratio of peak heights (O/R ratio) from Diffuse Reflectance Fourier Transform Infrared spectra of humic acid in the cultivated area at different landscape positions in Location \#4 (Philippines)

4.8 Ratio of peak heights (O/R ratio) from Diffuse Reflectance Fourier Transform Infrared spectra of humic acid in the non-cultivated areas at different landscape positions in Location \#4 (Philippines) 


\section{LIST OF FIGURES}

Figure

Page

2.1 Maps of area of study sites

2.2 The effect of fallow length on soil active $\mathrm{C}(\mathrm{MnOxC})$ in four communities in Location \#1 (Umala, Bolivia) situated at different elevations. San José de Llanga and San Juan Circa are at relatively low elevation( approximately 3,771 and

3,806 meters above sea level) and Kellhuiri and Vinto Coopani are at relatively high elevation (approximately 4,070 and 4,013 meters above sea level) .75

2.3 Comparison of soil active $\mathrm{C}(\mathrm{MnOxC})$ content in three communities of different elevations in Location \#2 (Cochabamba, Bolivia) with degraded and non-degraded soils. Within a bar, the numbers followed with the same letter are not significantly different to the LSD 0.05 value

2.4 Effects of manure applications on soil active $\mathrm{C}(\mathrm{MnOxC})$ for agroforestry and non agroforestry sites in Location \#3 (Indonesia).

Within a bar, the numbers followed with the same letter are not significantly different to the LSD 0.05 value.

2.5 The effects of landscape position in cultivated and non-cultivated areas on soil active $\mathrm{C}(\mathrm{MnOxC})$ for Location \#4 (Philippines) Within a bar, the numbers followed with the same letter are not significantly different to the LSD 0.05 value

2.6 A comparison between the field and laboratory methods for soil active $\mathrm{C}$ (MnOxC) determination in Location \#1 (Umala, Bolivia)

2.7 A comparison between laboratory and field methods for soil active $\mathrm{C}$ (MnOxC) determination in Location \#2 (Cochabamba, Bolivia)

2.8 A comparison between laboratory and field methods for soil active $\mathrm{C}$ (MnOxC) determination for Location \#3 (Indonesia)

2.9 A comparison between laboratory and field methods for soil active C ( $\mathrm{MnOxC}$ ) determination for Location \#4 (Philippines) .78

3.1 Representative soil VNIR reflectance spectra from the four study locations: Location \#1 (Umala, Bolivia); Location \#2 (Cochabamba, Bolivia);Location \#3 (Indonesia); and Location \#4 (Philippines)

$$
\text { - viii - }
$$




\section{Figure}

3.2 VNIR calibration curve for $\mathrm{MnOxC}$ for soil samples from Location \#1 (Umala, Bolivia). (RPD= Ratio of standard deviation to root mean square error of prediction; $\mathrm{R}^{2}=$ Coefficient of determination)

3.3 VNIR calibration curve for POM-C from Location \#1(Umala, Bolivia). $(\mathrm{RPD}=$ Ratio of standard deviation to root mean square error of prediction; $\mathrm{R}^{2}=$ Coefficient of determination)

3.4 VNIR calibration curve for SOC for Location \#1(Umala, Bolivia). $(\mathrm{RPD}=$ Ratio of standard deviation to root mean square error of prediction; $\mathrm{R}^{2}=$ Coefficient of determination)

3.5 VNIR calibration curve for $\mathrm{MnOxC}$ for soil samples from Location \#2 (Cochabamba, Bolivia). (RPD= Ratio of standard deviation to root mean square error of prediction; $\mathrm{R}^{2}=$ Coefficient of determination)

3.6 VNIR calibration curve for POM-C from Location \#2 (Cochabamba, Bolivia). (RPD= Ratio of standard deviation to root mean square error of prediction; $\mathrm{R}^{2}=$ Coefficient of determination)

3.7 VNIR calibration curve for SOC for Location \#2 (Cochbamba, Bolivia). ( $\mathrm{RPD}=$ Ratio of standard deviation to root mean square error of prediction; $\mathrm{R}^{2}=$ Coefficient of determination) 106

3.8 VNIR calibration curve for $\mathrm{MnOxC}$ for soil samples from Location \#3 (Indonesia). (RPD= Ratio of standard deviation to root mean square error of prediction; $\mathrm{R}^{2}=$ Coefficient of determination)

3.9 VNIR calibration curve for POM-C from Location \#3 (Indonesia). (RPD= Ratio of standard deviation to root mean square error of prediction; $\mathrm{R}^{2}$ = Coefficient of determination)

3.10 VNIR calibration curve for SOC for Location \#3 (Indonesia). ( $\mathrm{RPD}=$ Ratio of standard deviation to root mean square error of prediction; $\mathrm{R}^{2}=$ Coefficient of determination

3.11 VNIR calibration curve for $\mathrm{MnOxC}$ for soil samples from Location \#4 (Philippines). (RPD= Ratio of standard deviation to root mean square error of prediction; $\mathrm{R}^{2}=$ Coefficient of determination) 


\section{Figure}

3.12 VNIR calibration curve for POMC for soil samples from Location \#4 (Philippines). ( $\mathrm{RPD}=$ Ratio of standard deviation to root mean square error of prediction; $\mathrm{R}^{2}=$ Coefficient of determination)

3.13 VNIR calibration curve for SOC for soil samples from Location \#4 (Philippines). (RPD $=$ Ratio of standard deviation to root mean square error of prediction; $\mathrm{R}^{2}=$ Coefficient of determination)

4.1 Pre-experiment comparing the Mid-Infrared Diffuse Reflectance spectra of humic acid with and without hydrofluoric acid treatment of soils from a long-term cultivated plot from Sanborn Field (Plot 6) and an undisturbed prairie site in Missouri (USA)

4.2 Diffuse Reflectance Fourier Transform Infrared Spectra of humic acids due to in different fallow length $(0,8,10,20$ and 40 years $)$ in soils collected from Location \#1 (Umala, Bolivia)

4.3 Diffuse Reflectance Fourier Transform Infrared Spectra of humic acids due to in different fallow length in 4 communities in Location \#1 (Umala, Bolivia)

4.4 Diffuse Reflectance Fourier Transform Infrared Spectra of humic acids in degraded land in three communities at different elevations (Toralapa Baja (low land area), Waylla Puiru (relatively intermediate area) and Sanyacani (high land area) located in Location \#2 (Cochabamba, Bolivia)

4.5 Diffuse Reflectance Fourier Transform Infrared Spectra of humic acids in non-degraded land in three communities at different elevations Toralapa Baja (low land area), Waylla Puiru (relatively intermediate area) and Sanyacani (high land area) located in Location \#2 (Cochabamba, Bolivia) ......138

4.6 Comparing the ratio of peak heights intensity $(\mathrm{O} / \mathrm{R})$ of humic acids with degraded and non-degraded land in Location \#2 (Cochabamba, Bolivia). Within a bar, the numbers followed with the same letter are not significantly different to the LSD 0.05 value

4.7 Diffuse Reflectance Fourier Transform Infrared Spectra of humic acids in agroforestry area receiving different amounts of manure in Location \#3 (Indonesia)

4.8 Diffuse Reflectance Fourier Transform Infrared Spectra of humic acids in non- agroforestry area receiving different amounts of manure in Location \#3 (Indonesia) 
4.9 Comparing ratio of peak heights intensity $(\mathrm{O} / \mathrm{R})$ of HA under agroforestry, and non-agroforestry systems and different manure amendments in Location \#3 (Indonesia). Within a bar, the numbers followed with the same letter are not significantly different to the LSD 0.05 value.

4.10 Diffuse Reflectance Fourier Transform Infrared Spectra of humic acids in cultivated area at different landscape positions in Location \#4 (Philippines)

4.11 Diffuse Reflectance Fourier Transform Infrared Spectra of humic acids in non-cultivated area at different landscape positions in Location \#4 (Philippines)

4.12 Comparing ratio of peak heights intensity $(\mathrm{O} / \mathrm{R})$ of HA with different landscape positions in cultivated, and non-cultivated areas in Location \#4 (Philippines). Within a bar, the numbers followed with the same letter are not significantly different to the LSD 0.05 value 


\title{
ASSESSING SOIL CARBON AND SOIL QUALITY FOR SUSTAINABLE AGRICULTURAL SYSTEMS IN HILLSLOPE SOILS USING SPECTROSCOPIC METHODS
}

\author{
Bunjirtluk Jintaridth
}

Dr. Peter Motavalli, Dissertation Supervisor

\begin{abstract}
Soil quality is a concept that integrates physical, chemical, and biological components and processes of soil across landscapes. Identifying and developing appropriate methods to quantify and assess changes in soil quality are necessary for evaluating soil degradation and improving management practices. Many parameters that are associated with soil quality depend on soil organic matter (SOM) levels and composition. The objectives of this research were to: 1) conduct a literature review of soil quality assessment techniques to evaluate soil quality across a wide-range of environments and agricultural practices; 2) determine if some standard soil sampling and analytical protocols could be identified or developed to enhance soil quality comparisons across a wide range of environments around the world; and 3) assess the efficacy of spectroscopic-based (i.e. near-infrared, mid-infrared, and visible range) analytical methods to evaluate soil organic matter fractions and soil quality. To assess soil quality for sustainable agricultural systems in hillslope soils using spectroscopic methods, surface soil samples $(0-20 \mathrm{~cm})$ were collected from hillslope agricultural sites in Bolivia, the Philippines and Indonesia which had differences in length of fallow, levels of soil degradation, and cultivation by landscape position. To determine the efficacy of spectroscopic-based on visible range, the use of the potassium permanganate test $(\mathrm{MnOxC})$ for active organic carbon was studied.
\end{abstract}


The $\mathrm{MnOxC}$ test was generally responsive to a range of fallow lengths among different agricultural fields and communities in Umala Municipality in Bolivia. A major objective of fallowing agricultural fields in this region is to restore soil fertility in the field after cropping. This general increase in $\mathrm{MnOxC}$ with increased length fallowing may be due to inputs of residue and roots from regrowth of native vegetation after cropping in fallowed areas and possible manure inputs from sheep that generally graze these fallow areas. In addition, higher concentrations of $\mathrm{MnOxC}$ were generally observed in non-degraded soil compared to that of degraded soil in all sampled communities in Cochabamba, Bolivia. Comparisons of soil quality among agroforestry and nonagroforestry sites were studied near Bogor, Indonesia. Both agroforestry and nonagroforestry sites had been managed with different types and rates (low, medium, and high) of amendments including manure, compost and chemical fertilizer. Soil MnOxC was generally higher with increasing amounts of added animal manure and in agroforestry areas compared to that of non-agroforestry areas. A set of soil samples was collected along a hill-slope transect from the top to the bottom of agricultural valley on Mindanao Island in the Philippines. The transect across the landscape was divided into summit, shoulder, backslope, footslope and toeslope landscape positions. Soil MnOxC from cultivated fields areas at each landscape position were generally lower than noncultivated areas at similar landscape positions. Among the non-cultivated sites, soil $\mathrm{MnOxC}$ was the highest at the summit position and the lowest at the backslope positions while soil $\mathrm{MnOxC}$ among cultivated sites were relatively similar across the hill-slope transect. This comparison of the use of the soil MnOxC test to determine changes in active $\mathrm{C}$ among a wide range of environmental conditions, cropping systems and soil 
management practices among agroecosystems with hillslopes in tropical countries around the world indicates that the soil $\mathrm{MnOxC}$ test is a sensitive indicator to assess changes in active $\mathrm{C}$ with changes in crop and soil management. Several advantages to using this procedure include its ease of use that requires a minimal of training for the field method, its low relative cost and growing research results that facilitate interpretation of the test results. Therefore, this method has potential for supporting management decisions, and sustainable management of agricultural systems in tropical hillslope ecosystems.

The ability of visible/near-infrared (VNIR) spectroscopy to estimate soil organic carbon and carbon fractions from diverse soils in tropical hillslope agroecosystems around the world that were under different soil management and cropping systems was evaluated in this research. It was shown that VNIR spectroscopy could be an effective technique to estimate SOC and soil organic carbon fractions for a wide range of soils from tropical hillslope agroecosystems around the world. Several potential advantages of use of VNIR compared to conventional soil testing methods in developing countries are that it may allow for simultaneous evaluation of several soil properties and it can be done rapidly and possibly in the field.

Diffuse Reflectance Fourier Transform Infrared Spectroscopy (DRIFT) is considered to be one of the most sensitive infrared techniques for analyzing the structural composition of soil organic matter. The benefit of the DRIFT technique is the ability to characterize the functional group composition of heterogeneous materials with minimal sample preparation. Results showed that this method can be used to characterize the functional groups of heterogeneous soil organic materials and it may be a more direct method to determine changes in soil organic matter and soil quality caused by soil 
management practices than several other chemical and spectral techniques. The high resolution of the spectra and quantitative estimations of functional groups can be used to analyze soil organic carbon composition. Therefore, in future work this technique has great potential to be an accurate and simple method for helping to understand the changes in the composition of soil organic carbon due to soil organic management practices and to estimate changes in soil quality resulting from those practices in these hillslope agroecosystems. 


\section{CHAPTER 1 \\ GENERAL INTRODUCTION}

\section{Definition of Soil Quality}

Soil quality has been defined as the capacity of the soil to function, within natural or managed ecosystem boundaries and to sustain plant and animal productivity, to maintain or enhance water and air quality, and to support human and animal health (Karlen et al., 1998). Larson and Pierce (1994) and Doran and Zeiss (2000) also supported the concept that soil quality should be evaluated based on soil function. They defined soil quality as the capacity of soil to support diverse functions including those that sustain biological activity, diversity, and productivity; regulate and partition water and solute flow, filter and buffer, immobilize and detoxify organic and inorganic materials including industrial and municipal waste and atmospheric deposition; store and cycle nutrient and other elements, and provide support of socio-economic structures. Lal (2003) stated that soil quality is the fundamental foundation of environmental quality and is largely governed by soil organic matter (SOM) content, which is dynamic and responds to changes in soil management. Agricultural practices, such as tillage, could negatively affect soil quality. Soil tillage alters many soil physical properties, including bulk density, water holding capacity, and soil aggregation (Spedding et al., 2004). Degradation of soil quality through water and wind erosion is due to organic matter and nutrient depletion, increase in soil penetration resistance and soil acidity, and decreased soil microbial activity (Bezdicek et al., 2003).

Soil quality can be influenced by its inherent quality that is determined by factors of soil formation (i.e., climate, topography, biota, parent material, and time) and also its dynamic quality which is determined by soil properties that are influenced by human use 
and management decisions (Larson et al., 1991). These properties are dependent on land use or management practices. Sometimes the differing views of the definition of soil quality depend on the individual's background and relationship to the land. Some people have suggested that soil quality is simply related to the quantity of crops produced (Hornick, 1992). Others have emphasized the importance of demonstrating how soil quality affects seed and food quality or agricultural production (Hornick, 1992).

Surveys by Romig et al. (1995) and Sojka (1999) found that farmers characterized soils based on descriptive and qualitative properties by using direct value judgments, while scientists focus on the analytical and quantitative properties of soil and quantitative linkages between those properties and various functions in terms of distinct management or environmental considerations specific in soils. More recent efforts for implementation of soil quality assessment have been to develop a more systematic quantitative soil quality index that relies on soil physical, biological and chemical indicators that are appropriate for the region and cropping practice (Andrews et al., 2004; Gugino et al., 2009)

\section{Importance of Soil Quality in Developing Countries}

Agricultural production in developing and developed countries over the last 40 years has increased as a result of greater inputs and improved use of fertilizer, water and pesticides, new crop strains, and other technologies (David et al., 2002). The use of these management practices has generally increased the global per capita food supply, reduced hunger, and improved nutrition for humans and animals. However, to improve or enhance long-term agricultural production without major impacts on the environment, soil quality 
must be a concern, especially with increasing intensification of land use due to increased food demand for a growing world population (Harris, 1996).

Soil degradation is a major problem in both developed and developing countries, but developing countries have been particularly negatively affected by soil degradation in resource-poor regions (Lal and Reich, 2001). In Africa, around 55\% of the land is unsuitable for any kind of agriculture except grazing (Eswaran et al., 2001). Most of this marginal land consists of deserts, salt flats, dune and rock lands, and steep to very steep lands. The productivity of these areas has declined by $50 \%$ due to soil erosion and desertification. It was shown that yield reduction may range from 2 to $40 \%$, with a mean loss of $8.2 \%$ for the continent of Africa due to past soil erosion (Eswaran et al., 2001). Agriculture in sub-Saharan Africa is in crisis than any other region of the world (Borlaug and Dowswell, 1994). The low-input and -output systems of agriculture are still maintained on a large proportion of the land. Africa at current production levels is no longer able to feed its people. In addition, there are some associated problems of land degradation that are accelerated by low-input systems, and exceed the resilience threshold of soils. Because of many factors, including sustained droughts, poor farmers of Africa have few options today to enhance their soil quality and agricultural productivity. Oldeman (1994) indicated that around five million hectares of soil in Africa are degraded to a point where their original biotic functions have been fully destroyed.

In Asia, there has been a serious effort to match technology with resource conditions. Advancements in the development and use of high yielding cultivars have been accompanied by appropriate soil, water, and nutrient management. However, soil quality issues in Asia are complicated by the poverty, political and social instability, and 
high rates of weathering that occur throughout the region. Major threats to soil quality in this region are from salinity, erosion, and land pollution (Cheng et al., 1998).

South America has many areas where productivity is low due to poor soil quality, and erratic rainfall. People in the region adapted to climate changes expanding agricultural production into the highland areas when possible. These conventional agricultural practices in the region may contribute in the long-term to poverty, increasing rates of soil degradation, and lower food security (Lal and Reich, 2001).

Generally, continuous cropping and inadequate replacement of nutrients removed in harvested materials or lost through erosion and leaching can cause soil organic matter levels to decline, and thus affect soil quality (Wander, 2004). Soil tillage can increase speed decomposition of soil organic matter and the release of mineral nutrients. Erosion can be severe on steep slopes where windbreaks have been cleared and ground vegetation has been removed. The negative effects of land degradation on productivity can sometimes be compensated for by increased fertilization, irrigation, and disease control (Oldeman, 1994). Crop rotation, reduced tillage, cover crops, fallow periods, soil organic matter inputs, or balanced fertilizer application can help maintain and restore soil nutrients. From 1945 until the present, approximately 17 percent of vegetated land in the world has been degraded due to human-induced soil degradation resulting in a loss of agricultural productivity. This degradation is often due to erosion and shortened fallow periods as a result of poor fertilizer and water management practice and higher intensity of land use due to increased population (FAO/UNDP/UNEP, 1994). 


\section{Extent of Land Degradation}

Land degradation refers to negative changes in soil which are induced by natural, human and animal activities (FAO, 1984). One consequence of land degradation is a decreased potential of soils for productive use since crop yields are reduced due to insufficient nutrients and available water for plant growth among other potential reasons. Degradation may also cause decreased plant nutrient use efficiency. Improper land use and poor land management technologies are the most important factors leading to soil degradation (Johnson, 2007).

Degraded land can be rehabilitated through improved land management practices such as adding organic materials, proper fertilization, sound crop rotation, and good irrigation practices. ISCRIC (2004) reported that around 562 million hectares (38\%) of the global agricultural land area are degraded, $46.4 \%$ of soil decreased in productivity, and some have reduced biological functions. A third of all degraded land in Asia and a fifth of degraded land is in Africa. Over 15\% of soil can no longer be used for farming because its biological functions have been impaired and it would cost too much to restore them.

Over $50 \%$ of the soils that have been degraded by deforestation are situated in Asia, and around $15 \%$ are in South America where deforestation is the main cause of soil degradation. In Europe the amount of degraded land is around 38\%. In Africa, a total of $36 \%$ of soils have been degraded by overgrazing, and $37 \%$ of soils have been degraded by inappropriate land use are in Asia. In Africa, degraded land is around $25 \%$ and in North and Central America the amount of degraded land is which are around 58\% (ISCRIC, 2004) 
Human activities, such as irrigation and poor soil drainage, are the main cause of soil degradation. The spreading of chemical fertilizers and pesticides contributes to environmental problems through surface runoff. Depending on environmental conditions, overgrazing, use of heavy farming equipment, and tillage may destroy soil structure by causing soil compaction and decreasing soil organic matter, which may lead to a decrease in agricultural production (Barrow, 1991). In some urban areas, pollutants, such as heavy metals, can negatively affect soils, and can leave behind waste land with severely polluted soils (Raymon and Felix, 2011).

Water erosion is a land degradation problem which may cause a change in water quality, especially when soil particles are washed into water thus increasing their turbidity, nitrogen, and phosphorus content of runoff that may enter into water resources (FAO, 1984). Wind erosion has worsened in the continent of Africa due to overgrazing and soil tillage. Large amounts of soil particles leave the continent every year, and thus decrease soil fertility. Changes in soil structure in agriculture may makes it more difficult for carbon to be sequestered in soil, and conversion of forest land into crop land may reduce soil carbon storage and soil biodiversity (Hurni et al., 2006).

The challenge of preventing and rehabilitating degraded land requires technical, political, and social mobilization, including promoting favorable policy, along with encouraging and facilitating the participation of farmers and their organizations (Eswaran et al., 2001).

\section{Management Practices that Cause Soil Degradation}

Management practices that cause soil degradation and cause a decline in agricultural productivity account for about $85 \%$ of land degradation worldwide (Scherr, 
1999). Soil fertility decline refers to deterioration in soil's physical, chemical and biological properties that cause reduction in plant growth. Degradation in soil physical and chemical properties include changes in structure, aeration, water holding capacity, and changes in nutrient status and reduction in availability of macro and micronutrients.

Development of nutrient imbalances can cause increases in soil toxicities, such as toxic metals content, the presence of toxic and persistent xenobiotics, and acidification (Appenroth, 2010). Waterlogging is caused by over-irrigation and restricted infiltration of water into the soil and the presence of poor drainage. Salinization is caused by an accumulation of soluble salts in the soil. They occur through planning mistakes such as mismanagement of irrigation and poor pasture management, which can lead to overgrazing of pasture areas. There are some other types of land degradation, which include deforestation, and forest degradation. Other types of land degradation include soil destruction through mining activities, low input agricultural practices, urban and industrial encroachment on to agricultural land and global climate change. Climate change causes modifications in general atmospheric circulation, and brings about changes in rainfall patterns or extreme weather occurrences (e.g., drought or flooding) (Eswaran, 1993; Oldeman et al., 1994; Lal and Reich, 2001).

\section{Measurement of Soil Quality}

Soil quality is a concept that integrates the physical, chemical, and biological components and processes of soil interconnected with landscapes (Karlen et al., 1997). Identifying and developing appropriate methods to quantify and assess changes in soil quality are essential for evaluating the extent of soil degradation and the effectiveness of improved management practices. Poor soil quality is a major concern in Asia, Africa and 
South America because it leads to declining agricultural productivity, poverty, and food insecurity (Eswaran et al., 2001). In addition, a fast growing population requires growth in agricultural output many of the parameters or factors that measure and are associated with soil quality are often dependent on soil organic matter (SOM) levels and composition (Murage et al., 2000).

Soil quality is an assessment of the capacity of the soil to perform its functions (e.g., for growth of crops) and how well those functions will be preserved for future use. It cannot be determined by measuring only a single outcome by itself, such as by crop yield or water quality (Doran et al., 1994; Garlynd, et al., 1994). Soil quality cannot be measured directly, so it is evaluated by using a combination of selected soil biological, chemical and biological indicators. Indicators are measurements of the properties of soil or plants that would be sensitive to how well the soil can perform a certain function. They can also be visual features or some morphological characteristics of plants. The selected indicators should be easy to measure, low-cost, rapid, and accurate. They should be able to determine changes in soil status that affects soil functions, be accessible to many users and possibly be adapted for field assessments (Ditzler and Tugel, 2002). Indicators of soil quality can be assessed by qualitative or quantitative techniques. After measurements are collected, they can be evaluated by looking for patterns and comparing results to measurements taken at a different time or in different fields.

\section{Soil Quality Index}

There has been an interest in soil and land quality and development of a concept that would be useful for improving soil management practices (Karlen et al., 2003). Alexander (1971) suggested developing an 'SQ criteria' in reference to agriculture's role 
in environmental improvement. Warkentin and Fletcher (1977), Swift et al. (2004), and Sanchez et al. (2003) also introduced the concept of soil environmental and fertility management for intensive agriculture. The concept of soil quality was developed to describe the fitness of soils to perform specific or multiple ecosystem functions. This approach contrasts with the traditional approaches that focused solely on productive functions of soil.

There are numerous ways to evaluate soil quality. These indicators generally describe specific soil properties by physical, chemical and biological properties, and soil quality assessments often rely on them. Physical indicators measure the size, stability, and arrangement of the soil particles and soil pore space. These properties directly influence water relations, gas exchange, resistance to degradation, and root growth. Chemical indicator, include current nutrient status, organic matter level, $\mathrm{pH}$, salinity, and cation exchange capacity. Biological indicators can include measurements of the type and amount of microorganisms or their activity, such as respiration, and enzyme activity (Sanchez et al., 2003).

The soil quality index (SQI) provides an assessment of the potential impacts of changes in soil management (Amacher, 2007). It also integrates measured soil physical and chemical properties into a single parameter that can be used as an assessment of overall fitness of the soil for the particular soil function. The SQI may also be an indicator of the potential for soil quality to change because of the influence of environmental stressors such as atmospheric deposition or changes in global cycles (Fisher, 1995; USDA, 2003).

One example of use of SQI is a study by O'Neill et al. (2005) that compared soil 
quality at 0-10 and 10-20 cm soil depths. Soil samples were analyzed for sample weight, bulk density, water content, course fragment content, water and salt $\mathrm{pH}$, carbon (total organic and inorganic C), and total nitrogen (N). The SQI was calculated based on the sum of individual soil property index values. After analysis, it was found that samples from the 10-20 cm soil cores tended to have lower SQI levels than the $0-10 \mathrm{~cm}$ soil cores. The 10-20 cm soil cores tended to have higher bulk density and lower organic carbon and nitrogen levels than the $0-10 \mathrm{~cm}$ soil cores which skewed the SQI levels to lower numbers (O’Neill et al., 2005).

In general most people are interested in more than one function and thus indicators that access several functions are helpful. The use of SQIs is important for farmers, land managers and also for linking science with practice in the assessment of sustainability of management practices (Doran et al., 1999). In addition, an understanding of community perceptions and acceptance of proposed SQI methods is important for long-term research activities and possible future community adoption of an SQI method that could be used for developing sustainable agricultural management practices.

\section{Soil Quality Kits for Field Assessment}

In many rural areas around the world, access to soil testing laboratories is limited and the cost of soil analysis is relatively high for resource-poor farmers (Janssen et al., 1990). In additional the turn-around time for laboratory analysis may be too long for timely management decisions in the field. Portable soil quality test kits have been developed to permit rapid and relatively inexpensive assessment of simple in-field measurements of soil physical, chemical and biological properties and numerous soil characteristics recognized as basic indicators of soil quality (USDA, 1998) 
A field test kit refers to any suite of in-field soil tests conducted by land managers agricultural or environmental professionals to provide semi-quantitative data. Laboratory assessments are based on indicators requiring more specialized equipment and more precise measurement than possible with field test kits, such as microbial biomass carbon (Nelson and Sommers, 1975). Normally, all studies evaluating these kits have been conducted to determine the accuracy and precision of indicator measurements contained in the field soil quality test kit compared to standard laboratory analyses. Repeatability and overall variation of some kit measurements have been found to be similar to laboratory measurements (Craig and Tugel, 2002).

The purpose in developing the USDA soil quality test kit was to provide farmers with a tool that would be inexpensive, provide rapid results and would also be simple to use (Craig and Tugel, 2002). From the farmer's perspective, the tests should be meaningful in the context of their understanding of soils and related processes. The resulting product for farmers would facilitate recording observations and then assessing, comparing, and monitoring soil quality on their farms to help guide in future management decisions. From the researcher's perspective, the tests should be reliable, have an acceptable range of accuracy, and be interpretable (Sarrantonio et al., 1996). Therefore, the approach for assessing soil quality by test kit is well suited for trained professionals who can collect samples, conduct tests, interpret results, and make recommendations for management changes that will lead to improved soil quality.

The USDA soil quality test kit measures several soil physical, chemical, and biological properties. For example, physical properties addressed by the kit include bulk density, water content, infiltration rate, aggregate stability, slaking, and morphological 
estimations. Biological properties measured include soil respiration and earthworm populations. Soil chemical properties measured include $\mathrm{pH}$, electrical conductivity (EC), and soil nitrate levels The EC levels of the soil and water is a good indication of the amount of nutrients available for crops. Not all parameters have equal relevance to all soils and situations. The EC test may not be useful where salinity is not a problem. However, soil EC can be changed over the growing season because of excessive fertilizer applications (USDA, 1999). For a minimum data set of soil properties, some from each of the three soil components are selected based on their ability to indicate the capacity of the soil to function for a specific land use, climate, and soil type. Indicators in the USDA soil quality kit have been selected primarily for agricultural soil quality assessments. The kit can be used as a screening tool to know the general trend or direction of soil quality. Proper use of the kit and interpretation of results depends on the selection of the appropriate indicators and techniques for measuring each of the field indicators (Seabold et al., 1997).

Soil quality assessment with the USDA kit can be done in several ways. For example, measurements can be taken periodically over time to monitor changes or trends in soil quality as affected by soil management. Measured values can be compared to a standard or reference soil condition, and side-by-side comparisons of different soil management systems or with natural systems can be made to determine their relative effects on soil quality (Doran et al., 1999). It can also be used in problem areas, such as small areas where crop stands are poor within a field (Larson and Pierce, 1991).

\section{Problems with Measurement of Soil Quality}

Riley (2001) reported that tests to monitor air and water quality should be 
standardized and widely adopted internationally. However, no standardized SQ tests exist currently, despite the large proportion of land area or soils that have been degraded (Winder, 2003). The World Soils Agenda developed by the International Union of Soil Scientists (IUSS) mentioned that it is necessary to establish international SQ standards. These could be useful for agricultural research and extension agencies, non-governmental organizations, governments and farmers to better understand, implement and monitor sustainable soil management practices (USDA, 1999). The integrative SQ measurements are soil physical, biological and chemical conditions. They would be accomplished by use of SQ indicators that represent soil processes relevant to soil functions and provide information that is useful for practical soil management (FAO, 2005).

Researchers have developed practical tools to assess how management practices affect soil quality and ecosystem function (FAO, 2005). They found that because dynamic soil quality indicators vary widely with soil, universal calibration of soil quality indicators is not generally possible. Instead, comparative data for interpretation should be collected that includes long-term measurement of indicators from the same site or soil type, laboratory characterization data from Natural Resources Conservation Service (NRCS) databases, or published research results (USDA, 1998). In addition, the practical tools for soil quality assessment should be accurate, simple to use, and have standards and guidelines for interpretation. Because the constraints for a farmer are different from those of a researcher and opinions are mixed on which indicators or suites of indicators are the most useful, researchers have proposed a wide range of soil quality assessment methodologies. Each methodology has a different level of accuracy, appropriate spatial scale, and intended use (Arshad et al., 1996; Doran et al., 1996). 


\section{Soil Testing Constraints for Soil Quality in Asia}

In general, soil testing involves four distinct phases: sample collection, extraction or digestion and nutrient determination, interpreting the analytical results, and providing fertilizer recommendations (Garfield, 1991). Routine soil tests for agricultural production purposes primarily focus on essential primary macronutrient mineral elements that are supplied by commercial fertilizers, such as nitrogen $(\mathrm{N})$, phosphorus $(\mathrm{P})$, and potassium (K). Depending upon the soil resources, soil tests are also conducted for secondary macronutrients, such as calcium (Ca), magnesium (Mg), and sulfur (S) (Taylor, 1987).

In more developed countries of the Asian and Pacific regions, such as South Korea and China, overuse of chemical fertilizer is a common problem. Another problem is that fertilizer applications are often imbalanced in the plant nutrients that are applied. As a result, the soil nutrient status may be excessively high which can lead to toxicity or deficiencies of other nutrients in plants. For example, excessive $\mathrm{N}$ fertilizer application, may increase vegetative growth, and result in poor flowering and fruit production. Also applying excessive $\mathrm{N}$ to rice may cause rice blast. An effective soil and plant testing program based on a foundation of soil fertility research can help to diagnose these problems. However, the cost of soil testing is relatively high in relation to farm incomes in Asia, where normally soil testing for small-scale farmers is supported by government funding. In general, the service is either free to the user or heavily subsidized (Delavalle, 1992; FAO/ UNDP/ UNEP, 1994).

Important stages of establishing a soil testing service consists of determining appropriate extractants for benchmark agricultural soils, developing interpretative ranges for each soil test based on crop yield response and conducting field trials to establish 
research-based fertilizer recommendations. In most countries in Asia, the focus is generally on rice production. Recommendations for other crops are developed later. In Indonesia, a national program initiated in 1970 conducted soil testing and soil surveys to measure soil quality. The results served as the basis for fertilizer recommendations, and also for monitoring fertilizer quality. Accuracy and flexibility may be improved by the use of expert systems. Because the average farm size in Indonesia is only 0.5 hectare and farm income is low, small-scale farmers are generally not able to afford the cost of soil testing (FFTC, 2009).

In Taiwan, soil diagnosis is operated by the Taiwan Agricultural Research Institute (TARI) and the various district agricultural improvement stations. Soil samples are collected by farmers and extension staff, and sent to TARI for analysis. The interpretation of the results and fertilizer recommendations are computerized. The recommendation sheets are sent back to the district stations, and after confirmation are distributed to farmers. In Taiwan, this soil testing service is free of charge to farmers (FFTC, 2009).

In Korea, soil testing is carried out by county agricultural research centers under the Provincial Governments. The National Institute for Agricultural Science and Technology (NIAST) has also developed an on-line soil information system, which provides detailed soil management information using GIS technology via the Internet. This technology gives farmers more information such as the fertility status of their farm, the management history, the soil type, and fertilizer recommendations, as well as recommendations for land use. However, inefficient testing methods often cause a considerable time delay between sending in the samples and receipt of the soil test 
results. This means that the results often cannot be used as a guide for fertilizing the growing crop (FFTC, 2009).

Thailand uses mobile soil testing laboratories for its rural soil testing program. Agricultural extension professionals visit villages in rural areas, analyze soil samples, and then make fertilizer recommendations. The program is operated by the Land Development Department (LDD, 2009). Farmers need information about the fertilizer requirements for the particular crops and soil types of their farms. Therefore, it is very important to teach farmers to take proper soil samples because if the sample is not taken properly, all subsequent analysis may not be useful. Farmers are taught how to take soil sample, and how to process them before they are tested. On the day when the mobile laboratory is scheduled to visit their village, farmers take their soil samples to the van at some central point, such as the local temple or school. While farmers are waiting for the samples to be analyzed, staffs members take the opportunity to educate farmers about soil testing and fertilizer use (LDD, 2009).

\section{Importance of Soil Organic Carbon Fractions as the Indicators of Soil Quality}

Soil organic matter (SOM) is that fraction of the soil composed of living cells and tissues of soil organisms, including substances from plant roots and soil microorganisms in various stages of decomposition (Edwards et al., 1999). Additions of organic materials to soil affects soil biological, physical, and chemical properties because of its effects on increasing SOM. Soil organic matter in the form of humus enhances nutrient availability.

Organo-mineral complexes in SOM formed with ions, such as $\mathrm{Fe}^{3+} \mathrm{Cu}^{2+}, \mathrm{Zn}^{2+}$, and $\mathrm{Mn}^{2+}$, will make them more available for plant uptake (Blair et al., 2003).

Soil organic matter influences many soil properties including infiltration rate, 
bulk density, aggregate stability, cation exchange capacity, and biological activity, all of which are related to soil functions. Therefore, SOM content is frequently identified as a primary attribute for soil quality. Soil organic matter serves as a slow-release reservoir for plant macronutrients (especially nitrogen) and also aids in the supply of plant micronutrients. It facilitates the infiltration of water and air into the soil, and increases water retention by the soil (Duxbury et al., 1989). Over time, increases in SOM can lead to a larger and more diverse population of soil organisms. During the decomposition process, organic material is broken down which released nutrients. This material also acts to bind soil particles into aggregates and improve water-holding capacity of soil.

There are relationships between soil quality and organic matter. Soil quality can be connected to organic matter level because SOM affects the chemical and physical properties of the soil and its overall quality. A highly productive soil will produce more total biomass than a less productive soil. In the long term if much of the biomass remains in the field, soil in that area is likely to have a higher SOM content than a less productive soil. However, the unproductive soils can be improved with large additions of organic matter to build soil quality (Wallace, 1994). The composition and breakdown rate of SOM affects the soil structure and porosity, water infiltration rate, soil moisture holding capacity, diversity and biological activity of soil organisms, and plant nutrient availability.

Many of the parameters and factors that are measured and associated with soil quality are dependent on SOM levels. For example, intensive tillage will cause SOM levels to decrease through accelerated decomposition (Wiermann et al., 2000). Conservation tillage can help decrease loss of SOM levels. It was found that increasing 
surface SOM levels with conservation tillage is one way to increase crop yields. Many common agricultural practices, especially disc-tillage and vegetation burning, accelerate the decomposition of soil organic matter and leave the soil susceptible to wind and water erosion (Edwards et al., 1999).

The levels of SOM are a function of organic matter inputs (e.g., residues and roots) and litter decomposition as well as environmental factors, such as soil moisture, temperature and aeration (Christensen, 1992). Conventional land use practices and farming systems tend to decrease soil nutrient levels and reduce SOM levels through crop and residue removal and inadequate efforts to replenish nutrients and restore soil quality. This decline continues until management practices are improved or until a fallow period allows a gradual recovery through natural ecological processes (Schutter and Dick, 2002).

Best management practices (BMPs) enable farmers to maintain a balance in nutrient and organic matter supply in order to restore soil resources which would help to maximize the retention and recycling of organic matter and plant nutrients and to minimize environmental losses caused by leaching, runoff and erosion. Pennock et al. (1994) assessed soil redistribution in landscapes with different cultivation histories and results showed that SOM was the major soil quality indicator. Some other studies have characterized soil quality in different farming systems and observed that the benefits of frequent additions of crop residues improve soil quality and SOM in particular (Boehm and Anderson, 1997).

Cao et al. (1994) assessed the cumulative effect of soil erosion and redistribution under intensive potato production and found that both soil loss and gain were related to 
SOM. Gregorich et al. (1998) reviewed the relationship between soil erosion and deposition processes on the distribution and loss of SOM using the Century Model, a well validated computer simulation model. Arshad and et al. (1996) identified several soil physical and chemical properties that could serve as attributes of soil quality, such as the ability of the soil to store and transmit liquids, solutes, gases, and heat. Soil organic matter regulates nutrient supply to plants and microbes, soil moisture, and long-term C storage.

Soil organic matter is a heterogeneous, dynamic substance that varies in $\mathrm{C}$ and $\mathrm{N}$ content, molecular structure, decomposition rate, and turnover time (Oades, 1988) and when the pool size of SOM is considered, it is found that there was a negative relationship between pool size and decomposition rate where the smallest SOM pools decomposed most rapidly (Jenkinson, 1990; Parton et al., 1988; Smith et al., 1997). Addition of organic materials to the soil, in the form of crop residues or organic amendments, increased low-density macroorganic matter, which can represent up to 45 percent of total SOM (Carter et al., 1998; Kay, 1998).

Soil organic matter contains diverse organic constituents. Soil total organic carbon (SOC), the dominant elemental constituent of SOM, is more commonly measured and reported in scientific literature. In general, SOC varies across landscapes, soil types and climatic zones. It is characterized by high levels of $\mathrm{C}$ in recalcitrant or humified forms. Small changes in SOC resulting from changes in soil management are often difficult to measure. Proper management of SOM is central to sustainable agriculture. Many researchers have recognized SOM as an important indicator of soil quality and 
health. Therefore, it is important to maintain proper levels of SOM to sustain soil productivity (Greer et al., 1996).

An approach to evaluate the impact of agricultural management of SOM dynamics is to separate SOM into pools, based on differences in biological decomposition rates (Wander et al., 1994). Changes in labile fractions of SOC provide an early indication of soil degradation or improvement in response to management practices. The labile fractions of SOC often termed the active soil C pool, can be distinguished from the bulk of SOC which belongs to a highly recalcitrant or passive C pool (Gregorich et al., 1996). Fractions of SOC that are thought to represent the active $\mathrm{C}$ pool, have served as sensitive indicators of changes in management-induced soil quality (Islam and Weil, 2000). The labile $\mathrm{C}$ fraction has been recognized to be an important soil nutrient reservoir and has been recommended as a fertility index (Wander et al., 1994).

Most simulation models divide SOM into three C pools: a labile pool (turnover time of several years), an intermediate pool (turnover time of several decades) and a stable C pool. For example, the CENTURY model is a three-pool exponential decomposition SOM model (Parton et al., 1987). The lability of SOM is defined as the ease and speed with which SOM is decomposed by microbes and depends on both chemical recalcitrance and physical protection from microbes. Chemical recalcitrance can be explained by high molecular weight, irregular structure, and/or aromatic structures (Krull et al., 2003).

Soil organic matter can be vulnerable to microbial degradation due to low chemical recalcitrance of its components and a lack of stabilization onto clay mineral surfaces (Krull et al., 2003). Both labile and intermediate quantities of SOM are sensitive 
to land management, especially in agricultural areas, which reduces inputs to SOM through removal of plant biomass (Vityakon et al., 2000). Tillage also increases outputs of SOM through physical disturbance of soil structure and erosion which exposes organic matter to oxidation by microbes. To more fully understand the response of SOM dynamics to changes in tillage and other soil management actions, the sizes and turnover times of different SOM pools must be measured accurately and consistently (Six et al., 2000).

Active SOM refers to a heterogeneous mix of living and dead organic materials that are readily circulated through biological pools. It is a major soil nutrient reservoir. The balance between decay and renewal processes in this pool controls nutrient availability and SOM status which determines whether organic matter is aggrading or degrading overall (Six et al., 2000).

Loss of particulate SOM (POM) is an important aspect of SOM degradation. Soil POM contents declined in newly cropped soil and were lower in conventionally-tilled than in no-tilled soil (Oades and Swinger, 1968). Some studies suggest that POM characteristics may also serve as early indicators of SOM aggradation. Particulate organic matter accumulated as SOM was restored in cover-cropped soil, a nutrient reservoir in soils (Wander et al., 1994). The intermediate turnover times associated with these materials are appropriate for nutrient supply demands in agricultural systems.

Because SOC represents one of the major pools in the global cycle, even small changes in SOC stocks cause important $\mathrm{CO}_{2}$ fluxes between terrestrial ecosystems and the atmosphere. However, SOC stocks are difficult to quantify accurately due to their high spatial variability. Considering the important SOC loss on conversion of changing 
land use from forest to agricultural land, SOC stock in agricultural land is low. If there is a potential of $\mathrm{C}$ sequestration through land use change or improved management practices, SOC will be recovered (Lal, 2004). However, the current capacity to detect temporal changes in SOC stocks using traditional sampling and analysis techniques is quite limited due to the large spatial variability.

\section{Separation of Soil Organic Carbon Fractions}

There are many techniques that measure the size and turnover time of SOM pools. Many of these techniques are used sequentially in analyses, but few have been directly compared. Those techniques have been used to separate SOM into labile and recalcitrant pools. All methods rely on chemical, physical, or biological separation (Doran et al., 1999; Karlen et al., 1998). Most methods quantify either a labile pool and an intermediate pool, and calculate the passive or recalcitrant pool or a recalcitrant pool by difference from SOC. Temporal changes in small active fractions of SOM may provide an early indication of soils functional capability in response to management practices.

One of the methods to determine active carbon is using a highly simplified method in which neutral dilute solutions of potassium permanganate $\left(\mathrm{KMnO}_{4}\right)$ react with the most readily oxidizable (active) forms of soil carbon (Tirol-Padre et al., 2004). It has many characteristics that make it suitable for a routine field method. It reacts with most of the active fractions of SOM, changing the deep purple color of the solution to a light pink color. The greater the $\mathrm{KMnO}_{4}$ color loss, the greater the amount of active organic matter content, and the better the quality of soil. The intense purple color of the $\mathrm{KMnO}_{4}$ solution enables it serve to as its own indicator. If properly prepared and stored, permanganate solutions can be stable over several months. It is also safe to handle when 
the solution ranges from 0.006 to $0.3 M$ since it is already recommended for use in human and veterinary medicine at this range in concentration as an antiseptic treatment for skin infections and wounds (Brander et al., 1982).

Potassium permanganate is a powerful oxidizing agent because the redox potential between the $\mathrm{Mn}^{2+}$ and $\mathrm{MnO}_{4}^{-}$ions is large which is negative value $(-1.45 \mathrm{~V})$ (Cotton and Wilkinson, 1965). At $\mathrm{pH} 7.2$, portions of SOC react with $\mathrm{KMnO}_{4}$ to partially bleach the deep purple permanganate color to a light pink or clear (Loginow et al., 1987). Specifically, slightly alkaline $\mathrm{KMnO}_{4}$ can hydrolyze and oxidize simple carbohydrates, amino acids, amine/amide sugars, and C-compounds containing hydroxyl, ketone, carboxyl, double-bond linkages and aliphatic compounds, to create a light pink color (Loginow et al., 1987; Skoog and West, 1969).

Lefroy et al. (1993) used several concentrations of $\mathrm{KMnO}_{4}$ in an attempt to measure soil $\mathrm{C}$ fractions that were related to such soil quality properties as aggregation and infiltration. Blair et al. (1995) examined the separation of soil carbon fractions based on their degree of oxidation with $\mathrm{KMnO}_{4}$, and the development of carbon management index for agricultural systems. They concluded that only one $\mathrm{KMnO}_{4}$ concentration $(0.333 M)$ was needed to distinguish labile soil C (oxidized by $\mathrm{KMnO}_{4}$ ) from intermediate or recalcitrant (not oxidized by $\mathrm{KMnO}_{4}$ ), and then Weil et al., 2003 modified this method by using $\mathrm{KMnO}_{4}$ concentration at $0.02 \mathrm{M}$. He found that $\mathrm{KMnO}_{4}$ at $0.02 M$ was more sensitive, easier to manage, and less costly than $0.333 M$. He also suggested that $\mathrm{KMnO}_{4}$ at higher concentration can be more hazardous to work with and measured a larger fraction of SOM than just the labile SOM fraction. The lower 
concentration $0.02 M$ is a simpler, less costly and faster alternative that better measures the labile SOM fraction.

Culman et al. (2012) supported the idea that potassium permanganate oxidizable (POX) carbon reflected processed soil fraction that would be sensitive to management. It was shown that POX C was significantly related to particulate organic $\mathrm{C}$ (POC), biomass carbon (MBC), and soil organic carbon (SOC). These relationships were closely related to smaller-sized (53-250 $\mu \mathrm{m})$, but not larger-size POC fractions $(250-2000 \mu \mathrm{m})$. Comparing POX C with POC, MBC, and SOC, it was demonstrated that POC was sensitive to changes in management or environment. Therefore, it would be useful to assess changes in the labile soil $\mathrm{C}$ pool.

Another technique for assessing soil C fractions is infrared spectroscopy. Infrared spectroscopy is the study of the molecular vibrations of bonded atoms (Bellamy, 1980). The frequency of the absorption is characteristic of the atom in the bond and the type of motion associated with the vibration. The observed frequency can be used to distinguish the component atoms as well as the bonding characteristics of those atoms (Stevenson, 1994; Shepherd and Walsh, 2007). Hydrogen bonding may also be apparent as it causes greater separation of the bonds between $\mathrm{H}$ and other atoms in the covalent bond, thereby decreasing the frequency of the absorption. Detailed interpretation of the spectra to determine the structure is possible in simple molecules, but it is generally not so in complex molecules or mixtures of molecules. However, useful information can be gained by comparing the spectra of different samples and changes in the spectra after chemically altering a sample. 
Reflectance characteristics of soils are related to chemical groups known as "chromophores". Soil organic matter contains "spectrally active" groups, such as chlorophyll, oil, cellulose, pectin, lignin and humic acid in the visible (400-700 nm), near infrared (700-2500 nm) and mid-infrared (MIR, 2500-25000 nm) regions (Ben-Dor et al., 1997). Soil mineral and organic matter will show the results of absorption in specific infrared spectral signatures due to the vibrations of molecule groups within the mineral and organic molecule groups. In the NIR region $(700-2500 \mathrm{~nm})$ the spectral show vibrational absorbance due to $-\mathrm{OH},-\mathrm{CH}$, $-\mathrm{NH}$ organic functional groups in $\mathrm{SOM}$ (Shepherd et al., 2003). For the MIR region $(2500-25000 \mathrm{~nm})$ or $4000 \mathrm{~cm}^{-1}-400 \mathrm{~cm}^{-1}$, the proton containing heavier functional groups such as $\mathrm{Si}-\mathrm{O}, \mathrm{Al}-\mathrm{O}$, and $\mathrm{Fe}-\mathrm{O}$ in minerals, for example, quartz and kaolinite clays give strong spectral signatures near 1100-1000 $\mathrm{cm}^{-1}$ (Si-O stretching vibration) and 3690 to $3620 \mathrm{~cm}^{-1}$ for clay lattice Al-OH vibration (Janik, 2007). Chang et al. (2001) found that spectra generally show three peaks near 1400,1900 , and $2200 \mathrm{~nm}$ and a few smaller ones between 2200 and $2500 \mathrm{~nm}$, are overtones and combinations bonds of $\mathrm{C}-\mathrm{H}, \mathrm{N}-\mathrm{H}$, and $\mathrm{O}-\mathrm{H}$ bonds vibrating in the MIR region.

Diffuse Reflectance Fourier Transform Infrared Spectroscopy (DRIFT) is considered to be one of the most sensitive infrared techniques for humic substance analysis (Niemeyer et al., 1992; Ding et al., 2000). The DRIFT technique can be used to rapidly characterize the functional group composition of heterogeneous materials with minimal sample preparation. This technique offers several advantages over transmission infrared spectroscopy: (i) a simple sample preparation procedure; (ii) high resolution of the spectra because of reduction in the sensitivity towards light scattering; and (iii) a 
more reliable method for quantitative estimations of functional groups (Painter et al., 1985; Niemeyer et al., 1992, and Stevens et al., 2006).

In DRIFTS, IR radiation penetrates the sample to a depth, which is dependent on the reflective and absorptive characteristics of the sample. This partially absorbed light is then diffusely re-emitted from the sample and collected on a mirror that focuses energy coming from the sample onto the detector. The resulting spectrum is more dependent on spectral properties of the sample interface (Griffiths and de Haseth, 1986).

Diffuse reflectance infrared Fourier transform spectroscopy (DRIFTS) is one of the method which entails minimal sample preparation. Soil sample should be uniformly and finely ground $(<900 \mu \mathrm{m})$ to avoid artifacts and further homogenize samples. The courser particle sizes trap light more effectively than finer particle sizes which can increase IR scattering (Parikh, 2014). This can result in higher absorbance and a shifted baseline, altered peak widths, and non-linear absorbance. DRIFT can be use $\mathrm{KBr}$ dilution of soil samples (2-10\% sample). The suitability of $\mathrm{KBr}$ dilution is assessed empirically to determine if spectral quality is improved (Margenot et. al, 2017).

Wander and Traina (1996a) characterized physically and chemically isolated SOM fractions collected from organic matter from organically and conventionally managed soils. They used ratios of reactive (O-containing) and recalcitrant $(\mathrm{C}, \mathrm{H}$ and/or N) functional group heights to characterize SOM fraction composition. Based on peak ratio comparisons, they showed that humic acid (HA) in the manure-amended organic rotation was more reactive than HA isolated from crop-residue amended soils. Reactive/recalcitrant (O/R) peak ratio indicated that fulvic acid (FA) and particulate organic matter or light fraction (LF) isolated were most reactive in the organic cash- 
grain-based rotation. Light fraction reactivity had changed; O/R ratios of LF and litter (LT) fraction isolated from the conventional and organic cash-grain soils were greater than the manure-amended soil's ratios.

The diffuse reflectance signal can be described by the Kubelka-Munk function $(\mathrm{KM})$, where $\mathrm{KM}$ is the ratio of diffuse reflectance from the sample and the diffuse reflectance from a non-absorbing power. This ratio is related to sample absorbance (a), concentration (c), and a scattering coefficient (s) in the following manner as $\mathrm{KM}=(2.303$ $\mathrm{ac} / \mathrm{s}$ ) where $\mathrm{a}=$ absorbance, $\mathrm{c}=$ concentration of the absorbing species, and $\mathrm{s}=$ scattering coefficient. If the spectral reflectance is small and scattering is constant, then KM should vary linearly with sample concentration. This relationship is useful for quantification of the functional group composition in spectra of heterogeneous organic materials.

Wave numbers and assignments for peaks in DRIFT are the same as in IR and FTIR spectroscopy (Bases and Bloom, 1989; Niemeyer et al., 1992). For analysis of humic acid (HA) and fulvic acid (FA), the wave numbers and peaks assignments have been shown to be the following; the peak at 1715 to $1730 \mathrm{~cm}^{-1}$ (mostly COOH groups), at $1620 \mathrm{~cm}^{-1}$ (mostly aromatic C), and at $1200 \mathrm{~cm}^{-1}$ (mostly $\mathrm{OH}$ or $\mathrm{COOH}$ ) were distinct and sharp in all the spectra. The HA exhibited the most distinct $\mathrm{COOH}$ bands the both the 1720 and $1200 \mathrm{~cm}^{-1}$ regions. The high intensity of these bands was a typical characteristic of HA, and their presence reflected the high solubility and acidity. The signal between 3000 to $3700 \mathrm{~cm}^{-1}$ was of low intensity and appeared in regions of little importance to humic material (Niemeyer et al., 1992).

Assignment of the $\mathrm{OH}$ stretching band to phenolic $\mathrm{OH}$ rather than an aliphatic alcoholic $\mathrm{OH}$ was supported by the $\mathrm{C}-\mathrm{OH}$ stretching band centered about $1250 \mathrm{~cm}^{-1}$ 
which was characteristic of oxygen on an aromatic ring. The center of the band was much more apparent in the HA compared to the FA spectra. The C-OH stretching vibration of phenolic $\mathrm{OH}$ occurred at frequencies above $1200 \mathrm{~cm}^{-1}$. Aliphatic alcohols were indicated by a broad and intense $\mathrm{C}-\mathrm{OH}$ stretching band at lower frequencies $\left(1015-1150 \mathrm{~cm}^{-1}\right)$ (Conley, 1972).

\section{Future Challenges}

Soil quality is a major concern in Asia, Africa, and South America because lower soil quality or soil degradation leads to declining agricultural productivity, poverty and food insecurity (Eswaran et al., 1994). In addition, a fast-growing population requires growth in agricultural production. Therefore, an important research issue is assisting policy-makers in designing policy interventions that will contribute to a sustainable intensification of agriculture. Technologies which have the potential to simultaneously

reach the objectives of increasing productivity and sustainability need to be identified and developed. An appropriate research instrument to address these problems also has to include an evaluation of socio-economic factors that influence farmers' decision making and practices.

A critical research challenge that has not yet been solved is improving the understanding of the key factors affecting land management and assessing the technique that would be appropriate to evaluate soil quality that simultaneously meets growth and sustainability goals. Another important and difficult task is designing effective policy strategies to make these technologies affordable and adoptable for farmers, including poor farmers. Many studies have been conducted to analyze the factors that influence the adoption of technology (i.e. farm size, tenure, age, education and risk) (Romig, 1996). 


\section{Objectives}

The overall objective of the research presented in this dissertation was to examine common soil quality issues across a wide range of climates, cropping systems and socioeconomic conditions.

Specific objectives of this research were to:

1. Conduct a literature review of soil quality assessment techniques and identify scientifically sound techniques that would be appropriate to evaluate soil quality across a wide-range of environments and agricultural practices. Based on an initial review of the literature and consultation with soil quality experts, it is anticipated that soil carbon/organic matter content will likely be the principal component of a soil quality index. This review will also include working with ongoing research activities to determine if some standard soil sampling and analytical protocols could be identified or developed to enhance soil quality comparisons across wide range of environments around the world.

2. Determine the efficacy of spectroscopic-based (i.e. near-infrared, mid-infrared, and visible range) analytical methods to evaluate total soil organic carbon and soil carbon in degraded and non-degraded soils in a wide range of environments and agricultural management practices.

\section{Dissertation Organization}

In this dissertation, research was conducted to determine the efficacy of spectroscopic-based (i.e. near-infrared, mid-infrared, and visible range) analytical methods to evaluate soil organic matter fractions and soil quality in degraded and nondegraded soils in a wide range of environments in three countries - Bolivia, the 
Philippines, and Indonesia. They are reported in Chapters 2, 3, and 4. Conclusions regarding the research are provided in Chapter 5. Results of an additional community survey assessing perceptions of soil quality are presented in the Appendix. 


\section{REFERENCES}

Amacher, M.C., O’Neil, P.Katherine, and C.H. Perry. 2007. Soil vital signs: A new Soil Quality Index (SQI) for assessing forest soil health. Res. Pap. RMRS-RP-65. WWW. Fort Collins, CO: U.S. Department of Agriculture, Forest Service, Rocky Mountain Research Station.

Ann, L., and Z. Mark, 1999. Assessing the soil system. Minnesota Department of Agriculture Energy and Sustainable Agriculture Program. MDA Website: www.mda.state.mn.us.

Andrews, S.S., D.L. Karlen, and C.C. Cambardella. 2004. The soil management assessment framework: A quantitative soil quality evaluation method. Soil Sci. Soc. Am. J. 68:1945-1962.

Alexander, M. 1971. Agriculture's responsibility in establishing soil quality criteria. In: Environmental Improvement - Agriculture's Challenge in the Seventies. National Academy of Sciences, Washington, D.C.

Appenroth, K.J. 2010. Definition of "heavy metals" and their role in biological systems. In: Sherameti I., Varma A. (eds.) Soil heavy Metals, Soil Biology. Berlin: Springer. 19: 19-29.

Arshad, M.A., B. Lowery, and B. Grossman. 1996. Physical tests for monitoring soil quality. In: J.W. Doran and A.J. Jones (eds.). Methods for assessing soil quality. Soil Sci. Soc.Am. Spec. Publ. 49:123-142.

Barrow, C.J. 1991. Land Degradation: Development and Breakdown of Terrestrial Environments. Cambridge University Press. New York.

Bases, A.U., and P.R. Bloom, 1989. Diffuse reflectance Fourier transform infrared (DRIFT) spectroscopy of humic and fluvic acids. Soil. Sci. Soc. Am.J. 53:695700 .

Bellamy, L.J., 1980. The Infrared spectra of complex molecules. Chapman and Hall. London and New York.

Ben-Dor, E., Y. Inbar and Y. Chen. 1997. The reflectance spectra of organic matter in the visible near-infrared and short wave infrared region (400-2500 nm) during controlled decomposition process. Remote Sens. Environ. 61:1-15.

Bezdicek, D.F., T.Beaver, and D. Granatstein. 2003. Subsoil ridge tillage and lime effects on soil microbial activity, soil $\mathrm{pH}$, erosion, and wheat and pea yield in the Pacific Northwest, USA. Soil Tillage Res. 74: 55-63 
Blair, G.J., R.D.B. Lefroy, and L. Lise. 1995. Soil carbon fractions based on their degree of oxidation, and the development of a carbon management index for agricultural systems. Aust. J. Agric. Res. 46:1459-1466.

Blair, N., Faulkner, R.D., Till, A.R. \& Prince, K.E. 2003. The impact of plant residues with different breakdown rates on soil carbon and soil structure. In Proc. 16th ISTRO Conference, 13-18 July 2003, Brisbane, Australia.

Boeham, M.M. and D.W. Anderson, D.W. 1997. A landscape-scale study of soil quality in three prairie farming systems. Soil Sci. Soc. Am. J. 61:1147-1159.

Borlaug, N.E. and C.E. Dowswell. 1994. Feeding a human population that increasingly crowds a fragile planet. Keynote lecture, $15^{\text {th }}$ World Congress of Soil Science, Acapulco, Mexico.

Brander, G.D. Pugh, and R. Bywater. 1982. Veterinary applied pharmacology and therapeutics. Bailliere and Tindall, London.

Cao, Y. Z., D. R.Coote, H. W. Rees, C.Wang, and T.L.Chow. 1994. Effects of intensive potato production on soil quality and yield at a benchmark site in New Brunswick. Soil Tillage Res. 29:23-34.

Carter, M.R., E.G. Gregorich, D.A. Angers, R.G. Donald, and M.A. Bolinder. 1998. Organic $\mathrm{C}$ and $\mathrm{N}$ storage, and organic $\mathrm{C}$ fractions, in adjacent cultivated and forested soils of eastern Canada. Soil Tillage Res. 47:253-261.

Chang, C., D.A. Laird, M.J. Mausbach, and C.R. Hurburgh. 2001. Near inferred reflectance spectroscopy-principal components regression analysis of soil properties. Soil Sci. Soc. Am. J. 65:480-490.

Cheng, H. H., C. Huang, T.C.Tso, F.Tuan, and M. Faust. 1998. IDEALS: Beltsville Inc press, Maryland.

Christensen, B.T. 1992. Physical fractionation of soil organic matter in primary particlesize and density separates. Advances in Soil Science. 20:1-90.

Conley, R.T. 1972. Infrared spectroscopy. Allyn and Bacon, Boston.

Conteh, A., G.J. Blair, and I.J. Rochester. 1998. Soil organic carbon fractions in a Vertisol under irrigated cotton production as affected by burning and incorporating cotton stubble. Aust. J. Soil Res. 36: 655-667.

Cotton, F.A. and G. Wilkinson. 1965. Advanced inorganic chemistry. $4^{\text {th }}$ ed. Interscience Publishers, John Wiley and Sons, New York.

Craig, A.D. and A.J. Tugel. 2002. Soil quality field tools. Agron. J. 94:33-38. 
Culman, S.W., S.S. Snapp, M.A. Freeman, M.E. Schipanski, J. Beniston, R. Lal, L.E. Drinkwater, A.J. Franzleubbers, J.D. Glover, A.S. Grandy, J. Lee, J. Six, J.E. Maul, S.B. Mirsky, J.T. Spargo, and M.W. Wander. 2012. Permanganate oxidizable carbon reflects a processed soil fraction that sensitive to management. Soil Sci. Soc. Am. J. 76:494-504.

David, T.G., K.A. Cassman, M. Pamela, N. Rosamond and P. Stephen. 2002. Agricultural sustainability and intensive production practices. Nature 418:671-677

Delavalle, N.B. 1992. Assurance plans for agricultural testing laboratories. Handbook on reference methods for soil analysis. Quality Soil and Plant Analysis Council, Inc, Athens, Georgia.

Ding, G., D. Amarasiriwardena, S. Herbert, J. Novak, and B. Xing. 2000. Effect of cover crop systems on the characteristics of soil humic substances. In E.A. Ghabbour and G. Davis (ed.) humic substances: Versatile components of plants, soil and water. The Royal Society of Chemistry. Cambridge.

Ditzler, C.A., and A.J. Tugel. 2002. Soil quality field tools: Experiences of USDA-NRCS Soil Quality Institute. Agron. J. 94:33-38.

Doran, J.W., D.C. Coleman, D.F. Bedzicek, and B.A. Stewart (ed.). 1994. Defining and assessing soil quality. In: J.W. Doran, D.C. Coleman, D.F. Bezdicek, and B.A. Stewart (eds.). Defining soil quality for a sustainable environment. SSSA Spec. Pub. No.35. Soil Sci. Soc. Am., Am. Soc. 35:3-21.

Doran J.W., and A.J. Jones (ed.). 1996. Methods for assessing Soil Quality. Soil Sci. Soc. Am., Am. Soc.49:143-157.

Doran, J.W., A.J. Jones, M.A. Arshad, and J.E. Gilley. 1999. Determinants of soil quality and health. In R. Lal (ed.) Soil quality and soil erosion. Lewis Publ., Boca Raton, Florida.

Doran, J.W., and M.R. Zeiss. 2000. Soil health and sustainability: managing the biotic component of soil quality. Applied Soil Ecology 15: 3-11

Duxbury, J.M., M.S. Smith, and J.W Doran. 1989. Soil organic matter as a source and sink of plant nutrients. In D.C. Coleman, J.M. Oades \& G. Uehara, eds. Dynamics of soil organic matter in tropical ecosystem, University of Hawaii Press, Hawaii.

Edwards, J.H., C.W. Wood, D.L. Thurlow, and M.E. Ruf. 1999. Tillage and crop rotation effects on fertility status of a Hapludalf soil. Soil Sci. Soc. Am. J. 56:1577-1582.

Eswaran, H. 1993. Soil resilience and sustainable land management in the context of Agenda 21. In Soil Resilience and Sustainable Land Use, eds. D.J Greenland and I. Szabolcs, Wallingford. 
Eswaran, H., and J. Dumanski. 1994. Land degradation and sustainable agriculture: A global perspective. In Proceedings of the 8th International Soil Conservation Organization (ISCO) Conference, eds. L.S. Bhushan, I.P. Abrol, and M.S. Rama Mohan Rao. Dehra Dunn: Indian Association of Soil and Water Conservationists 1:208-226.

Eswaran, H., R. Lal and P.F. Reich. 2001. Land degradation: an overview. In Bridges, E.M., I.D. Hannam, L.R. Oldeman, F.W.T. Pening de Vries, S.J. Scherr, and S. Sompatpanit (eds.). Responses to Land Degradation. Proc. 2nd. International Conference on Land Degradation and Desertification, Khon Kaen, Thailand. Oxford Press, New Delhi, India.

FAO. 1984. Land, food and people. United Nations. Statistical yearbook. Annual publication. FAO, Rome.

FAO. 2005. Land degradation assessment, TERRASTAT CD-ROM, FAO Land and Water Digital Media Series \#20.

Fisher, R.F. 1995. Soil organic matter: clue or conundrum. In W.H. Mcfee and J.M. Kelly, (ed.). Carbon forms and functions in forest soils. Soil Sci. Soc. Am. J. Madison, WI.

FFTC. 2009. Food and Fertilizer Technology Center (FFTC). Available from World Wide Web $<$ http://www.agnet.org/library/soil fert/, Taiwan.

Garfield, F.M. 1991. Quality assurance principles for analytical laboratories. Association of Official Analytical Chemistry, Arlington, Virginia.

Garlynd, M.J., D.E. Romig, R.F. Harris, and A.V. Kurakov. 1994. Descriptive and analytical characterization of soil quality/health. In J.W. Doran et al. (ed.) Defining soil quality for a sustainable environment. SSSA Spec. Publ. 35. SSSA and ASA, Madison, Wisconsin.

Greer, K.J., D.W. Anderson, and J.J. Schoeman. 1996. Soil erosion, organic matter decline and soil quality indicators. In G.M. Coen and H.S. Vanderpluym (ed.) Proc. Of Soil Quality Assessment for the Prairies Workshop, Alberta, Canada.

Gregorich, E.G. and H.H. Janzen. 1996. Storage of soil carbon in the light fraction and macroorganic matter. P. 167-190. In M.A. Carter and B.A. Stewart (ed.) Structure and organic matter storage in agriculture soils. Lewis Publ., Boca Raton. Florida.

Gregorich, E.G., K.J. Greer, D.W. Anderson and B.C. Liang. 1998. Carbon distribution and losses: erosion and deposition effect. Soil Till. Res. 47:291-302.

Griffiths, P.R., and de Haseth, J.A.1986. Fourier transform infrared spectrometry. Science (Washington, DC). John Wiley \& Sons, Inc, pp. 57-74. 
Gugino, B.K., O.J. Idowu, R.R. Schindelbeck, H.M. van Es, D.W. Wolfe, B.N. MoebiusClune, J.E. Thies, and G.S. Abawi. 2009. Cornell soil health assessment training manual. Second Edition. College of Agriculture and Life Sciences, Cornell University, Ithaca, New York.

Harris, R.F., D.L. Karlen, and D.J. Mulla. 1996. A conceptual framework for assessment and management of soil quality and health. In J.W. Doran et al. (ed) Methods for assessing soil quality. SSSA Spec. Publ. 49. SSSA and ASA, Madison, Wisconsin.

Herrick, J.E., J.R. Brown, A.J. Tugel, P.L. Shaver, and K.M. Havstad. 2002. Application of soil quality to monitoring and management. Agron. J. 94:3-11.

Hurni, H., M. Giger, K. Meyer (Eds.). 2006. Soils on the global agenda. In Developing international mechanisms for sustainable land management. Prepared with the support of an international group of specialists of the IASUS Working Group of the International Union of Soil Science (IUSS). Centre for Development and Environment, Bern, Germany.

Hornick, S.B. 1992. Factors affecting the nutritional quality of crops. Am. J. Altern. Agric. 7:63-68.

Islam, K.R., and R.R. Weil, 2000. Soil quality indicator properties in mid-Atlantic soils as influenced by conservation management. J. Soil Water Conserv. 55:69-78

ISCRIC, 2004. World Map of Human Induced Soil Degradation (GLASOD) [Online]. [Accessed 21/03/04]. Available from World Wide Web <http://lime.isric.nl/. The Netherlands.

Janik L.J., J.O. Skjemstad, K.D. Shepherd, and L.R. Spouncer. 2007. The prediction of soil carbon fractions using mid-infrared partial least square analysis. Aust. J. of Soil Research 45:73-81.

Janssen, B.H., F.C.T. Guiking, D. van der Eijk, E.M.A. Smaling, J. Wolf, and H. van Reuler. 1990. A system for quantitative evaluation of the fertility of tropical soils (QUEFTS). Geoderma 46:299-318.

Jenkinson, D.S. 1990. The turnover of organic carbon and nitrogen work in soil. Philos. Trans: Biol. Sci. 329:361-367

Johnson, D.L., and L.A. Lewis. 2007. Land degradation: Creation and destruction, 2nd edition, Rowman and Littlefield, Lanham, Boulder, New York, Toronto, Oxford.

Karlen, D.L., J.C. Gardner, and M.J. Rosek. 1998. A soil quality framework for evaluating the impact of CRP. J.Prod. Agric. 11:56-60. 
Karlen, D.L., C.A. Ditzler, and S.S. Andrews. 2003. Soil quality: why and how? Geoderma 114:145-156.

Kay, B.D. 1998. Soil structure and organic carbon: A review. p. 169-197. In R. Lal et al. (ed.) Soil processes and the carbon cycle. CRC Press, Boca Raton, FL.

Krull, E.S., J.A. Baldock, and J.O. Skjemstad. 2003. Importance of mechanisms and processes of the stabilisation of soil organic matter for modeling carbon turnover, Funct. Plant Biol. 30:307-222.

Lal, R. 1998. Soil erosion impact on agronomic productivity and environmental quality. Critical Reviews in Plant Science 17:319-464.

Lal, R. and P.F. Reich. 2001. "Land degradation: an overview". Responses to Land Degradation. Proc. 2nd. International Conference on Land Degradation and Desertification. New Delhi, India: Oxford Press. http://soils.usda.gov/use/worldsoils/papers/land-degradation-overview.html. Retrieved 2006-06-20.

Lal, R. 1994. Tillage effects on soil degradation, soil resilience, soil quality, and sustainability. Soil Tillage Research. 27:1-8.

Lal, R. 2003. Soil erosion and the global carbon budget. Environment International 29(4): 437-450.

Lal, R. 2004. Soil carbon sequestration to mitigate climate change. Geoderma 123:1-22.

Larson, W.E., and F.J. Pierce. 1991. Conservation and enhancement of soil quality. p. 175-203. In. J. Dumanski et al., (ed.) Evaluation for sustainable land management in the developing world. Vol. 2: Technical Papers. Proc. Intl. Workshop15-21 Sept. 1991, Chiang Rai. Bangkok Thailand.

Larson, W.E. and F.J. Pierce. 1994. The dynamics of soil quality as a measure of sustainable management. In J.W. Doran, D.C. Coleman, D.F. Bezdicek, and B.A. Stewart (eds.), Defining soil quality for a sustainable environment. Soil Sci. Soc. Am J. 35:37-51.

LDD. 2009. Land Development Department (LDD). Available from World Wide Web $<\mathrm{http} / / / \mathrm{www}$. ldd.go.th/, Thailand.

Lefroy, R.D.B., G.L. Blair, and W.M. Stog.1993. Changes in soil organic matter with cropping as measured by organic carbon fraction and ${ }^{13} \mathrm{C}$ natural isotope abundance. Plant and Soil 155/156:399-402

Loginow W., W. Wisniewski, S.S. Gonet, and B. Ciescinska. 1987. Fractionation of organic carbon based on susceptibility to oxidation. Polish J. Soil Sci. 20:47-52. 
Margenot, A.J., F.J. Calderon, K.W. Goyne, F.N.D. Mukome, and S.J. Parikh. 2017. IR spectroscopy, soil analysis application. Encyclopedia of Spectroscopy and Spectrometry. Third Edition. 2: 448-454.

Murage, E.W., N.K. Karanja, P.C. Smithson, and P.L. Woomer. 2000. Diagnostic indication of soil quality in productive and non productive smallholders' field of Kenya's Central highlands. Agric. Ecosyst. Environ. 79:1-8.

Nelson, D.W., and Sommers, L.E. 1975. A rapid and accurate procedure for estimation of organic carbon in soil. Proc. Indiana Acad. Sci. 84:456-462.

Niemeyer J., Y. Chen, and J.M. Bollag. 1992. Characteristics of humic acids, composts, and peat by diffuse reflectance Fourier transform infrared spectroscopy. Soil Sci. Soc. Am. J. 56:135-140.

Oades, J.M. and G.D. Swinger. 1968. Effect of time of sampling and cropping system sequence on the carbohydrates in red brown earth. p. 183-192. In J.W. Holmes (ed.) Trans Int. Congr. Soil Sci. $9^{\text {th }}$ Adelaide. 1968. Vol. 3. Elsevier. New York.

Oldeman, L.R. 1994. The global extent of land degradation. In D.J. Greenland and I. Szabolc (eds.), Land resilience and sustainable land use. CAB International. Wallingford. UK.

Oldeman, L.R., V.W.P. van Engelen, and J.H.M. Pulles. 1994. The extent of humaninduced soil degradation, Annex 5 of L.R. Oldeman, R.T.A. Hakkeling, and W.G. Sombroek, World Map of the Status of Human-Induced Soil Degradation: In An Explanatory Note, rev. 2ed.1990. International Soil Reference and Information Centre, Wageningen, the Netherlands.

O’Neill, K.P., M.C. Amacher, and C.H. Perry. 2005. Soils as an indicator of forest health: In A guide to the collection, analysis, and interpretation of soil indicator data in the Forest Inventory and Analysis Program. General Technical Report. NC-GTR258. U.S. Department of Agriculture, Forest Service, North central Research Station.St. Paul, MN:

Painter, P., M. Starsinic, and M. Coleman. 1985. Determination of functional groups in coal by Fourier transform infrared interferometry.p. 169-241. In J.R. Ferraro and L.J. Basile (ed.) Fourier transform spectroscopy. Application to chemical systems. Vol.4. Academic Press, Orlando, Florida.

Parikh, J.S., W.G. Goyne, J.M. Andrew, N.D.M. Fungai, and J.C. Francisco. 2014. Soil chemical insights provided through vibrational spectroscopy. Advances in Agronomy, First Edition. pp. 1-148.

Parton, W.J., J.W.B. Stewart, and C.V. Cole. 1988. Dynamics of C, N, P and S in grassland soils: a model. Biogeochemistry 5:109-131. 
Pennock, D.J., D.W. Anderson, and E. de Jong. 1994. Landscape-scape changes in indicators of soil quality due to cultivation in Saskatchewan. Canada. Geoderma 64:1-19

Raymon A.W. and F.E. Okieimen. 2011. Heavy metals in contaminated soils: A review of sources, chemistry, risks and best available strategies for remediation. ISRN Ecology. Volume 2011. dx.doi.org/10.5402/2011/402647

Riley, J. 2001. The indicator explosion: Local needs and international challenges-Preface. Agriculture Ecosystems \& Environment. 87:119-120.

Reeves, J.B., A.F. Barry, and K.H. Stephen. 2005. Specular reflection and diffuse reflectance spectroscopy of soils. Applied Spectroscopy. 59:39-46.

Romig, D.E., M.J. Garland, R.F. Harris, and K. McSweeney. 1995. How farmers assess soil health and quality. J. Soil Water Conserv. 50:229-236.

Romig, D.E., M.J. Garland, and R.F. Harris. 1996. Farmer-based assessment of soil quality: A soil health scorecard. p. 39-60. In J.W. Doran and A.J. Jones (ed.) Methods for assessing soil quality. SSSA Spec. Publ. 49.SSSA, Madison, Wisconsin.

Sanchez, P.A., C.A. Palm, S.W. Buol. 2003. Fertility capability soil classification: a tool to help assess soil quality in the tropics. Geoderma. 114:157-185.

Sarrantonio, M., J.M. Doran, M.A. Liebig, and J.J. Halvorson. 1996. On-farm assessment of soil quality and health. P. 83-105. In J.W. Doran and A.J. Jones (ed.). Methods for assessing soil quality. SSSA Spec. Publ. 49. SSSA, Madison, Wisconsin.

Scherr, S. J. 1999. Soil Degradation. A Threat to Developing-Country Food Security by 2020? International Food Policy Research Institute, Washington, DC.

Schutter, M.E. and P.R. Dick, 2002. Microbial community profile and activities among aggregates of winter fallow and cover-cropped soil. Soil Sci. Soc. Am. J. 66:142153.

Seybold, C.A., M.J. Mausbach, D.L. Karlen, and H.H. Rogers. 1997. Quantification of soil quality. In R. Lal, J.M. Kimble, R.F. Follett and B.A. Stewart, eds. Soil Processes and the Carbon Cycle. CRC Press. Washington, D.C., USA

Shepherd, K.D., and M.G. Walsh. 2007. Review: Infrared spectroscopy-enabling an evidence-based diagnostic surveillance approach to agricultural and environmental management in developing countries. J. of Near Infrared Spectroscopy 15:1-20. 
Shepherd, K.D., M.G. Walsh, and A. Awiti. 2003. Use of soil spectral indicators for assessing and monitoring soil quality. ASA Abstracts (CD-ROM). Agron J., Madison, WI.

Six J., E.T. Elliott, and K. Paustian. 2000. Soil macroaggregate turnover and microaggregate formation: A mechanism for $\mathrm{C}$ sequestration under no-tillage agriculture. Soil Biol. Biochem. 32:2099-2103.

Skoog D.A., and D.M. West. 1969. Applications of oxidation-reduction reagents to volumetric organic analysis. In Fundamentals of analytical Chemistry. $2^{\text {nd }}$ ed. Holt, Rinehart and Winston, New York

Smith, P., J.U. Smith, D.S. Powlson W.B. McGill, J.R.M. Arah, O.G. Chertov, K. Coleman, U. Franko, S. Frolking, D.S. Jenkinson, L.S. Jenssen, R.H. Kelly, H. Klein-Gunnewiek, A.S. Komarov, C.Li, J.A.E. Molina, T. Muller, W.J. Parton, J.H.M. Thornley, and A.P. Whitmore. 1997. A comparison of the performance of nine soil organic matter models using datasets from seven long-term experiments. Geoderma 81:153-225.

Sojka, R.E., and D.R. Upchurch. 1999. Reservations regarding the soil quality concepts. Soil Sci. Soc. Am. J. 5:1039-1054.

Spedding, T.A., Hamel, C., Mehuys, G.R., Madramootoo, CA., 2004. Soil microbial dynamics in maize-growing soil under different tillage and residue management systems. Soil Biology and Biochemistry 36, 499-512.

Stevenson, F.L.1994. Humus chemistry: Genesis, composition, reactions, $2^{\text {nd }}$ ed. John Wiley and Sons, New York.

Stevens, A., B. van Wesemael, G. Vandenschrick, S. Touré, and B. Tychon. 2006. Detection of carbon stock change in agricultural soils using spectroscopic techniques. Soil Sci. Soc. Am. J. 70:844-850.

Swift, M.J., A. Izac, and M. Van Noordwijk. 2004. Biodiversity and ecosystem services in agricultural landscapes - are we asking the right questions? Agriculture, Ecosystems and Environment. 104:113-134.

Tirol-Padre, A., and J. K. Ladha. 2004. Assessing the reliability of permanganateoxidizable carbon as an index of soil labile carbon. Am. Soc. Agron. J. 68:969978.

Taylor, J.K. 1987. Quality assurance of chemical measurements. Luwis Publishers, Inc. Chelsea, Michigan.

U.S. Department of Agriculture, Natural Resources Conservation Service. 1998. Soil quality test kit guide. Soil Quality Institute. Natural Resources Conservation 
Service and Agricultural Research Service. U.S. Dept of Agriculture. Lincoln, NE and Washington, DC.

U.S. Department of Agriculture. 1999. Soil quality card design manual. Version 1.0. A guide to develop locally adapted conservation tools. Soil Quality Institute. Natural Resources Conservation Service. U.S, Dept of Agriculture. Washington, DC.

U.S. Department of Agriculture, Natural Resources Conservation Service, Soil Quality Institute. 2003. Managing soil organic matter. Soil Quality Technical Note No.5. U.S. Department of agriculture. Natural Resources Conservation Service. Soil Quality Institute, Auburn, Alabama. Available: http://soils.usda.gov/sqi.

Visser, S., and D. Parkinson. 1992. Soil biological criteria as indicators of soil quality: Soil microorganisms. Am. J. Altern. Agric. 7:33-37.

Vityakon, P., S. Meepetch, G. Cadisch, and B. Toomsan. 2000. Soil organic matter and nitrogen transformation mediated by plant residues of different qualities in sandy acid upland and paddy soils. Netherlands Journal of Agricultural Science. 48:7590 .

Wallace A. 1994. Soil organic matter is essential to solving soil and environmental problems. Commun. Soil Sci. Plant Anal 25:37.

Wander, M.M., S.J. Traina, B.R. Stinner, and S.E. Peters. 1994. Organic and conventional management on biologically active organic matter pools. Soil Sci. Soc. Am. J. 58:1130-1139.

Wander, M.M., and S.J. Traina. 1996a. Organic fractions from organically and conventionally managed soils: I. Carbon and nitrogen distribution Soil Sci. Soc. Am. J. 60:1081-1087.

Wander, M. 2004. Soil organic matter fractions and their relevance to soil function. In Soil Organic Matter in Sustainable Agriculture, Magdoff, F. and R.R. Weil, eds. CRC Press. USA.

Warkentin, B.P., and H.R. Fletcher. 1977. Soil quality for intensive agriculture. In Proceedings of the International Seminar on Soil Environment and Fertility Management in Intensive Agriculture. Society of Science of Soil and Manure. Japan.

Weil, R.R., K.R. Islam, M.A. Stine, J.B. Gruver, and S.E. Samson-Liebig. 2003. Estimating active carbon for soil quality assessment: A simplified method for laboratory and field use. Amer. J. of Alternative Agric. 1:18:3-15. 
Wiermann, C., Werner, D., Horn, R., Rostek, J., Werner, B., 2000. Stress/ strain processes in a structured unsaturated silty loam Luvisol under different tillage treatment in Germany. Soil Tillage Res. 53:117-128

Winder, J. 2003. Soil Quality Monitoring Programs: A Literature Review. Alberta Environmentally Sustainable Agriculture Soil Quality Monitoring Program, Edmonton, Canada. 


\title{
CHAPTER 2
}

\section{USE OF THE POTASSIUM PERMANGANATE TEST FOR DETERMINING ACTIVE SOIL ORGANIC CARBON IN TROPICAL HILLSLOPE AGROECOSYSTEMS}

\author{
ABSTRACT \\ Methods that measure labile or active soil organic carbon (C) have been proposed \\ as soil quality indicators that are sensitive to short-term management changes. \\ Information from such tests may assist farmers to make appropriate management \\ decisions in support of sustainable agriculture. However, these tests must be quick, \\ accurate, inexpensive, and sufficiently rugged to be conducted under a range of \\ environmental conditions in a field setting. Moreover, they must be able to be conducted \\ by personnel in diverse countries and cultures with a minimum of training and possible \\ educational background. Extensive research has been conducted in temperate agricultural \\ systems, but less has been conducted using this test in tropical agroecosystems and \\ conditions, especially in hillslopes where rapid soil degradation may occur. The \\ objectives of this research were to compare the results of a field-based potassium \\ permanganate active $\mathrm{C}$ test $(\mathrm{MnOxC})$ to that of laboratory-based $\mathrm{MnOxC}$ methods across \\ a wide range of tropical environments and cropping systems; and to determine the \\ sensitivity of the $\mathrm{MnOxC}$ test compared to total soil organic $\mathrm{C}$ (SOC) and particulate \\ organic matter $\mathrm{C}$ (POMC) tests to differences in soil management at the different \\ locations around the world. Surface soil samples $(0-20 \mathrm{~cm})$ were collected from hillslope \\ agricultural sites in Bolivia, the Philippines and Indonesia which had differences in \\ length of fallow, levels of soil degradation, and cultivation by landscape position. \\ Laboratory- and field-based methods for determination of soil $\mathrm{MnOxC}$ were conducted
}


on all samples and compared with results for SOC and POMC. Based on these comparisons, the field-based $\mathrm{MnOxC}$ method was as accurate as the laboratory-based method suggesting its potential for field-based determination of soil quality to assist management decisions. Total soil organic $\mathrm{C}$ and $\mathrm{MnOxC}$ were consistently significantly correlated among all sites. Active $\mathrm{C}$ was also sensitive to differences in management practices that may affect soil quality. Results showed that $\mathrm{MnOxC}$ increased as the number of years of fallow increase. Non-degraded soils, had higher MnOxC than degraded soils. Comparing $\mathrm{MnOxC}$ in cultivated and non-cultivated areas for each landscape position, this research showed that the cultivated area had more MnOxC than non-cultivated area. Active $\mathrm{C}$ was higher at the summit, toeslope and footslope landscape position compared to shoulder and backslope positions in the non-cultivated area, but no differences among landscape positions were detected in corresponding cultivated areas. Based on these results, the field-based $\mathrm{MnOxC}$ method may be useful for assessing the effects of changes in levels of soil degradation in tropical hillslope agricultural systems. However, further research would be needed to establish criteria for interpretation of the results and the effects of environmental conditions on field-based test results.

\section{INTRODUCTION}

Changes in soil organic matter over time may be evaluated on changes in total organic C (SOC); however, SOC tends to respond slowly to management changes (Murage et al., 2000). Farmers attempting to assess changes in soil quality may need more sensitive methods to monitor short-term management-induced changes that affect crop production and the environment. Methods that measure labile or active soil $\mathrm{C}$ have been proposed as soil quality indicators sensitive to short-term management changes. To 
assist farmers and land managers in evaluating the effects of particular management strategies, inexpensive and reliable monitoring methods are needed to increase adoption of such services by analytical testing laboratories (Karlen and Cambardella, 1996).

Particulate organic matter carbon (POMC) has been found to be more sensitive to soil management than SOC (Tiessen and Stewart, 1983; Beare et al., 1994; Wander et al., 1994; Six et al., 1998). Particulate organic matter C is isolated by chemical, or sonic disassociation of soil aggregates, followed by sieving at the sand particle size (50-2000 $\mu \mathrm{m})$ (Gregorich and Ellert, 1993). Analysis for POMC, or macroorganic matter, has been found to be useful to estimate soil active C (Skjemstad, 2006). The residence time of POMC has been estimated to range from 5 to $20 \mathrm{yr}$ and is dominated by undecomposed plant residues that retain recognizable cell structures, but also includes fungal hyphae, seeds, spores, and faunal skeletons (Carter et al., 1998; Gregorich and Janzen, 1996).

Particulate organic matter shows high sensitivity to management changes from perennial to annual cropping systems, and from conventional to reduced tillage systems (Tiessen and Stewart, 1983; Besnard et al., 1996; Hussain et al., 1999). Even though POM is an effective indicator of soil quality (Cambardella and Elliott, 1994), the method is quite costly because POM analysis is labor-intensive and requires expensive dry combustion with a $\mathrm{C}$ analyzer or some other standard procedure for determining total $\mathrm{C}$ (Tiessen and Stewart, 1983; Besnard et al., 1996; Hussain et al., 1999).

Mirsky et al. (2008) tested the relationship between POMC and chemically labile organic matter, and evaluated the effects of soil management on POM and labile C. The study was conducted within a long-term crop rotation $\times$ fertility treatment study in central Pennsylvania and it was found that both POMC and active or labile $\mathrm{C}$ concentrations 
were the greatest for manure-based fertility treatments and for crop rotations receiving the most frequent applications of manure.

Because active $\mathrm{C}$ is important in management, a method that is quick, accurate, inexpensive, and can be conducted in a field setting was developed. Weil et al. (2003) proposed a method using oxidizing agents to determine the amount of active or labile $\mathrm{C}$ $(\mathrm{MnOxC})$. Chemical oxidation of active soil organic matter is less costly and may prove to be an equally effective indicator. Oxidizing agents of different strength chemical properties may be able to access the relative proportions of different forms of SOM in terms of the ease with which they are broken down. Solutions of potassium permanganate $\left(\mathrm{KMnO}_{4}\right)$ have been extensively used for the oxidation of organic compounds. Oxidation with less than the amount of permanganate required for complete oxidation may reveal the quantity of readily-oxidizable components in SOM (Tirol-Padre, and Ladha. 2004).

Potassium permanganate has many characteristics that are appropriate for a routine method. The intense purple color of the $\mathrm{KMnO}_{4}$ solution enables it to act as its own indicator. It can be prepared and stored in solution for several months (Weil, 2003). Brander et al. (1982) recommended that it is safe to handle solutions ranging from 0.006 to $0.3 M$ since these concentrations are recommended in human and veterinary medicine as an antiseptic treatment for skin infections and wounds. In a neutral to slightly alkaline solution, $\mathrm{KMnO}_{4}$ is a powerful oxidizing agent because of the large negative value $(-1.45$ V) of the potential between the $\mathrm{Mn}^{2+}$ and $\mathrm{MnO}_{4}^{-}$ions (Cotton and Wilkinson, 1965). At pH 7.2, portions of SOC react with $\mathrm{KMnO}_{4}$ to partially bleach the deep purple permanganate color to light pink or clear solution (Loginow et al., 1987). Slightly alkaline $\mathrm{KMnO}_{4}$ is known to hydrolyze and oxidize simple carbohydrates, amino acids, 
amine/amide sugars, and C compounds containing hydroxyl, ketone, carboxyl, double bond linkages, and aliphatic compounds (Loginow et al., 1987; Skoog and West, 1969). Weil et al. (2003) reported that the $\mathrm{KMnO}_{4}$ procedure was easy to follow, repeatable, and suitable for use in the field as all the components could be readily transported and employed. The authors found the simplified methodology provided results that were similar to those obtained by using more complex laboratory procedures. They concluded that the newly developed procedure was more sensitive to management effects and related to soil productivity and soil properties, such as respiration, aggregation, and microbial biomass. It was also more sensitive to the effects of soil management than procedures based on measurements of SOC. Soil analytical laboratories may be more receptive to offer labile SOM testing as a component of their services if the method were more economical and easily repeatable. Chemical methods to evaluate labile organic matter such as the potassium permanganate test may offer a more economical alternative to physical techniques (Lefroy et al., 1993; Blair et al., 1995). Chemical fractionation is more affordable because the methodology requires less labor and an additional procedure to measure total $\mathrm{C}$, such as dry combustion, is not necessary for analysis. To be adopted, chemical fractionation methods must isolate a labile $\mathrm{C}$ fraction that has a similar response to soil management practices as accepted physical fractionation techniques such as particulate organic matter measurement. Typically, chemical fractionation of SOM involves the reaction between SOM and a strong oxidizing agent. Attempts to simulate microbial decomposition in a way that reflects the in situ enzymatic digestion of labile $\mathrm{SOM}$ prompted the use of $\mathrm{KMnO}_{4}$ as an oxidizing agent (Loginow et al., 1987). The method may have potential to be sensitive to the effects 
of soil management and also meet the necessary criteria for widespread adoption for soil quality assessment including being rapid, inexpensive and easy to use. The objectives of this project were to: (1) compare the results of a field-based potassium permanganate active $\mathrm{C}$ test $(\mathrm{MnOxC})$ to that of laboratory-based $\mathrm{MnOxC}$ methods across a wide range of tropical environments and cropping systems; and (2) to determine the sensitivity of the MnOxC test compared to total soil organic $\mathrm{C}$ (SOC) and particulate organic matter $\mathrm{C}$ (POMC) tests to differences in soil management at the different locations around the world.

\section{MATERIALS AND METHODS}

\section{Study Sites}

Tests of the procedures were conducted in the field and laboratory with surface soil samples $(0-20 \mathrm{~cm}$ depth) collected from a range of agricultural management and environmental conditions from tropical hillslope sites located in Latin America and Asia. A map of the general location of each site is shown in Fig 2.1.

\section{Location \#1:}

One set of surface soil samples was collected from fallow agricultural fields with different lengths of fallowing in Umala Municipality in the central region of the Andean Highlands in Bolivia. These fallow lengths (4 locations) were 1, 10, 20, 30 and 40 years of fallow. These fields were often under potato-based crop rotation. The most frequent crop rotation is potato-quinoa/barley-barley/oat/-fallow or potato-quinoa/barleybarley/oat-perennial grasses. Fallow is a traditional practice used for soil restoration and grazing and the average fallow length range from 3 to 5 years but it might last up to 20 years in less fertile soils. There is a general trend of suboptimal and inadequate use of 
organic (e.g., cow and sheep manure) and inorganic fertilizers (i.e., diammonium phosphate and urea). In Umala, four representative rural communities were selected for this study. Two communities (i.e. San José de Llanga and San Juan Circa) were located at relatively low elevation (approximately 3,771 and 3,806 meters above sea level) and the another two communities (i.e., Kellhuiri and Vinto Coopani) at relatively high elevation (approximately 4,070 and 4,013 meters above sea level). Farmers identified soil problems as one of several factors limiting their crop production (Aguilera et al., 2010). These problems included low soil quality and soil fertility (i.e., low soil nutrient content, high clay content making the soil hard to crop, and stoniness), excessive water- and windinduced soil erosion and inadequate soil management practices. Inadequate soil management practices cited were inappropriate tractor tillage practices, lack of a clear crop rotation strategy, carelessness of incorporating manure, and overgrazing by sheep. Farmers identified different soil types, according to the local criteria of each community and they listed soil characteristics or properties of each soil type. Soil maps drawn by the representative farmers in the first workshop show a general predominance of sandy soils in the four communities. The land and crop management had a slight variation among soil types and among communities. For instance in Kellhuiri, in the clayey soils, farmers grew only barley and quinoa; whereas in Vinto Coopani farmers grew potato, barley and alfalfa. In San Juan Circa, farmers grew potato, quinoa and barley, and in San José de Llanga they grew alfalfa, barley, faba beans, and quinoa (Aguilera et al., 2010).

A total of 49 soil samples were analyzed to determine soil active C. All soil samples were ground, air-dried (5 days) and sieved $(<2 \mathrm{~mm})$. 
Two methods to determine soil active $\mathrm{C}(\mathrm{MnOxC})$ adapted from Weil et al (2003) were compared with soil samples from this location. One method was designed for laboratory analysis (lab method) and used techniques with higher precision (e.g., weighed samples rather than volume measurement of sample; filtering rather than separation by settling); and the other method was designed to be done in the field (field method) and to be convenient, fast and less labor-intensive than the laboratory method.

\section{Location \#2:}

Another set of soil samples was collected from degraded and non-degraded agricultural land located in Cochabamba, Bolivia where three communities (Toralapa Baja, Waylla Pujru and Sancayani) were located at relatively low, medium and high elevation, respectively. All sites were located in the province of Tiraque. At this site, 60 soil samples (30 degraded soils and 30 non-degraded soils) were collected from representative farmer fields. The criteria for separating degraded and non-degraded land included the degree of soil erosion, low soil fertility, poor management practices, monoculture, extent of pests, and lack of soil conservation practices, and deforestation. These criteria were based on the judgment of Bolivian agricultural professionals working in the region. Criteria to identify a non-degraded soil were black color soil and its direct relation with organic matter $(\mathrm{OM})$, good texture (loose), high productivity, deep and flat soils, good structure, good drainage, and the presence of macroorganisms. To identify degraded soils, the criteria used were low productivity, clay texture, low soil organic matter (SOM) content and shallow, rocky and compressed soils, and the low microbial activity. 
Comparison of the $\mathrm{MnOxC}$ method using laboratory and field-kit methods from three locations (Toralapa Baja, Waylla Pujru and Sancayani Alto) in Cochabamba, Bolivia was also conducted. To compare the results obtained from these two methods, 60 subsamples from all three locations were analyzed to detect the labile fractions of soil organic matter by both methods.

\section{Location \#3:}

Location \#3 in Indonesia was situated in Kecamatan Nanggung, West Java. The study site was originally covered with a typical humid tropical forest. Soil samples were collected from agroforestry (primarily alley cropping) and non-agroforestry areas. These areas received different types and rates of amendments which included manure, compost and chemical fertilizer. The climate of the area was tropical with monsoons occurring in the rainy season. Soils were poorly to moderately drained and occurred on undulating to flat uplands. The elevation was less than 200-1800 m above sea level.

Both agroforestry and non-agroforestry sites had been managed with different types and rates (low, medium, and high) of amendments including manure, compost and chemical fertilizer. The climate of the area was tropical monsoon with rainy season. Soils were poorly to moderately drained and occurred on upland areas in a hillslope region. The elevation was approximately $50 \mathrm{~m}$ above sea level.

In the agroforestry areas, crops were grown between trees and the control plot was cassava, no manure, no compost, and no fertilizer: All areas receiving manure were applied with poultry manure. The low manure plot was planted to corn, sweet potato, a low rate of compost. A low rate of fertilizer and manure was applied at the rate of less than 5,000 $\mathrm{kg} \mathrm{ha}^{-1}$ per planting season. The medium manure plot was scallion, chili, corn, 
with no compost, no fertilizer and manure was applied at the rate of 5,000-15,000 $\mathrm{kg} \mathrm{ha}^{-1}$ per planting season.

Soil samples were collected from agroforestry and non-agroforestry sites located near Bogor, Indonesia. A total of 135 soil samples were collected from farm fields at hillslope locations. The study site was originally covered with typical tropical forest vegetation in this region. Part of the soil samplings were from alley cropping systems with fruit trees in vegetative buffer strips and vegetables raised in the cropped areas. Based on local soil classifications, the soils were described by agricultural professionals and farmers as brown soils with loam and sandy loam texture, good drainage, and poor fertility. Trees and vegetables were cultivated (Appendix Table 24).

\section{Location \#4:}

An additional set of samples was collected along a hill-slope transect from the top to the bottom of agricultural valley on Mindanao Island in the Philippines. The transect across the landscape was divided into summit, shoulder, backslope, footslope and toeslope landscape positions. Cultivated and non-cultivated fields were sampled at each landscape position. Farmers identified their land, according to the local criteria. They characterized soil characteristics or properties of each soil type as reddish soil and fine texture, good drainage, and low fertility (Appendix Table 39). A total of 30 soil samples were collected of which 15 soil samples were collected from non-cultivated land and 15 soils samples were taken from cultivated areas at each landscape position.

\section{Soil Processing}

All sampling sites were geo-referenced, cropping history, and major vegetation recorded. Any available information on soil classification was also collected. Sampling 
depth was $0-20 \mathrm{~cm}$. Soils were collected using a push probe or hand trowel and 10 to 15 subsamples were collected from each field and composited in a bucket. All samples were air-dried, and ground by hand using a mortar and pestle and passed through a $2 \mathrm{~mm}$ sieve prior to analysis.

\section{Soil Chemical and Physical Analyses}

\section{Soil Characterization}

Two composite samples of each major agricultural soil type were sent to the University of Missouri Soil and Plant Testing Laboratory to be characterized for soil chemical properties (i.e., $\mathrm{pH}$ in $0.01 \mathrm{M} \mathrm{CaCl}_{2}$, soil test phosphorus [Bray P1], soil test potassium $\left[\mathrm{NH}_{4} \mathrm{AOc}\right.$-extractable $\left.\mathrm{K}\right]$, exchangeable calcium [Ca], exchangeable magnesium $[\mathrm{Mg}]$, neutralizable acidity and cation exchange capacity [CEC]) using standard procedures (Nathan et al., 2006).

\section{Total organic C}

For determination of total organic $\mathrm{C}(\mathrm{SOC})$, soil samples were dried at $40^{\circ} \mathrm{C}$ and then finely ground to pass a sieve with $<0.5 \mathrm{~mm}$ openings. Samples containing approximately $350 \mu \mathrm{g} \mathrm{C}$ were weighed into tin cups and analyzed for total organic $\mathrm{C}$ by combustion using a LECO TruSpec C N analyzer (LECO Cooporation, St. Joseph, MI). None of the soil samples contained carbonates.

\section{Particulate organic matter}

Particulate organic matter (POMC) was separated from the soil mineral fraction the method recommended by Cambardella and Elliott (1994). Thirty grams of whole soil were dispersed with $100 \mathrm{~mL}$ of $5 \mathrm{~g} \mathrm{~L}^{-1}$ of sodium hexametaphosphate for $16 \mathrm{hr}$ using an electric shaker at $200 \mathrm{rpm}$, and the solution poured through $53 \mu \mathrm{m}$ sieve. After wet 
sieving and washing with deionized water, the sand and organic material remaining on all sieves was oven - dried at $50^{\circ} \mathrm{C}$. The total organic $\mathrm{C}$ of this fraction was then determined by combustion using a LECO TruSpec C N analyzer (LECO Corporation, St. Joseph, MI) as shown in Table 2.1 and 2.2.

\section{Potassium permanganate active $\mathrm{C}(\mathrm{MnOx} C)$ analysis}

Soil permanganate-oxidizable $\mathrm{C}(\mathrm{MnOxC})$ levels were determined for the soils by using the field and laboratory methods recommended by Weil et al (2003). These recommendations covered details, such as the amount of soil $\mathrm{C}$ that reacted increased with concentration of $\mathrm{KMnO}_{4}$ used $(0.01$ to $0.1 \mathrm{M}$ ), degree of soil drying (moist fresh soil compared to soil air-dried for 24 hour) and time of shaking ( 1 - 15 minutes). It was found that shaking of air-dry soil in a $0.02 \mathrm{M} \mathrm{KMnO}_{4}$ solution for 2 minutes produced consistent and management sensitive results. The field method for the $\mathrm{MnOxC}$ test was suggested by Islam and Sundermeir (2008) for more rapid analysis in the field and to lower the costs for conducting the analysis. The modifications for the field test compared to the laboratory test to make the field method more rapid and inexpensive included using a calibrated spoon, minimum soil preparation and manual sample shaking.

\section{Field-kit method}

The field kit method is a highly simplified and relatively inexpensive method in which a neutral $(\mathrm{pH} 7.2)$ dilute solution of potassium permanganate $\left(\mathrm{KMnO}_{4}\right)$ reacts with active fractions of SOC (Weil et al., 2003). This reaction causes a color change of the solution from a deep purple color to a light pink color. The lighter the color of the $\mathrm{KMnO}_{4}$ solution after reacting with soil, the greater the amount of active $\mathrm{C}$ content). 
The field method recommended by Weil et al. (2003) was followed. Soil samples were air-dried by laying soil in the sunlight for 10 minutes on a black plastic sheet. A 5 $\mathrm{mL}$ sub-sample of the air-dried soil was taken using a calibrated scoop and mixed with 20 $\mathrm{mL}$ of $0.02 \mathrm{M} \mathrm{KMnO}_{4}$ and $1 \mathrm{M} \mathrm{CaCl}_{2}$ solution and shaken for two minutes by hand. After shaking, the suspensions were left to settle for approximately 10 minutes to allow separation of the supernatant from the solid materials. Absorbance was promptly measured at $550 \mathrm{~nm}$ using a Pocket Colorimeter II Filter Photometer (Hach, InC., Loveland, CO). Calibration standards of $0,0.005,0.01$ and $0.02 \mathrm{MMnO}_{4}$ in $0.1 \mathrm{M}$ $\mathrm{CaCl}_{2}$ were used to determine the concentration of $\mathrm{KMnO}_{4}$ remaining in the sample solutions after separation. The quantity of active $\mathrm{C}$ oxidized was calculated assuming 1 mole of permanganate $\left(\mathrm{MnO}_{4}\right)$ was consumed in the oxidation of 0.75 mole of $\mathrm{C}$ (Blair et al., 1995).

\section{Laboratory method}

Soil sample weights of $5.0 \mathrm{~g}$ were reacted with $20 \mathrm{~mL}$ of $0.02 \mathrm{M} \mathrm{KMnO}_{4}$ and $1 M$ $\mathrm{CaCl}_{2}$ solution in $50 \mathrm{~mL}$ screw top polycarbonate centrifuge tubes following the procedure recommended by Weil et al. (2003). The soil was added and followed by sequential aliquots of DI water $(18 \mathrm{~mL})$ and permanganate reagent $(2 \mathrm{~mL})$ using a plastic pipette, respectively. The permanganate reagent stock solution containing $0.2 \mathrm{M} \mathrm{KMnO}_{4}$ and $1 \mathrm{M} \mathrm{CaCl}_{2}$ was adjusted to a $\mathrm{pH}$ of 7.2 using $\mathrm{NaOH}$. The $\mathrm{CaCl}_{2}$ solution was included to promote rapid flocculation of soil colloids. Tubes were capped and shaken by shaker (240 oscillations per minute) for 2 minutes. After shaking, the soils were centrifuged for 10 min to separate the soil from the solution. The supernatant was subsequently filtered using a PTFE filter with $0.45 \mu \mathrm{m}$, openings. 
An aliquot of $1.0 \mathrm{~mL}$ of supernatant was transferred to each tube and diluted to 50 $\mathrm{mL}$ with distilled water $\left(\mathrm{d}-\mathrm{H}_{2} \mathrm{O}\right)$. After the color reaction took place, they were promptly measured at $550 \mathrm{~nm}$ using a Spectronic $20 \mathrm{D}^{+}$(Thermo Fisher Scientific, Waltham, MA). Calibration standards were treated similarly. During each analysis, standards of 0, 0.005, 0.01 and $0.02 \mathrm{M} \mathrm{KMnO}_{4}$ in $0.1 \mathrm{M} \mathrm{CaCl}_{2}$ were used to determine the concentration of $\mathrm{KMnO} 4$ remaining in the sample solutions. Standards were treated similarly to the samples. The quantity of $\mathrm{C}$ oxidized was calculated assuming 1 mole of permanganate $\left(\mathrm{MnO}_{4}\right)$ was consumed in the oxidation of 0.75 mole of $\mathrm{C}$. Active soil organic carbon was calculated using the following equation (Weil et al., 2003):

Active $C\left(\mathrm{mg} \mathrm{kg}^{-1}\right)$

$=\left[0.02 \mathrm{~mol} \mathrm{~L}^{-1}-(a+b X\right.$ absorbance $\left.)\right] \times\left(9000 \mathrm{mg} \mathrm{C} \mathrm{mol}^{-1}\right) \times(0.02$ solution $/ 0.005 \mathrm{~kg}$ soil $)$ Where;

$0.02 \mathrm{~mol} \mathrm{~L}^{-1}$ is the initial solution concentration

$a$ is the intercept and $b$ is the slope of the standard curve

9000 is $\mathrm{mg} C$ ( $0.75 \mathrm{~mol}$ ) oxidized by $1 \mathrm{~mol}$ of $\mathrm{MnO}_{4}$ changing from $\mathrm{Mn}^{7+}$ to $\mathrm{Mn}^{2+}$

0.02 is the volume of $\mathrm{KMnO}_{4}$ solution reacted

0.005 is the $\mathrm{kg}$ of soil used.

\section{Statistical analysis}

Linear regression relationships were developed between POM-C and $\mathrm{MnOxC}$ for each method and each location using the SAS statistical software package (SAS Institute, 1999). The data were subjected to analysis of variance (ANOVA) using the general linear model (GLM) procedure in the SAS statistical program. The multiple comparison Tukey- 
Kramer significant difference test and Fisher's Least Significant Difference (LSD) were used for means comparison with a $p$ value of 0.05 .

\section{RESULTS AND DISCUSSION}

\section{Responsiveness of $\mathrm{KMnO}_{4}$-Oxidizable $\mathrm{C}$ Test to Differences in Management}

Selected soil properties of the four communities at Location \#1 (Umala, Bolivia)

are presented in Table 2.1 and 2.2. The concentrations of SOC, soil test P and

exchangeable potassium, calcium and magnesium were determined to be higher in

Kellhuiri and Vinto Coopani (higher elevation communities) than in San Juan Circa and

San José (lower elevation communities) generally indicating the presence of more

organic and inorganic nutrients in fields located in the two higher elevation communities.

Results of the MnOxC test's responsiveness to different fallow lengths at Location \#1

generally showed that as fallow length increased so did $\mathrm{MnOxC}$ with some differences

among the communities tested (Fig. 2.2). The purpose of fallowing cultivated areas in

this region is to restore soil fertility in the field after cropping (Aguilera et al., 2010). This

general increase in $\mathrm{MnOxC}$ with fallowing may be due to inputs of residue and roots

from regrowth of native vegetation after cropping in fallowed areas and possible manure

inputs from sheep that generally graze these fallow areas. Miranda et al. (2009) reported

that type and length of fallow are also important for soil fertility restoration and

improvement of soil properties. Five-year fallow fields recovered higher total porosity, macroporosity, and saturated hydraulic conductivity than fields with two years of fallow Soil organic carbon (SOC) and soil nutrient $(\mathrm{N}, \mathrm{P}$, and potassium $[\mathrm{K}])$ concentrations significantly increased with increasing fallow duration up to seven years. These increases have been attributed to the decay of above-ground and root biomass of fallow vegetation 
and the presence of native leguminous species among the vegetation (Samake et al., 2005). Other researchers have also observed a gradual accumulation of soil organic matter and improvements in other soil properties at 10 years of fallow (Areola et al, 1982).

\section{Location \#1 (Umala, Bolivia)}

A possible reason for the differences in soil fertility among the communities in Location \#1 is that communities in the higher elevations, such as Kellhuiri and Vinto Coopani, have soil tillage practices that are more dependent on animal traction. The communities had a higher proportion of steep slope and rocky areas with a predominance of animal-based tillage systems and sheep livestock. They usually use only manure as soil amendments.

In contrast, the lower elevation communities of San Juan Circa and San José are situated in relatively flat areas where people frequently use mechanical traction for tillage which may cause more rapid SOM decomposition. They mainly used tractors for operating tillage equipment and cows for livestock. The low elevation area has less native vegetation. The soils are generally sandier and show greater evidence of erosion mainly attributed to a high wind frequency and intensity (Aguilera et al., 2014). Blevins et al. (1983) reported that soil organic matter accumulation in the surface layer is greater under low intensity tillage and when residues were left to decompose on the soil surface.

Powlson and Jenkinson (1981) reported that there was significantly lower $(\mathrm{p}<0.05)$ SOC concentration at $0-20 \mathrm{~cm}$ depth in plots cropped for a period of 13 years than in plots kept fallow for 38 years. 


\section{Location \#2 (Cochabamba, Bolivia)}

Higher concentrations of $\mathrm{MnOxC}$ were generally observed in non-degraded soil compared to degraded soil in all sampled communities (Fig. 2.3). Concentrations of MnOxC in Toralapa Baja, Waylla Puiru, Sanyacani Alto were 24, 53 and 11\% lower in the degraded soil compared to the non-degraded soil, respectively.

The data results indicated that the $\mathrm{MnOxC}\left(\mathrm{mgC} \mathrm{kg}^{-1}\right.$ soil) in the non-degraded soil was significantly greater than degraded land especially in the Torala Baja and Sancayani Alto sites, but not in Waylla Pujru. (Fig. 2.3).

A general trend of increasing soil $\mathrm{MnOxC}$ with higher elevation land area compared with lower elevation land areas ( Toralapa Baja $<$ Waylla Pujru $<$ Sancayani Alto) was observed. This was probably because soils in Toralapa Baja had more frequent and intense wind erosion resulting in lower SOC. Other researchers have observed that surface SOC concentrations were higher in areas of soil accumulation compared to areas of soil removal by soil erosion (Gregorich and Anderson, 1985; Heckrath et al., 2005; Papiernik et al., 2007).

\section{Location \#3 (Indonesia)}

Soil MnOxC was generally higher with increasing amounts of animal manure added and in agroforestry areas compared to that of non-agroforestry areas in which the low manure plot was planted to corn, sweet potato, a low rate of compost. A low rate of fertilizer and manure was applied at the rate of less than $5,000 \mathrm{~kg} \mathrm{ha}^{-1}$ per planting season. The medium manure plot was scallion, chili, corn, with no compost, no fertilizer and manure was applied at the rate of 5,000-15,000 $\mathrm{kg} \mathrm{ha}^{-1}$ per planting season. 
The concentrations of $\mathrm{MnOxC}\left(\mathrm{mg} \mathrm{C} \mathrm{kg}^{-1}\right.$ soil) in the agroforestry sites were significantly greater than non-agroforestry sites with medium manure plot (manure was applied at the rate of 5,000-15,000 $\mathrm{kg} \mathrm{ha}^{-1}$ per planting season), but not in the low manure and no manure plots. There is no statistically significant difference in $\mathrm{MnOcX}$ between low manure and no manure plots (Fig. 2.4). In these locations, a medium rate of manure application can increase soil active $\mathrm{C}$ fractions. In addition, planting trees in alley cropping agroforestry practice may represent an alternative method for increasing soil fertility and maintaining agricultural production, with important practical applications for the sustainability of tropical agriculture. Agroforestry alley cropping practices affect the microclimate, the activity of soil microorganisms and have different amounts and composition of residues compared to monoculture systems (Pinho, 2012). Agroforestry with alley cropping can protect fragile soils through a network of roots produced by the trees and supplemental ground-cover resulting from fallen leaves and the companion crop. Rows of trees, shrubs, and/or grasses planted on the contour of a slope will also serve to reduce soil movement down the slope. Nutrient cycling and soil quality are impacted as deeply-rooted trees exploit lower soil horizons and cycle the nutrients to the surface through litterfall. Additional nitrogen is added to the nutrient pool if a nitrogenfixing tree or shrub is used. Reduced soil erosion by wind and water help maintain soil quality. Additional moisture is added to the site through interception of rainfall by the tree canopy (Garrett, 2009; Center for Agroforestry, 2015). The synergistic interaction between the tree and crop species may increase soil C sequestration (Lal, 2005). Agricultural management practices such as conservation tillage, planting cover crops, nutrient management, and manure applications generally enhance the soil organic carbon 
(SOC) content and stocks in soil (Lal, 2004). Other research has also shown an increase in soil C sequestration with applications of manure. For example, Purakayastha et al. (2008) reported that manure and fertilizers could enhance soil C sequestration leading to higher soil quality. Nair et al. (2009) stated that agroforestry systems can play a major role in soil C sequestration because of higher inputs of organic material to the soil. In agroforestry systems, food production is combined with tree planting which stores more carbon as plant biomass and has a higher potential for soil carbon sequestration than conventional agricultural systems (Jose, 2008; Nair, 2009). In agroforestry, inclusion of multiple species provides greater organic root exudates and a more favorable microenvironment to support microbial and soil faunal communities, root exudates, faunal excretion, and detritus which add to SOM and improves soil aggregate stability (Kremer and Kussman, 2011). Average carbon storage by agroforestry practices is estimated at around 10 tons $\mathrm{ha}^{-1}$ in semi-arid regions, 20 tons ha $^{-1}$ in sub-humid and 50 tons ha $\mathrm{a}^{-1}$ in humid regions, with sequestration rates of smallholder agroforestry systems in the tropics being around 1.5 to 3.5 tons of carbon ha $^{-1}$ year $^{-1}$ (Montagnini, and Nair, 2004). Plantations can sequester significant amounts of carbon and are generally considered to be carbon sinks, unless they replace natural forests, which are usually higher in carbon. The largest potential carbon gains for tree plantations are on marginal agricultural land and degraded soils (Lal, 2004).

\section{Location \#4 (Philippines)}

The $\mathrm{MnOxC}\left(\mathrm{mg} \mathrm{C} \mathrm{kg}^{-1}\right.$ soil) from cultivated field areas at each landscape position were generally lower than non-cultivated areas at similar landscape positions. The $\mathrm{MnOxC}$ levels at each landscape position from non-cultivated field areas showed 
statistically significant difference but not in cultivated area. Among the non-cultivated sites, soil $\mathrm{MnOxC}$ was the highest at the summit position (1,110 $\mathrm{mg} \mathrm{C} \mathrm{kg}^{-1}$ soil), and the lowest at the backslope positions (597 $\mathrm{mg} \mathrm{C} \mathrm{kg}^{-1}$ soil) while soil MnOxC among cultivated sites were relatively similar across the hill-slope transect. The range of soil MnOxC across the cultivated sites was between 440 to $550 \mathrm{mg} \mathrm{C} \mathrm{kg}^{-1}$ soil. Comparing soil $\mathrm{MnOxC}$ among cultivated and non-cultivated area, the non-cultivated area had statistically significant higher $\mathrm{MnOxC}$ than hat of the cultivated area in summit, shoulder, footslope and toeslope landscape positions but not at the backslope position (Fig. 2.5).

Other research has had similar results (Gregorich and Anderson, 1985; Malo et al., 2005; Papernik et al., 2007). These studies compared SOC between cultivated and non-cultivated sites, and reported that soil concentrations of nutrients and organic matter were higher throughout the upper soil profile in non-cultivated landscapes than cultivated landscape at the same landscape position. Gregorich et al. (1998) and Sauerbeck (2001) reported that water, tillage and wind erosion contributed to the redistribution of soil in non-cultivated areas within each landscape position. Spatial and temporal patterns of soil organic carbon were a function of soil redistribution, vegetative productivity, mineralization of soil organic carbon, landscape position and management (West and Marland, 2003). Ritchie et al. (2007) reported that SOC decreased as slope increased, and soils on concave slopes had higher SOC than soils on convex slopes. These data suggested that soil redistribution patterns and topographic patterns may influence SOC distribution across landscapes. Lobb et al. (1999) observed that soil loss from erosion was usually greater at shoulder and backslope landscape positions. Therefore, SOC was 
higher in areas of soil accumulation (i.e., toeslope or footslope) compared to areas of soil removal by erosion (Pennock et al., 1994).

\section{Comparison Between Laboratory and Field MnOxC Methods Among the Field Locations}

Laboratory and field $\mathrm{MnOxC}$ procedures were compared among the diverse locations of this research that represent wide differences in soil resources and management. These comparisons did not include the effects of actually conducting the field test under field conditions and, therefore, are more of an assessment of the different procedures.

Results for soils from Location \#1 (Umala, Bolivia) showed a highly significant relationship $\left(\mathrm{R}^{2}=0.83, \mathrm{p} \leq 0.01\right)$ between the field and laboratory methods (Fig. 2.6). However, $\mathrm{MnOxC}$ measured by the field method was approximately $16 \%$ lower than that which was measured using the laboratory method. This result may be accounted for by the differences in sample measurement and shaking between the two methods.

Similar results were obtained for samples from Location \#2 (Cochabamba, Bolivia). Results for the lab and field methods for $\mathrm{MnOxC}$ determination of labile fractions of soil organic matter from two methods were significantly related $\left(\mathrm{R}^{2}=0.81\right.$, $p<0.05, n=60$ ) (Fig. 2.7). In addition, the field method was on average $36 \%$ lower than that of the laboratory method although at higher levels of $\mathrm{MnOxC}$ the values were generally lower than those observed by Weil et al (2003) possibility due to the greater diversity of soil samples tested in this research.

For Location \#3 (Indonesia), results for the laboratory and field methods for soil MnOxC determinations were significantly related $\left(\mathrm{R}^{2}=0.89, \mathrm{p}<0.05, \mathrm{n}=135\right)$, but the data was generally skewed between low and high $\mathrm{MnOxC}$ results (Fig. 2.8). For this site, a 
general 1:1 correspondence for $\mathrm{MnOxC}$ between the laboratory and field methods was observed.

Results of comparing field and lab methods to determine $\mathrm{MnOxC}$ with samples from Location \#4 (Philippines) showed a significant relationship between the two methods $\left(\mathrm{R}^{2}=0.83, \mathrm{p}<0.05, \mathrm{n}=30\right.$ ) (Fig. 2.9). These results were similar to that of Location \#3 in that they were also highly skewed and showed approximately a 1:1 correspondence (Fig. 2.8).

\section{Comparison of MnOxC with Other Indicators and SOC}

Results for $\mathrm{MnOxC}$ were compared with measures of other soil quality indicators (i.e., SOC and POMC) among the soils at each location that represent differences in soil management (Table 2.3). Soils for all locations showed significant or highly significant relationships between soil $\mathrm{MnOxC}$ and SOC or POM C. In general the relationship between $\mathrm{MnOxC}$ using the laboratory method had a stronger relationship with POM C at all four locations than that of the field method (Table 2.1). Soil MnOxC using the laboratory method was also generally more strongly related with SOC than with POM C (Table 2.1).

Culman et al. (2012) observed in a temperate Kansas site that soil MnOxC was more significantly related to POM C $\left(\mathrm{r}^{2}=0.85^{* *}, \mathrm{p}<0.001\right)$ as compared to SOC $\left(\mathrm{r}^{2}=0.68^{* *}, \mathrm{p}<0.001\right)$. They also observed a significant relationship between soil $\mathrm{MnOxC}$ and microbial biomass $\mathrm{C}\left(\mathrm{r}^{2}=0.73^{* *}, \mathrm{p}<0.001\right)$. A major factor affecting these differences may be the particle size fractions represented by each soil $\mathrm{C}$ fraction. The sand-sized organic $\mathrm{C}$ particles in POM are typically organic material that is more labile than the small-sized C particles fractions. Differences in aggregate sizes may also affect MnOXc. 
In one study, the amount of soil $\mathrm{MnOxC}$ was more affected by the smaller-sized aggregate fraction $(53-250 \mu \mathrm{m})$ than the larger aggregate fraction $(250-2000 \mu \mathrm{m})$. The proportion of variation in $\mathrm{MnOxC}$ accounted by the different size aggregate fractions was 4,31 , and $63 \%$ in the $1000-2000,250-1000$, and $53-250 \mu \mathrm{m}$ fractions, respectively.

\section{CONCLUSIONS}

This study assessed the use of the soil $\mathrm{MnOxC}$ test to determine changes in active $\mathrm{C}$ among a wide range of environmental conditions, cropping systems and soil management practices among agroecosystems with hillslopes in tropical countries around the world. In addition, a comparison was made of the recommended laboratory-based method for determining $\mathrm{MnOxC}$ with the recommended field-based method.

These results suggest $\mathrm{MnOxC}$ is a sensitive indicator to assess changes in active $\mathrm{C}$ with changes in crop and soil management, such as different lengths of fallow duration, degraded and non-degraded areas, agroforestry and non-agroforestry sites, cultivated and non-cultivated areas at different landscape positions and areas receiving different amounts of organic and non-organic amendments. Several advantages to using this procedure include its ease of use that requires a minimal training for the field method, its relative low cost especially if a color chart is substituted for the spectrophotometer, and the growing availability of information to interpret the results. Some disadvantages for this method include the necessity to obtain and store chemical reagents in rural areas in some countries, the challenge of doing wet chemistry procedures in a field setting, and the possible differences in results among diverse operators and environmental conditions (e.g., the effects of solar radiation degrading $\mathrm{KMnO}_{4}$ ). However, effective low cost fieldbased methods for soil testing which support management decisions are important for 
sustainable management of agricultural systems in regions which have had limited access to soil testing in the past. 


\section{REFERENCES}

Aguilera, J., P.P. Motavalli, M.A. Gonzales, and C. Valdivia. 2010. Response of a potato-based cropping system to conventional and alternative fertilizers in the Andean Highlands. Int. J. of Plant \& Soil Sci. 3(2):139-162.

Blair, G.J., R.D.B. Lefroy, and L. Lise. 1995. Soil carbon fractions based on their degree of oxidation, and the development of a carbon management index for agricultural systems. Australian J. Agric. Res. 46:1459-1466.

Blevins, R.L., G.W. Thomas, M.S. Smith, W.W. Frye, and P.L Cornelius.1983. Changes in soil properties after 10 years of continuous no tilled and conventionally tilled corn. Soil Tillage Res. 3:135-145.

Beare, M.H., P.F. Hendrix, and D.C. Coleman. 1994. Water-stable aggregates and organic matter fractions in conventional and no-tillage soils. Soil Sci. Soc. Am. J. 58:777-786.

Besnard, E., C. Chenu, J. Balesdent, P. Puget, and D. Arrouays. 1996. Fate of particulate organic matter in soil aggregates during cultivation. Eur. J. Soil Sci. 47:495-503.

Cambardella, C.A., and E.T. Elliott. 1994. Particulate soil organic matter change across a grassland cultivation sequence. Soil Sci. Soc. Am. J. 56:777-783.

Christensen, B.T. 1992. Physical fractionation of soil organic matter in primary particle-size and density separates. Advances in Soil Science. 20:1-90.

Cotton, F.A. and G.Wilkinson. 1965. Advanced inorganic chemistry. $4^{\text {th }}$ ed. InterScience Publishers, John Wiley and Sons, NY.

Eswaran, H., R. Lal, and P.F. Reich. 2001. Land degradation: an overview. In: Bridges, E.M., I.D. Hannam, L.R. Oldeman, F.W.T. Pening de Vries, S.J. Scherr, and S. Sompatpanit (eds.). Responses to Land Degradation. Proc. 2nd. International Conference on Land Degradation and Desertification, Khon Kaen, Thailand. Oxford Press, New Delhi, India.

Garrett, H.E. 2009. North American Agroforestry: An Integrated Science and Practice (2nd Edition). American Society of Agronomy. pp. 133-162.

Gregorich, E.G., and D.W. Anderson. 1985. Effect of cultivation and erosion on soils of four toposequences in the Canadian prairie. Geoderma 36:343-354.

Gregorich, E.G. and B.H. Ellert. 1993. Light fraction and macroorganic matter in mineral soils. p. 397-407. In MR Carter (ed) Soil sampling and methods of analysis. Lewis Publ, Boca Raton, FL. 
Gregorich, E.G. and H.H. Janzen. 1996. Storage of soil carbon in the light fraction and macroorganic matter. P. 167-190. In M.A. Carter and B.A. Stewart (ed.) Structure and organic matter storage in agriculture soils. Lewis Publ., Boca Raton. FL.

Gregorich, E.G., K.J. Greer, D.W. Anderson, and B.D. Liang. 1998. Carbon distribution and losses: erosion and deposition effects. Soil and Tillage Research. 47:291-302.

Heckrath, G., J. Djurhuu, T.A.Quine, K.Van Oost, G. Govers, and Y. Zhang, 2005. Tillage erosion and its effect on soil properties and crop yield in Denmark. J. Environ. Qual. 34:312-324.

Hussian, I., K.R. Olson, and S.A. Ebelhar. 1999. Long term tillage effects on soil chemical properties and organic matter fractions. Soil Sci. Soc. Am. J. 63:1335-1341.

Islam, R., and A. Sundermeier. 2008. Soil quality test kit. A simple test for organic matter as a measure of soil quality. Ohio State University Extension. Columbus, $\mathrm{OH}$.

Jose, S., 2008. Agroforestry for ecosystem services and environmental benefits: an overview agroforestry system. 76:1-10.

Karlen, D.L., and C.A. Cambardella. 1996. Conservation strategies for improving soil quality and organic matter storage. p. 395-420. In MR Carter and BA Stewart (ed) Structure and organic matter storage in agricultural soils Advances in Soil Science CRC Press, Boca Raton, FL.

Karlen, D.L., M.J. Mausbach, J.W. Doran, R.G. Cline, R.F. Harris, and G.E. Schuman. 1997. Soil quality: A concept, definition, and framework for evaluation. Soil Sci. Soc. Amer. J. 61:4-10.

Kremer, R.J., and Kussman, R.D. 2011. Soil quality in a pecan-kura clover alley cropping system in the Midwestern USA. Agroforest. Syst. 83: 213-223.

Lal, R. 2004. Soil carbon sequestration to mitigate climate change. Geoderma 123:1-22.

Lal, R. 2005. Soil carbon sequestration in natural and managed tropical forest ecosystems. J. Sustain. Forestry. 21:1-30.

Lefroy, R.D.B., G.L. Blair, and W.M. Stog.1993. Changes in soil organic matter with cropping as measured by organic carbon fraction and ${ }^{13} \mathrm{C}$ natural isotope abundance. Plant and Soil 155/156:399-402.

LECO Corporation. 2003. Total/ organic carbon and nitrogen in soils. LECO Corporation. Organic Application Note. 203-821-165. St. Joseph, MO.

Lobb, D.A., R.G. Kachanoski, M.H. Miller. 1999. Tillage translocation and tillage erosion in the complex upland landscapes of southwestern Ontario. Soil tillage Res. 51:189-209. 
Loginow, W., W. Wisniewski, S.S. Gonet, and B. Ciescinska. 1987. Fractionation of organic carbon based on susceptibility to oxidation. Polish J. Soil Sci. 20:47-52.

Malo, D., T.E. Schumacher, and J.J. Doolittle. 2005. Long term cultivation impacts on selected soil properties in the northern great plains. Soil Tillage Res. 81:277-291.

Miranda JP, Silva LM, Lima RL, Donagemma GK, Bertolino AVA, Fernandes NF, Correa FM, Polidoro JC, Tato G. 2009. Fallow effects on improving soil properties and decreasing erosion: Atlantic forest, southeastern Brazil. Geophysical Research Abstracts, Vol. 11. EGU2009-12276.

Mirsky, S.B., E.L. Les, and A.N. Brian. 2008. Evaluating soil management using particulate and chemically labile soil organic matter fractions. Soil Sci. Soc. Am. J. 72: 180-185

Montagnini, F. and P. K. Nair. 2004. Carbon Sequestration: An under-exploited environmental benefit of agroforestry systems. Agroforestry Systems. 61:281-295.

NAC (United States Department of Agriculture National Agroforestry Center). 2000. Working Trees for Carbon Cycle Balance/Agroforestry: Using trees and shrubs to produce social, economic, and conservation benefits. Gary Kuhn, USDA National Agroforestry Center, $<$ http://www.unl.edu/nac $>$.

Nair, P.K.R. 2009. Soil carbon sequestration in tropical agroforestry systems: a feasibility appraisal. Environmental Science \& Policy. 12:8.

Nathan, M., J. Stecker, and Y. Sun. 2006. Soil testing in Missouri: A guide for conducting soil tests in Missouri. Extension Circular 923, 4/06 revision. Missouri Cooperative Extension Service. Columbia, MO.

Papiernik, S.K., M.J. Lindstorm, J.A.Schumacher, T.E. Schumacher, J.A. Malo, and D.A. Lobb. 2007. Characterization of soil profiles in a landscape affected by long-term tillage. Soil Tillage Res. 93:335-345.

Pennock, D.J., D.W. Anderson, and E. de Jong. 1994. Landscape-scale changes in indicators of soil quality due to cultivation in Saskatchewan, Canada. Geoderma. 6:41-19.

Pinho, R.C., P.M. Robert, and S.A. Sonia. 2012. Agroforestry and the improvement of soil fertility: Applied and environmental soil science. http://dx.doi.org/10.11552012/616383

Powlson, D.S., and D.S. Jenkinson.1981. A comparison of the organic matter, biomass, adenosine triphosphate and mineralizable nitrogen contents of ploughed and direct-drilled soils. J. Agr. Sci. 97:713-721.

Purakayastha T.J., L. Rudrappa, D. Singh, A. Swarup, and S. Bhadraray. 2008. Long-term impact of fertilizers on soil organic carbon pools and sequestration rates in maize-wheatcowpea cropping system. Geoderma 144: 370-378. 
Reeves, J.B., A.F. Barry, and K.H. Stephen. 2005. Specular reflection and diffuse reflectance spectroscopy of soils. Applied Spectroscopy. 59:39-46.

Ritchie, J.C., G.W. McCarty, R.V. Erik, and T.C. Kasper. 2007. Soil and soil organic carbon redistribution on the landscape. Geomorlogy. 89:163-171.

Samake' O, Smaling EMA, Kropff MJ, Stomph TJ, Kodio A. 2005. Effects of cultivation practices on spatial variation of soil fertility and millet yields in the Sahel of Mali. Agriculture, Ecosystems \& Environment 109:335-345.

Sanchez, P.A, C.A.Palm, and S.W.Buol. 2003. Fertility capability soil classification: a tool to help assess soil quality in the tropics. Geoderma 114: 157-185.

Sauerbeck, D.R., 2001. $\mathrm{CO}_{2}$ emissions and $\mathrm{C}$ sequestration by agriculture-perspectives and limitations. Nutient cyling in Agroecosystems. 60:253-266.

SAS Institute. 1999. SAS user's guide: Statistics $5^{\text {th }}$ ed SAS Inst, Cary, NC.

Schutter, M.E. and P.R. Dick, 2002. Microbial community profile and activities among aggregates of winter fallow and cover-cropped soil. Soil Sci. Soc. Am. J. 66:142-153.

Six, J., E.T. Elliott, K. Paustian, and J.W. Doran. 1998. Aggregation and soil organic matter accumulation in cultivated and native grassland soils. Soil Sci. Soc. Am. J. 62:13671377.

Skoog D.A., and D.M. West. 1969. Applications of oxidation-reduction reagents to volumetric organic analysis. Chapter 21 Fundamental of analytical Chemistry. $2^{\text {nd }}$ ed. Holt, Rinehart and Winston, NY.

Skjemstad, J.O., R.S. Swift, and J.A. McGowan. 2006. Comparison of the particulate organic carbon and permanganate oxidation methods for estimating labile soil organic carbon. Aust. J. Soil Res. 44:255-263.

The Center for Agroforestry, the University of Missouri. 2015. http://www.centerfor agroforestry.org

Tiessen, H., and J.W.B. Stewart. 1983. Particle size fractions and their use in studies of soil organic matter. II. Cultivation effects on organic matter composition in size fractions. Soil Sci. Soc. Am. J. 47:509-514.

Tirol-Padre, and J. K. Ladha. 2004. Assessing the reliability of permanganate-oxidizable carbon as an index of soil labile carbon. Soil Sci. Soc. Am. J. 68:969-978

Wander, M.M., S.J. Traina, B.R. Stinner, and S.E. Peters. 1994. Organic and conventional management on biologically active organic matter pools. Soil Sci. Soc. Am. J. 58: 11301139. 
Wander M.M., 2004. Soil organic matter fractions and their relevance to soil fraction. p. 67-102. In Magdoff.F. and R.R. Weil (ed.). Soil organic matter in sustainable agriculture. CRC Press, Boca Raton. FL.

Weil, R.R., K.R. Islam, M.A. Stine, J.B. Gruver, and S.E. Samson-Liebig. 2003. Estimating active carbon for soil quality assessment: A simplified method for laboratory and field 
Table 2.1 Selected soil properties due to different fallow length in Umala communities at relatively lower elevation.

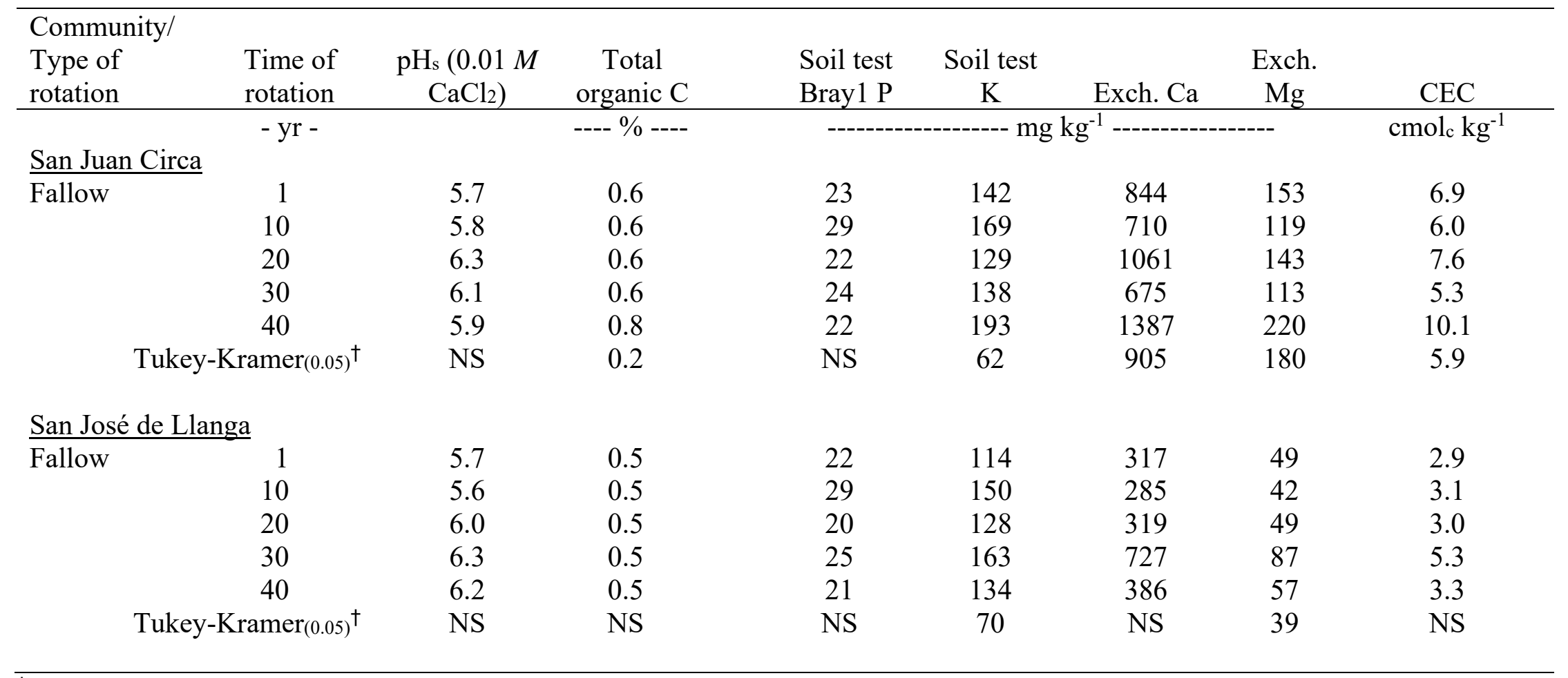

† Tukey-Kramer minimum difference at $\mathrm{p} \leq 0.05$; NS $=$ not significant 
Table 2.2. Selected soil properties due to different fallow length in Umala communities at relatively higher elevation.

\begin{tabular}{|c|c|c|c|c|c|c|c|c|}
\hline $\begin{array}{l}\text { Community/ } \\
\text { Type of rotation }\end{array}$ & $\begin{array}{l}\text { Time of } \\
\text { rotation }\end{array}$ & $\begin{array}{c}\mathrm{pH}_{\mathrm{s}}(0.01 M \\
\left.\mathrm{CaCl}_{2}\right)\end{array}$ & $\begin{array}{c}\text { Total organic } \\
\text { C }\end{array}$ & $\begin{array}{l}\text { Soil test } \\
\text { Bray1 P }\end{array}$ & Soil test K & Exch.Ca & Exch.Mg & CEC \\
\hline & $-\mathrm{yr}-$ & & -----\%"---- & $-\cdots$ & ----- mg k & $5^{-1}----\cdot-$ & - & $\begin{array}{l}\mathrm{cmol}_{\mathrm{c}} \\
\mathrm{kg}^{-1}\end{array}$ \\
\hline \multicolumn{9}{|l|}{$\underline{\text { Kellhuiri }}$} \\
\hline \multirow[t]{5}{*}{ Fallow } & 1 & 5.5 & 1.1 & 49 & 242 & 1197 & 124 & 10.0 \\
\hline & 10 & 6.0 & 1.1 & 35 & 316 & 1904 & 171 & 12.8 \\
\hline & 20 & 5.8 & 1.2 & 15 & 250 & 1267 & 164 & 10.3 \\
\hline & 30 & 7.0 & 1.1 & 19 & 162 & 1550 & 159 & 10.7 \\
\hline & $\operatorname{Kramer}_{(0.05)}{ }^{\dagger}$ & NS & NS & NS & NS & NS & NS & NS \\
\hline \multicolumn{9}{|l|}{$\underline{\text { Vinto Coopani }}$} \\
\hline \multirow[t]{6}{*}{ Fallow } & 1 & 5.8 & 0.8 & 18 & 155 & 1276 & 221 & 10.0 \\
\hline & 10 & 5.9 & 1.0 & 26 & 294 & 1562 & 240 & 11.7 \\
\hline & 20 & 6.6 & 1.1 & 22 & 243 & 3479 & 188 & 20.8 \\
\hline & 30 & 7.6 & 1.1 & 28 & 173 & 3345 & 193 & 20.0 \\
\hline & 40 & 5.8 & 1.2 & 34 & 238 & 1262 & 203 & 10.1 \\
\hline & $\operatorname{Kramer}_{(0.05)}{ }^{\dagger}$ & NS & 0.4 & NS & NS & NS & NS & NS \\
\hline
\end{tabular}

† Tukey-Kramer minimum difference at $\mathrm{p} \leq 0.05$; $\mathrm{NS}=$ not significant 
Table 2.3. Linear regressions for soil active carbon $(\mathrm{MnOxC})$ determined by the laboratory or field method and soil total organic carbon (SOC) or soil particulate organic matter carbon (POM C) for soils at different tropical locations.

\begin{tabular}{ccccc}
\hline & SOC & & \multicolumn{2}{c}{ POM C } \\
\cline { 2 - 2 } Location $^{\dagger}$ & Laboratory & & Laboratory & Field \\
\cline { 4 - 5 }$\# 1(\mathrm{n}=49)$ & $\mathrm{Y}=0.0024+0.0966$ & & $\mathrm{Y}=0.0006 \mathrm{X}+0.2731$ & $\mathrm{Y}=0.0007 \mathrm{X}+0.1985$ \\
& $\mathrm{R}^{2}=0.75^{* * \dagger}$ & & $\mathrm{R}^{2}=0.64^{*}$ & $\mathrm{R}^{2}=0.56^{*}$ \\
$\# 2(\mathrm{n}=60)$ & $\mathrm{Y}=0.004 \mathrm{X}-0.0767$ & & $\mathrm{Y}=0.0004 \mathrm{X}+0.1092$ & $\mathrm{Y}=0.0005 \mathrm{X}+0.0071$ \\
& $\mathrm{R}^{2}=0.78^{* *}$ & & $\mathrm{R}^{2}=0.72^{*}$ & $\mathrm{R}^{2}=0.71^{*}$ \\
$\# 3(\mathrm{n}=135)$ & $\mathrm{Y}=0.0066 \mathrm{X}-0.3036$ & & $\mathrm{Y}=0.0047 \mathrm{X}+1.011$ & $\mathrm{Y}=0.0004 \mathrm{X}+1.514$ \\
& $\mathrm{R}^{2}=0.72^{* *}$ & & $\mathrm{R}^{2}=0.64^{*}$ & $\mathrm{R}^{2}=0.56^{*}$ \\
$\# 4(\mathrm{n}=30)$ & $\mathrm{Y}=0.0143 \mathrm{X}-2.469$ & $\mathrm{Y}=0.0003 \mathrm{X}+0.1777$ & $\mathrm{Y}=0.0004 \mathrm{X}+0.1684$ \\
& $\mathrm{R}^{2}=0.75^{* *}$ & & $\mathrm{R}^{2}=0.60^{*}$ & $\mathrm{R}^{2}=0.58^{*}$ \\
& & & &
\end{tabular}

Location\#1: Umala, Bolivia; Location \#2: Cochabamba, Bolivia; Location \#3: Indonesia; Location \#4: Philippines

$\dagger+*, * *$ indicates $\mathrm{p} \leq 0.05$ and $\mathrm{p} \leq 0.01$, respectively. 


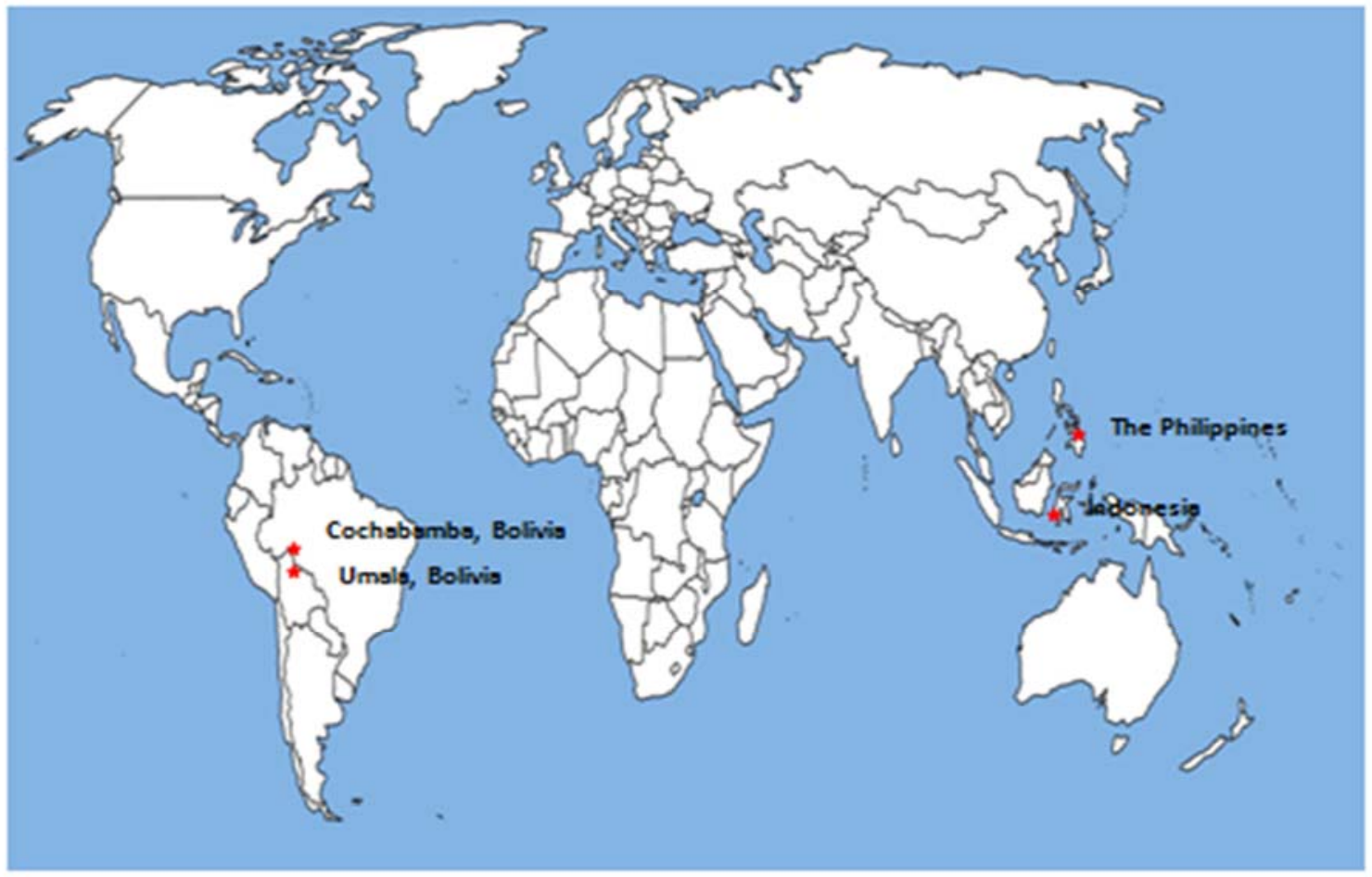

Fig. 2.1. World map indicating general location of study sites. 


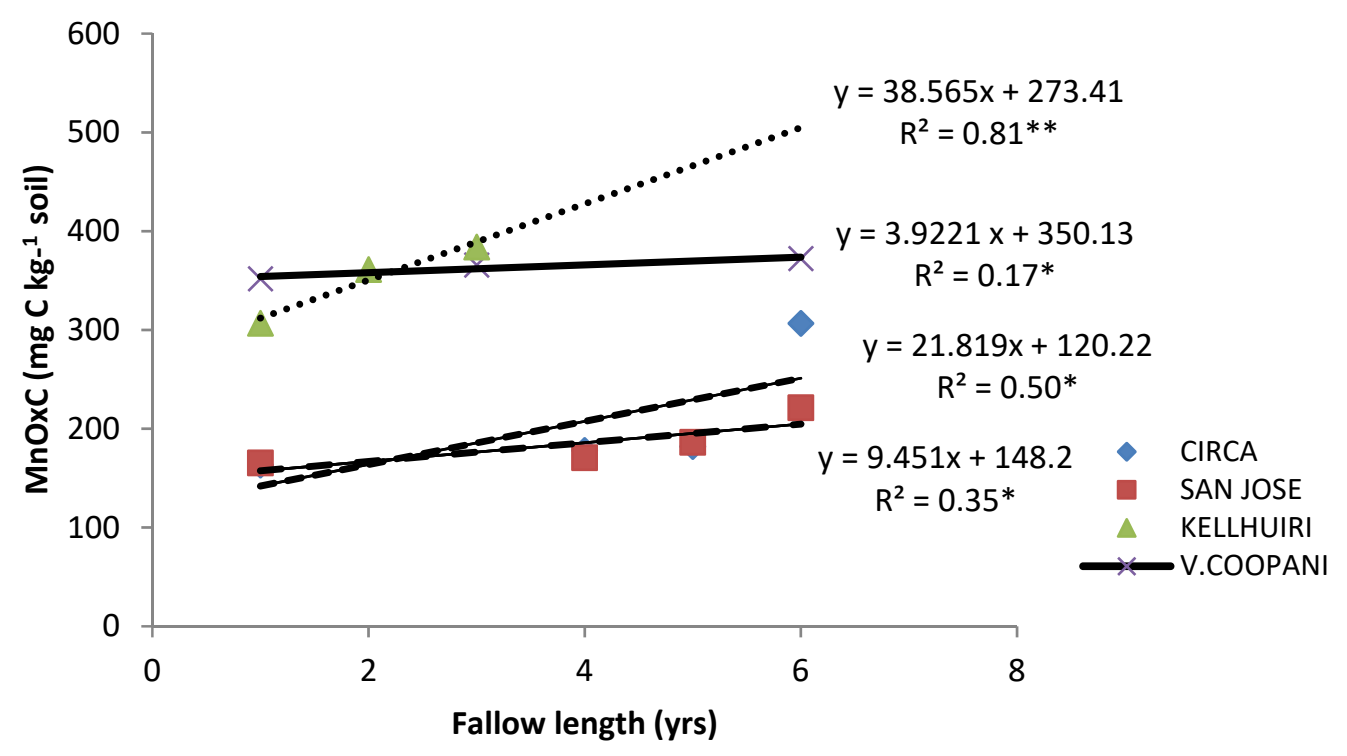

Fig. 2.2. The effect of fallow length on soil active $\mathrm{C}(\mathrm{MnOxC})$ in four communities in Location \#1 (Umala, Bolivia) situated at different elevations. San José de Llanga and San Juan Circa are at relatively low elevation (approximately 3,771 and 3,806 meters above sea level) and Kellhuiri and Vinto Coopani are at relatively high elevation (approximately 4,070 and 4,013 meters above sea level).

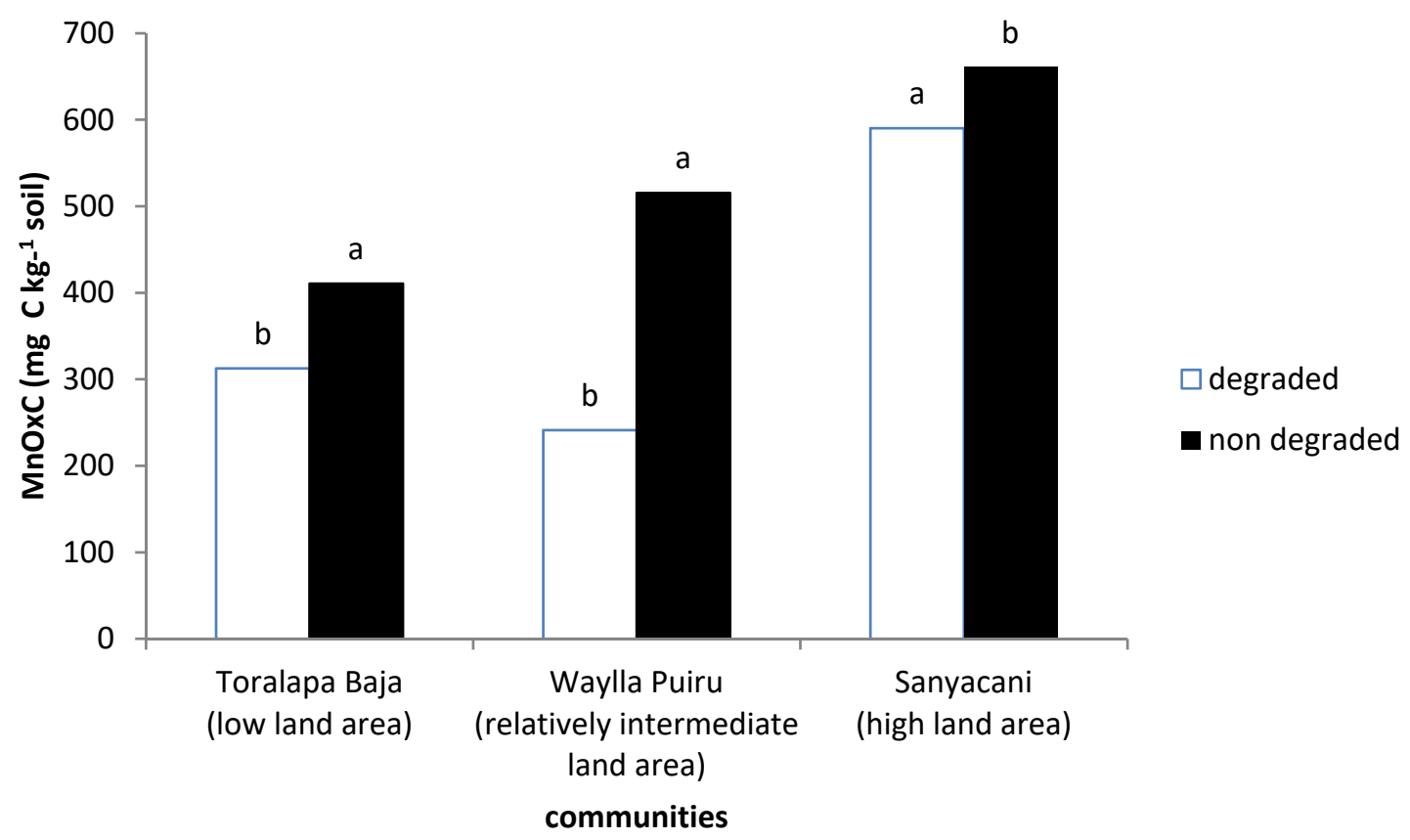

Fig. 2.3.Comparison of soil active $\mathrm{C}(\mathrm{MnOxC})$ content in three communities of different elevations in Location \#2 (Cochabamba, Bolivia) with degraded and nondegraded soils. Comparing each land area, the bars followed with the same letter are not significantly different based on the LSD 0.05 value. 


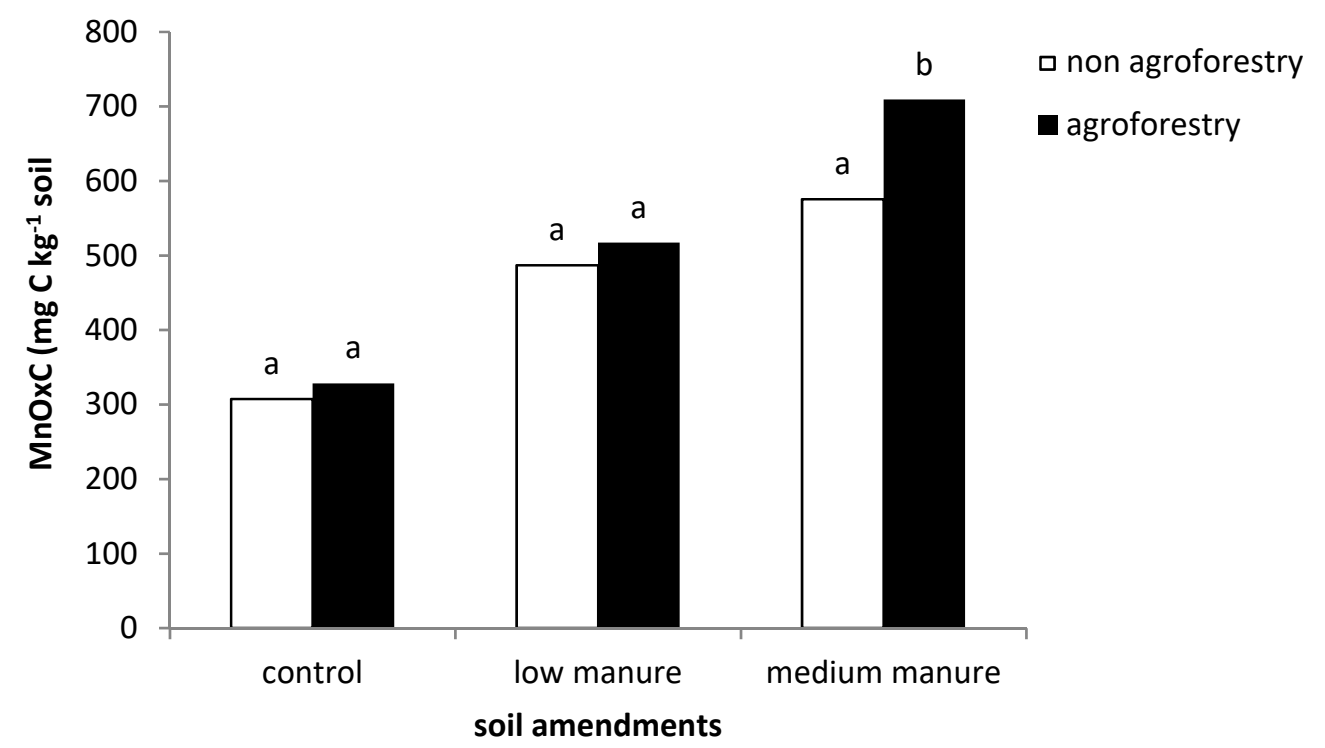

Fig. 2.4. Effects of manure applications on soil active $\mathrm{C}(\mathrm{MnOxC})$ for agroforestry and non agroforestry sites in Location \#3 (Indonesia). Comparing each soil amendment treatment, the bars followed with the same letter are not significantly different based on the LSD 0.05 value.

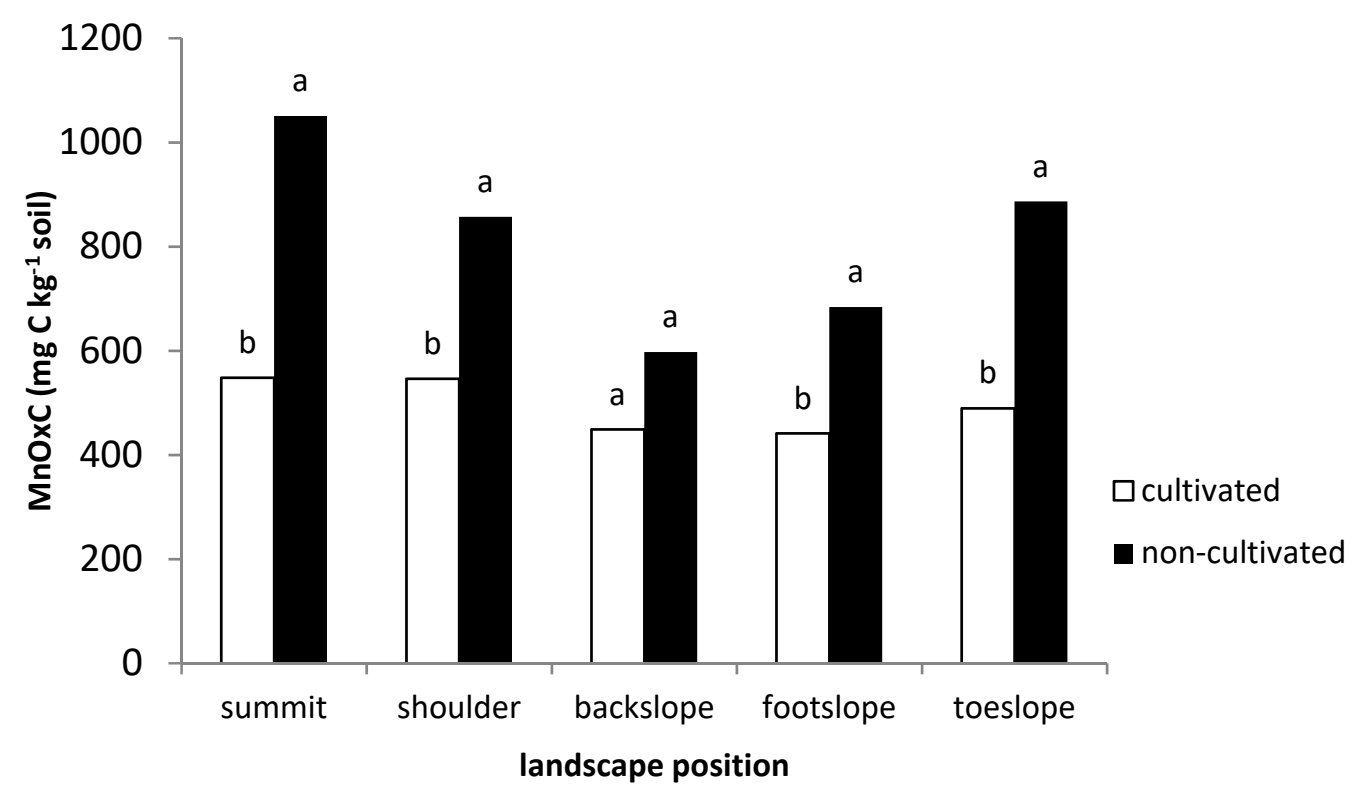

Fig. 2.5. The effects of landscape position in cultivated and non-cultivated areas on soil active $\mathrm{C}(\mathrm{MnOxC})$ for Location \#4 (Philippines). Comparing each landscape position, the bars followed with the same letter are not significantly different based on the LSD 0.05 value. 


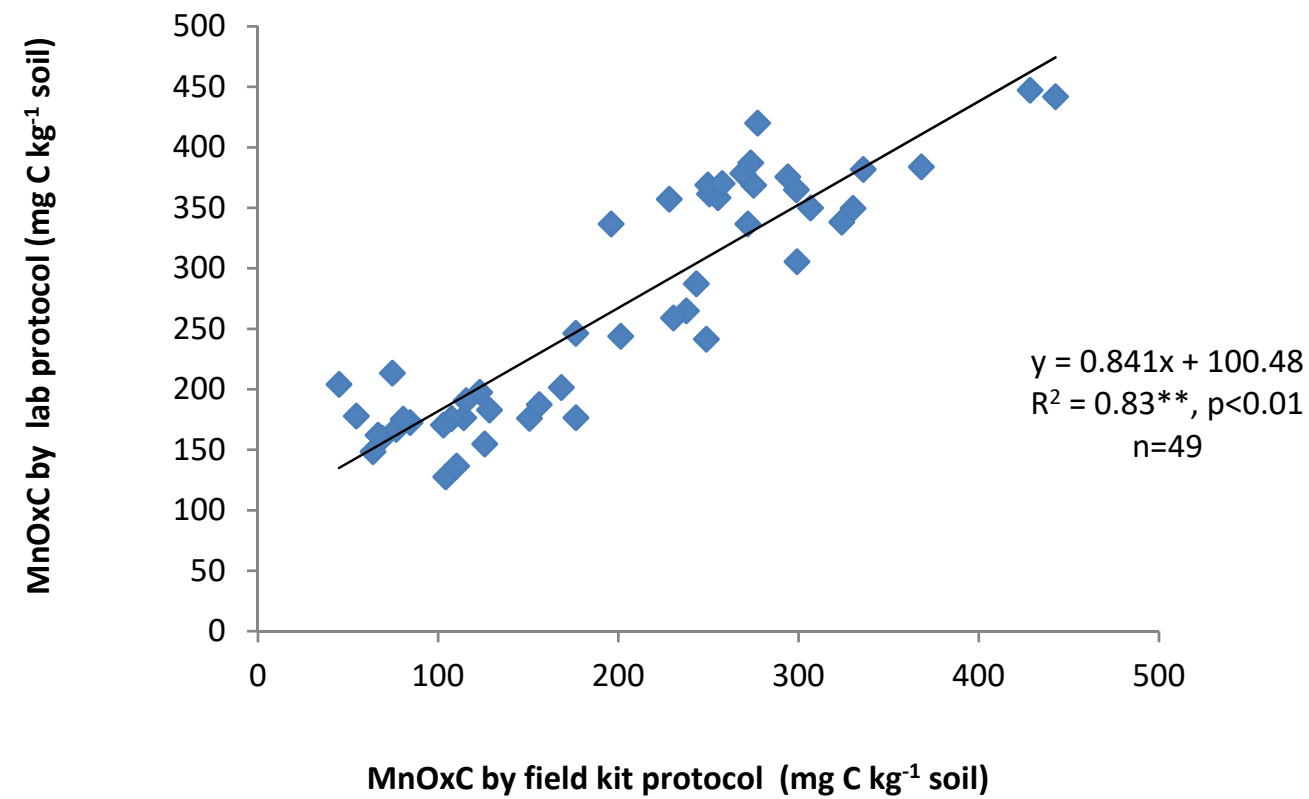

Fig 2.6. A comparison between the field and laboratory methods for soil active $\mathrm{C}$ ( $\mathrm{MnOxC})$ determination in Location \#1 (Umala, Bolivia).

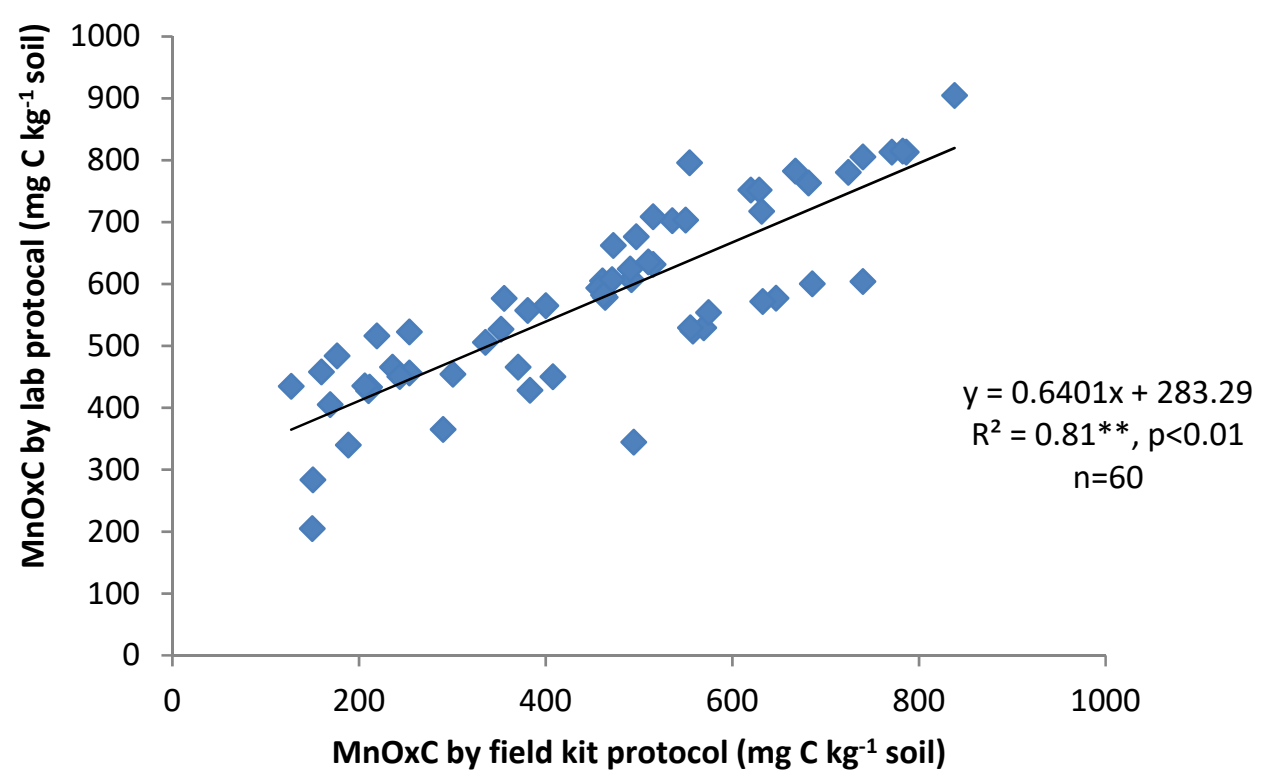

Fig. 2.7 A comparison between laboratory and field methods for soil active $\mathrm{C}(\mathrm{MnOxC})$ determination in Location \#2 (Cochabamba, Bolivia). 


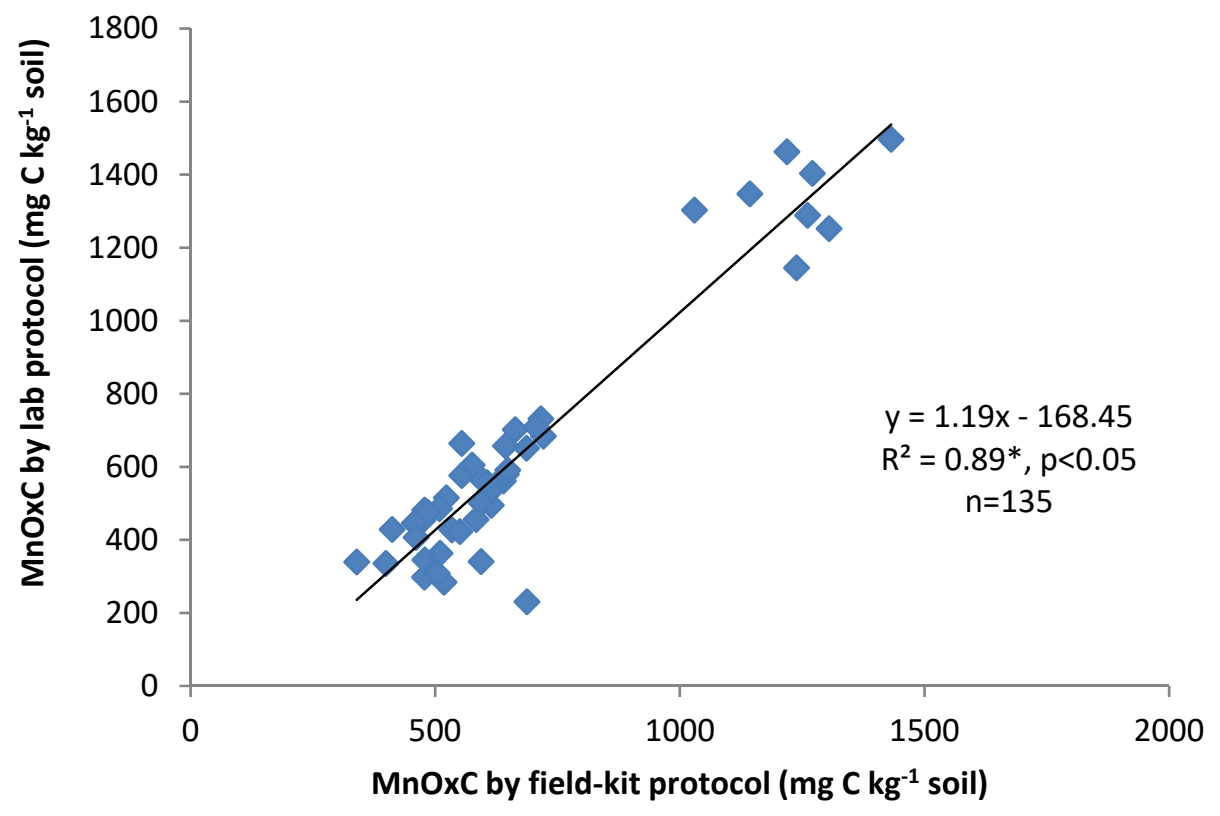

Fig. 2.8. A comparison between laboratory and field methods for soil active $\mathrm{C}(\mathrm{MnOxC})$ determination for Location \#3 (Indonesia).

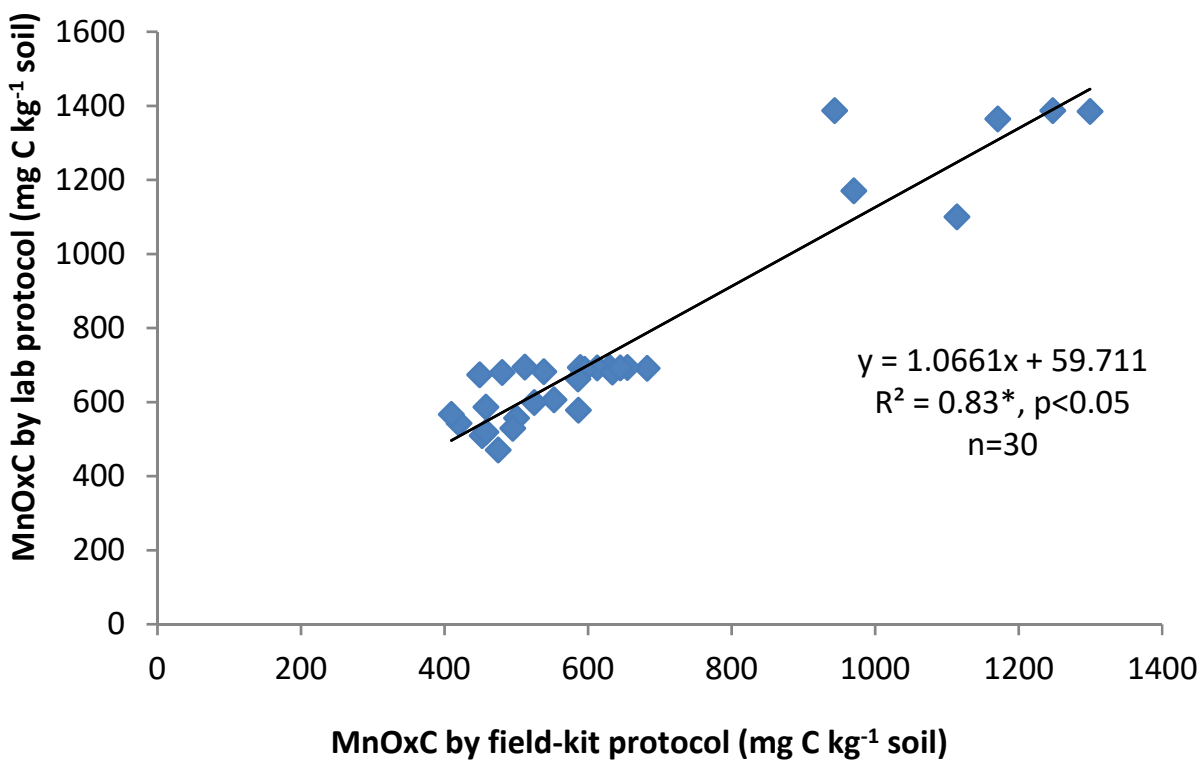

Fig. 2.9. A comparison between laboratory and field methods for soil active $\mathrm{C}(\mathrm{MnOxC})$ determination for Location \#4 (Philippines). 


\title{
CHAPTER 3
}

\section{USE OF VISIBLE NEAR INFRARED SPECTROSCOPY TO EVALUATE TOTAL SOIL ORGANIC CARBON AND SOIL CARBON FRACTIONS IN TROPICAL HILLSLOPE AGROECOSYSTEMS}

\author{
ABSTRACT \\ Total soil organic carbon (SOC) and carbon fractions are important soil properties \\ to assess the effects of management practices on soil quality. To measure these properties \\ using standard methods requires considerable time and expense, and in many countries \\ access to soil testing facilities is challenging. Therefore a sensor-based approach would \\ be useful for assessing soil carbon. This study is to evaluate the ability of visible/near- \\ infrared (VNIR) spectroscopy to estimate SOC and carbon fractions from diverse soils \\ around the world that were under different soil management and cropping systems. \\ Samples were obtained from 0 to $20 \mathrm{~cm}$ depth of soils with contrasting management from \\ agricultural regions in the Bolivian Altiplano, the Island of Mindanao in the Philippines \\ and from Java, Indonesia and analyzed for selected chemical properties. Laboratory \\ analyses were conducted for potential indicators of soil quality, including potassium \\ permanganate oxidizable carbon $(\mathrm{MnOxC})$, total organic carbon (SOC), and particulate \\ organic carbon (POM-C). Soil samples were dried, sieved, and analyzed using a VNIR \\ spectrometer with a wavelength range from 700 to $2500 \mathrm{~nm}$. The data were normalized \\ then transformed to optical density [( $\log 10(1 /$ normalized reflectance $)]$, and analyzed by \\ using partial least square regression (PLSR) to calibrate NIR reflectance to soil organic \\ carbon. According to the PLSR results, VNIR spectroscopy could be an effective \\ technique to estimate SOC and fractions for a wide range of soils from around the world.
}




\section{INTRODUCTION}

Soil organic carbon (SOC) represents one of the major pools in the global C cycle. However, SOC stocks are difficult to quantify accurately due to high spatial variability. Soil organic carbon (SOC) is the carbon content of SOM that is used as a standard laboratory measurement for soil quality indices (SQIs) (Wander et al., 1994). However, Wander et al. (1994) concluded that total SOC was not suitable for tracking changes in soil fertility occurring during the 3 to $4 \mathrm{yr}$ transition period to organic farming management. Biologically active SOM fractions are important for nutrient cycling and supply and may be controlled more by management than total SOC (Marriott and Wander, 2006).

Particulate organic matter carbon (POM-C) is composed of partially decomposed plant, animal, and microbial residues, which serve as a readily available energy source for soil microorganisms and is related to indices of $\mathrm{N}$ supply and nutrient cycling (Joann et al., 2010). The detection and qualification of sensitive or responsive fractions, such as POM-C, might be better indicators of the effects of management changes (Franzluebbers and Stuedemann, 2008).

In general, desirable traits for soil analytical methods include that they should be quick, accurate, and inexpensive and readily adaptable to analyze large numbers of samples. Among the presently available methods for total soil $\mathrm{C}$ quantification, methods based on the combustion of soil samples is considered sufficiently accurate (Watson et al., 2000). However, this type of procedure can be relatively expensive. Procedures based on wet digestion (Nelson and Sommers, 1996) are time-consuming and require the use of harsh chemicals and can be highly variable (Watson et al., 2000). Soil analysis also 
often requires disturbance and processing of the sample which may also change soil properties. Analytical methods based on spectroscopic data collection may overcome these problems compared to conventional laboratory procedures and provide for in situ analysis in agricultural fields (Sudduth et al., 2014).

The advantages of infrared techniques over other analytical techniques are the minimal sample preparation, reduced need for training of staff, the capacity for simultaneous determination of several constituents in every sample, and the ability to analyze samples remotely, since spectra can be acquired electronically and transported electronically for analysis (Russell and Janik, 2008). All of these advantages contribute to a reduced cost of analysis. Diffuse reflectance spectroscopy is a method for the rapid assessment of soil quality and this method is based on components of complex material mixture, such as those contained in the soil (Viscarra et al., 2009). They can be distinguished on the basis of their spectral signatures and they can be explained by their reflectance, as a function of wavelength (Shepherd and Walsh, 2007).

Infrared spectroscopy with soils is more challenging than with plant materials because soil is a complex and variable medium (Ben-dor et al., 1997; Reeves et al., 1999). A spectral library of all samples from a study is first established and then a subset of samples, or calibration set, are selected and used to predict values of the soil properties. Therefore, visible/near infrared diffuse reflectance spectroscopy (VNIR, 700$2500 \mathrm{~nm}$ ) can help provide increased speed and precision needed for soil analysis compared to traditional wet chemistry analytical methods. This method is based on the interaction between light and the surface of materials to which it is directed. The light which reflects from the surface is dependent on the reflectance characteristics of chemical 
and physical properties in soil. It can be estimated through statistical analysis (Dalal and Henry, 1986). Near infrared spectroscopy is important for monitoring soil quality, or the ability of a soil to production and environmental protection goals. Due to the fact that organic carbon is the backbone of organic structures and one of the important elements of plant growth, it has been identified as important for calculating an overall index of soil quality (Andrews et al., 2004).

Near infrared spectroscopy is primarily based on absorbance by covalent bonds between $\mathrm{H}, \mathrm{C}, \mathrm{O}, \mathrm{N}$ such as protein, starch, cellulose, carboxyl, amino acids, water and other molecules (Maria, 2004). They are the primary constituents of organic molecules. Also, soils with higher organic matter contents are generally visually darker in color. These characteristics of NIR and the visual spectrum make it the basis for development of rapid and non-destructive methods to detect changes in soil $\mathrm{C}$ and organic matter (Alexander, 1969; Sudduth and Hummel, 1996).

The VNIR results rely on calibrations, which utilize absorbance at many wavelengths to predict the composition of constituents in samples (Murray, 1993). The VNIR technique combines applied spectroscopy and correlation statistics together. Soil spectra generally show three peaks near 1400, 1900, and $2200 \mathrm{~nm}$ and a few smaller ones between 2200 and $2500 \mathrm{~nm}$, which are overtones and combinations band C-H, N-H, and $\mathrm{O}-\mathrm{H}$ bonds. Spectral data from absorbance of light in the near infrared range are correlated with concentrations or functional properties of the samples. During preparation, this method requires minimal sample preparation and drying (Shepard and Walsh, 2002). 
Several researchers, with the specific goal of soil quality assessment have used VNIR spectroscopy to estimate various SOM components. Vasques et al. (2009) estimated four organic $\mathrm{C}$ fractions, which were described as recalcitrant $\mathrm{C}$, hydrolyzable $\mathrm{C}$, hot-water-soluble $\mathrm{C}$, and mineralizable $\mathrm{C}$ by using samples obtained across a northcentral Florida watershed. It was found that VNIR models accounted for between 65 to $82 \%$ of the variation present in a validation dataset. Ludwig et al. (2002) used VNIR analysis to estimate chemical and biological properties related to soil sustainability. They found good results for $\mathrm{C}, \mathrm{N}$, microbial $\mathrm{C}$, and a number of other variables. Chang et al. (2001) related NIR data to a range of chemical and biological soil properties and they found that among the properties with the strongest relationships to the VNIR data were C, $\mathrm{N}$, and biomass $\mathrm{C}$ (Reeves et al., 2006).

Spectra of soil in the VNIR are largely nonspecific due to the overlapping absorption of soil constituents. This characteristic lack of specificity is compounded by scatter effects caused by soil structure or specific constituents, such as quartz. All of these factors result in complex absorption patterns that need to be mathematically extracted from the spectra and correlated with soil properties. Hence, the spectra require the use of multivariate calibrations (Martens and Naes, 1989). Therefore, statistical methods for data analysis for VNIR include multiple linear regression, and partial least square regression (PLSR) has been used to relate spectral measurements to SOC contents (Sudduth and Hummel, 1993; Chang and Laird, 2002; Martin et al., 2002). Spectroscopy has been used to accurately determine SOC contents in the laboratory and in the field with a portable spectrometer (Shonk et al., 1991; Barnes et al., 2003). Several commercial software packages are available for the recording and manipulation of 
spectral data, development of calibrations and prediction of constituents for unknown samples. Sudduth and Hummel (1991) reported that VNIR data analyzed by PLSR held the most promise for prediction of soil organic carbon content. Excellent correlation $\left(\mathrm{r}^{2}=0.92, \mathrm{SEP}=0.20\right)$ was retained when VNIR data were smoothed to a 60 -nm data point spacing and wavelength range reduced to 1720 to $2380 \mathrm{~nm}$. Partial least square analysis used cross-validation with a split of ten randomly selected subsets. In cross-validation, a subset was removed from dataset and the rest of the data creates a prediction residual for the removed data set. This process continues until each data subset has been removed and data prediction residuals calculated for each data subset. For the analysis, the root mean squared error (RMSE), which measures the difference between an estimator and the true value of the quantity being estimated, is used. The coefficient of determination $\left(\mathrm{R}^{2}\right)$, which predicts the probability future data will correlate to the model, were obtained. Values that are considered "good" or show strong statistical correlation were defined as having an $\mathrm{R}^{2}$ of 0.8 and above. The ratio of prediction error to standard deviation (RPD) is calculated by dividing the data standard deviation (SD) by RMSE to describe the quality of the data (Lee et al., 2009). These statistical operations are performed on spectral data to obtain an optimal statistical relationship between the spectral data and the reference data.

The objective of this study was to assess the use of NIR spectroscopy to determine SOC, POM-C, and active $\mathrm{C}$ or potassium permanganate oxidizable (MnOxC) across a range of soil types and management practices. 


\section{MATERIALS AND METHODS}

\section{Study Sites and Soil Sampling}

Location \#1 was in the Central Andean Highlands (Altiplano) of Bolivia in an agricultural region in Umala Municipality. Soil samples were collected from agricultural fields that represented soils under contrasting management and soil quality including different lengths of fallow periods. These fields are often under potato-based crop rotations (Aguilera et al., 2010). In Umala, four representative rural communities were selected for this study. Two communities (i.e. San José de Llanga and San Juan Circa) were located at relatively low elevation (approximately 3,771 and 3,806 m above sea level) and the another two communities (i.e., Kellhuiri and Vinto Coopani) at relatively high elevation (approximately 4,070 and 4,013 $\mathrm{m}$ above sea level). The most frequent crop rotation is potato-quinoa/barley-barley/oat/-fallow or potato-quinoa/barleybarley/oat-perennial grasses. Fallow is a traditional practice used for soil restoration and grazing and the average fallow length range from 3 to 5 years but it might last up to 20 years in less fertile soils. There is a general trend of suboptimal and inadequate use of organic (e.g., cow and sheep manure) and inorganic fertilizers (i.e., diammonium phosphate and urea). In Umala, four representative rural communities were selected for this study. Two communities (i.e. San José de Llanga and San Juan Circa) were located at relatively low elevation (approximately 3,771 and 3,806 meters above sea level) and the another two communities (i.e., Kellhuiri and Vinto Coopani) at relatively high elevation (approximately 4,070 and 4,013 meters above sea level).

Farmers identified soil problems as one of several factors limiting their crop production (Aguilera et al., 2010). These problems included low soil quality and soil 
fertility (i.e., low soil nutrient content, high clay content making the soil hard to crop, and stoniness), excessive water- and wind-induced soil erosion and inadequate soil management practices. Inadequate soil management practices cited were inappropriate tractor tillage practices, lack of a clear crop rotation strategy, carelessness of incorporating manure, and overgrazing by sheep. Farmers identified different soil types, according to the local criteria of each community and they listed soil characteristics or properties of each soil type. Soil maps drawn by the representative farmers in the first workshop show a general predominance of sandy soils in the four communities. The land and crop management had a slight variation among soil types and among communities. For instance in Kellhuiri, in the clayey soils, farmers grew only barley and quinoa; whereas in Vinto Coopani farmers grew potato, barley and alfalfa. In San Juan Circa, farmers grew potato, quinoa and barley, and in San José de Llanga they grew alfalfa, barley, faba beans, and quinoa (Aguilera et al., 2010).

In the higher elevation communities selected for this study, the land had more hills and steeper slopes and soil tillage practices were generally dependent on animal traction and their soils often have more coarse fragments or rocks. Farmers in the higher elevations generally do not use adequate amounts of manure and manufactured fertilizers for optimizing crop growth (Aguilera et al., 2010).

The lower elevation communities selected for this study were situated in relatively flat areas. People in this area frequently use mechanical traction for tillage. Soils in the lower elevation are generally sandier. All areas are exposed to frequent adverse climatic conditions, mainly frost and drought events, which limit agricultural production to just a few crops, such as potato (Solanum tuberosum L.), quinoa 
(Chenopodium quinoa Wild.), and barley (Hordeum vulgare L.) (Valdivia et al., 2001; Valdivia and Quiroz, 2003). In general, farm size in this region is small due to land subdivision for inheritance purposes. Individual farm agricultural plots were generally small averaging only two hectares or less. (FAO and SNAG, 1995).

Location \#2 was in Cochabamba, Bolivia in the localities of Toralapa Baja, Waylla Pujru and Sancayani Alto, in the province of Tiraque, department of Cochabamba, Bolivia. For this study, 60 soil samples (30 degraded soils and 30 nondegraded soils) were collected from the $0-20 \mathrm{~cm}$ depth from selected farmers' fields. This area has had minimal soil testing conducted previously so separating for degraded and non-degraded land depended on the judgement of agricultural professionals working in the communities and observed factors affecting soil degradation in the communities. Based on community surveys, the main agricultural and environmental problems in this area were identified as soil erosion, low soil fertility, monoculture, pests, contamination and poor soil conservation practices (See Appendix). Community members also consider physical and chemical soil factors, deforestation and land habilitation for cultivation as issues. They believed these problems affect the agricultural production of the area.

Location \#3 was in Indonesia and soil sampling sites were located around Kecamatan Nanggung, a district located in the western part of West Java Province. Some of the soil samples from Indonesia were from areas under traditional management and other samples were from areas under agroforestry practices (primarily alley cropping). Both agroforestry and non-agroforestry systems sampled in Indonesia were managed with different types and rates of amendments including manure, compost and chemical fertilizer with low, medium, and high rates applied. 
The climate in this area is tropical monsoon with a rainy season. Annual rainfall varies between 3,000 to $4,000 \mathrm{~mm}$ and the average annual temperature ranges between $22^{\circ} \mathrm{C}$ and $43^{\circ} \mathrm{C}$. The soils are poorly to moderately drained and occur on undulating to flat uplands. The elevation is approximately $200-1800$ meters above sea level.

Location \#4 was in the Philippines from the Lantapan region of Mindanao Island. Soil samples were collected along a hill-slope transect in which paired samples from cultivated and non-cultivated areas were taken at each transect point. The study site was originally covered with typical tropical forest vegetation for this region. Part of the soil samplings were from agroforestry sites which contained alley cropping systems with fruit trees in vegetative buffer strips and vegetables raised in the cropped areas. Both agroforestry and non-agroforestry sites that were sampled had been managed with different types (i.e., manure, compost and chemical fertilizer) and rates (i.e., low, medium and high) of soil amendments. The climate of the area is tropical monsoon with a rainy season. Soils were poorly to moderately drained and occurred on undulating to flat uplands.

To compare the results and relationships, 49 samples from Location \#1 (Umala, Bolivia), 60 samples from Location \#2 (Cochabamba, Bolivia), 135 samples from Location \#3 (Indonesia) and 30 samples from Location \#4 (Philippines) were analyzed for total soil organic $\mathrm{C}$ and soil $\mathrm{C}$ fractions using several procedures.

\section{Spectral Data Acquisition and Analysis}

Soil spectral reflectance data were obtained in the laboratory using an ASD FieldSpec Pro FR spectrometer (Analytical Spectral Devices, Boulder, Colo.) equipped with an ASD high intensity source probe (mug lamp). For reflectance data collection, 
subsamples of the soils collected in the field were air dried and sieved with a 2-mm screen. Approximately $15 \mathrm{~cm}^{3}$ of soil was packed in a glass-bottomed sample cup for reflectance acquisition determination. Spectra recorded between 700 and $2500 \mathrm{~nm}$ were on a $1 \mathrm{~nm}$ interval. Three detection systems within the machine included: 1) a silicon photodiode array for 350-1000 nm, 2) an InGaAS detector for 1001-1830 nm, and an enhanced InGaAs detector for $1831-2500 \mathrm{~nm}$. Ten-scan data collection with three repeats runs were completed on each soil sample. The ceramic reference disk was scanned after every 5 soil samples. Each soil spectrum was obtained as the mean of 10 scans.

The sample was illuminated through the bottom of a glass-bottomed sample cup. The first 100 readings at the lower visible wavelengths were deleted due to their low signal-to-noise ratio. Each spectral scan was transformed from reflectance to absorbance $(\log 10[1 /$ reflectance $])$.

\section{Data Collection Procedures}

Instrument setup and data collection procedures were adapted from a protocol used by Viscara et al. (2006c) to provide consistent and standard procedures for data information placed into database. The instrument and lamp warmed up for minimum of 1 $\mathrm{hr}$ before measurements. Configuration of the instrument settings consisted of a number of spectrum samples, a number of dark current samples, a number of white reference samples, and a wavelength interval. During analysis, dry samples were loaded into glassbottomed sample dishes, with a white reference (WR) in one dedicated dish of the same type. Each sample dish on the optical window was rotated $30^{\circ}$ between each reading for a total of three readings. 


\section{Data Analysis}

Unscrambler v 9.8 software (Camo Softer, Oslo, Norway, 2006) was used to view and analyze the collected data. This program is able to take the data from the FieldSpec Pro, create graphs, and modify the data using mathematical equations. After viewing the data, the wavelengths $350-399 \mathrm{~nm}$ were deleted due to excessive noise.

One-third of the data was randomly selected as validation points and the rest were used for calibration. With the Unscrambler software, statistical analysis was done using partial least squares regression (PLSR). This method uses information from all wavelengths in the spectrum to develop a calibration algorithm and it is similar to the principal component regression method. It creates a linear regression model by projecting predicted and observed variables in a new space. Unscrambler chooses this number to minimize the errors in a validation dataset (Lee et al., 2009).

Partial least squares regression was used to develop calibrations between soil properties and spectra. A cross-validation procedure was used to select the number of PLS factors to use in the regression, increasing predictive capability and decreasing the potential for overfitting. Model evaluation was based on the coefficient of determination $\left(\mathrm{R}^{2}\right)$ and the root mean square error of prediction (RMSEP). Our basic PLSR analysis used cross-validation with a split of ten randomly selected subsets. From this analysis the RMSEP of validation, which measures the difference between an estimator and the true value of the quantity have been estimated. The $\mathrm{R}^{2}$ predicted the probability of future data to correlate to the model. The ratio of standard deviation to root mean square error of prediction (RPD) was also considered. The RPD statistic is useful when comparing results from datasets containing different degrees of variability or to describe the quality 
of the data fit. Lee et al. (2009) mentioned that RPD values of less than 1.5 are considered poor, good RPD values are between 1.5 and 2.0, and excellent values are above 2.0 . The $\mathrm{R}^{2}$ values less than 0.6 are poor, good $\mathrm{R}^{2}$ values are between $0.6-0.8$, and 0.8 or above are excellent.

\section{Soil Laboratory Analysis}

Soil samples were analyzed for reference data in the laboratory including SOC, POM-C, and $\mathrm{MnOxC}$. Total soil organic $\mathrm{C}$ was determined with dry combustion $\left(900^{\circ} \mathrm{C}\right)$ using a LECO Tru-Spec C/N Analyzer I (LECO Corp., St. Joseph, Mich.) since no carbonates were present in any of the soil samples.

Active $\mathrm{C}$ was determined using the MnOxC test (Weil et al., 2003). A soil mass of $5 \mathrm{~g}$ was reacted with $20 \mathrm{~mL}$ of $0.02 \mathrm{M}$ permanganate solution in $50 \mathrm{~mL}$ screw top polycarbonate centrifuge tubes. The soil was added first followed by sequential aliquots of DI water $(18 \mathrm{~mL})$ and permanganate reagent $(2 \mathrm{~mL})$ using a plastic pipette, respectively. The permanganate reagent contained $0.2 \mathrm{M} \mathrm{KMnO}_{4}$ in $1 \mathrm{M} \mathrm{CaCl}_{2}$ and was adjusted to a $\mathrm{pH}$ of 7.2 using $\mathrm{NaOH}$. The $\mathrm{CaCl}_{2}$ was included to promote rapid flocculation of soil colloids. Tubes were capped and shaken by shaker (240 oscillations per min.) for $2 \mathrm{~min}$. After shaking, the suspensions were centrifuged for $10 \mathrm{~min}$. The supernatant was filtered using a $0.2 \mu \mathrm{m}$ cellulose acetate membrane filter. Aliquots of 1.0 $\mathrm{mL}$ of supernatant were then measured at $550 \mathrm{~nm}$ using a Thermo Electron Corporation Spectronic $20 \mathrm{D}^{+}$at a $550 \mathrm{~nm}$ wavelength. Calibration standards were treated similarly. The quantity of $\mathrm{C}$ oxidized was calculated assuming 1 mol of permanganate $\left(\mathrm{MnO}_{4}\right)$ was consumed in the oxidation of $0.75 \mathrm{~mol}$ of $\mathrm{C}$. An aliquot of $1.0 \mathrm{~mL}$ of supernatant was transferred to each tube and diluted to $50 \mathrm{~mL}$ with $\mathrm{d}-\mathrm{H}_{2} \mathrm{O}$ and after the color reaction took 
place promptly measured at $550 \mathrm{~nm}$ using a Spectronic $20 \mathrm{D}^{+}$(Thermo Fisher Scientific, Waltham, MA). Calibration standards were treated similarly. During each analysis, standards of $0,0.005,0.01$ and $0.02 \mathrm{MKnO}_{4}$ in $0.1 \mathrm{M} \mathrm{CaCl}_{2}$ were used to determine the concentration of $\mathrm{KMnO} 4$ remaining in the sample solutions. Standards were treated similarly to the samples.

To estimate the amount of $\mathrm{C}$ oxidized in the soil, 1 mole $\mathrm{MnO}_{4}$ is consumed (reduced from $\mathrm{Mn}^{7+}$ to $\mathrm{Mn}^{2+}$ ) in the oxidation 0.75 mole $(9000 \mathrm{mg}$ ) of $\mathrm{C}$ which the equations would be $\left[0.02 \mathrm{~mol} \mathrm{~L}^{-1}-(a+b *\right.$ absorbance $\left.)\right] \times\left(9000 \mathrm{mg} \mathrm{C} \mathrm{mol}^{-1}\right) \times(0.02 \mathrm{~L} /$ $0.005 \mathrm{~kg}$ soil) where $0.02 \mathrm{~mol} \mathrm{~L}^{-1}$ is the initial solution concentration, $a$ is the intercept and $b$ is the slope of the standard curve, 9000 is $\mathrm{mg} \mathrm{C}(0.75 \mathrm{~mol})$ oxidized by $1 \mathrm{~mol}$ of $\mathrm{MnO}_{4}$ changing from $\mathrm{Mn}^{7+}$ to $\mathrm{Mn}^{2+}, 0.02 \mathrm{~L}$ is the volume of $\mathrm{KMnO}_{4}$ solution reacted, and 0.005 is the $\mathrm{kg}$ of soil used (Weil et al., 2003).

Particulate organic matter C (POM-C) was analyzed by the methods developed by Cambardella and Elliott (1992) and Marriott and Wander (2006). Particulate organic matter was separated from the soil mineral fraction by dispersion in sodium hexametaphosphate. Thirty grams of whole soil was dispersed with $100 \mathrm{~mL}$ of $5 \mathrm{~g} \mathrm{~L}^{-1}$ sodium hexametaphosphate for $16 \mathrm{hr}$ in a shaker at $200 \mathrm{rpm}$. The suspension was passed through a 53- $\mu \mathrm{m}$ sieve and rinsed with distilled water until a clear solution was obtained. After washing with deionized water, the sand and organic material remaining on all sieves were oven - dried at $50^{\circ} \mathrm{C}$. The dried material was ground with a mortar and pestle and analyzed for total organic $\mathrm{C}$. The total organic $\mathrm{C}$ of this fraction was determined by combustion using a LECO TruSpec C N analyzer (LECO Crop., St. Joseph, MI). 


\section{RESULTS AND DISCUSSION}

Representative spectra from $700 \mathrm{~nm}$ to $2500 \mathrm{~nm}$ generally showed differences in magnitude of reflectance among the soils collected from the different regions and management practices of the four locations (Figure 3.1). Changes in soil properties, brought about by soil management practices can influence VNIR spectra (Viscara et al., 2009). However, the main focus for use of VNIR has been to assess basic soil composition characteristics, particularly soil organic matter (SOM) content, texture, and clay mineralogy (Viscara et al., 2009).

Wavelengths in the visible region $(400-700 \mathrm{~nm})$ are associated with iron containing minerals (Sherman and Waite, 1985). For soil organic matter, such as humic acid was found that it is primarily associated with NIR range $(700-2,500 \mathrm{~nm})$ due to harmonics and overtones of O-H, C-H and N-H absorptions (Clark, 1999; Clark et al. 1990). In general, with all of the soils analyzed, spectral noise mostly occurred in the ends of the range at $350 \mathrm{~nm}$ and at $2500 \mathrm{~nm}$. Because of low signal to noise ratio at the ends of the spectra, only data in the $700 \mathrm{~nm}$ to $2467 \mathrm{~nm}$ range were included in the analyses. The observed spectra across the range of wavelengths were associated with absorption from plant residues, soil organic matter and from some minerals in the soil matrix (Dalal and Henry, 1986; Morra et al.,1991; Daughtry, 2011).

The region between 700 to $800 \mathrm{~nm}$ is thought to be associated with humic compounds produced from decomposition of SOM and plant residues (Daughtry, 2011; Fidencio et al., 2002). Wavelengths around $1400 \mathrm{~nm}$ are related to $\mathrm{OH}$ second overtone and water. Other wavelengths are related to other chemical groups such as $1700 \mathrm{~nm}\left(\mathrm{CH}_{2}\right.$ 
overtone), $1900 \mathrm{~nm}$ (OH overtone related with water), and 2200 and $2300 \mathrm{~nm}$ represent aliphatic C-H and $\mathrm{OH}$ phenolic compounds (Murray, 1986).

\section{Evaluation of the MnOxC, POM-C, and SOC Analyses}

The cross-validation results from the Unscrambler PLS analysis are shown in scatter plots in Figure. 3.2 to 3.13. The results in Table 3.1 show the calibration $\mathrm{R}^{2}$, the validation $\mathrm{R}^{2}$, the standard errors of calibration and prediction/ validation and the RPD values for each location and parameter. In the figures, the values along the $\mathrm{x}-$ or independent variable axis are those from laboratory analysis (i.e., $\mathrm{MnOxC}, \mathrm{POM}-\mathrm{C}$ and SOC) and the $\mathrm{y}$ - or dependent variable axis are the spectral predictions. Each data point on the graph shows the relationship between the measured and predicted data.

For soil samples from Location \#1 (Umala, Bolivia), results for the relationship between actual soil MnOxC and predicted values from VNIR had a good RPD and good coefficient of determination $\left(\mathrm{R}^{2}\right)$ which $\mathrm{RPD}=1.84$ and $\mathrm{R}^{2}=0.71$ (Figure 3.2 ). For actual POM-C, results showed that RPD and the $\mathrm{R}^{2}$ of POM-C showed a poor RPD and low $\mathrm{R}^{2}$ (Figure 3.3). For the SOC analysis, RPD was 2.32 and $\mathrm{R}^{2}=0.86$ (Figure 3.4 ) which indicated that the relationship was excellent and data had an excellent fit in a statistical model using VNIR.

For soil samples from Location \#2 (Cochabamba, Bolivia), the results had the same trend as in Umala. The relationship between actual soil $\mathrm{MnOxC}$ and predicted values from VNIR had a good RPD and good $\mathrm{R}^{2}$. (Figure 3.5). For actual POMC, results showed a poor RPD and poor $\mathrm{R}^{2}$ (Figure 3.6). However SOC, $\mathrm{R}^{2}$ and RPD were excellent $\left(\mathrm{RPD}=2.27\right.$ and $\left.\mathrm{R}^{2}=0.87\right)($ Figure 3.7$)$. 
For soil samples from Location \#3 (Indonesia), results for the relationship between actual soil MnOxC and predicted values from VNIR had a good value with RPD and $\mathrm{R}^{2}$ value of 1.76 and 0.75 , respectively. (Figure 3.8). The RPD for actual versus predicted POM-C based on the NIR spectra was poor $(\mathrm{RPD}=1.39)$ and the $\mathrm{R}^{2}$ was poor $\left(\mathrm{R}^{2}=0.34\right)$ (Figure 3.9). The SOC analysis, $\mathrm{R}^{2}$ and $\mathrm{RPD}$ were excellent $(\mathrm{RPD}=2.86$ and $\mathrm{R}^{2}=0.87$ ) (Figure 3.10).

For soil samples from Location \#4 (Philippines), the relationship between actual soil MnOxC and predicted VNIR values had a good RPD and $\mathrm{R}^{2}$ (Figure 3.11). For actual POM-C, had a poor RPD and $\mathrm{R}^{2}$ (Figure 3.12). For SOC, had an excellent RPD and $\mathrm{R}^{2}$ (Figure 3.13).

Results from analysis of all locations showed that RPD and $\mathrm{R}^{2}$ values for POM-C were relatively low compared to that of the $\mathrm{MnOxC}$ test. A possible explanation for this poor detection of POM C with VNIR is that VNIR reflectance is affected by high residue content (Antoine et al., 2013; Travis et al., 2007). Therefore, VNIR would not have been sensitive to samples which contained high residue content while POM-C would have been higher with these samples. In contrast to the results for POM-C, the relationship between predicted (based on VNIR) and actual SOC was excellent across the different sampling areas with an RPD that ranged from 2.27 to 2.37 and on $\mathrm{R}^{2}$ between 0.86 to 0.93 (Table 3.1).

The PLSR analysis of MnOxC, POM-C and total C showed that soil from different locations exhibited different VNIR reflectance measurements, possibly due to inherent variations in soil properties among these areas as well as the effects of management and environmental factors, such as landscape position. The problem with 
using NIR for measurement of soil properties often occurs because soil color or reflectance are functions of multiple properties, such as texture, mineralogy, SOM, and parent materials. Sudduth and Hummel (1996) tested an NIR sensor's ability to estimate SOC and found that the RPD of SOC in a B-horizon soil was 2.05 and $\mathrm{R}^{2}=0.77$ which means that the quality of data was excellent and data had a good fit in a statistical model. Veum et al. (2014) evaluated the use of VNIR for assessing soil biological indicators and soil organic matter characteristics resulting from different agricultural management practices. They showed that VNIR models estimated several soil quality indicators such as total $\mathrm{N}\left(\mathrm{R}^{2}=0.78\right.$ and $\left.\mathrm{RPD}=2.02\right)$ and phenol oxidase activity $\left(\mathrm{R}^{2}=0.67\right.$ and $\mathrm{RPD}=$ 1.72).

Madari et al. (2005b) conducted an NIR assessment of soil compositional parameters and showed that SOC analysis using NIR for a set of 120 samples had a $\mathrm{R}^{2}$ > 0.97. Other reports showed the same trend for SOC including $\mathrm{R}^{2}=0.86$ (McCarty et al., 2002); $\mathrm{R}^{2}=0.96$ (Reeves et al., 1999); and a $\mathrm{R}^{2}=0.74$ to 0.96 (Madari et al., 2005b).

\section{CONCLUSIONS}

This research provided an opportunity to evaluate the potential use of VNIR spectroscopy as a method for evaluating SOC and selected organic C fractions across a range of soil environments and management conditions. Several potential advantages of use of VNIR compared to conventional soil testing methods in developing countries are that it may allow for simultaneous evaluation of several soil properties and it can be done rapidly and possibly in the field. However, the need for extensive calibration with often difficult statistical techniques and the relative high cost of current NIR instruments has prevented the widespread use of this method. 
Our exploratory results with relatively small sample sizes indicates that this technique may work well with some soil properties, such as soil SOC and MnOxC, but possibly not with POM-C. Variation in calibration results also existed among the different sample areas tested in this research indicating the importance of developing separate calibrations appropriate for the specific environment. Further development of relatively inexpensive field VNIR instruments that are simple to use and maintain is necessary for more widespread adoption of the technique. Development of appropriate calibration information for the environmental conditions encountered around the world in agricultural regions would also expand the potential use of VNIR as a soil diagnostic tool in areas where often soil testing laboratories are expensive and difficult to access.

\section{ACKNOWLEDGEMENTS}

We acknowledge the assistance of Scott T. Drummond with data processing and analysis. We also greatly appreciate the excellent suggestions and guidance from Dr. Kenneth A. Sudduth with the Agricultural Research Service of the U.S. Department of Agriculture. 


\section{REFERENCES}

Aguilera, J., P.P. Motavalli, M.A. Gonzales, and C. Valdivia. 2010. Response of a potatobased cropping system to conventional and alternative fertilizers in the Andean Highlands. Int. J. of Plant \& Soil Sci. 3(2):139-162.

Alexander, J.D. 1969. A color chart for organic matter. Crops Soils. 21:15-17.

Andrews, S.S., D.L. Karlen, and C.A. Cambardella. 2004. This soil management assessment framework: A quantitative soil quality evaluation method. Soil Sci. Soc. Am. J. 68:1945-1962.

Antoine, S., N. Marco, T. Gergely, M. Luca, and Bas van Wesemael. 2013. Prediction of soil organic carbon at the European scale by visible and near infrared reflectance spectroscopy. DOI: 10.1371/journal.pone.0066409

Barnes, E., K.A. Sudduth, J.W. Hummel, S.M. Lesch, D.L. Corwin, C. Yang, C.S.T. Daughtry, and W.C. Bausch. 2003. Remote and ground-based sensor techniques to map soil properties. Photogramm. Eng. Remote Sens. 69:619-630.

Ben-Dor, E., Y. Inbar, and Y. Chen.1997. The reflectance spectra of organic matter in the visible near-infrared and short wave infrared region (400-2500 nm) during controlled decomposition process. Remote Sens. Environ. 61:1-15.

Cambardella, C.A., and E.T. Elliott. 1992. Particulate soil organic matter changes across a grassland cultivation sequence. Soil Sci. Soc. Am. J. 56:777-783.

Camo. 2006. The Unscrambler User Manual. Oslo, Norway: Como software AS.

Chang, C., D.A. Laird, M.J. Mausbach, and C.R. Hurburgh Jr. 2001. Near-infrared reflectance spectroscopy - principal component regression analysis of soil properties. Soil Sci. Soc. Am. J. 65:480-490.

Chang, C.W., and D.A. Laird. 2002. Near-infrared reflectance spectroscopic analysis of soil C and N. Soil Sci J. 167:110-116.

Clark, R.N., 1999. Spectroscopy of rocks and minerals and principals of spectroscopy. In "Remote Sensing for the Earth Sciences" (A.N. Rencz, Ed.), pp. 3-58. John Wiley \& Sons, Chichester, UK.

Clark, R.N., T.V.V.King,. M. Klejwa, G.A. Swayze, and N.Vergo. 1990. High spectral resolution reflectance spectroscopy of minerals. J. Geophys. Res. 95:1265312680 . 
Dalal, R.C., and R.J. Henry. 1986. Simultaneous determination of moisture, organic carbon, and total nitrogen by near-infrared reflectance spectrophotometry. Soil Sci Soc Am. J. 50:120-123.

Daughtry, C.S.T. 2001. Discriminating crop residues from soil by shortwave infrared reflectance. Agron. J. 93:125-131.

Fidencio, P.H., R.J. Poppi, J.C De Andrade, H. Cantarella,. 2002. Determination of organic matter in soil using near-infrared spectroscopy and partial least square regression. Common. Soil. Sci. Plant. Anal. 33:1607-1605.

Franzluebbers, A.J., and J.A. Stuedemann. 2008. Early response of soil organic fractions to tillage and integrated crop-livestock production. Soil Sci. Soc. Am. J. 72:613625 .

Lee, K.S., D.H. Lee, K.A. Sudduth, S.O. Chung, N.R. Kitchen, and S.T. Drummond. 2009. Wavelength identification and diffuse reflectance estimation for surface and profile soil properties. Transactions of ASABE. 52:683-695.

Ludwig, B., P.K. Khanna, J. Bauhus, and P. Hopmans. 2002. Near infrared spectroscopy of forestry soils to determine chemical and biological properties related to soil sustainability. For. Ecol. Management. 171:121-132.

Madari, B.E., J.B Reeves III, M.R. Coelho, P.L.O.A. Machado, H. De-Polli, R.M. Coelho, V.M. Benites, L.F. Souza, and G.W. McCarty. 2005b. Mid- and nearinfrared spectroscopic determination of carbon in a diverse set of soils from the Brazilian National Soil Collection. Spectrosc. Lett. 38:721-740.

Martin, P.D., D.F. Malley, G. Manning, and L. Fuller. 2002. Determination of soil organic carbon and nitrogen at the field using near infrared spectroscopy. Can. J. Soil Sci. 82:413-422.

Malley, D.F., H. Ronicke, D.L. Findley,and B. Zipple. 1998. Feasibility of using near infrared reflectance spectroscopy for the analysis of C N P and diatoms in lake sediment, Journal of Paleolimnology 31:295-306.

Marriott, E.E. and M.M. Wander. 2006. Total and labile soil organic matter in organic and conventional farming systems. Soil Sci. Soc. Am. J. 70:950-959.

Maria, E. H., P. Jerry and J.M. William. 2004. Use of near infrared reflectance spectroscopy (NIR) to determine total carbon and total nitrogen in wetland soils. Annual report (Olentangy River Wetland Research Park). pp. 99-102.

Martens, H. and T. Naes. 1989. Multivariate Calibration. John Wiley \& Sons, Chichester, UK. 419 pp. 
McCarty, G., J.B. Reeves, V.B. Reeves, R.F. Follett, and J. Kimble. 2002. Mid-infrared and near-infrared diffuse reflectance spectroscopy for soil carbon measurement. Soil Sci. Am. J. 66:640-646.

Morra, M.J., M.H Hall, and I.L Freeborn. 1991. Carbon and nitrogen analysis of soil fraction using near-infrared reflectance spectroscopy. Soil Sci. Soc. Am. J. $55: 288-291$

Murray, I. 1986. The NIR spectra of homologous series of organic compounds. In: Hollo, J. Kffka, K.J. Gonczy, J.J. (eds.). Proceedings of the International NIR/NIT Conference, Akademiai Kiado. Budapest. pp. 13-28.

Murray, I. 1993. Forage analysis by near-infrared spectroscopy. In Davies, A., R.D. Baker, S.A. Grant, and A.S. Laidlaw (eds.) Measurement handbook. British Grassland Society (Chapter 14). Reading. UK.

Nelson, D.W., and L.E. Sommers. 1996. Total carbon, organic carbon, and organic matter. In D.L.Sparks et al. (eds.) Methods of soil analysis. Part 3. SSSA and ASA, Madison, WI.

Reeves, J.B., G.W. McCarthy, and J.J. Meisinger. 1999. Near infrared reflectance spectroscopy for the analysis of agricultural soil. J. Near Infrared Spectrosc. 7:179-193.

Reeves, J.B., R.F. Follett, G.W. McCarty, and J.M. Kimble. 2006. Can near or midinfrared diffuse reflectance spectroscopy be used to determine soil carbon pools? Commun. Soil Sci. Plant Anal. 37:2307-2325.

Russell, C., and L. Janik. 2008. Infrared Analytical Service. Australia soil club. http:// www.soil.org.au.

Shepherd, K.D., and G.W. Markus. 2007. Infrared spectroscopy-enabling an evidencebased diagnostic surveillance approach to agricultural and environmental management in developing countries. J. Near Infrared Spectrosc. 15:1-9.

Shepherd, K.D., and M.G. Walsh, 2002. Development of reflectance spectral libraries for characterization of soil properties. Soil Sci. Soc. Am. J. 66:988-998.

Sherman, D.M.,and T.D.Waite. 1985. Electronic spectra of Fe3 oxides and oxyhydroxides in the near infrared to ultraviolet. Am. Mineral. 70:1262-1269.

Shonk, J.L., L.D. Gaultney, D.G. Schulze, and G.E. Van Scoyoc. 1991. Spectroscopic sensing of soil organic matter. Trans. ASAE 34:1978-1984.

Sudduth, K.A., and J.W. Hummel. 1991. Evaluation of reflectance methods for soil organic matter sensing. Transaction of the ASAE. 34:1990-1909. 
Sudduth, K.A., and J.W. Hummel. 1993. Soil organic matter, CEC, and moisture sensing with a portable NIR spectrophotometer. Trans. ASAE 36:1571-1582.

Sudduth, K.A., J.W. Hummel, and S.J. Birrell. 1996. Sensors for site-specific management. In The State of Site-Specific Management for Agriculture, p.183210.ASA, CSSA, and SSSA. Madison,WI

Sudduth, K.A., H.J. Kim, and P.P. Motavalli. 2014. Soil. p. 23-61. In L.M. Moretto and K. Kalcher (eds.). Environmental analysis by electrochemical sensors and biosensors. Vol. 1. Fundamentals. Springer, Berlin, Germany.

Travis, H.W., L.S. Cristine, J.B. David, and C.T. Hallmark. 2007. In site characterization of soil clay content with Visible Near-Infrared Diffuse Reflectance Spectroscopy.doi.10.2136/sssajv2006.0211.

Vasques, G.M., S. Grunwald, and J.O. Sickman. 2009. Modeling of soil organic carbon fractions using visible-near-infrared spectroscopy. Soil Sci. Soc. Am. J. 73:176184.

Viscara, R.A., S.R Cattle, A. Ortega, and Y. Fauad. 2009. In situ measurements of soil color, mineral composition and clay content by vis-NIR spectroscopy. Geoderma 150: 253-266.

Viscarra R.A., D.J.J. Walvoort, A.B. McBratney, L.J. Janik, and J.O. Skjemstad. 2006c. Visible, near infrared, mid infrared or combined diffuse reflectance spectroscopy for simultaneous assessment of various soil properties. Geoderma 131:59-75.

Veum, K.S, W.G. Keith, R.J. Robert, J.M. Randall, and A.S. Kenneth. 2014. Biological indicators of soil quality and soil organic matter characteristics in an agricultural management continuum. Biogeochemistry 117:81-99.

Wander, M.M., S.J. Traina, B.R. Stinner, and S.E. Peters. 1994. Organic and conventional management on biologically active organic matter pools. Soil Sci. Soc. Am. J. 58: 1130-1139.

Watson, R.T., I.R. Noble, B. Bolin, N.H. Ravindranath, and D.J. Verardo. 2000. Land use, land use change and forestry. A special report of the IPCC. Cambridge University Press, Cambridge.

Weil, R.R., K.R. Islam, M.A. Stine, J.B. Gruver, and S.E. Samson-Liebig. 2003. Estimating active carbon for soil quality assessment: a simplified method for laboratory and field use. Am. J. Altern. Agric. 18:3-17.

Whalen, J.K., and L. Sampedro. 2010. Soil ecology and management. CABI. UK. 
Table 3.1. Model evaluation statistics for partial least square analysis for predicting soil total organic $\mathrm{C}$ and selected organic $\mathrm{C}$ fractions using VNIR spectroscopy for each study location.

\begin{tabular}{|c|c|c|c|c|c|}
\hline \multirow[b]{2}{*}{$\begin{array}{l}\text { Location/ } \\
\text { Soil Property }\end{array}$} & \multicolumn{5}{|c|}{ Model evaluation statistics } \\
\hline & $\mathrm{R}^{2} \mathrm{Cal}^{\dagger \dagger}$ & $\mathrm{R}^{2} \mathrm{Val}$ & SEC & SEP & RPD \\
\hline$\frac{\text { Location \#1 }}{\text { (Umala, Bolivia }}$ & & & & & \\
\hline $\mathrm{MnOxC}^{\dagger}$ & 0.71 & 0.70 & 50.77 & 51.74 & 1.84 \\
\hline POMC & 0.42 & 0.25 & 4.43 & 5.14 & 1.14 \\
\hline $\begin{array}{c}\text { SOC } \\
\text { Location \#2 } \\
\text { (Cochabamba, Boli }\end{array}$ & 0.86 & 0.82 & 0.09 & 0.11 & 2.32 \\
\hline $\mathrm{MnOxC}$ & 0.74 & 0.64 & 95.87 & 114.69 & 1.65 \\
\hline POMC & 0.41 & 0.27 & 0.08 & 0.09 & 1.15 \\
\hline $\begin{array}{c}\text { SOC } \\
\text { Location \#3 } \\
\text { (Indonesia) }\end{array}$ & 0.87 & 0.81 & 0.33 & 0.40 & 2.27 \\
\hline $\mathrm{MnOxC}$ & 0.76 & 0.92 & 30.78 & 39.89 & 1.67 \\
\hline POMC & 0.71 & 0.51 & 0.48 & 0.66 & 1.40 \\
\hline $\begin{array}{c}\text { SOC } \\
\text { Location \#4 } \\
\text { (Philippines) }\end{array}$ & 0.92 & 0.87 & 0.28 & 0.37 & 2.78 \\
\hline $\mathrm{MnOxC}$ & 0.75 & 0.82 & 95.41 & 107.23 & 1.76 \\
\hline POMC & 0.32 & 0.47 & 3.23 & 0.09 & 1.14 \\
\hline SOC & 0.93 & 0.88 & 0.77 & 1.41 & 2.37 \\
\hline
\end{tabular}

$\bar{\dagger}$ Potassium permanganate oxidizable carbon (MnOxC); Particulate organic matter carbon (POMC); Total Soil organic carbon (SOC).

${ }^{\dagger} \mathrm{R}^{2} \mathrm{Cal}=$ coefficient of determination of calibration, $\mathrm{R}^{2} \mathrm{Val}=$ coefficient of determination of validation, $\mathrm{SEC}=$ standard error of calibration, $\mathrm{SEP}=$ standard error of prediction/or validation, $\mathrm{RPD}=$ Ratio of standard deviation to root mean square error of prediction. 


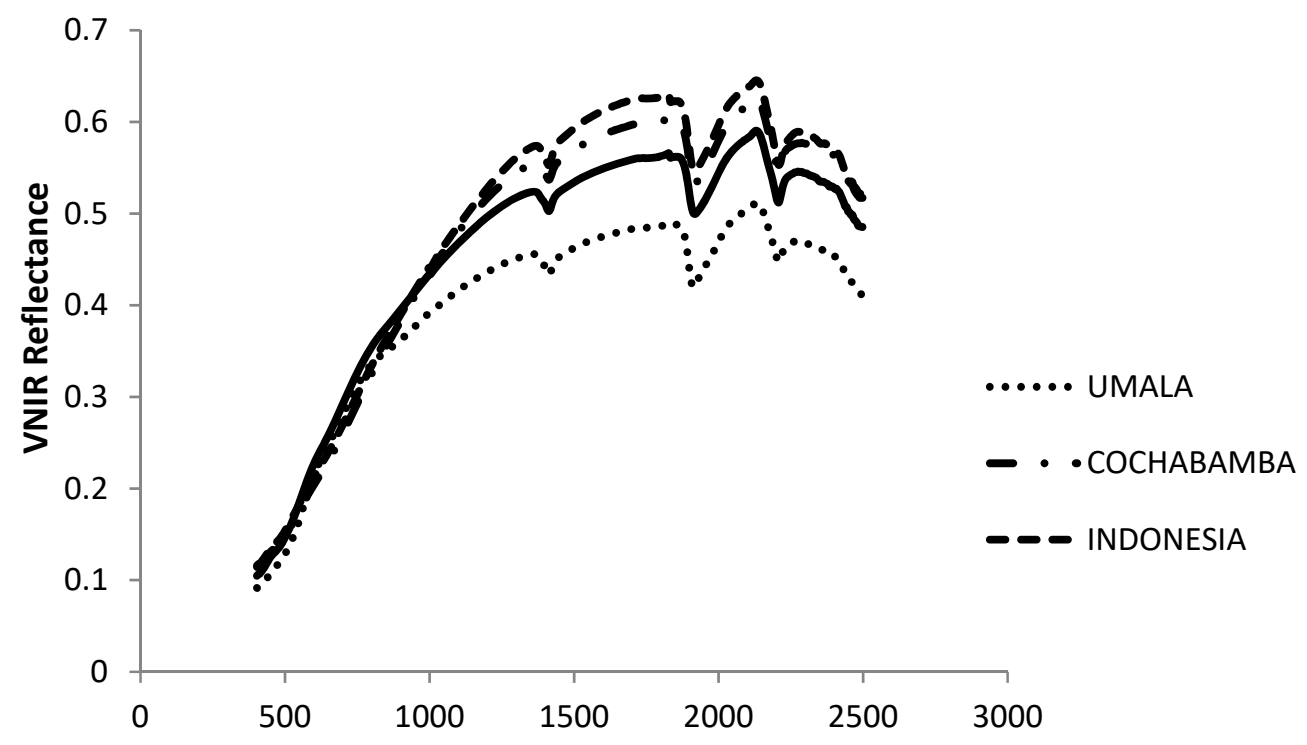

Wavelength $(\mathrm{nm})$

Figure 3.1. Representative soil VNIR reflectance spectra from the four study locations Location \#1 (Umala, Bolivia); Location \#2 (Cochabamba, Bolivia); Location \#3 (Indonesia); and Location \#4 (Philippines).

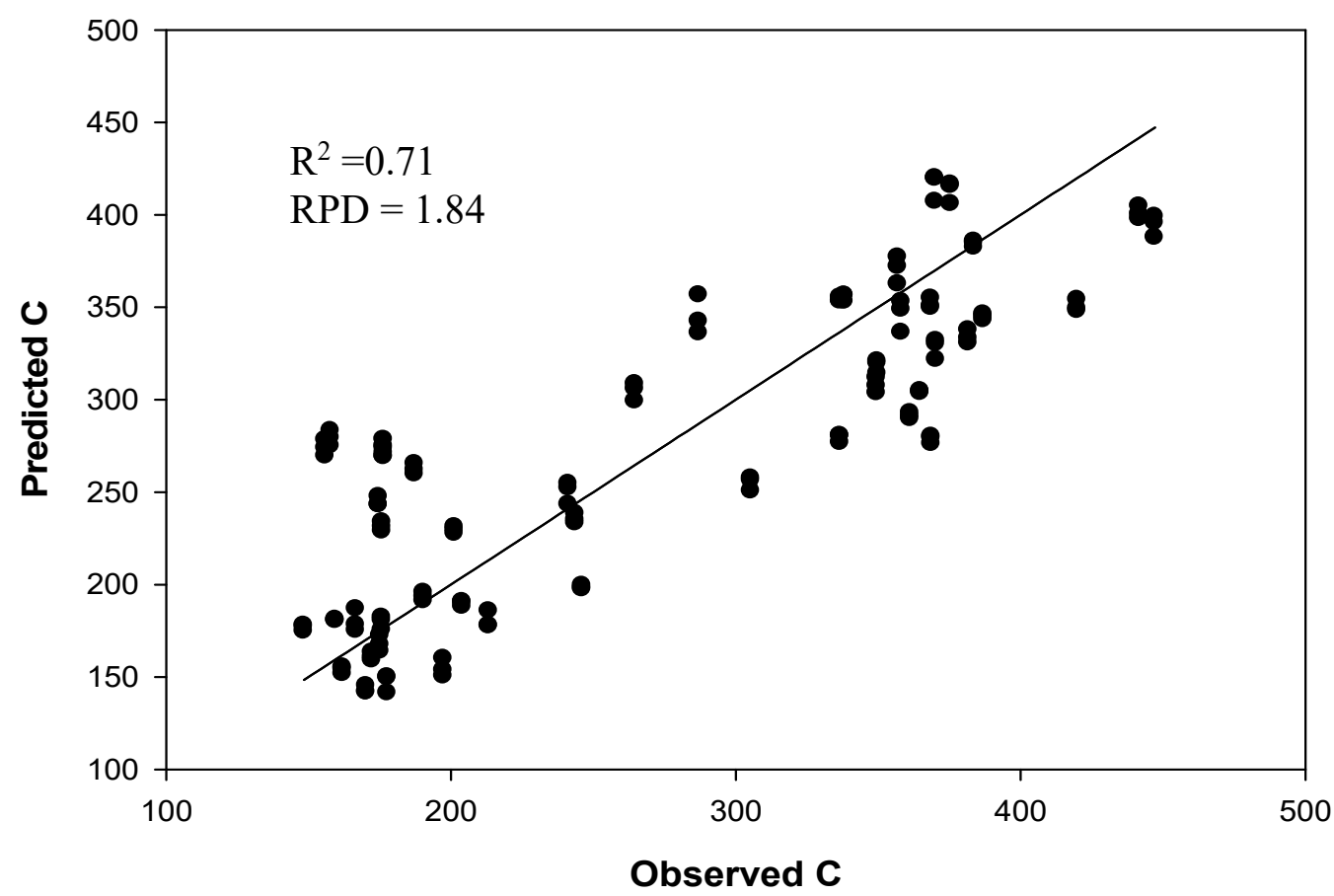

Figure 3.2. VNIR calibration curve for $\mathrm{MnOxC}\left(\mathrm{mg} \mathrm{C} \mathrm{kg}^{-1}\right.$ soil) for soil samples from Location \#1. (Umala, Bolivia). (RPD= Ratio of standard deviation to root mean square error of prediction; $\mathrm{R}^{2}=$ Coefficient of determination). 


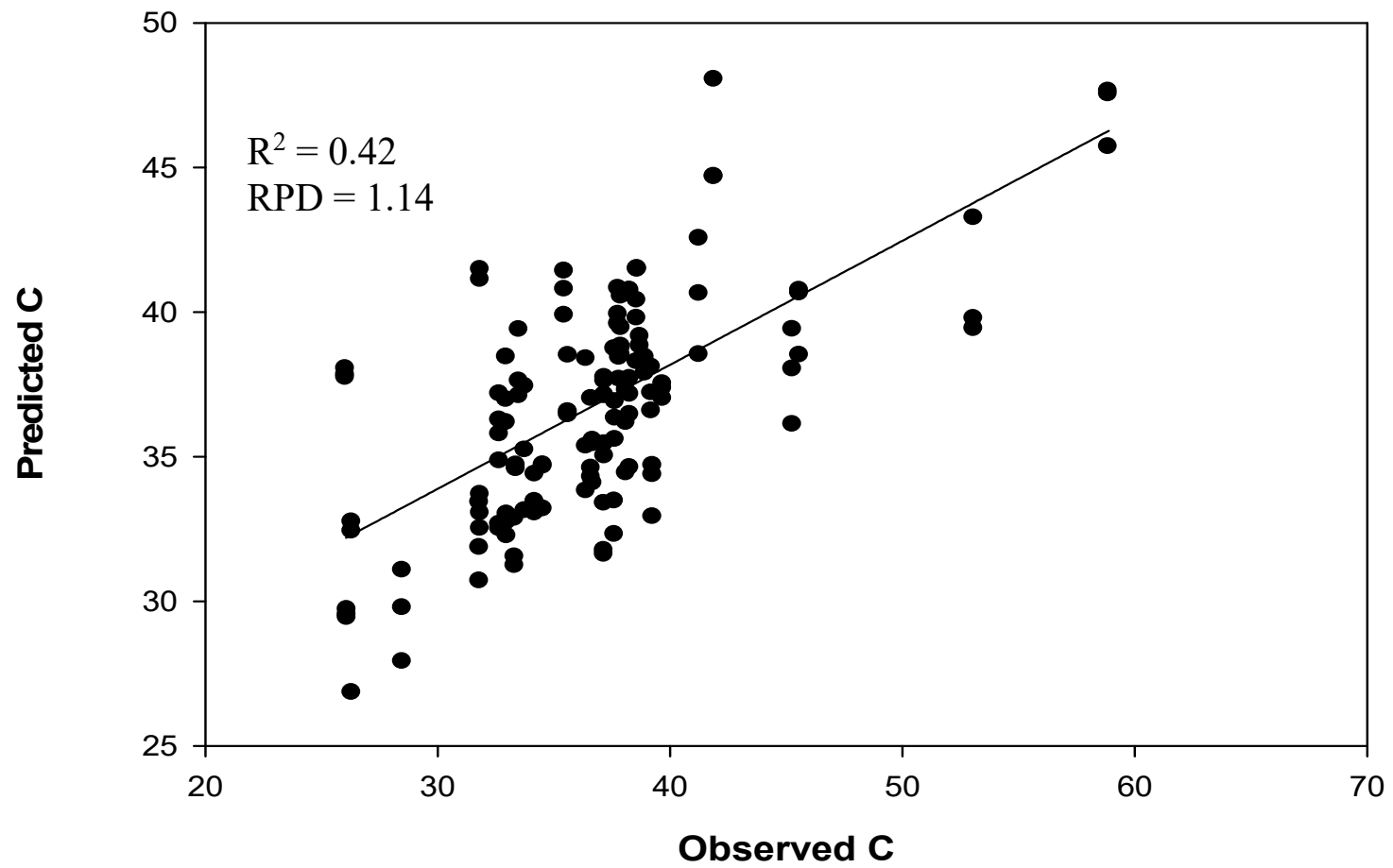

Figure 3.3. VNIR calibration curve for POM-C (\% of total C) from Location \#1 (Umala, Bolivia). (RPD= Ratio of standard deviation to root mean square error of prediction; $\mathrm{R}^{2}=$ Coefficient of determination).

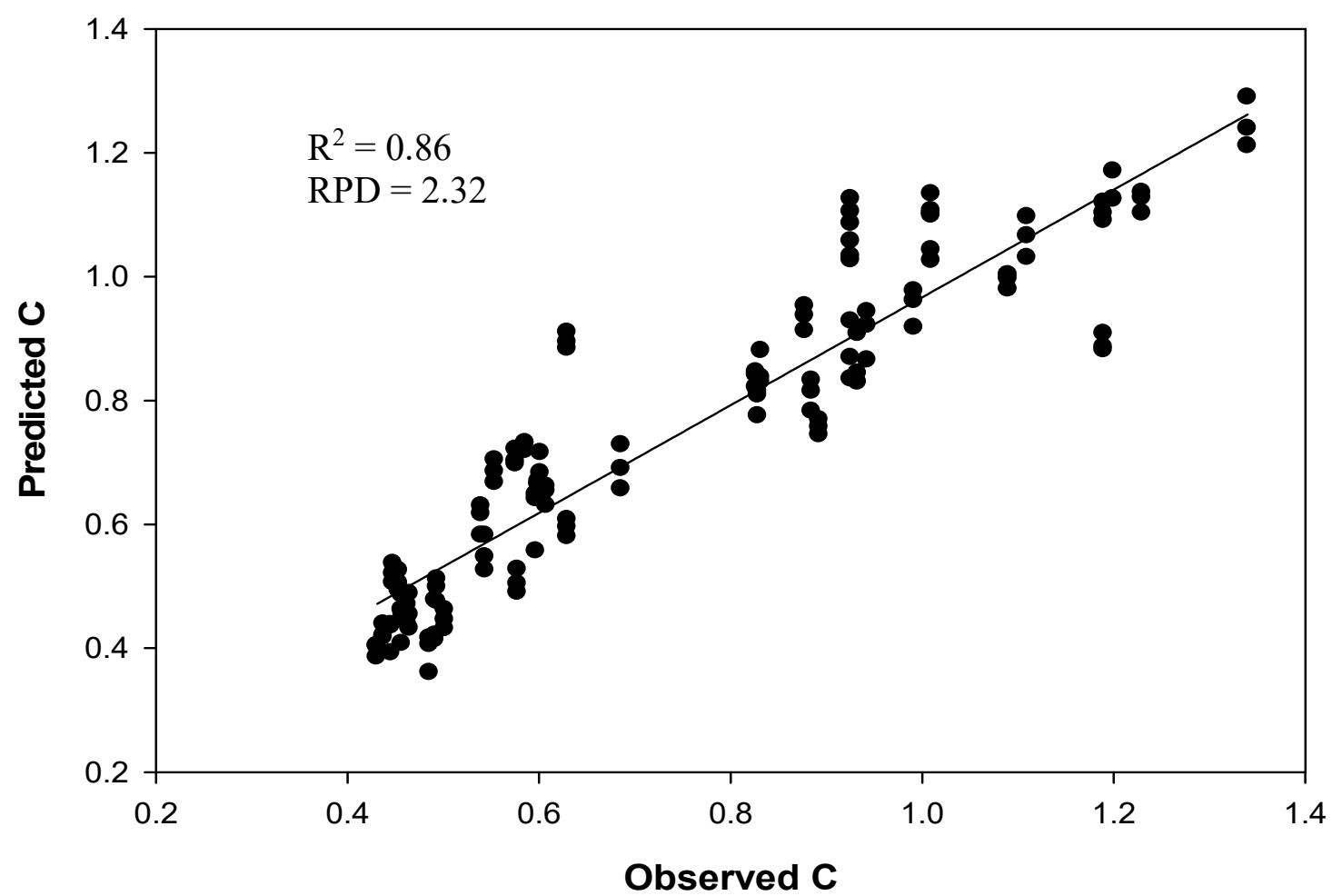

Figure 3.4. VNIR calibration curve for SOC (\%) for Location \#1 (Umala, Bolivia). (RPD= Ratio of standard deviation to root mean square error of prediction; $\mathrm{R}^{2}=$ Coefficient of determination). 


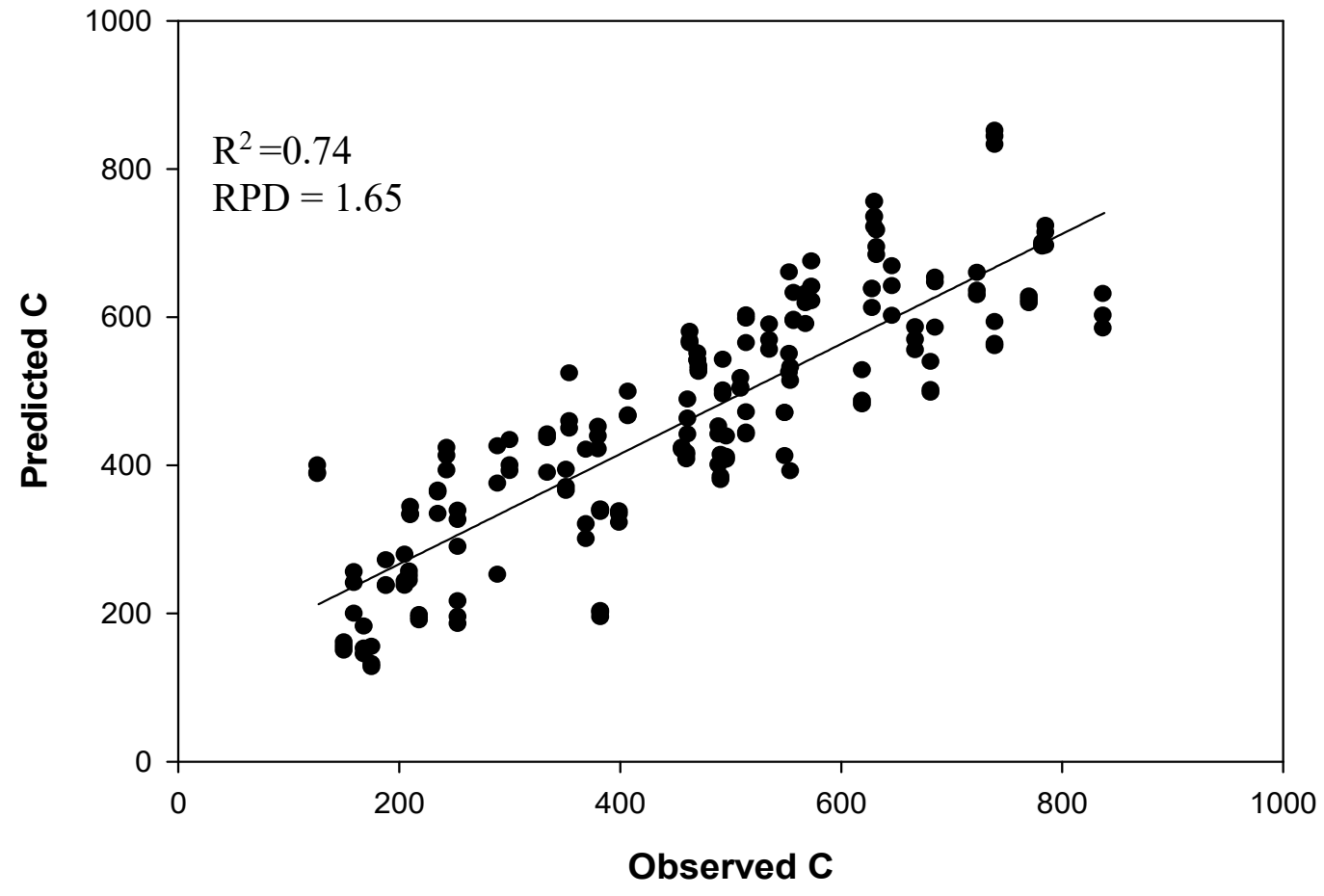

Figure 3.5. VNIR calibration curve for $\mathrm{MnOxC}\left(\mathrm{mg} \mathrm{C} \mathrm{kg}^{-1}\right.$ soil) for soil samples from Location \#2 (Cochabamba, Bolivia). (RPD= Ratio of standard deviation to root mean square error of prediction; $\mathrm{R}^{2}=$ Coefficient of determination $)$.

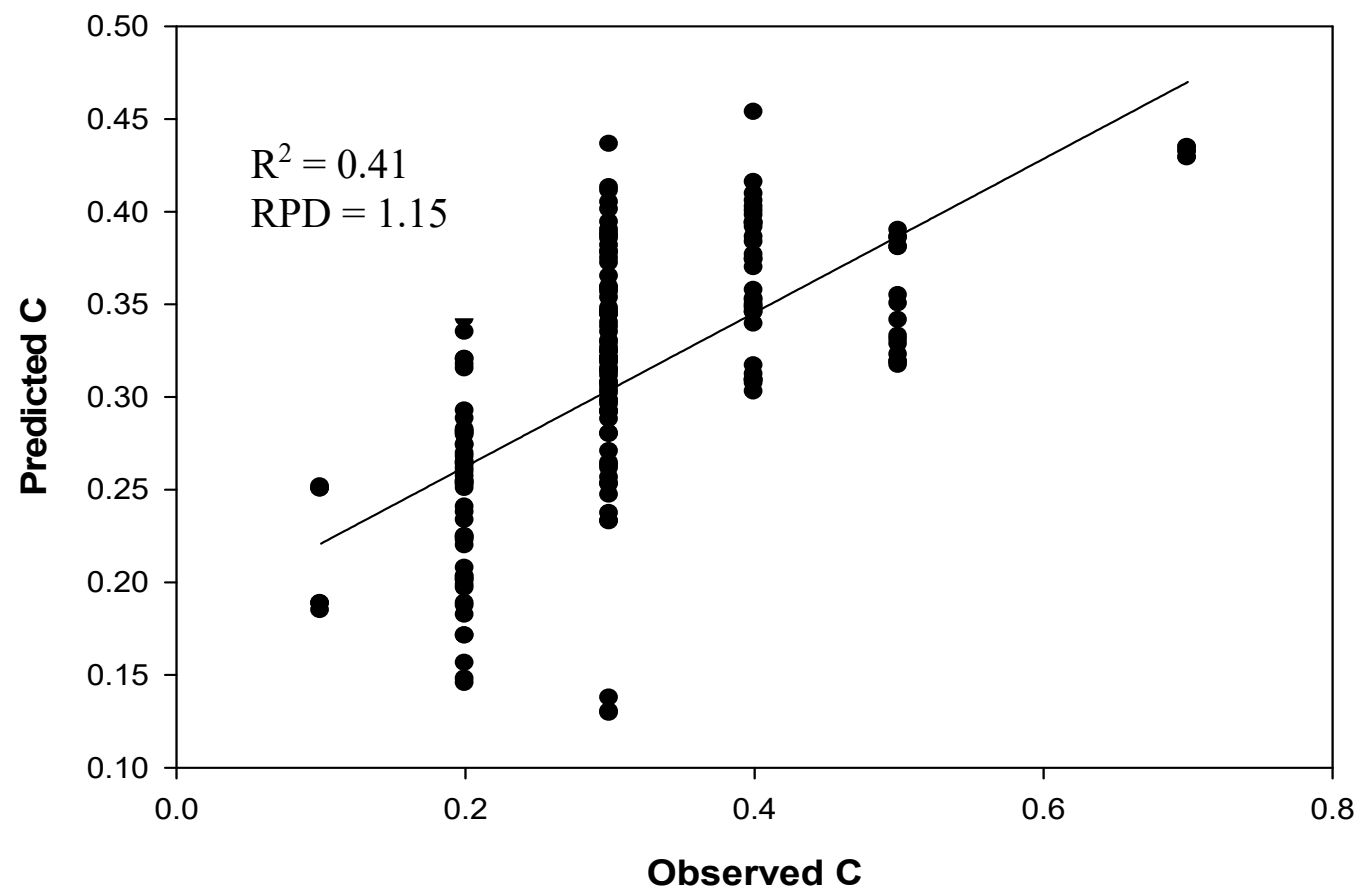

Figure 3.6. VNIR calibration curve for POM-C (\% of total C) from Location \#2 (Cochabamba, Bolivia). (RPD= Ratio of standard deviation to root mean square error of prediction; $\mathrm{R}^{2}=$ Coefficient of determination). 


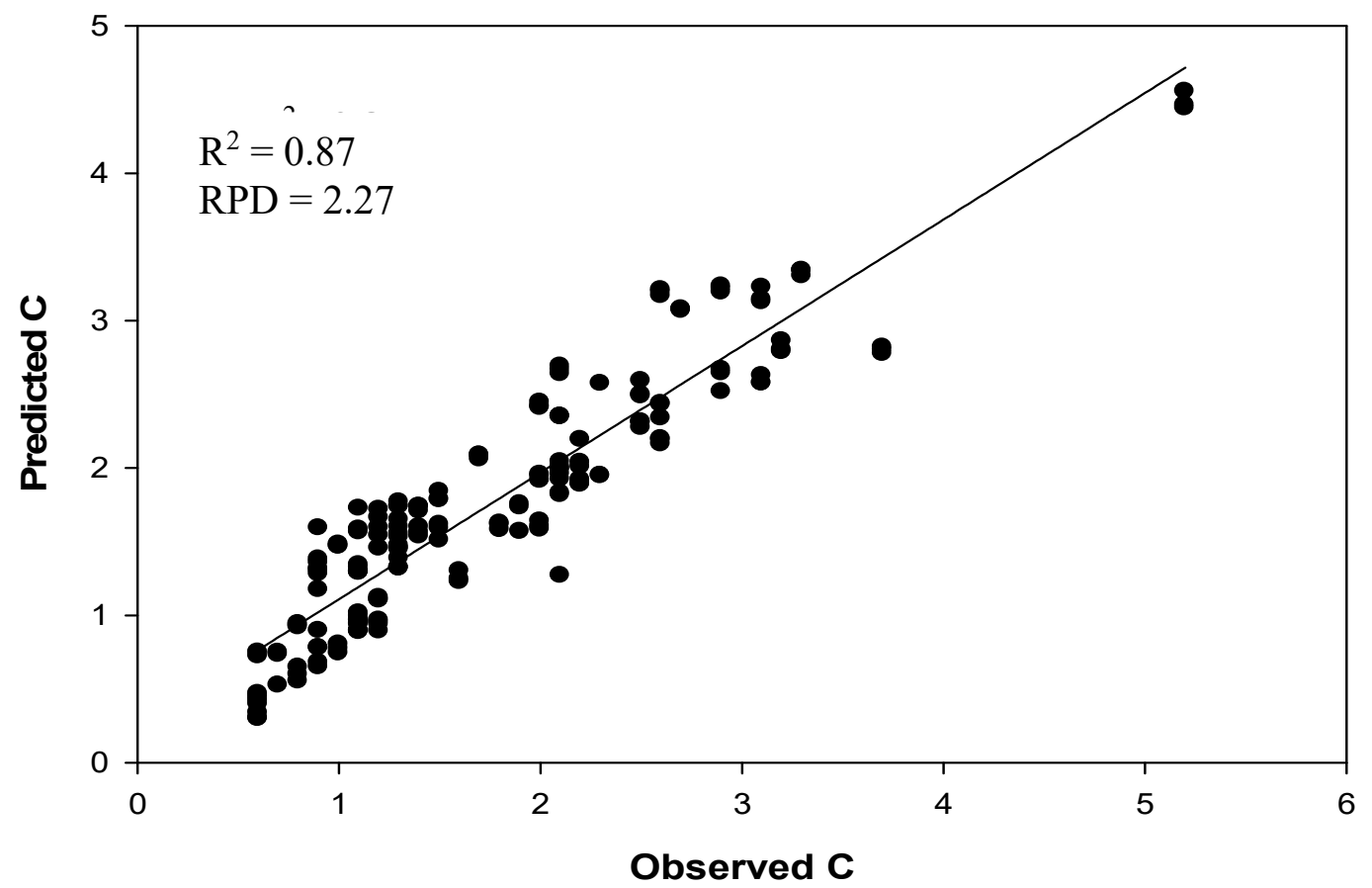

Figure 3.7. VNIR calibration curve for SOC (\%) for Location \#2 (Cochbamba, Bolivia). $(\mathrm{RPD}=$ Ratio of standard deviation to root mean square error of prediction; $\mathrm{R}^{2}=$ Coefficient of determination).

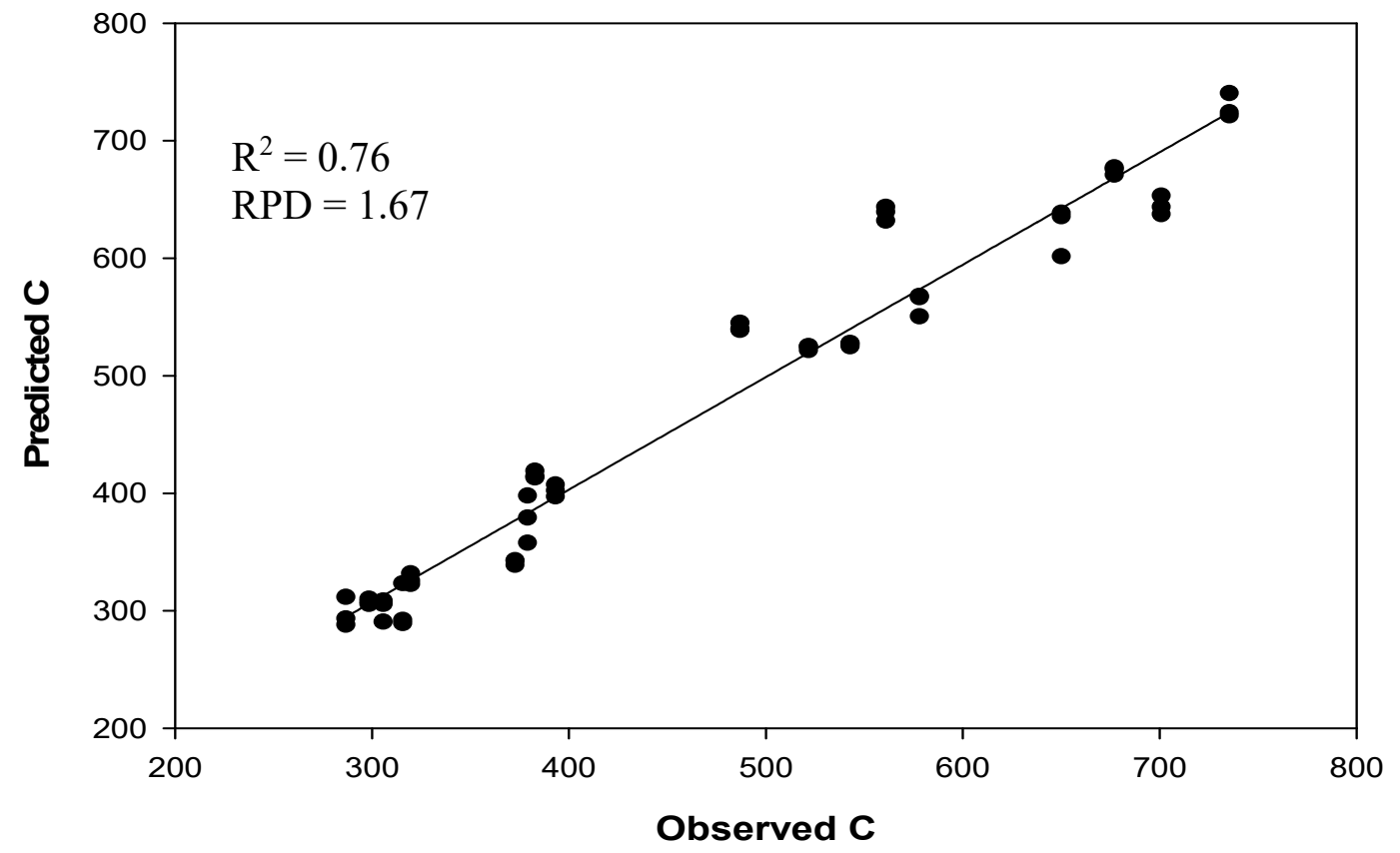

Figure 3.8. VNIR calibration curve for $\mathrm{MnOxC}\left(\mathrm{mg} \mathrm{C} \mathrm{kg}^{-1}\right.$ soil)for soil samples from Location \#3 (Indonesia). ( $\mathrm{RPD}=$ Ratio of standard deviation to root mean square error of prediction; $\mathrm{R}^{2}=$ Coefficient of determination). 


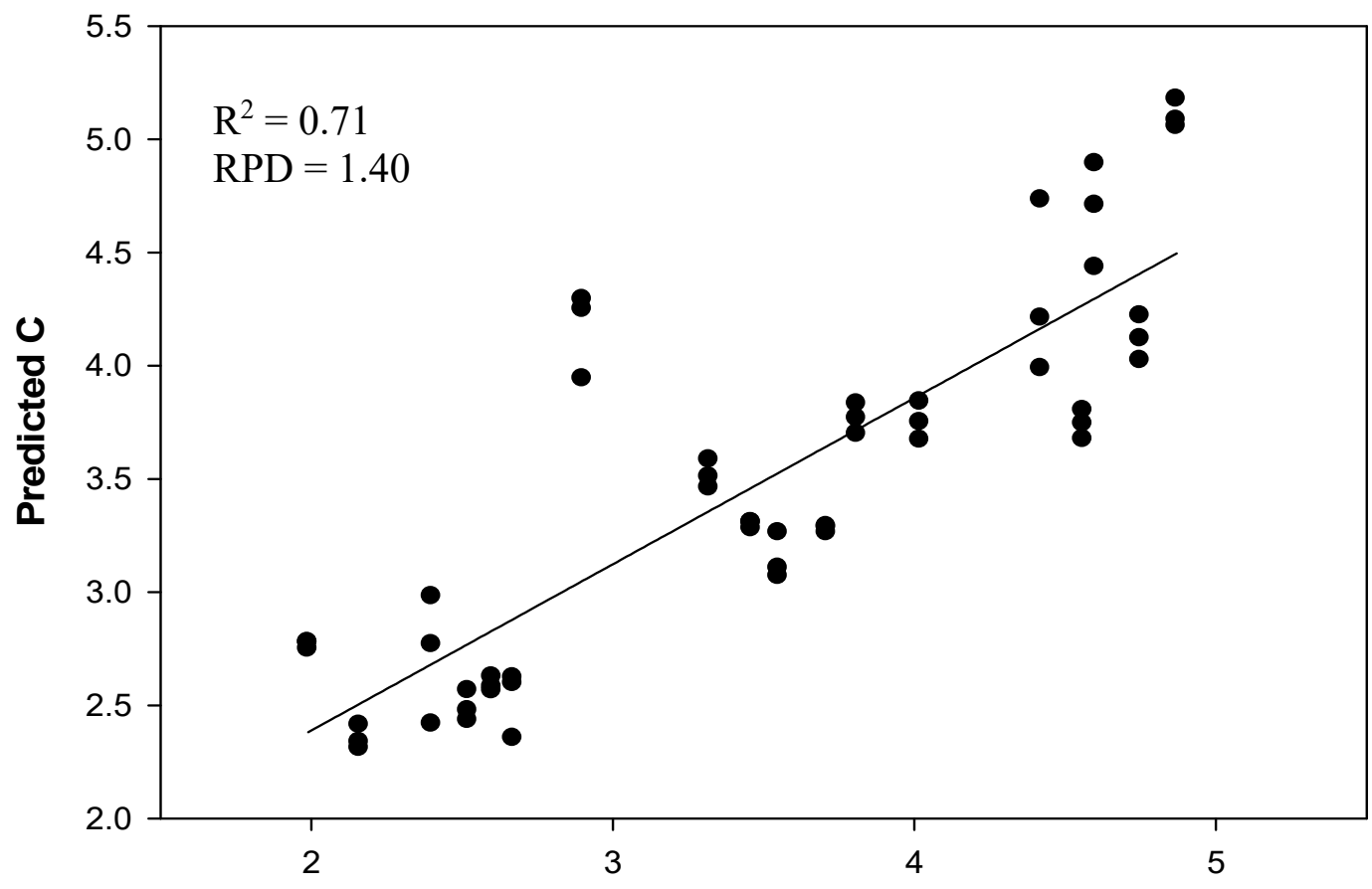

Observed C

Figure 3.9. VNIR calibration curve for POM-C (\% of total C) from Location \#3 (Indonesia). ( $\mathrm{RPD}=$ Ratio of standard deviation to root mean square error of prediction; $\mathrm{R}^{2}=$ Coefficient of determination).

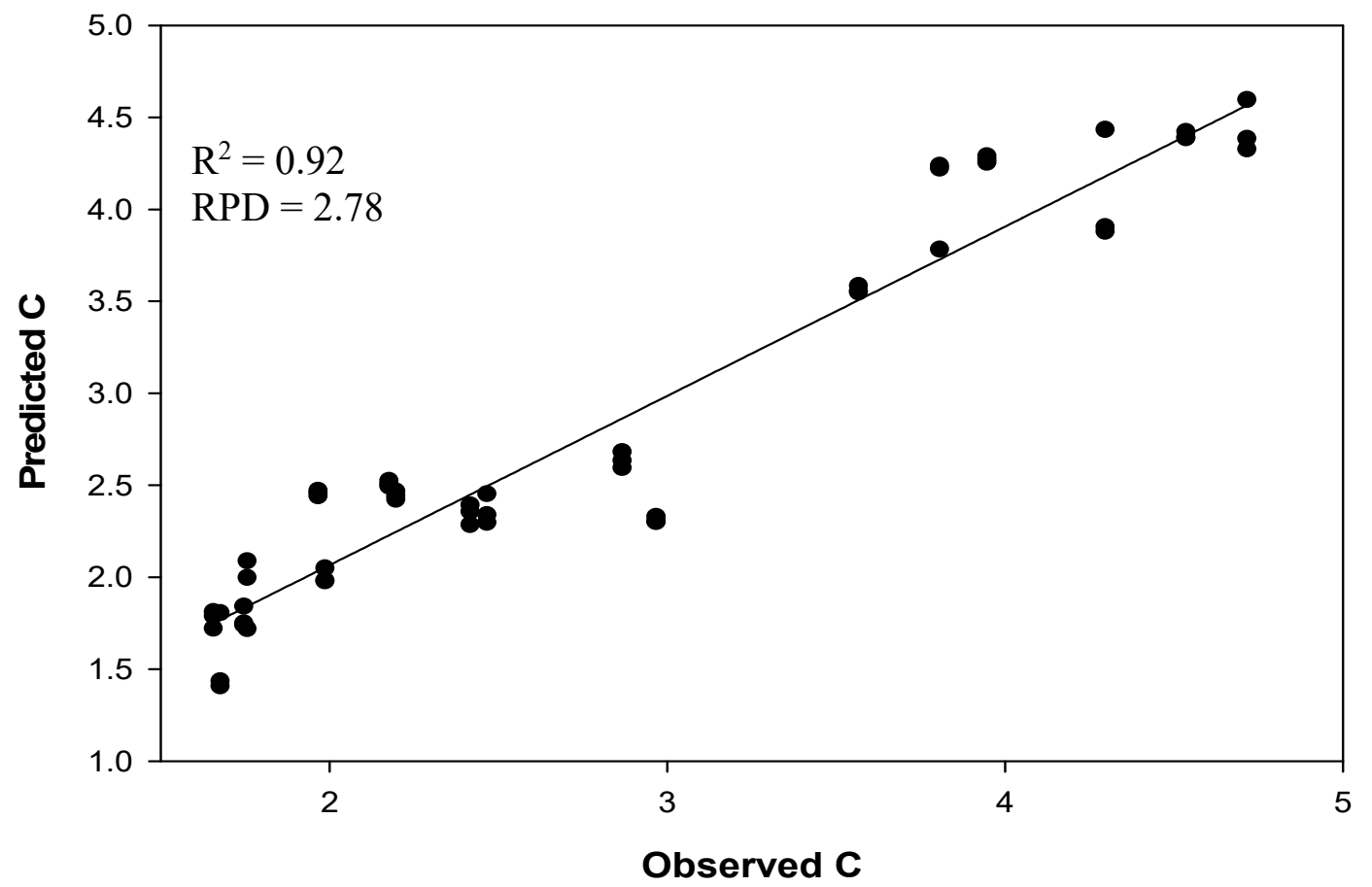

Figure 3.10. VNIR calibration curve for SOC (\%) for Location \#3 (Indonesia). (RPD= Ratio of standard deviation to root mean square error of prediction; $R^{2}=$ Coefficient of determination). 


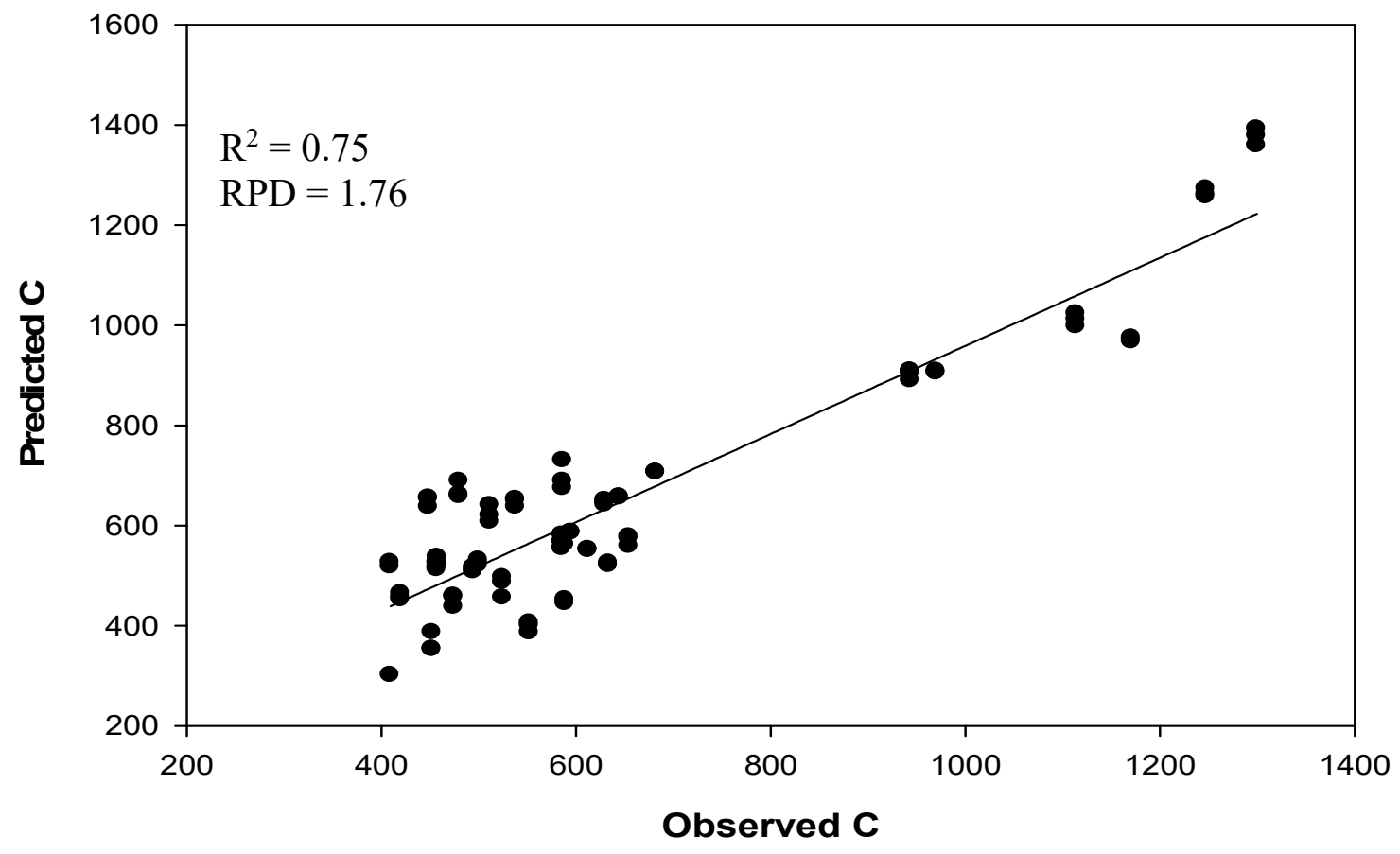

Figure 3.11. VNIR calibration curve for $\mathrm{MnOxC}\left(\mathrm{mg} \mathrm{C} \mathrm{kg}^{-1}\right.$ soil)for soil samples from Location \#4 (Philippines). (RPD= Ratio of standard deviation to root mean square error of prediction; $\mathrm{R}^{2}=$ Coefficient of determination).

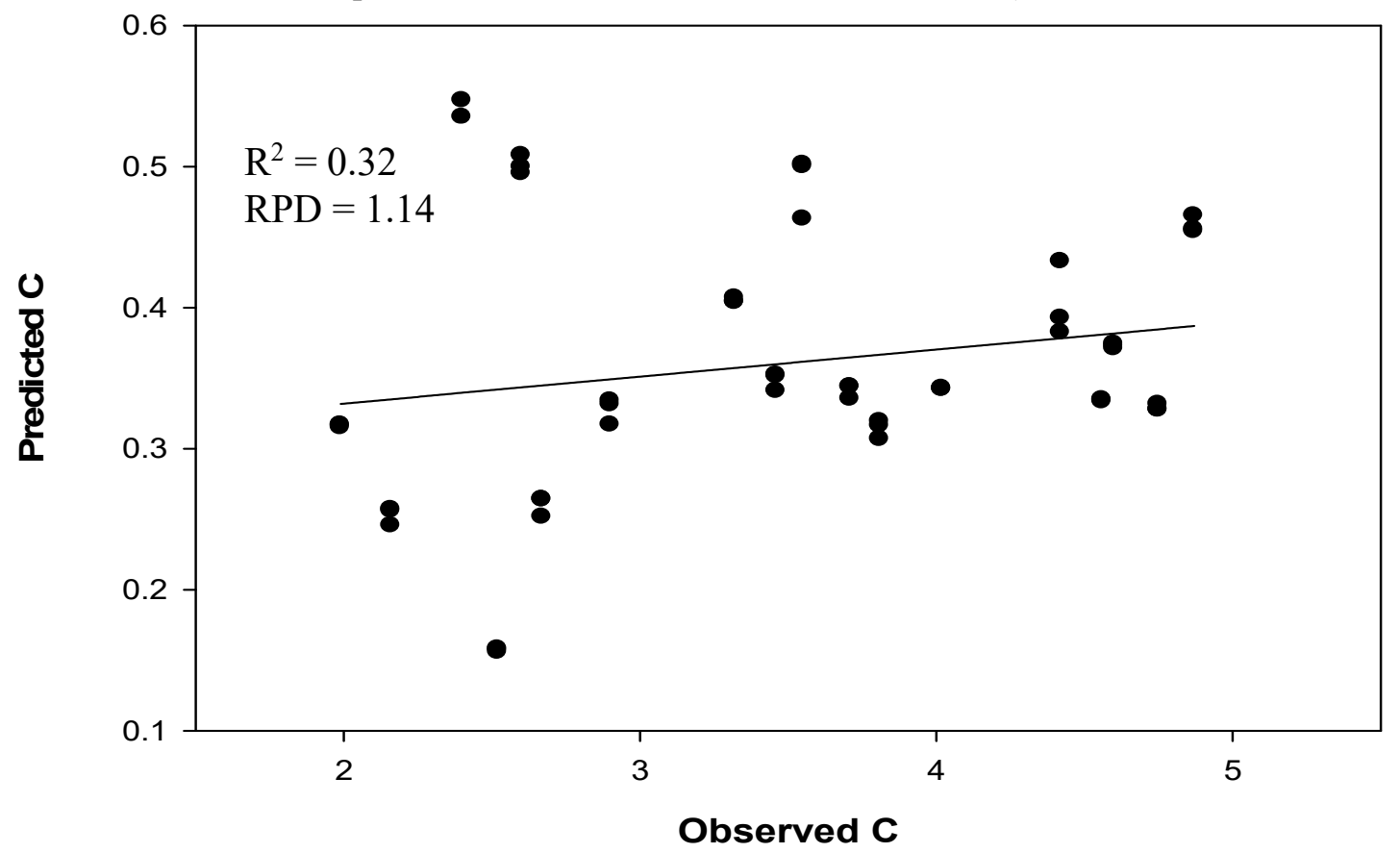

Figure 3.12. VNIR calibration curve for POMC ( $\%$ of total C) for soil samples from Location \#4 (Philippines). (RPD= Ratio of standard deviation to root mean square error of prediction; $\mathrm{R}^{2}=$ Coefficient of determination). 


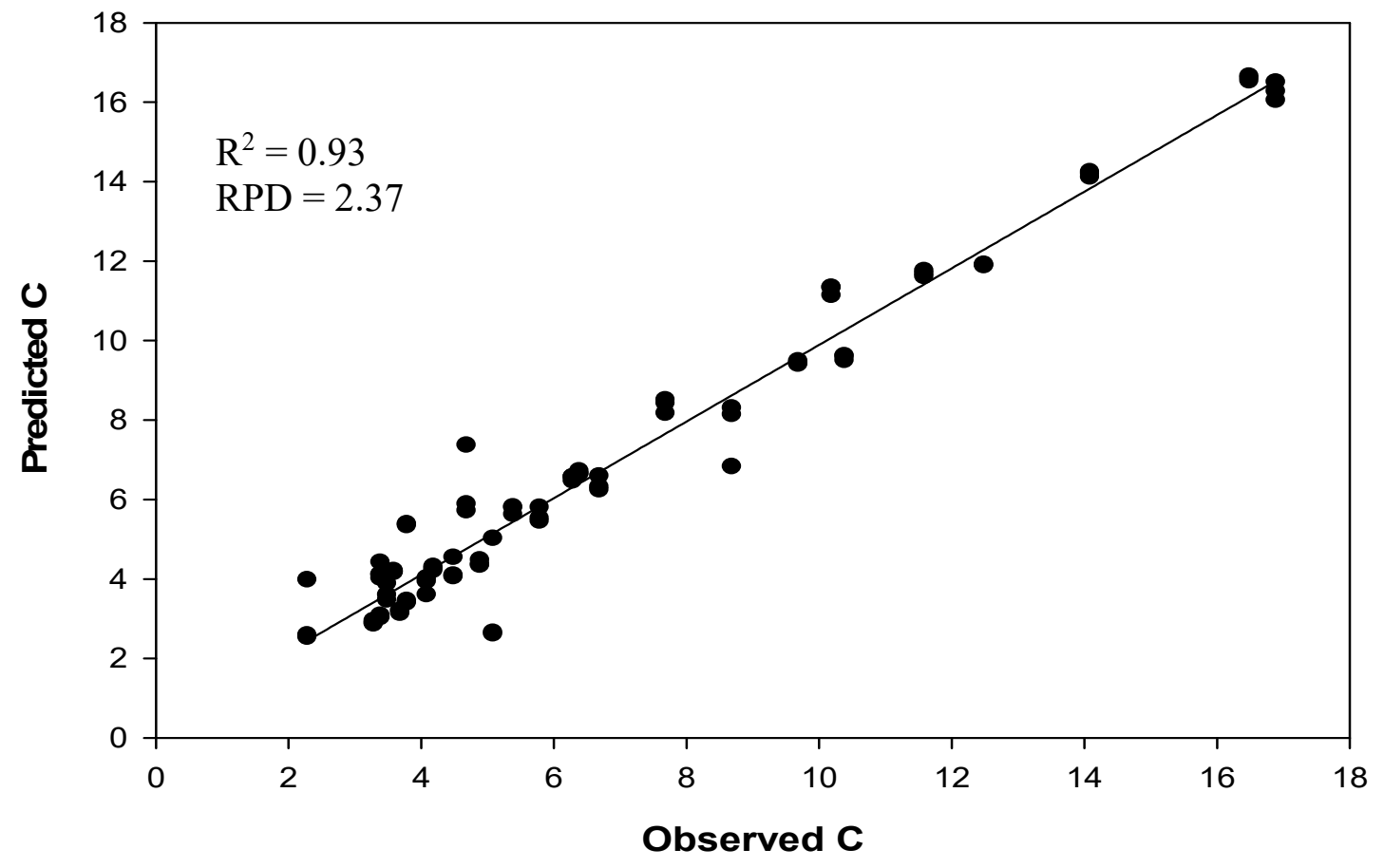

Figure 3.13. VNIR calibration curve for SOC (\%) for soil samples from Location \#4 (Philippines). (RPD= Ratio of standard deviation to root mean square error of prediction; $\mathrm{R}^{2}=$ Coefficient of determination). 


\title{
CHAPTER 4
}

\section{USE OF MID-INFRARED DIFFUSE REFLECTANCE TO ASSESS THE EFFECTS OF SOIL MANAGEMENT ON SOIL QUALITY IN TROPICAL HILLSLOPE AGROECOSYSTEMS}

\begin{abstract}
Diffuse Reflectance Fourier Transform Infrared Spectroscopy (DRIFT) is considered to be one of the most sensitive infrared techniques for analyzing the structural composition of soil organic matter. The benefit of the DRIFT technique is the ability to characterize the functional group composition of heterogeneous materials with minimal sample preparation. The objective of this study was to determine the effectiveness of using mid-infrared (MIR) spectroscopic methods to assess changes in soil quality based on differences in soil organic $\mathrm{C}$ composition in soils with a history of diverse agricultural management practices from several countries. We compared the ability of the DRIFT spectroscopy to obtain information regarding the structural composition of humic acid from all soil samples, and compare the $\mathrm{O}$ (reactive components)/R (recalcitrant component) ratio as an index of soil quality. Soil samples were collected from selected locations across the world including Bolivia, Indonesia, and the Philippines. Humic acid (HA) extracts of the soil samples were analyzed by DRIFT analysis in the mid-infrared $(2,500-25,000 \mathrm{~nm})$ regions. The effects of different agricultural practices and cropping systems such as fallow length, degraded and non-degraded area, agroforestry and nonagroforestry, and cultivated and non-cultivated area with different landscape positions, were studied for their effects on the structural composition of soil organic matter. Results showed that the different agricultural practices and cropping systems affected the HA peak height ratio or $\mathrm{O} / \mathrm{R}$ ratio. For the comparison of the effects of fallow length in
\end{abstract}


Bolivian soils in Umala, the $\mathrm{O} / \mathrm{R}$ ratio ranged from 1.06 to 2.27 . The $\mathrm{O} / \mathrm{R}$ ratio also increased as fallow length increased. The $\mathrm{O} / \mathrm{R}$ ratio of degraded and non-degraded soils in Cochabamba, Bolivia ranged from 1.06 to 1.11 and 1.10 to 1.14, respectively. Analysis of soils from agroforestry and non-agroforestry sites in Indonesia showed that the agroforestry soils had $\mathrm{O} / \mathrm{R}$ ratios higher than non-agroforestry soils. Soils from cultivated and non-cultivated areas with different landscape positions in the Philippines showed that the $\mathrm{O} / \mathrm{R}$ ratios were the highest on the summit (1.21) and the lowest on the backslope (0.74) landscape position. These results using the DRIFT technique and the $\mathrm{O} / \mathrm{R}$ ratio related to changes in soil quality among these diverse soils and farming practices. The mid-infrared (MIR) region may provide a more accurate method to assess soil quality since it directly measures changes in functional groups of soil organic matter. However, some possible restrictions for increased use of this technique include possible interferences with soil mineral material and water, the sample preparation time, and the cost and training required for using the equipment.

\section{INTRODUCTION}

Soil organic matter (SOM) is one of the most important components in soils because it affects many soil functions, such as nutrient cycling, and water movement, thermal properties, and the fate of chemicals use for crop management (Karlen et al., 1998, Larson and Pierce, 1994, and Carter, 2002). The assessment of changes in soil organic matter is a key issue for soil quality. Soil organic carbon consists of humic and non-humic substances, which are formed by decomposition of natural organic matter. Humic substances are strong complexing and chelating entities whose sorption characteristics depend on their chemical composition. They contribute significantly to the 
chemical, physical and biological properties of soil (Garcia et al., 1992; Chefetz et al., 1998, and Varanini and Pinton, 1995). Due to the relatively slow biodegradation rate of some soil humic substances, their influence on soil properties and performance last over a long time (Jakobson, 1995).

Soil organic matter and drainage tend to stabilize at a certain level in natural ecosystems over time periods greater than 10 years (Raupp, 2006). However, there has not been an effective way to quantitatively characterize soil organic matter that relates to soil organic matter turnover and elemental cycling. Traditionally, SOM was characterized by its chemical properties (solubility), but more recently analytical methods have been developed based on separating the soil fraction and biological lability (Parton et. al., 1987). The pools of SOM range from labile organic matter derived from plant debris to moderately to highly resistant carbon from humified organic matter, or highly protected organic matter (Skjemstad et al., 1998).

The primary measurement to characterize soil organic matter has been analysis for total soil organic carbon (SOC) content. This soil property is normally measured using some form of chemical oxidation (e.g. Walkley and Black, 1934) or by dry combustion (Merry and Spouncer, 1988) with possible pre-treatment for inorganic C. Total organic carbon values may not adequately explain the role of carbon in many soil processes, and it may not quantify the several pools or fractions with varying degrees of reactivity or biological stability contained in the soil (van Veen et al., 1984; Parton et al., 1987; Jenkinson and Coleman, 1994). The methods to measure SOC are also timeconsuming and expensive. For the routine analysis of carbon fractions on a large number 
of soils, a simpler and cheaper method of acceptable accuracy is needed. Techniques such as infrared spectroscopy can provide useful structural information on SOM.

Infrared spectroscopy is the study of the molecular vibrations of bonded atoms. The frequency of the absorption is characteristic of the atom in the bond and the type of motion associated with the vibration. The observed frequency can be used to distinguish the component atoms as well as the bonding characteristics of those atoms (Niemeyer et al., 1992).

Diffuse reflectance infrared Fourier transform spectroscopy (DRIFTS) is a method which entails minimal sample preparation. The soil sample should be uniformly and finely ground $(<900 \mu \mathrm{m})$ to avoid artifacts and further homogenize samples. The courser particle sizes trap light more effectively than finer particle sizes which can increase IR scattering (Parikh, 2014). This can result in higher absorbance and a shifted baseline, altered peak widths, and non-linear absorbance. DRIFT can be use $\mathrm{KBr}$ dilution of soil samples (2-10\% sample). The suitability of $\mathrm{KBr}$ dilution is assessed empirically to determine if spectral quality is improved (Margenot et. al, 2017). In DRIFTS, IR radiation penetrates the sample to a depth, which is dependent on the reflective and absorptive characteristics of the sample. This partially absorbed light is then diffusely reemitted from the sample and collected on a mirror that focuses energy coming from the sample onto the detector. The resulting spectrum is more dependent on spectral properties of the sample interface (Griffiths and de Haseth, 1986). According to Painter et al. (1985) and Niemeyer et al. (1992), the DRIFT technique offers several advantages over transmission infrared spectroscopy: (i) a simple sample preparation procedure; (ii) high resolution of the spectra because of reduction in the sensitivity towards light scattering; 
and (iii) a more reliable method for quantitative estimations of functional groups. Wander and Traina (1996) used DRIFT spectroscopy to examine functional groups of SOM fractions. They also reported that the characteristics and distribution of individual SOM fractions may provide a means for assessing management impacts on SOM quality that can influence soil and plant productivity.

Reflectance characteristic of soils are related to chemical functional groups known as 'chromophores'. Soil organic matter contains such 'spectrally active' groups, as chlorophyll, oil, cellulose, pectin, lignin and humic acid. Soil mineral and organic matter will show the results of absorption in specific infrared spectral signature due to the vibrations of functional groups within the mineral and organic substances. In the near infrared (NIR) region (700-2500 $\mathrm{nm}$ ), the spectra has sensitive vibrational absorbance due to $-\mathrm{OH}$, $-\mathrm{CH}$, and $-\mathrm{NH}$ organic functional groups in SOM. In MIR (2500-25000 nm) or $4000 \mathrm{~cm}^{-1}-400 \mathrm{~cm}^{-1}$ the spectra show sensitivity to group protons such as $\mathrm{Si}-\mathrm{O}, \mathrm{Al}-\mathrm{O}$, and Fe-O. For example, in minerals quartz and kaolinite clays give a particularly strong spectral signature near $1100-1000 \mathrm{~cm}^{-1}$ (Si-O stretching vibration) and 3690 to $3620 \mathrm{~cm}^{-1}$ for clay lattice Al-OH vibration (Janik, 2007). Chang et al. (2001) found that spectra generally show three peaks near 1400, 1900, and $2200 \mathrm{~nm}$ and a few smaller ones between 2200 and $2500 \mathrm{~nm}$, which are overtones and combinations bonds of C-H, N-H, and $\mathrm{O}-\mathrm{H}$ bonds vibrating in the mid-infrared (MIR) region. Van de Marel and Beutelspacher (1976); Wander and Traina (1996) and Janik et al.(1998) also reported that MIR spectroscopy is characterized by fundamental vibrations of molecules associated with particular chemical functional groups. For example, one technique allows for the identification of specific soil minerals and organic matter functional groups, such as 
alkyl, carboxylic (protonated and non-protonated), carbohydrates, amide, amine, and most importantly aromatic functional groups.

Wave numbers and assignments for peaks in the DRIFT spectrum are the same as in the IR spectrum (Bases and Bloom, 1989; Niemeyer et al., 1992). The characteristic peaks for humic acid (HA) and fulvic acid (FA) appear distinctly and sharply at the following wave numbers 1715 to $1730 \mathrm{~cm}^{-1}$ (mostly COOH groups), $1620 \mathrm{~cm}^{-1}$ (mostly aromatic C), and at $1200 \mathrm{~cm}^{-1}$ (mostly $\mathrm{OH}$ or $\left.\mathrm{COOH}\right)$. The HA exhibited the most distinct $\mathrm{COOH}$ bands at wavenumbers in both the 1720 and $1200 \mathrm{~cm}^{-1}$ regions. The high intensity of these bands was a typical characteristic of HA, and their presence reflected the high solubility and acidity. The signal between 3000 and $3700 \mathrm{~cm}^{-1}$ was of low intensity and appeared in regions of little importance to humic material (Niemeyer et al., 1992). Assignment of the $\mathrm{OH}$ stretching band to phenolic $\mathrm{OH}$ was supported by the $\mathrm{C}$ $\mathrm{OH}$ stretching band centered at $1250 \mathrm{~cm}^{-1}$ which was characteristic of oxygen on an aromatic ring. The center of the band was much more apparent in the HA compared to the FA spectra. The $\mathrm{C}-\mathrm{OH}$ stretching vibration of phenolic $\mathrm{OH}$ occurred at frequencies above $1200 \mathrm{~cm}^{-1}$. Aliphatic alcohols were indicated by a broad and intense $\mathrm{C}-\mathrm{OH}$ stretching band at lower frequencies (1015-1150 $\left.\mathrm{cm}^{-1}\right)$ (Conley, 1972).

Research examining use of DRIFT to characterize soil organic matter has found that this process was impeded by the presence of a mineral matrix which leads to dilution of the organic matter (Preston, 1996). During HA extraction, demineralization by hydrochloric and hydrofluoric acid ( $\mathrm{HF} / \mathrm{HCl}$ treatment) was developed to eliminate mineral matter. Purification of SOM using HF is based on the breakdown of Si-O bonds, leading to the solubilization of minerals. The HF treatment of SOM uses dilute $(2-10 \%)$ 
HF. Functional groups are reactive and undergo secondary reactions (such as dehydration) upon drastic acid treatment.

Wander and Traina (1996b) characterized physically and chemically isolated SOM fractions collected from organic matter from organically and conventionally managed soils. They used ratios of reactive (O-containing) and recalcitrant $(\mathrm{C}, \mathrm{H}$ and/or N) functional group heights to characterize SOM fraction composition. The range of soils and cropping practices that tested this technique was limited. The diffuse reflectance signal can be described by the Kubelka-Munk function (KM) where KM is the ratio of diffuse reflectance from the sample and the diffuse reflectance from a non-absorbing power. This ratio is related to sample absorbance (a), concentration (c), and a scattering coefficient (s) in the following manner: $\mathrm{KM}=(2.303 \mathrm{ac} / \mathrm{s})$. If the spectral reflectance is small and scattering is constant, then KM should vary linearly with sample concentration. This relationship is useful for quantification of the functional group composition in spectra of heterogeneous organic materials.

The objective of this work was to determine the effectiveness of using midinfrared (MIR) spectroscopic methods in assessing soil quality based on the status of soil organic $\mathrm{C}$ using $\mathrm{O} / \mathrm{R}$ ratios across a range of soils from agricultural management practices in different countries with tropical hillslope agricultural systems. It was hypothesized that the $\mathrm{O} / \mathrm{R}$ ratios from MIR would provide a sensitive indicator of soil quality changes due to agricultural management and landscape positions.

\section{MATERIALS AND METHODS}

\section{Study Sites}

Soils with diverse properties and management were collected from locations including: 1) Umala municipality in Bolivia; 2) Cochabamba in Bolivia, 3) Kecamatan 
Nanggung, West Java, Indonesia, and 4) the Lantapan region of Mindanao, Philippines (See Chapter 2 for additional site information).

Location \#1 was located in the Umala municipality of the Central Altiplano Andean region of Bolivia. Four representative communities (San Juan Circa, and San José de Llanga, Kellhuiri, and Vinto Coopani) located in the Central Altiplano were selected for this research. These communities were selected to represent traditional indigenous communities located at relatively low and high elevations.

The Umala Municipality is mostly a semi-arid region situated between 3,750 and 4,100 meters above sea level (MASL), with low and erratic rainfall (annual average of $350 \mathrm{~mm}$ ) and low air temperatures (annual average of $11^{\circ} \mathrm{C}$ ) during the growing season (PROINPA, 2005). The communities of Kellhuiri and Vinto Coopani are situated at relatively higher elevations, and San Juan Circa and San José de Llanga are located at relatively lower elevations. The most frequent crop rotation is potato-quinoa/barleybarley/oat/-fallow or potato-quinoa/barley-barley/oat-perennial grasses. Fallow is a traditional practice used for soil restoration and grazing and the average fallow length range from 3 to 5 years but it might last up to 20 years in less fertile soils. There is a general trend of suboptimal and inadequate use of organic (e.g., cow and sheep manure) and inorganic fertilizers (i.e., diammonium phosphate and urea). In Umala, four representative rural communities were selected for this study. Two communities (i.e. San José de Llanga and San Juan Circa) were located at relatively low elevation (approximately 3,771 and 3,806 meters above sea level) and the another two communities (i.e., Kellhuiri and Vinto Coopani) at relatively high elevation (approximately 4,070 and 4,013 meters above sea level). Farmers identified soil problems as one of several factors 
limiting their crop production (Aguilera et al., 2010). These problems included low soil quality and soil fertility (i.e., low soil nutrient content, high clay content making the soil hard to crop, and stoniness), excessive water- and wind-induced soil erosion and inadequate soil management practices. Inadequate soil management practices cited were inappropriate tractor tillage practices, lack of a clear crop rotation strategy, carelessness of incorporating manure, and overgrazing by sheep. Farmers identified different soil types, according to the local criteria of each community and they listed soil characteristics or properties of each soil type. Soil maps drawn by the representative farmers in the first workshop show a general predominance of sandy soils in the four communities. The land and crop management had a slight variation among soil types and among communities. For instance in Kellhuiri, in the clayey soils, farmers grew only barley and quinoa; whereas in Vinto Coopani farmers grew potato, barley and alfalfa. In San Juan Circa, farmers grew potato, quinoa and barley, and in San José de Llanga they grew alfalfa, barley, faba beans, and quinoa (Aguilera et al., 2010).

Forty-nine subsamples were analyzed to determine soil active C. All soil samples were ground, air-dried (5 days) and sieved $(<2 \mathrm{~mm})$.

The altitude difference among communities in the higher elevation versus lower elevation communities is approximately $250 \mathrm{~m}$. At the higher elevations, the land has more hills and steeper slopes and soil tillage practices are generally dependent on animal traction and their soils mostly consist of rocks. Farmers do not use adequate amounts of manure and manufactured fertilizers for optimizing crop growth. In the lower elevations, communities are situated in relatively flat areas. People in this area frequently use mechanical traction for tillage. Soils in the lower elevation are generally highly in sand. 
This region is exposed to frequent adverse climatic conditions, mainly frost and drought events, which limit agricultural production to just a few crops, such as potato (Solanum tuberosum L.), quinoa (Chenopodium quinoa Wild.), and barley (Hordeum vulgare L.) (Valdivia et al., 2001; Valdivia and Quiroz, 2003). In general, farm size in this region is small due to land subdivision for inheritance purposes. Individual farm agricultural plots generally average only two hectares in area (FAO and SNAG, 1995).

For this project, soil samples were taken in the 2006-2007 growing season from the $0-20 \mathrm{~cm}$ depth of cultivated lands from each community with different fallow length ranging from 1, 6, 8, 10, 20 and more than 40 years.

Location \#2 was in Cochabamba, Bolivia in the localities of Toralapa Baja, Waylla Pujru and Sancayani Alto, in the province of Tiraque, Department of Cochabamba in Central Bolivia situated at approximately 2,500 $\mathrm{m}$ above sea level. To get this information, 60 soil samples (30 degraded soils and 30 non-degraded soils) from the 0-20 cm depth were collected in farmers' fields. This area has had minimal soil testing conducted previously so separating for degraded and non-degraded land depended on the judgement of agricultural professionals working in the communities and observed factors affecting soil degradation in the communities. Based on community surveys, the main agricultural and environmental problems in this area were identified as soil erosion, low soil fertility, monoculture, pests, contamination and poor soil conservation practices (See Appendix). Community members also consider physical and chemical soil factors, deforestation and land habilitation for cultivation as issues. They believe these problems affect the agricultural production of the area. 
Location \#3 in Indonesia was situated in Kecamatan Nanggung, West Java. The study site was originally covered with a typical humid tropical forest. Soil samples were collected from agroforestry (primarily alley cropping) and non-agroforestry areas. These areas received different types and rates of amendments which included manure, compost and chemical fertilizer. The climate of the area was tropical with monsoons occurring in the rainy season. Soils were poorly to moderately drained and occurred on undulating to flat uplands. The elevation was less than 200-1800 m above sea level.

In the agroforestry areas, crops were grown between trees and the control plot was cassava, no manure, no compost, and no fertilizer: All areas receiving manure were applied with poultry manure. The low manure plot was planted to corn, sweet potato, a low rate of compost. A low rate of fertilizer and manure was applied at the rate of less than 5,000 $\mathrm{kg} \mathrm{ha}^{-1}$ per planting season. The medium manure plot was scallion, chili, corn, with no compost, no fertilizer and manure was applied at the rate of 5,000-15,000 $\mathrm{kg} \mathrm{ha}^{-1}$ per planting season.

In the non-agroforestry area, the control plot was chili, corn, no manure, no compost, and no fertilizer. The low manure plot was scallion, taro, chili, low rates of compost, low rates of fertilizer and manure was applied at the rate of less than $5,000 \mathrm{~kg}$ $\mathrm{ha}^{-1}$ per planting season. The medium manure plot was planted to cabbage, scallion, a medium rate of chicken manure, no compost, and no fertilizer. Manure was applied at the rate of 5,000-15,000 $\mathrm{kg} \mathrm{ha}^{-1}$ per planting season.

Location \#4 was in the Lantapan region of the Philippines on the Island of Mindanao. In this study, soil samples were taken along a transect from the top to the bottom of a hillslope where both cultivated and non-cultivated areas were present. Each 
transect was divided into summit, shoulder, backslope, footslope and toeslope positions. Fifteen soil samples from the non-cultivated area and 15 soils samples from the cultivated area were collected from the farmers' fields.

At all the locations, soil samples were taken from approximately the $0-20 \mathrm{~cm}$ depth. Samples were air-dried and passed through a $2 \mathrm{~mm}$ sieve for analysis. For general characterization, the soils were sent to the University of Missouri Soil and Plant Testing Laboratory to be analyzed for selected soil chemical and physical properties (i.e., $\mathrm{pH}$ in $0.01 \underline{\mathrm{M} \mathrm{CaCl}}$, soil test phosphorus [Bray P1], soil test potassium [ $\mathrm{NH}_{4} \mathrm{AOc}-$ extractable $\mathrm{K}]$, exchangeable calcium $[\mathrm{Ca}]$, exchangeable magnesium $[\mathrm{Mg}]$, and cation exchange capacity [CEC]) using standard methods (Nathan et al., 2006). Total soil organic C (SOC) was determined on a LECO TruSpec combustion C and N analyzer (LECO Corp., St. Joseph, MI) as shown in Table 2.1 and 2.2.

\section{Analytical Procedures}

\section{Humic acid extraction and fractionation procedure}

To separate the humic acid fraction from each soil, $30 \mathrm{~g}$ of the sieved, air-dried soil were weighed into a $250-\mathrm{ml}$ plastic bottle polyethylene centrifuge bottle. The sample was equilibrated to a $\mathrm{pH}$ value between 1 to 2 with $1 \mathrm{M} \mathrm{HCl}$ at room temperature and the solution volume was adjusted with $0.1 \mathrm{M} \mathrm{HCl}$ to provide a final concentration with a ratio of $10 \mathrm{~mL}$ liquid/ $1 \mathrm{~g}$ dry sample. The suspension was shaken with a shaker for 1 hour, and the residue was separated from the supernatant and saved by decantation after allowing the solution to settle for 15 minutes. The soil residue was then neutralized with $1 \mathrm{M} \mathrm{NaOH}$ to $\mathrm{pH} 7.0$ and $0.1 \mathrm{M} \mathrm{NaOH}$ was added to obtain a ratio 10:1.

The air in the bottle with the solution was displaced by $\mathrm{N}$ gas $\left(\mathrm{N}_{2}\right)$ to minimize chemical changes due to auto-oxidation, and the plastic bottle with the soil extraction 
were shaken for 4 hours at room temperature. The alkaline suspension was then allowed to settle overnight and the supernatant was collected by centrifugation. The supernatant was separated from the residue by centrifugation at $4000 \mathrm{rpm}$ for 15 minutes.

The supernatant was then collected and acidified with $6 \mathrm{M} \mathrm{HCl}$ with constant stirring to $\mathrm{pH} 1.0$ and the suspension was allowed to stand for 12-16 hours. The suspension was then centrifuged at $4000 \mathrm{rpm}$ to separate the humic acid (precipitate) fractions and the humic acid fraction was redissolved by adding a minimum volume of $0.1 M \mathrm{KOH}$ under $\mathrm{N}_{2}$ gas. Solid $\mathrm{KCl}$ was added to attain $0.3 M\left(\mathrm{~K}^{+}\right)$and it was then centrifuged at a high speed $(8000 \mathrm{rpm})$ to remove suspended solids.

The dark colored suspended humic acids were precipitated in $0.1 \mathrm{M} \mathrm{HCl}$ and $6 \%$ $\mathrm{HF}$ in plastic test tubes with a $10 \mathrm{~mL}$ solution/ $1 \mathrm{~g}$ of ground organic horizon to remove possible silicates. The HA samples were shaken for 24 hours at room temperature with an $\mathrm{HCl} / \mathrm{HF}$ treatment. The insoluble residues (HA) were separated from the supernatant by centrifuging at 10,000 rpm for 20 minutes. The humic acid precipitates were transferred to a Visking dialysis tube (Spectrum*Spectra/Por* biotech cellulose ester (CE) dialysis membrane) with 10,000 Dalton molecular weight cut off (MWCO). Before transferring the HA, the precipitates were slurried with water and dialyzed against distilled water for 4-5 days until the dialysis water gave a negative $\mathrm{Cl}$ - test with $1 \mathrm{M}$ of silver nitrate (no white color appeared). The purified humic acid was then freeze-dried, ground to powder and stored at room temperature prior to chemical analysis (Stevenson, 1994).

\section{Sample preparation and analysis for DRIFT}

DRIFT was performed in an infrared Spectrophotometer with a DRIFT Smart Collector accessory (Thermo Electron Corp.). All HA fractions were powdered with a 
sapphire mortar and pestle, and stored in a drying box. HA fractions were mixed with ground $\mathrm{KBr}$ for diluting which samples were prepared of $8 \%$ in pre-ground $\mathrm{KBr}$. The mixed $\mathrm{KBr}$ and $\mathrm{HA}$ samples were subsequently ground with an agate mortar and pestle. The milled samples were transferred to a sample holder, and its surface was smoothed with a microscope glass slide. Before analysis, the diffuse reflectance cell containing the samples was flushed with $\mathrm{CO}_{2}$ and $\mathrm{H}_{2} \mathrm{O}$ free air for 15 minutes to eliminate interference from carbon dioxide and moisture (Ding et al., 2002; Wander and Traina, 1996a).

\section{Spectra data acquisition and analysis}

To obtain DRIFT data, samples were scanned from 4000 to $400 \mathrm{~cm}^{-1}$ and 400 scans were collected at a resolution of $4 \mathrm{~cm}^{-1}$ and spectra, as well as numerical values for major peaks' wave numbers and intensities, were recorded. Powder of $\mathrm{KBr}$ samples (and $\mathrm{KBr}$ reference), and mixed humic acid and $\mathrm{KBr}$ were placed in a $8 \mathrm{~mm}$ diameter flat plate, and spectra were collected using a Thermo Electron Corporation Nicolet 4700 FTIR spectrometer (Madison, WI). The background consisting of powdered $\mathrm{KBr}$ was scanned under $\mathrm{KBr}$ mixtures, and the spectrum of the reference of $\mathrm{KBr}$ was recorded and stored after the spectrum of the sample and $\mathrm{KBr}$ were measured. The ratio of the sample$\mathrm{KBr}$ mixture measurement against the $\mathrm{KBr}$ reference measurement gives the percent reflectance directly. The percent reflectance spectrum was converted to K-M units. Absorption spectra were converted to a Kubelka-Munk function and also baseline was corrected using Gram/32 software package (Galactic Corporation). Transformation to KM units typically results in better spectra, especially in the region of strong absorption below $1500 \mathrm{~cm}^{-1}$ (Childers and Palmer, 1986). Before spectra data acquisition, the spectra 
were baseline normalized. During spectral data acquisition, the silica band was removed at around 1800, 1900 and $2000 \mathrm{~cm}^{-1}$.

The peak assignments and intensity were calculated for determining the $\mathrm{O} / \mathrm{R}$ ratio, in which the reactive groups are O-containing, and recalcitrant groups are R-containing. Heights of peaks of $\mathrm{O} / \mathrm{R}$ ratio were characterized for SOM fraction composition. Peak assignments and intensity (by height) ratios were calculated and based on the methods of Baes and Bloom (1998), Niemeyer et al. (1992), Wander and Traina (1996b), and Ding et al. (2002) (Table 4.1). Based on these approximate peak assignments, the actual peaks for each set of soil samples from the different locations were identified and then used for $\mathrm{O} / \mathrm{R}$ ratio calculations.

\section{Statistical analysis}

The data were subjected to analysis of variance (ANOVA) using the Fisher's Least Significant Difference (LSD) for means comparison with a $p$ value of 0.05 .

\section{RESULTS AND DISCUSSION}

\section{DRIFT Spectra Acquisition}

Pre-testing of DRIFT spectra of humic acid (HA) fractions from a long-term cultivated plot in Sanborn Field and from an undisturbed prairie site with and without hydrofluoric acid (HF) treatment are presented in Figure. 4.1. These results suggest that the method by which the spectrum was obtained can influence the spectral signature. After the dark colored suspended humic acids were precipitated in $0.1 \mathrm{M} \mathrm{HCl}$ and $6 \% \mathrm{HF}$ in plastic test tubes with a $10 \mathrm{~mL}$ solution/ $1 \mathrm{~g}$ of ground organic horizon to remove possible silicates, samples for DRIFT analysis were used. Because the spectra of silica can influence the peak height, so the spectrum of silica before treating humic acid with hydrofluoric acid (HF) was examined by comparing with humic acid with $6 \% \mathrm{HF}$. In 
Figure. 4.1 showed that the specular reflection might cause problems in development of peak heights and interpretation. Therefore, the technique using $\mathrm{HCl} / \mathrm{HF}$ treatment was used to remove the silica bands found at around 1800 , and $1100 \mathrm{~cm}^{-1}$, as similarly suggested by Reeves (2005) in which the silica band was removed at around 1800, 1900 and $2000 \mathrm{~cm}^{-1}$.

\section{DRIFT Spectroscopy and Comparison of Peak Ratio (O/R ratio) of Humic Acids Across Location}

\section{Location \#1 (Umala, Bolivia):}

All spectra of HA of soils of different fallow lengths looked similar in all samples with minor differences (Fig. 4.2). A distinct peak presenting $\mathrm{COOH}$ bands of HA was indicated by the peak at around $1250 \mathrm{~cm}^{-1}$, which was attributed to $\mathrm{C}-\mathrm{O}$ stretch and $\mathrm{OH}$ deformation of $\mathrm{COOH}$ groups. The band around $1630-1608 \mathrm{~cm}^{-1}$ was assigned to aromatic $\mathrm{C}=\mathrm{C}$ (Bellany, 1975), and results showed a distinct peak height in all fallow lengths (Fig. 4.2). Peaks around $1535-1520 \mathrm{~cm}^{-1}$ were assigned to $\mathrm{C}=\mathrm{C}$ aromatic ring, amide (Inbar el al., 1989; Baes and Bloom, 1989) were frequently shown in the peak height in fallow lengths of 20 years, and more than 40 years. Aliphatic and alcoholic $\mathrm{OH}$ bands which were indicated by the peak at $1080-1050 \mathrm{~cm}^{-1}$, only appeared in samples of fallow lengths of 10 years, 20 years and more than 40 years. Peaks around 3279-3340 $\mathrm{cm}^{-1}$ indicated phenol $\mathrm{OH}$ and amide $\mathrm{N}-\mathrm{H}$, and $\mathrm{CH}_{2}$ symmetric stretch (around 32793340 and 2962-2950 $\mathrm{cm}^{-1}$ ). Griffiths and Fuller (1982) also distinguished different peak heighst in fallow lengths of $1,8,10,20$ and more than 40 years. The peak around 530$520 \mathrm{~cm}^{-1}$ was associated with unknown mineral compounds such as silicate and oxides (Bellany, 1975; Inbar et al., 1989). 
The comparison of $\mathrm{O} / \mathrm{R}$ ratio in fallow length are shown in Table. 4.2, and Fig. 4.3. These results show that the $\mathrm{O} / \mathrm{R}$ ratio generally increased with greater fallow length, but these increases were different among the communities sampled. The $\mathrm{O} / \mathrm{R}$ ratio in soil samples from San José increased with greater fallow length as did samples from San Juan Circa, where the $\mathrm{O} / \mathrm{R}$ ratio increased from 1.04 to $1.26,1.28$ and 1.71 from 1 year to 10 , 20 and $>40$ years, respectively.

Greater fallow length only had a small impact on the increase of $\mathrm{O} / \mathrm{R}$ ratio in samples from Kellhuiri and V. Coopani. However, the fallow length samples from these communities were only 1 to 8 years at both locations. During the fallow period, residues produced from native vegetation decompose and degrade possibly allowing for an increase in SOM, the restoration of nutrients, and an enhancement of the population and activity of indigenous microbe consortia (Aguilera et al., 2010). Fallowing may increase the bioavailability of SOM leading to the change of HA composition as well as the O/R ratio. Singh et al. (2005) showed that fallowing and cropping land had effects on soil organic carbon concentrations, and also reported that Fourier transform infrared (FTIR) spectra were different among spectra under different land management practices. Our results suggest that an increase of HA bioavailability could be achieved by greater fallow length in the Bolivian Altiplano environment.

\section{Location \#2 (Cochabamba, Bolivia):}

The DRIFT spectra of soils collected in Cochabamba, Bolivia showed similarly peaks for all three communities in degraded soils (Fig. 4.4) and non-degraded soils (Fig. 4.5). The distinct peak height at the band around $3279-3340 \mathrm{~cm}^{-1}$ was assigned to $\mathrm{CH}_{2}$ symmetric strength (Bellany, 1975). Peaks around $1850 \mathrm{~cm}^{-1}$ were assigned to $\mathrm{C}=\mathrm{O}$ 
strength; around 1550 to aromatic amide; and $1535-1520 \mathrm{~cm}^{-1}$ and $1509 \mathrm{~cm}^{-1}$ to $\mathrm{C}==\mathrm{C}$ aromatic ring, amide, and results showed a distinct peak in Waylla Pujru and Sanyacani than Toralapa Baja in degraded soils but not in non-degraded soils. The $\mathrm{CH}_{3}$ asymmetric strength, $\mathrm{CH}$ bend was shown in the peak height of $1457 \mathrm{~cm}^{-1}$. The $\mathrm{CO}, \mathrm{COOH}, \mathrm{COC}$, and phenol $\mathrm{OH}$ also were shown in the peak height of 1260-1240 $\mathrm{cm}^{-1}$ (Inbar el al., 1989; Baes and Bloom, 1989). Aliphatic and alcoholic $\mathrm{OH}$ bands, which were indicated by the peak at $1080-1050 \mathrm{~cm}^{-1}$, showed more distinct height at the Toralapa Baja than Waylla Pujru and Sanyacani. The peak around $530-520 \mathrm{~cm}^{-1}$ was associated with unidentified mineral compounds, such as silicate and oxides (Bellany, 1975; Inbar et al., 1989).

Among degraded soils, the $\mathrm{O} / \mathrm{R}$ ratios could be ranked Sanyacani $>$ Waylla Pujru>Toralapa Baja which were 1.06, 1.08 and 1.09, respectively, and no means were different based on differences in standard deviations (Table 4.3). The $\mathrm{O} / \mathrm{R}$ ratios ranked the same results (Sanyacani>Waylla Puiru>Toralapa Baja) at 1.10, 1.13 and 1.14 in nondegraded soils, respectively (Table 4.4).

No statistical difference $(P<0.05)$ was observed for the ratio of peak heights intensity $(\mathrm{O} / \mathrm{R})$ between degraded soils and non-degraded soils. However, the nondegraded soils had $\mathrm{O} / \mathrm{R}$ ratios higher than degraded soil for all communities (Sanyacani $>$ Waylla Puiru $>$ Toralapa Baja) (Figure 4.6). Reported problems for the degraded soils, such as low soil fertility, poor soil management, practices, monoculture, pests, contamination and lack of soil conservation practice, could lower the active component of HA.

Soils collected from low elevations had higher $\mathrm{O} / \mathrm{R}$ ratio than those of higher elevation. It is probable that agricultural practices, such as tillage methods affected soil 
quality. In non-degraded land, soils were more fertile compared to degraded lands, and selected soil characteristics showed that soil total carbon, phosphorus, potassium, calcium, magnesium and cation exchange capacity (Chapter 2) were all higher in nondegraded areas. Those factors normally influenced soil quality since agricultural management practices affect the levels of SOM by influencing the amount of plant residues returned to the soil. Campbell et al. (2000) found that the rate of residue decomposition affected soil organic carbon in soils, not only by the levels of organic residue input, but also due to biological activity, and overall nutrient status in soils (Kirchmann and Gerzabek, 1999). Management practices, such as crop rotation, soil tillage, and fertilization affect soil $\mathrm{C}$ inputs and turnover in arable cropping systems ( $\mathrm{Six}$ et al., 2000).

\section{Location \#3 (Indonesia):}

Under agroforestry systems in Indonesia, spectra of low and medium inputs of manure were similar compared to spectrum of the control (no manure) area indicating that the application of manure might have an impact on the composition of HA (Fig. 4.7). A peak in the regions of 3700 to $3500 \mathrm{~cm}^{-1}$ was observed in the spectrum of no manure. The HA in low an medium manure input system exhibited the most distinct $\mathrm{C}=\mathrm{O}$ stretch, $\mathrm{C}=\mathrm{O}$ ketonic, $\mathrm{COOH}$ bands in both 1850 , and $1735-1713 \mathrm{~cm}^{-1}$ region, respectively, while a unique peak in the $1200 \mathrm{~cm}^{-1}$ region, indicating $\mathrm{COOH}$ bands, was observed in the low manure system. It was observed that peak height (around 1535-1520 $\mathrm{cm}^{-1}$ ) which indicated $\mathrm{C}=\mathrm{C}$, aromatic ring, amide were similar for all treatments. Aliphatic and alcoholic $\mathrm{OH}$ bands which were indicated by the peak at $1190-1127 \mathrm{~cm}^{-1}$ showed more distinct height in the control area. 
In the non-agroforestry area, results were similar to those of the agroforestry area (Figure 4.8). The spectra of low and medium manure inputs were similar compared to the spectrum of the control (no manure), which also indicated that the application of manure might have impacts on the composition of HA. The distinct peak height at the band around 2962-2950 $\mathrm{cm}^{-1}$ was assigned to $\mathrm{CH}_{2}$ symmetric strength (Bellany, 1975). The $\mathrm{HA}$ in low and medium manure inputs exhibited the most distinct $\mathrm{C}=\mathrm{O}$ stretch, $\mathrm{C}=\mathrm{O}$ ketonic, $\mathrm{COOH}$ bands in both 1850 , and $1735-1713 \mathrm{~cm}^{-1}$ region, respectively. A unique peak in the $1200 \mathrm{~cm}^{-1}$ region, indicating $\mathrm{COOH}$ bands, was observed in low manure as in agroforestry. Aliphatic and alcoholic $\mathrm{OH}$ bands were indicated by the peak at 1190-1127 $\mathrm{cm}^{-1}$ and showed more distinct height in no manure in non-agroforestry. Peaks around $850-830 \mathrm{~cm}^{-1}$ were assigned to $\mathrm{CH}$ aromatic bend and were distinct in the no manure than low and high manure. The peak around $530-520 \mathrm{~cm}^{-1}$ was associated with unknown mineral compounds such as silicate and oxides (Bellany, 1975; Inbar et al., 1989).

A comparison of selected peak intensities in agroforestry and non-agroforestry are shown in Table 4.5 and 4.6. The $\mathrm{O} / \mathrm{R}$ ratio was highest in medium manure (3.30 \pm 0.04$)$. The lowest was in the control (no manure) and the average $\mathrm{O} / \mathrm{R}$ ratio was $1.29 \pm 0.39$. The HA fraction average in low manure was $1.14 \pm 0.14$. Based on the peak ratio comparison of $\mathrm{HA}$ in the non-agroforestry area, the $\mathrm{O} / \mathrm{R}$ ratios were similar to that in the agroforestry area. The lowest to the highest HA fraction average in the agroforestry was in the control (no manure), low manure, and medium manure and the average $\mathrm{O} / \mathrm{R}$ ratio was $1.29 \pm 0.39$. The HA fraction with low manure inputs was $2.05 \pm 1.46$ (Table 4.5). The $\mathrm{O} / \mathrm{R}$ ratios from agroforestry areas were not significantly different among non-agroforestry areas with no manure and low manure application (the rate of less than 5,000 $\mathrm{kg} \mathrm{ha}^{-1}$ per planting 
season). However, there were significant difference among agroforestry and nonagroforestry sites when manure was applied at a medium rate of application (the rate of 5,000-15,000 kg ha-1 per planting season) (Figure 4.9).

The impact of different management practices on $\mathrm{O} / \mathrm{R}$ ratio was in summarized in Figure 4.9. The $\mathrm{O} / \mathrm{R}$ ratio in soil samples taken from plots without the application of manure was lower than samples from plots with the application of manure in both agroforestry and non-agroforestry systems. The $\mathrm{O} / \mathrm{R}$ ratio increased as higher manure rates were applied. The HA peak ratio in agroforestry was higher than in non-agroforestry for all treatments as follows: $1.29 \pm 0.40$ and $0.79 \pm 0.03$ (control); $2.05 \pm 1.46$ and $1.10 \pm 0.03$ (low manure); and 3.30 \pm 0.04 (high manure). It is probable that the application of manure increased the bioavailability of SOM in soil, and also that more plant residues were produced under agroforestry than when agroforestry was not used.

With the increase of applied manure, the $\mathrm{O} / \mathrm{R}$ ratio increased, indicating that the application of manure could enhance the bioavailability of HA. Oxygen-containing functional groups were present in all major functional groups including carboxyl, phenolic, hydroxyl, alcohol, and carbonyl, and associated with soil organic matter (SOM) binding characteristics (Ding et al 2006). Manure consists of heterogeneous organic compounds which could be incorporated into SOM and enhance the bioavailability of SOM. Other differences were also present between the agroforestry and non-agroforestry systems including differences in plants and amendments. Under agroforestry, cassava (control); corn, sweet potato (low manure); scallion, chili, corn (medium manure) were planted (Table. 4.5). In the conventional non-agroforestry system, chilli, corn (control); 
scallion, taro, chili (low manure); and cabbage, scallion (medium manure) were planted (Table. 4.6).

The quantity of plant residues produced by the different vegetation under the two systems may have affected soil organic carbon. Sanchez et al.(2003) suggested that different management systems affected the soil organic carbon content by changing the annual inputs of organic residues. Higher HA contents observed in a soil were related to the formation of more stable organic mineral complexes (Stevenson, 1994). Maia (2007) compared agrosilvopasture, silvopasture, traditional agroforestry, intensive cropping, and native forestry to assess soil organic matter in those areas. The traditional agroecosystem, intensive cropping system, and agrosilvopastural systems caused significant losses in soil organic matter. In comparing agroforestry and non-agroforestry, the peak height for the HA ratio was higher in agroforestry than non-agroforestry, and HA peak ratio heights decreased with decreasing manure amendments. Therefore, the reductions in HA could be related to both differences in cropping systems and soil amendments.

\section{Location \#4 (Philippines):}

The DRIFT spectra of HA samples from soils collected from the footslope and toeslope landscape positions in the Philippines were similar in their basic assignments in both cultivated and non-cultivated areas (Figs. 4.10 and 4.11). Peak heights of summit, shoulder and backslope were different from each other. All results indicated that the landscape position and cultivation might have impacted the composition of HA. A peak in the regions of 3700 to $3500 \mathrm{~cm}^{-1}$ was observed in the spectrum for the summit position for both cultivated and non-cultivated areas which indicated mineral $\mathrm{OH}$. In the cultivated area, the band around $2924-2930 \mathrm{~cm}^{-1}$ was shown in all landscape positions 
which was assigned $\mathrm{CH}_{2}$ symmetric stretch, and was distinct in the footslope and toeslope locations. The HA peaks exhibited the most distinct $\mathrm{C}=\mathrm{O}$ stretch, $\mathrm{C}=\mathrm{O}$ ketonic, $\mathrm{COOH}$ bands in both 1850 and $1735-1713 \mathrm{~cm}^{-1}$ region, respectively, for all landscape positions. Also, the peak at $1650 \mathrm{~cm}^{-1}$ indicated $\mathrm{C}=\mathrm{O}, \mathrm{C}=\mathrm{O}-\mathrm{H}$ bonded, and amide $\mathrm{H}$ for all landscape positions. A peak in the $1200 \mathrm{~cm}^{-1}$ region, indicating $\mathrm{COOH}$ bands, was observed for the summit and backslope positions. It was observed that peak height (around1535-1520 $\mathrm{cm}^{-1}$ ) which indicated $\mathrm{C}=\mathrm{C}$, aromatic ring, amide were distinct for soils from the summit and backslope positions. A C-O aliphatic alcohol, which was indicated by the peak at $1080-1050 \mathrm{~cm}^{-1}$ showed more distinct height at the summit, footslope and toeslope positions. The band around $2924-2930 \mathrm{~cm}^{-1}$ was shown in all landscape positions which was assigned $\mathrm{CH}_{2}$ symmetric stretch, and was distinct at the shoulder, footslope and toeslope. A unique peak in $1420 \mathrm{~cm}^{-1}$ region, indicating aromatic ring stretching was distinct for the backslope position. A peak at $1080-1050 \mathrm{~cm}^{-1}$ which indicated $\mathrm{CO}$ aliphatic alcohol showed more distinct height in soils from the summit, footslope and toeslope which was the same as in the cultivated area. The peak around 530-520 $\mathrm{cm}^{-1}$ was associated with unknown mineral compounds such as silicate and oxides (Bellany, 1975; Inbar et al., 1989).

Results of comparison of selected peak height intensities in different landscape position under cultivated and non-cultivated areas are shown in Table 4.7 and 4.8. Comparing different landscape positions under the cultivated area, it was found that the highest to lowest of $\mathrm{O} / \mathrm{R}$ ratios was in summit $(1.21 \pm 0.03)$, toeslope $(1.19 \pm 0.08)$, footslope (1.15 \pm 0.07$)$, shoulder ( $1.07 \pm 0.05)$, and backslope $(0.74 \pm 0.22)$, respectively. For the peak ratio comparison of HA in non-cultivated area, $\mathrm{O} / \mathrm{R}$ ratio was in footslope 
(1.16 \pm 0.04$)$, toeslope (1.13 \pm 0.01$)$, summit $(1.08 \pm 0.01)$, shoulder $(1.08 \pm 0.02)$, and backslope (1.05 \pm 0.03$)$, respectively. The $\mathrm{O} / \mathrm{R}$ ratio of $\mathrm{HA}$ in the non-cultivated area was higher than the cultivated area except for the toeslope. It was probable that there was an addition of SOC from up-hill to down-hill during erosion, or addition of amendments during cultivation.

The $\mathrm{O} / \mathrm{R}$ ratio distribution in the cultivated area is summarized in Figure 4.12. The non-cultivated area had significantly greater $\mathrm{O} / \mathrm{R}$ ratios than those of cultivated areas in summit, shoulder, footslope and toeslope landscape positions but not at backslope positions (Fig. 4.12).

The $\mathrm{O} / \mathrm{R}$ ratio in soil samples taken from the cultivated area was lower than samples from non-cultivated area for each landscape position except the toeslope. Summit, footslope and toeslope tended to have higher peak height ratios than shoulder and backslope. The backslope particularly showed the lowest peak height ratio for both cultivated and non-cultivated areas. This was likely due to soil erosion along the landscape. Smith et al. (2001) reported that patterns of soil organic C may vary widely across the agricultural landscape where water, tillage, and wind erosion occurred. Upland areas had less SOC than soils in deposition areas. Total soil organic C decreased as the slope gradient increased, and soils on concave slopes had higher SOC than soil on convex slopes (Richie et al., 2007). Erosion was greatest on the area with the steepest slope which led to lower SOC compared to areas of less slope (Pennock and Frick, 2001).

\section{CONCLUSIONS}

These results suggest that use of the $\mathrm{O} / \mathrm{R}$ ratio calculated from Diffuse Reflectance Fourier Transform Infrared Spectroscopy (DRIFT) spectra of HA was a 
sensitive technique that was able to detect differences caused by land use and landscape position under a wide range of environments in tropical hillslope agroecosystems that may be related to changes in soil quality. This method can be used to compare SOM across various sites tested in this type of agroecosystem. It can characterize the functional groups of heterogeneous materials which may be a more direct method to determine changes in soil organic matter and soil quality caused by soil management practices than other chemical and spectral techniques. The high resolution of the spectra, and a more reliable method for quantitative estimations of functional groups could be used to analyze soil organic carbon composition. Therefore, future work using this technique is promising to develop this technique as an accurate and simple method for helping to understand the composition of soil organic carbon, and identifying soil $\mathrm{C}$ as an indicator of soil quality. Some drawbacks to this technique for use in these environments include the high cost for purchasing and maintaining the MIR instrument, the need for extensive training, the lengthy sample preparation time, and possible interference caused by minerals and water contained in the soil. 


\section{REFERENCES}

Aguilera, J., P.P. Motavalli, M.A. Gonzales, and C. Valdivia. 2010. Response of a potatobased cropping system to conventional and alternative fertilizers in the Andean Highlands. Int. J. of Plant \& Soil Sci. 3(2):139-162.

Bases, A.U., and P.R. Bloom. 1989. Diffuse reflectance Fourier transform infrared (DRIFT) spectroscopy of humic and fluvic acids. Soil. Sci. Soc. Am.J. 53:695700 .

Ben-Dor, E., and A. Banin. 1995. Near infrared analysis as a rapid method to simultaneously evaluate several soil properties. Soil. Sci. Soc. Am. J. 59:364-372.

Cambardella, C.A., and E.T. Elliott. 1994. Particulate soil organic matter change across a grassland cultivation sequence. Soil Sci. Soc. Am. J. 56:777-783.

Campbell, C.A., R.P. Zenter, B.C. Liang, G. Roloff, E.C. Gregoric, and B. Blomert. 2000. Organic $C$ accumulation in soil over 30 years in semiarid southwestern Saskatchewan - effect of crop rotations and fertilizers. Can. J. Soil Sci. 80:179182.

Carter, M.R. 2002. Soil Quality for sustainable land management: Organic matter and aggregation interactions that maintain soil function. Agron. J: 94:38-47.

Chang, C., D.A. Laird, M.J. Mausbach, and C.R. Hurburgh Jr. 2001. Mid- inferred reflectance spectroscopy-principal components regression analysis of soil properties. Soil. Sci. Soc. Am. J. 65:480-490.

Chefetz, B., A. Fabrizio, G. Pierluigi, T. Fulvia, H. Yitzhak, and C. Yona. 1998. Humic acid Transformation during composting of municipal solid waste. Environ. Qual. J. 27:794-800.

Childers, J.W., and R.A. Palmer, 1986. A comparison of photoacoustic and diffuse reflectance detection in FTIR spectroscopy. Am. Lab. 18:22-38.

Conley, R.T. 1972. Infrared spectroscopy. Allyn and Bacon, Boston, MA.

Ding, G, J.M. Novak, D. Amarasiriwardena, P.G. Hunt, and B. Xing. 2002. Soil organic matter characteristics as affected by tillage management. Soil. Sci. Soc. Am. J. $66: 421-429$.

Ding, G., J.D. Mao, S. Herbert, D. Amarasiriwardena, and B. Xing. 2007. Spectroscopic evaluation of human changes in response to soil management. In E.A. Ghabbour and G. Davis (ed.) Humic substances: Structure, models and functions. The Royal Society of Chemistry. Cambridge, London 
Garcia, C., T. Hernandez., F.Costa, and M.Ayuzo. 1992. Evaluation of the maturity of municipal solid waste compost using simple chemical parameters. Commun. Soil Sci. Plant Anal. 23:1501.

Griffiths, P.R. 1983. Fourier transform infrared spectrometry. Science (Washington, DC) 222:297-302.

Griffiths, P.R., and de Haseth, J.A.1986. Fourier transform infrared spectrometry. Science (Washington, DC). John Wiley \& Sons, Inc, pp. 57-74.

Inbar, Y., Y. Chen, and Y. Hadar. 1989. Solid state carbon-13 nuclear magnetic resonance and infrared spectroscopy of composted organic matter. Soil. Sci. Soc. Am. J. 53:1695-1701.

Jacobson, R. J. 1995. Resources to implement biological control in greenhouses. Thrips biology and management. pp.211-220. New York.

Janik, L.J., J.O. Skjemstad, K.D. Shepherd, and L.R. Spouncer. 2007. The prediction of soil carbon fractions using mid-infrared partial least square analysis. Aust. J. of Soil Research 45:73-81.

Jenkinson, J.S., and K.Coleman. 1994. Calculating the annual input of organic matter to soil from measurements of total organic matter and radiocarbon. European Journal of Soil Science. 45:167-174.

Kirchmann, H., and M.H.Gerzabe. 1999. Relationship between soil organic matter and micropores in a long-term experiment at Ultuna, Sweden. J. Plant Nutr. Soil Sci. 162: 493-498.

Maia, S.M.F., F.A.S. Xavier, and T.S. Oliveira. 2007. Organic carbon pools in a Luvisol under agroforestry and conventional farming systems in the semi-arid region of Ceará, Brazil.

Margenot, A.J., F.J. Calderon, K.W. Goyne, F.N.D. Mukome, and S.J. Parikh. 2017. IR spectroscopy, soil analysis application. Encyclopedia of Spectroscopy and Spectrometry. Third Edition. 2: 448-454.

Merry, R.H., and L.R. Spouncer. 1988. The measurement of carbon in soils using a microprocessor controlled resistance furnace. Commun. Soil. Sci. Plant Anal. 19:707-720.

Nathan, M., J. Stecker, and Y. Sun. 2006. Soil testing in Missouri: A guide for conducting soil tests in Missouri. University of Missouri, Columbia, MO. 
Niemeyer, J.L., Y. Chen, and J.M. Bollag. 1992. Characterization of humic acids, composts, and peat by Diffuse Transform Infrared Spectroscopy. Soil Sci. Soc. Am. J. 56:135-140.

Painter, P., M. Starsinic, and M. Coleman. 1985. Determination of functional groups in coal by Fourier transform interferometry. p. 169-241. In J.R. Ferraro and L.J. Basile (ed.) Fourier transform spectroscopy. Application to chemical systems. Vol. 4. Academic Press, Orlando, FL.

Parikh, J.S., W.G. Goyne, J.M. Andrew, N.D.M. Fungai, and J.C. Francisco. 2014. Soil chemical insights provided through vibrational spectroscopy. Advances in Agronomy, First Edition. pp. 1-148.

Parton, W.J., D.S. Schimel, C.V. Cole, and D.S. Ojima. 1987. Analysis of factors controlling soil organic matter levels in Great Plains grasslands. Soil Sci. Soc. Am. J. 51:1173-1179.

Pennock, D.J., and A.H. Frick. 2001. The role of field studies in landscape scale applications of process models: an example of soil redistribution and soil organic carbon modeling using CENTURY. Soil and tillage Research 58:183-191.

Preston, C.M. 1996. Application of NMR to soil organic matter analysis: history and prospects. Soil Sci. 16:829-852.

Raupp, J. 2001. Manure fertilization for soil organic matter maintenance and its effects upon crops and the environment, evaluated in a long-term trial. In. Sustainable management of soil organic matter, pp. 301-308. Eds R. M. Rees, B. C. Ball, C. D. Campbell and C. A. Watson. Wallingford: CAB International.

Reeves, J.B., A.F. Barry, and K.H. Stephen. 2005. Specular reflection and diffuse reflectance spectroscopy of soils. Applied Spectroscopy 59:39-46.

Ritchie, J.C., W.M. Gregory, R.V. Erik, and T.C. Kaspar. 2007. Soil and soil organic carbon redistribution on the landscape. Geomorphology. 89:163-171.

Sanchez, F.G., E.A. Carter, and J.F. Klepac. 2003. Enhancing the soil organic matter pool through biomass incorporation. Bioenergy 24:337-349.

Singh R., G.H. Martin, H. Georg, and E. Gerfried. 2005. Long-term effects of cropped vs. fallow and fertilizer amendments on soil organic matter. J. Plant Nutr. Soil Sci. 68:108-116.

Six, J., K. Paustian, E.T. Elliott, and C. Combrink, 2000. Soil structure and soil organic matter: 1. Distribution of aggregate size classes and aggregate associated carbon. Soil Sci. Soc. Am. J. 64:681-689. 
Skjimstad, J.O., J.A. Taylor, and R.J. Smirnik. 1990. Estimatimation of charcoal (char) in soils. Commun. Soil. Sci. Plant Anal. 30:2283-2289.

Smith, S.V., W.H. Renwick, R.W. Buddemier, and C.J. Crossland. 2001. Budgets of soil erosion and deposition of sediment and sedimentary organic matter across the conterminous united States. Global Biogeochemical Cycles. 15:697-707.

Stevenson F.J. 1994. Humus chemistry. Genesis, composition, reaction, second edition. John Wiley and Sons. New York.

Stevenson, F.J., E.T. Elliott, C.V. Cole., J. Ingram, J.M. Oades, C. Preston, and P.J. Sollins. 1989. Methodologies for assessing quantity and quality of soil organic matter. p. 249. In D.C. Coleman et al. (ed.) Dynamics of soil organic matter in tropical soils. NiFTAL, Honolulu. HI.

Van der Marel H.W., and H. Beutelspacher.1976. Clay and related minerals. In 'Atlas of infrared spectroscopy of clay minerals and their admixtures. Elsevier Scientific. Amsterdam.

Van Veen J.A., J.N. Ladd, and M.J. Frissel. 1984. Modelling C and N turnover through the microbial biomass of soil. Plant and Soil. 76:257-274.

Varanini, Z., and Pinton R. 1995. Humic substance and plant nutrition. Proc. Bot. 56. Bahnke, H.D., Luttge, U., Esser, K., Kadereit, J.W., and Runge, M., eds, Springer-Verlag, Berlin.

Walkley, A., and I.A. Black. 1934. An examination of the Dgtjareff method for determining soil organic matter, and a proposed modification of the chronic acid titration method. Soil Science 37:29-38.

Wander, M., and S.J. Traina. 1996. Organic fractions from organically and conventionally managed soils: II. Characterization. Soil Sci. Soc. Am. J. 60: 1087-1094. 
Table 4.1. Approximate DRIFT infrared spectra peak assignments and occurrences in physical and chemical organic matter fractions.

\begin{tabular}{|c|c|}
\hline Assignment & Wave Number $\left(\mathrm{cm}^{-1}\right)$ \\
\hline Mineral OH & 3690 \\
\hline Mineral OH & 3621 \\
\hline Phenol OH, amide $\mathrm{N}-\mathrm{H}$ & $3279-3340$ \\
\hline $\mathrm{CH}_{2}$ symmetric stretch & $2962-2950$ \\
\hline $\mathrm{CH}_{2}$ asymmetric stretch & 2924-2930 \\
\hline $\mathrm{CH}_{2}$ symmetric stretch & 2850 \\
\hline $\mathrm{CO}-\mathrm{OH} \mathrm{H}$ bonded & 2500 \\
\hline $\mathrm{C}=\mathrm{O}$ stretch & 1850 \\
\hline $\mathrm{C}=\mathrm{O}$ ketonic, $\mathrm{COOH}$ & $1735-1713$ \\
\hline $\mathrm{C}=\mathrm{O}, \mathrm{C}=\mathrm{O}-\mathrm{H}$ bonded,$\quad$ amide $\mathrm{H}$ & 1650 \\
\hline $\mathrm{C}=\mathrm{C}$ aromatic & $1630-1608$ \\
\hline Aromatic ring, amide & 1509 \\
\hline $\mathrm{CH}$, asymmetric stretch, $\mathrm{CH}$ bend & 1457 \\
\hline Aromatic ring stretching & 1420 \\
\hline $\mathrm{COO}$ salt, $\mathrm{COOH}$ & 1400 \\
\hline $\mathrm{COO}-, \mathrm{CH}$, symmetric stretch & $1379-1327$ \\
\hline $\mathrm{CO}, \mathrm{COOH}, \mathrm{COC}$, phenol $\mathrm{OH}$ & $1260-1240$ \\
\hline Aliphatic, alcoholic $\mathrm{OH}$ & $1190-1127$ \\
\hline $\mathrm{CO}$ aliphatic alcohol & $1080-1050$ \\
\hline Aliphatic COC, aromatic ether, $\mathrm{Si}-\mathrm{O}$ & 1030 \\
\hline $\mathrm{OH}, \mathrm{COOH}, \mathrm{Al}-\mathrm{OH}$ & $918-912$ \\
\hline $\mathrm{CH}$ aromatic bend, $\mathrm{Al}-\mathrm{O}-\mathrm{Si}$ & $850-830$ \\
\hline $\mathrm{Fe}-\mathrm{O}-\mathrm{Si}$ & 797 \\
\hline $\mathrm{CH}$ aromatic bend & 779 \\
\hline Unknown mineral peak & 750 \\
\hline Unknown mineral peak & 794 \\
\hline $\mathrm{COO}$ salt, $\mathrm{Mg} / \mathrm{Si}-\mathrm{O}$ aliphatic & 560 \\
\hline $\mathrm{Si}-\mathrm{O}$ & $530-520$ \\
\hline Aromatic ring & 480 \\
\hline
\end{tabular}

**Peak assignments based on Bellamy (1975), van der Marel and Beutlespacher (1976), Griffiths and Fuller (1983), Stevenson (1989), Baes and Bloom (1989), and Inbar et al. (1989) 
Table 4.2. Ratios of peak heights intensity from Diffuse Reflectance Fourier Transform Infrared spectra (DRIFT) of humic acid fractions with different fallow lengths and locations in Location \#1 (Umala, Bolivia).

\begin{tabular}{ccclc}
\hline Fraction & Fallow length & Location & Ratios of selected peak intensities & $\begin{array}{c}\text { O/ R } \\
\text { ratio }\end{array}$ \\
\hline HA $1^{\dagger}$ & $1 \mathrm{yr}$ & Circa & $(1650) /(2927+2850)$ & 0.83 \\
HA 2 & & San José & $(1650) /(2927+2850)$ & 0.83 \\
HA 3 & & Kellhuiri & $(3321+1650+1078) /(2926+2850+1520+1379+830)$ & 1.05 \\
HA 4 & & V.Coopani & $(1650+1250) /(2932+1521+1420)$ & 0.87 \\
\hline \hline HA 5 & \multirow{2}{*}{ yrs } & Kellhuiri & $(3323+1650+1405+1232+1160) /(2930+2850+1534)$ & 1.19 \\
\hline \hline HA 6 & \multirow{2}{*}{ yrs } & Kellhuiri & $(1650+1152) /(2930+2850+1420)$ & 0.84 \\
HA7 & & V.Coopani & $(1650+1240+1056) /(2925+2850)$ & 1.04 \\
\hline \hline HA8 & \multirow{2}{*}{$10 \mathrm{yrs}$} & Circa & $(1650+1050) /(2927+1608)$ & 1.27 \\
\hline HA9 & & Circa & $(1650+1050) /(2930+1608)$ & 1.25 \\
\hline HA10 & & San José & $(1650+1160) /(2927+2856+1611+1530+480)$ & 1.07 \\
HA11 & & San José & $(3296+1650+1400+1159) /(2926+2850+1520)$ & 1.06 \\
\hline \hline HA12 & \multirow{2}{*}{$20 \mathrm{yrs}$} & Circa & $(1650+1050+1240) /(2930)$ & 1.14 \\
HA13 & & San José & $(1650+1165+1050) /(2930+1521+1608+1520)$ & 1.51 \\
\hline \hline HA14 & $>40$ yrs & Circa & $(1650+1057) /(2927)$ & 1.71 \\
HA15 & & San José & $(1650) /(2850)$ & 1.56 \\
HA16 & & V.Coopani & $(3313+1650+1050) /(2850+1529+1420)$ & 1.24 \\
\hline HA humic acid fraction & & &
\end{tabular}

${ }_{\mathrm{HA}}=$ humic acid fraction. 
Table 4.3. Ratio of peak heights (O/R ratio) from Diffuse Reflectance Fourier Transform Infrared spectra of humic acid (HA) fractions from communities of different elevation with degraded land in Location \#2 (Cochabamba, Bolivia).

\begin{tabular}{|c|c|c|c|c|}
\hline Fraction & Location & Ratios of selected peak intensities & $\begin{array}{c}\mathrm{O} / \mathrm{R} \text { ratio } \\
\text { degraded } \\
\text { land }\end{array}$ & Average \\
\hline HA $1^{\dagger}$ & $\begin{array}{c}\text { Toralapa } \\
\text { Baja }^{\dagger \dagger} \\
\text { Toralapa }\end{array}$ & $(1717+1400+1076) /(2950+1457+850)$ & 1.07 & \\
\hline HA 2 & $\begin{array}{l}\text { Baja } \\
\text { Toralapa }\end{array}$ & $(1650+1080) /(2906+1625+1520+1420)$ & 1.20 & \\
\hline HA3 & $\begin{array}{l}\text { Baja } \\
\text { Toralapa }\end{array}$ & $(1717+1240) /(2936+1618+779)$ & 1.20 & \\
\hline HA4 & Baja & $(3289+1717+1240) /(2930+1650+1420+1072)$ & 1.04 & $1.12 \pm 0.08$ \\
\hline HA5 & Waylla Pujru & $(1650+1089) /(2950+862)$ & 1.09 & \\
\hline HA6 & Waylla Pujru & $(1723+1650) /(2929+1420)$ & 1.06 & \\
\hline HA7 & Waylla Pujru & $(1717+1650+1082) /(3260+2931+1520+1420)$ & 1.01 & \\
\hline HA8 & Waylla Pujru & $(3311+1650+1076) /(2930+1520+835)$ & 1.08 & $1.06 \pm 0.07$ \\
\hline HA9 & Sancayani & $(1717+1650) /(2924+1630+836+779)$ & 1.14 & \\
\hline HA10 & Sancayani & $((3312+1650+1054) /(2933+1626+1521+1420+836)$ & 1.04 & \\
\hline HA11 & Sancayani & $(1723+1068) /(2930+1625+1533+1420+834)$ & 1.05 & $1.08 \pm 0.06$ \\
\hline \multicolumn{5}{|c|}{$\begin{array}{l}\text { HA = humic acid fraction. } \\
{ }^{\dagger} \text { Toralapa Baja (low land area), Waylla Pujru (relatively intermediate land area), } \\
\text { and Sancayani (high land area) } \\
\text { Table 4.4. Ratio of peak heights (O/R ratio) from Diffuse Reflectanc }\end{array}$} \\
\hline Fraction & Location & Ratios of selected peak intensities & $\begin{array}{l}\mathrm{O} / \mathrm{R} \text { ratio } \\
\text { non- } \\
\text { degraded } \\
\text { area }\end{array}$ & Average \\
\hline HA $1^{\dagger}$ & Toralapa Baja ${ }^{\dagger \dagger}$ & $(1720+1650+1080) /(2950)$ & 1.17 & \\
\hline HA 2 & Toralapa Baja & $(3084+1723) /(2930+1625+1420)$ & 1.05 & \\
\hline HA3 & Toralapa Baja & $(1718+1650+1050) /(2950+1420+847)$ & 1.22 & \\
\hline HA4 & Toralapa Baja & $(1723+1650+1260+1050) /(2939+779)$ & 1.11 & $1.14 \pm 0.07$ \\
\hline HA5 & Waylla Pujru & $(1717+1080) /(2926+840)$ & 1.13 & \\
\hline HA6 & Waylla Pujru & $(1722+1650) /(2950+1420)$ & 1.10 & \\
\hline HA7 & Waylla Pujru & $(1650+1076) /(3277+2950+1520+1420+839)$ & 1.15 & \\
\hline HA8 & Waylla Pujru & $(3299+1719) /(2936+1624+1520+1420)$ & 1.02 & $1.10 \pm 0.07$ \\
\hline HA9 & Sancayani & $\begin{array}{l}(1726+1650+1375+1080) /(2929+1632+ \\
1420+840+779)\end{array}$ & 1.18 & \\
\hline HA10 & Sancayani & $(1650+1718+1063) /(2931+1630+1531+1420+834)$ & 1.06 & \\
\hline HA11 & Sancayani & $(1723+1068) /(2930+1625+1533+1420+834)$ & 1.14 & $1.13 \pm 0.06$ \\
\hline
\end{tabular}


Table 4.5. Ratios of peak heights (O/R ratio) from Diffuse Reflectance Fourier Transform Infrared spectra of humic acid in agroforestry fields in Location \#3 (Indonesia).

\begin{tabular}{|c|c|c|c|c|}
\hline Fraction & Treatment & Ratios of selected peak intensities & $\begin{array}{l}\mathrm{O} / \mathrm{R} \text { ratio } \\
\text { agroforestry }\end{array}$ & Average \\
\hline HA $1^{\dagger}$ & control & $(3319+1650+1063) /(1521+844)$ & 1.57 & \\
\hline HA 2 & control & $(1650+1127) /(2950+1535+830)$ & 1.01 & $1.29 \pm 0.40$ \\
\hline HA 3 & low manure & $(1650+1520+1058) /(2962)$ & 1.04 & \\
\hline HA 4 & low manure & $(3316+1650+1054) /(2950+1520+1420)$ & 1.24 & $1.14 \pm 0.14$ \\
\hline HA 5 & $\begin{array}{l}\text { medium } \\
\text { manure } \\
\text { medium }\end{array}$ & $(3396+3319+1063) /(2927+1650+1520)$ & 3.36 & \\
\hline HA 6 & manure & $(3296+3319+1063) /(2927+1650+1520)$ & 3.29 & $3.32 \pm 0.04$ \\
\hline
\end{tabular}

Table 4.6. Ratios of peak heights (O/R ratio) from Diffuse Reflectance Fourier Transform Infrared spectra of humic acid in non-agroforestry fields in Location \#3 (Indonesia).

\begin{tabular}{cclcc}
\hline Fraction & Treatment & \multicolumn{1}{c}{ Ratios of selected peak intensities } & $\begin{array}{c}\text { O/ R ratio } \\
\text { non-agroforestry }\end{array}$ & Average \\
\hline HA $^{\dagger}$ & control & $(1650+1050+916) /(779+460)$ & 0.82 & \\
HA 2 & control & $(1650+1127+1063) / 9779+480)$ & 0.77 & $0.79 \pm 0.03$ \\
\hline \hline HA 3 & low manure & $(1240+1050) /(2930+1535)$ & 1.08 & \\
HA 4 & low manure & $(1240+1050) /(2930+1535)$ & 1.12 & $1.10 \pm 0.03$ \\
\hline \hline & medium & $(3319+3310+1650+1249+1143+1071) /(2930+$ & & \\
HA 5 & manure & $1530+1457+844)$ & 1.17 & \\
& medium & $(3337+1650+1254+1154+1080) /(2925+1534$ & 1.22 & $1.20 \pm 0.03$ \\
\hline
\end{tabular}

${ }^{\dagger} \mathrm{HA}=$ humic acid fraction. 
Table 4.7. Ratios of peak heights (O/R ratio) from Diffuse Reflectance Fourier Transform Infrared spectra of humic acid in the cultivated area at different landscape positions in Location \#4 (Philippines).

\begin{tabular}{cclcc}
\hline Fraction & $\begin{array}{c}\text { Landscape } \\
\text { position }\end{array}$ & \multicolumn{1}{c}{ Ratios of selected peak intensities } & $\begin{array}{c}\text { O/ R ratio } \\
\text { cultivated area }\end{array}$ & Average \\
\hline HA $1^{\dagger}$ & summit & $(3279+1650+1087+912) /(2925+1535)$ & 1.18 & \\
HA 2 & summit & $(3300+1650) /(2943+1535+1420)$ & 1.22 & \\
HA3 & summit & $(3279+1650+1085+1050+914) /(1420)$ & 1.24 & $1.21 \pm 0.03$ \\
\hline \hline HA 3 & shoulder & $(3299+1650) /(2930+1535+1457)$ & 1.04 & \\
HA 4 & shoulder & $(3312+1650+1078) /(2950+1535)$ & 1.14 & \\
HA 5 & shoulder & $(3312+1650+1078) /(2950+1535)$ & 1.02 & $1.07 \pm 0.05$ \\
\hline \hline HA 6 & backslope & $(3319+1650) /(830+1535)$ & 0.64 & \\
HA7 & backslope & $(3298+1650+1127) /(830+1535)$ & 1.04 & \\
HA8 & backslope & $(3312+1650+1127) /(830+1535)$ & 1.12 & \\
\hline \hline HA9 & footslope & $(3312+1650+1058) /(2936+1528+1420)$ & 1.09 & \\
HA10 & footslope & $(3312+1650+1057) /(2937+1520+1420+779)$ & 1.22 & $1.15 \pm 0.07$ \\
HA11 & footslope & $(3312+1650+1058) /(2936+1528+1420+779)$ & 1.21 & \\
\hline \hline HA12 & toeslope & $(3290+1650+1058) /(3290+1650+1058)$ & 1.1 & \\
HA13 & toeslope & $(3305+1650+1061) /(2930+1520+1420)$ & 1.26 & $1.19 \pm 0.08$ \\
HA14 & toeslope & $(3298+1650+1061) /(2948+1520)$ & & \\
\hline HA $=$ humic acid fraction. & & & & \\
\hline
\end{tabular}


Table 4.8. Ratios of peak heights (O/R ratio) from Diffuse Reflectance Fourier Transform Infrared spectra of humic acid in non-cultivated areas at different landscape positions in Location \#4 (Philippines).

\begin{tabular}{|c|c|c|c|c|}
\hline Fraction & $\begin{array}{c}\text { Landscape } \\
\text { position }\end{array}$ & Ratios of selected peak intensities & $\begin{array}{c}\mathrm{O} / \mathrm{R} \text { ratio } \\
\text { non-cultivated } \\
\text { area } \\
\end{array}$ & Average \\
\hline HA $1^{\dagger}$ & summit & $(3320+1273+1240+1060) /(2930+1624)$ & 1.08 & \\
\hline HA 2 & summit & $(3320+1723+1240+1066) /(2930+1624)$ & 1.05 & \\
\hline HA3 & summit & $(3320+1723+1240) /(2930+1627+1060)$ & 1.06 & $1.06 \pm 0.01$ \\
\hline HA 3 & shoulder & $(3320+1650+1240+1066) /(2930+1624+1539)$ & 1.07 & \\
\hline HA 4 & shoulder & $(3320+1650+1240+1066) /(2930+1624+1539)$ & 1.07 & \\
\hline HA 5 & shoulder & $(3320+1650+1223+1066) /(2930+1625+1539)$ & 1.11 & $1.08 \pm 0.02$ \\
\hline HA 6 & backslope & $(3320+1650+1388+1083) /(2930+1625+1535)$ & 1.06 & \\
\hline HA7 & backslope & $(3320+1650+1400+1061) /(2930+1625+1532)$ & 1.02 & \\
\hline HA8 & backslope & $(3320+1650+1400+1088+784) /(2947+1625+1539)$ & 1.07 & $1.05 \pm 0.03$ \\
\hline HA9 & footslope & $(3320+1650+1058) /(2930+1624+1530)$ & 1.19 & \\
\hline HA10 & footslope & $(3320+1650+1049) /(2947+1625+1520)$ & 1.18 & \\
\hline HA11 & footslope & $(3320+1650+1072) /(2947+1533+1420)$ & 1.12 & $1.16 \pm 0.04$ \\
\hline HA12 & toeslope & $(3320+1650+1400+1227+1066) /(2947+1530)$ & 1.13 & \\
\hline HA13 & toeslope & $(3320+1650+1400+1127+1065) /(2947+1530)$ & 1.14 & \\
\hline HA14 & toeslope & $(3320+1650+1400+1227+1039) /(2947+1520)$ & 1.12 & $1.13 \pm 0.01$ \\
\hline
\end{tabular}




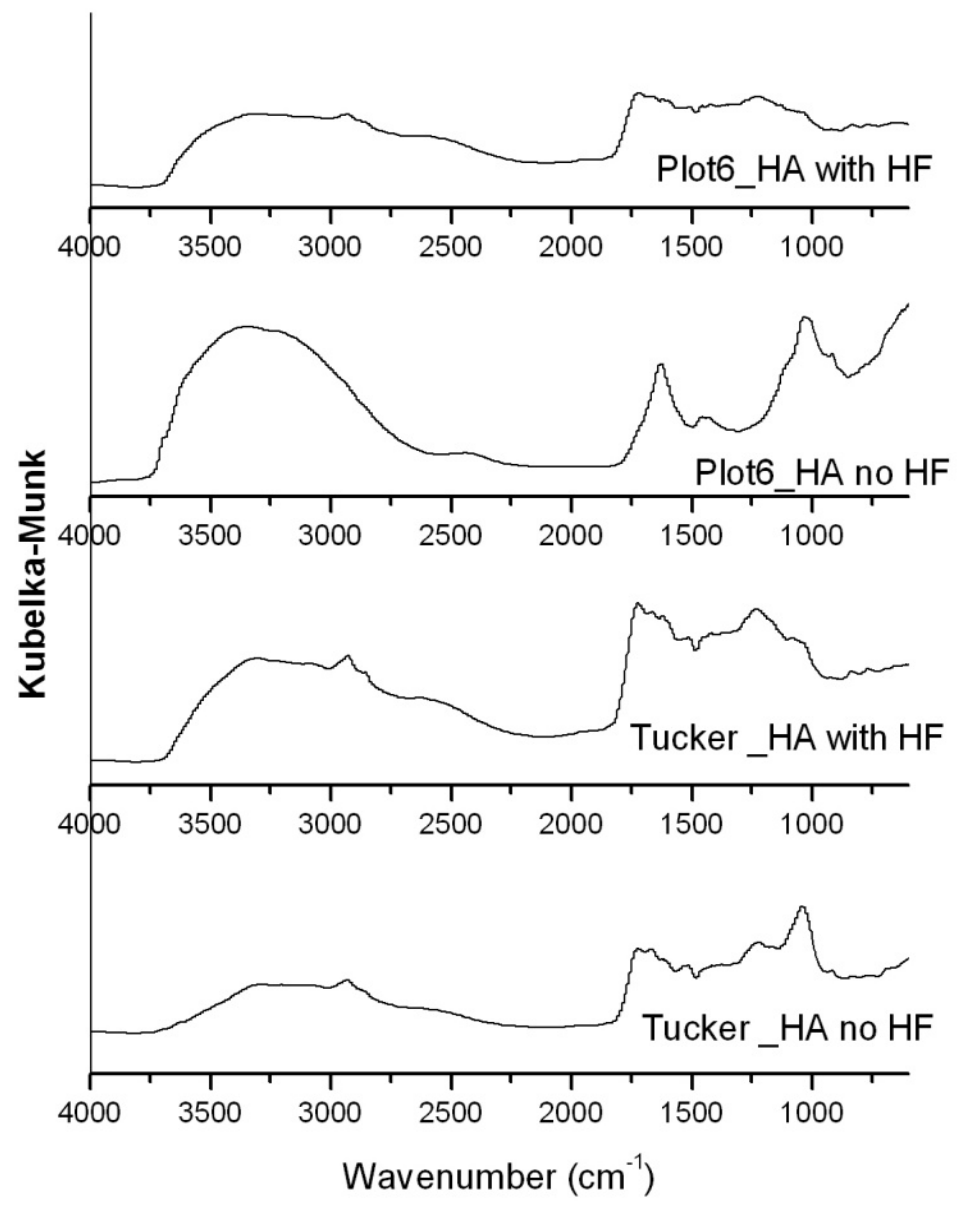

Figure 4.1. Pre-experiment comparing the Mid-Infrared Diffuse Reflectance spectra of humic acid (HA) with and without hydrofluoric acid (HF) treatment of soils from a long-term cultivated plot from Sanborn Field (Plot 6) and an undisturbed prairie site (Tucker) in Missouri (USA). 


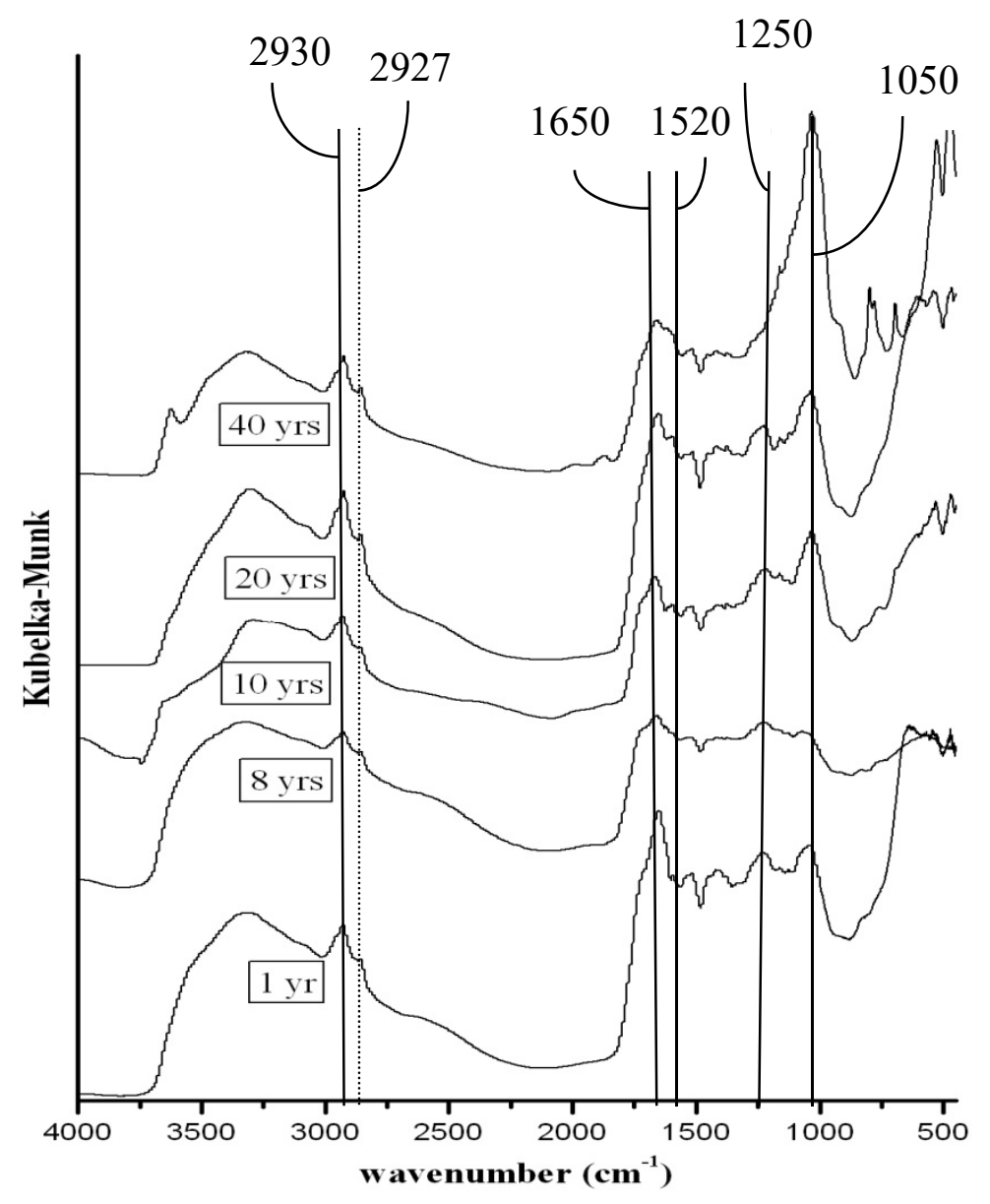

Figure 4.2. Diffuse Reflectance Fourier Transform Infrared spectra of humic acids due to in different fallow length $(0,8,10,20$ and 40 years) in soils collected from Location \#1 (Umala, Bolivia). 


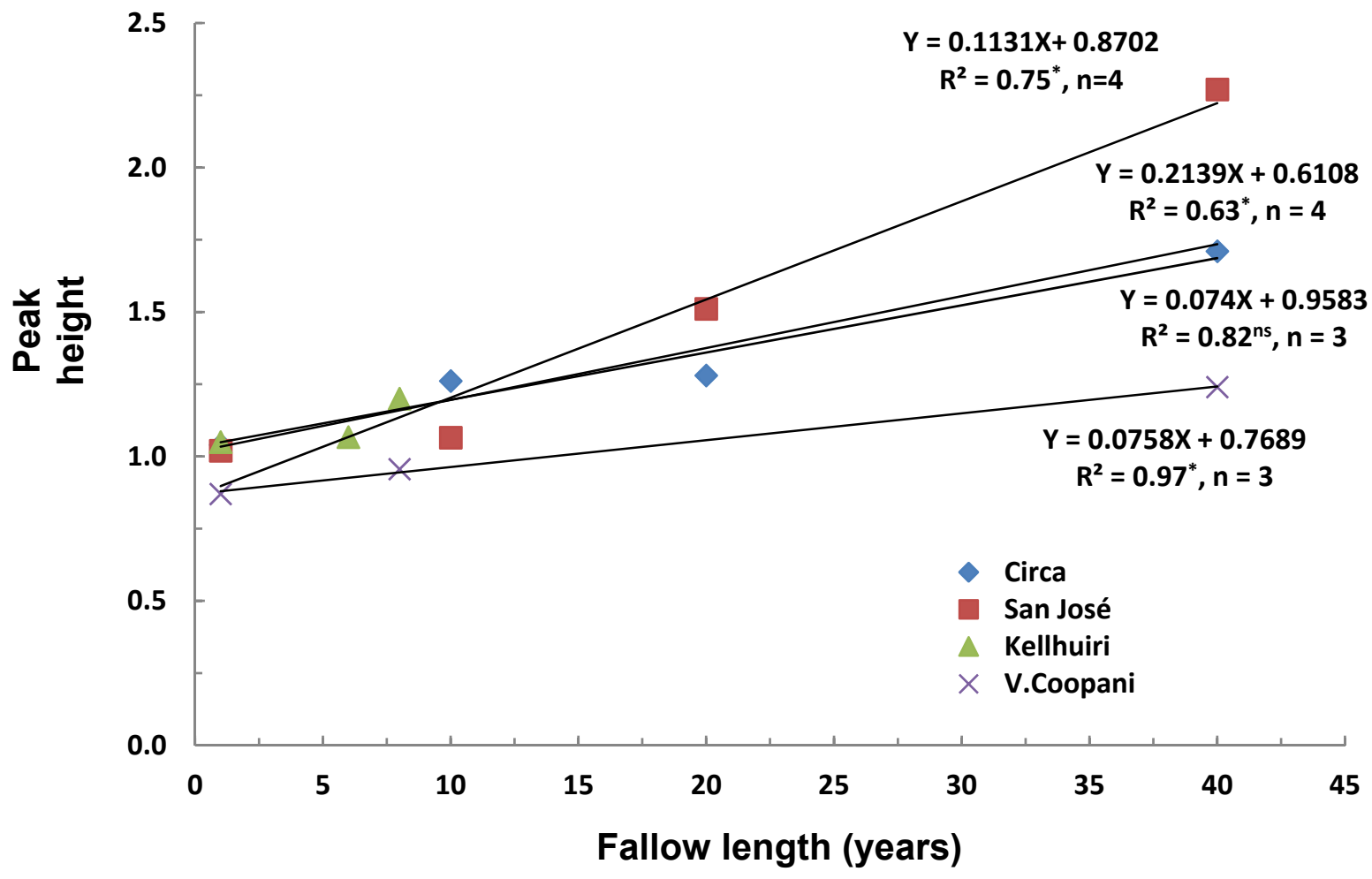

Figure 4.3. Comparing ratio of peak height intensity $(\mathrm{O} / \mathrm{R})$ of humic acids with different fallow length in 4 communities in Location \#1 (Umala, Bolivia). * significant at $\mathrm{p} \leq 0.05 ; \mathrm{ns}=$ not significant. 


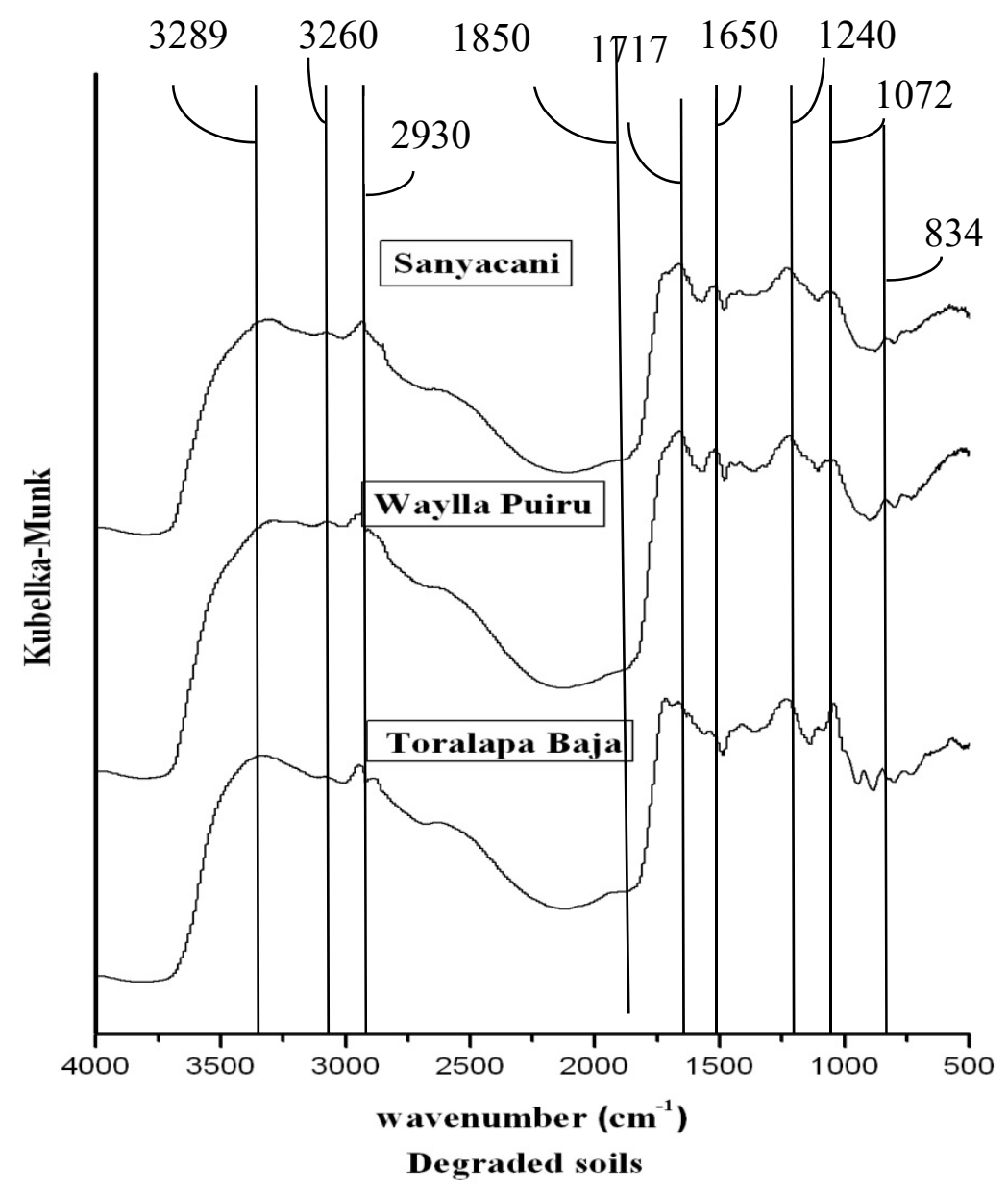

Figure 4.4. Diffuse Reflectance Fourier Transform Infrared spectra of humic acids in degraded land in three communities at different elevations (Toralapa Baja (low elevation), Waylla Puiru (medium elevation) and Sanyacani (high elevation)) located in Location \#2 (Cochabamba, Bolivia). 


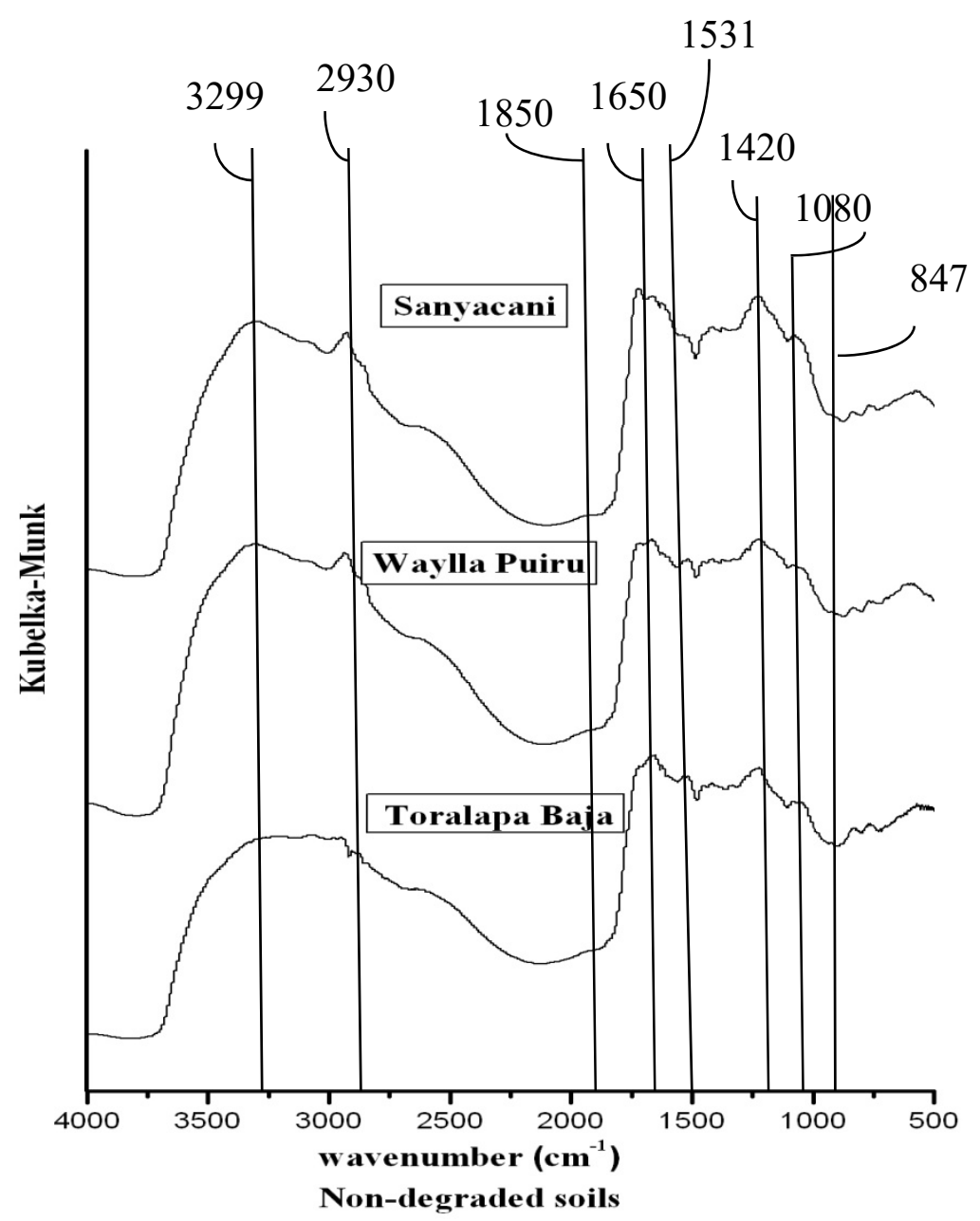

Figure 4.5. Diffuse Reflectance Fourier Transform Infrared spectra of humic acids in non-degraded land in three communities at different elevations (Toralapa Baja (low elevation), Waylla Puiru (medium elevation) and Sanyacani (high elevation)) located in Location \#2 (Cochabamba, Bolivia). 


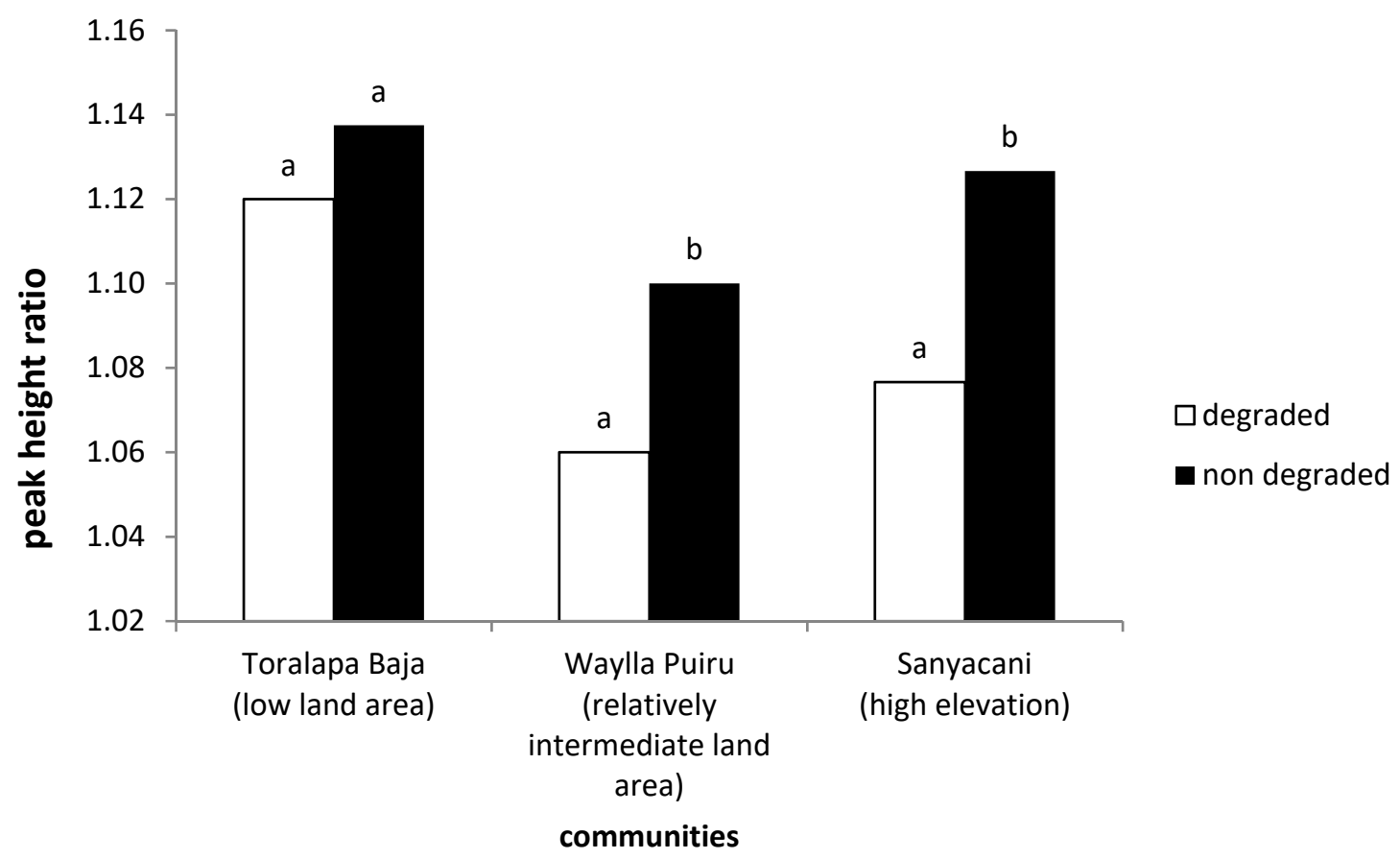

Figure 4.6. Comparing the ratio of peak heights intensity (O/R) of humic acids with degraded and non-degraded land in Location \#2 (Cochabamba, Bolivia). Within a bar, the numbers followed with the same letter are not significantly different to the LSD 0.05 value . 


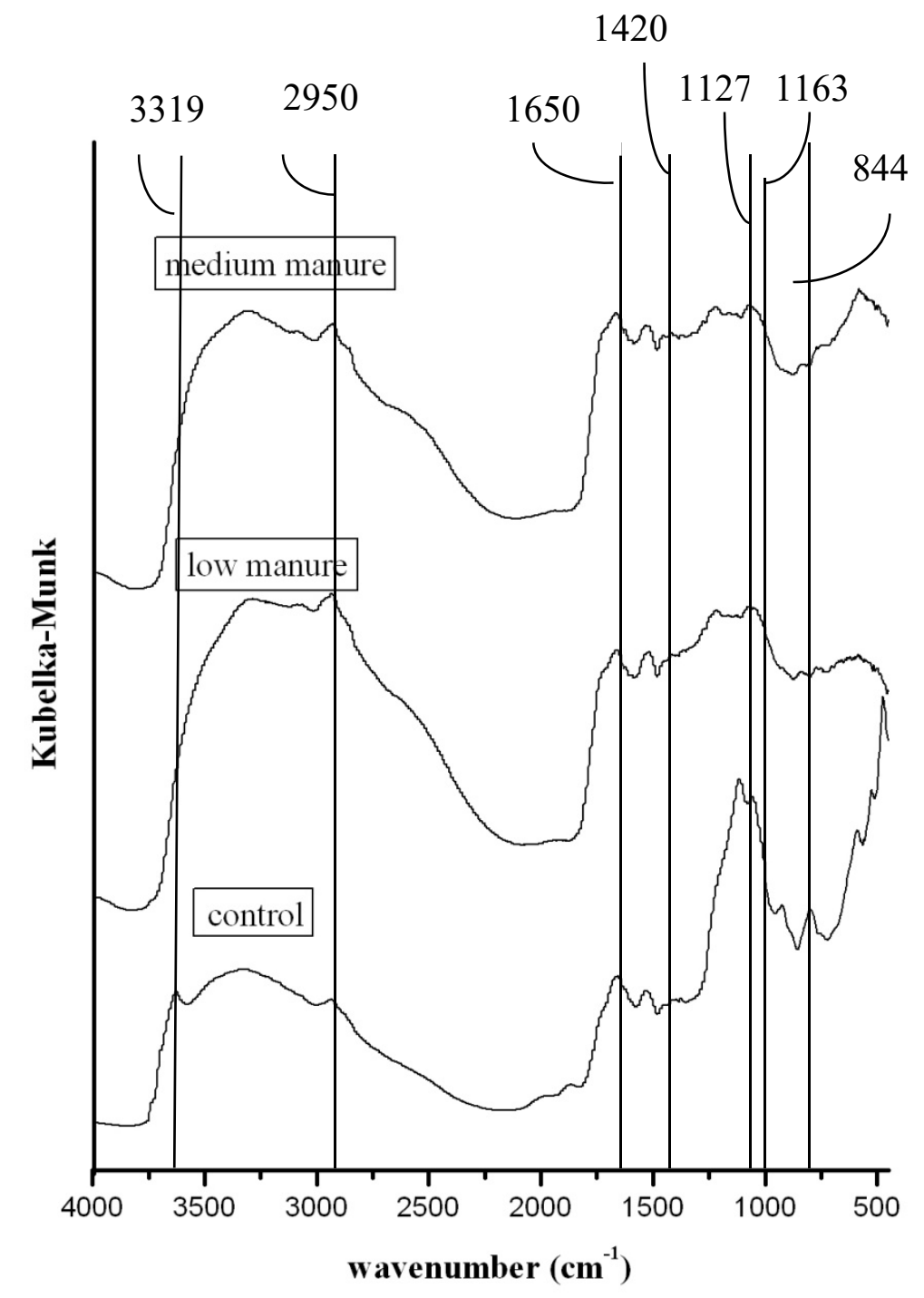

Agroforestry

Figure 4.7 Diffuse Reflectance Fourier Transform Infrared spectra of humic acids in agroforestry area receiving different amounts of manure in Location \#3 (Indonesia). 


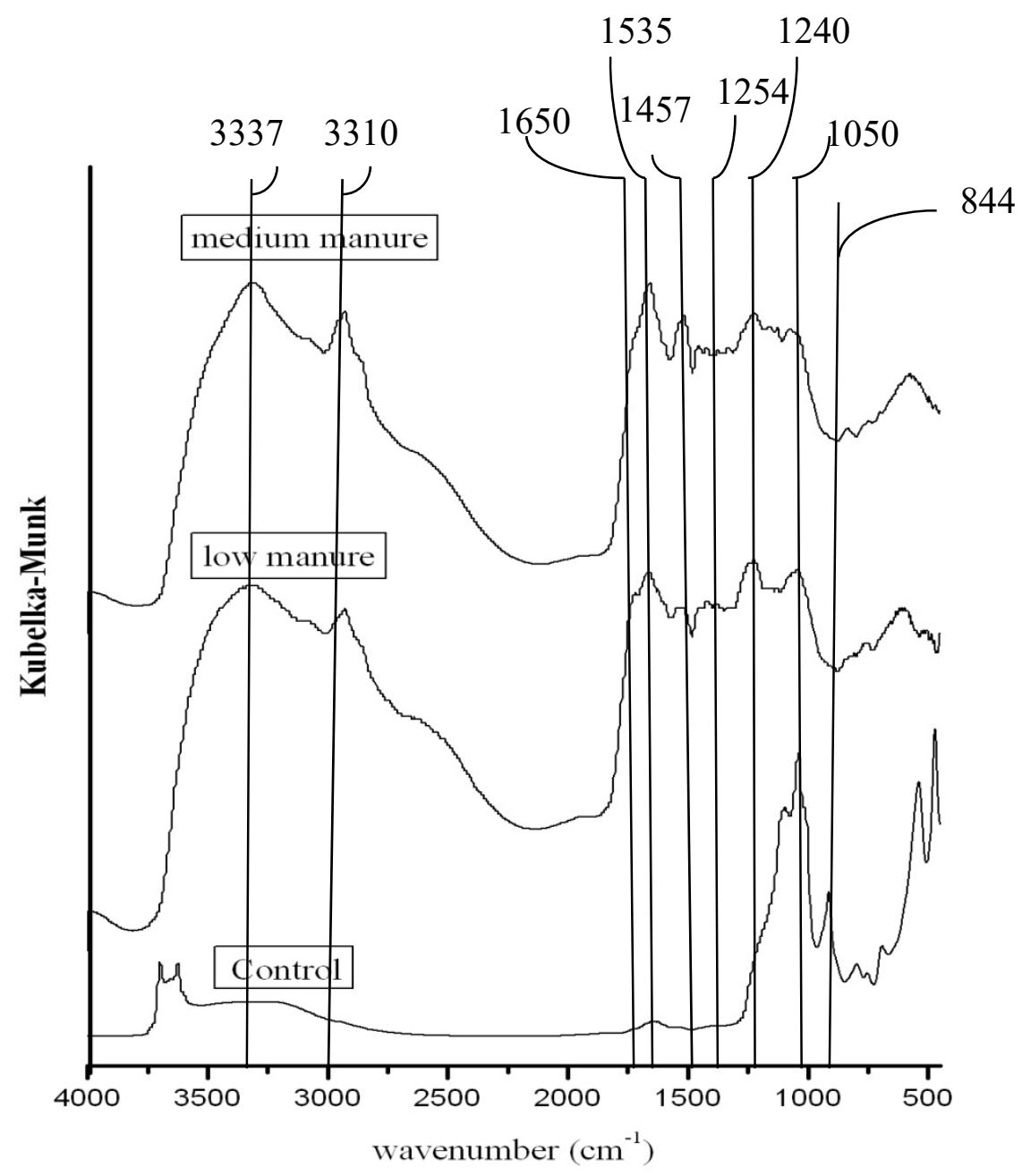

\section{Non-agroforestry}

Figure 4.8. Diffuse Reflectance Fourier Transform Infrared spectra of humic acids in non- agroforestry area receiving different amounts of manure in Location \#3 (Indonesia). 


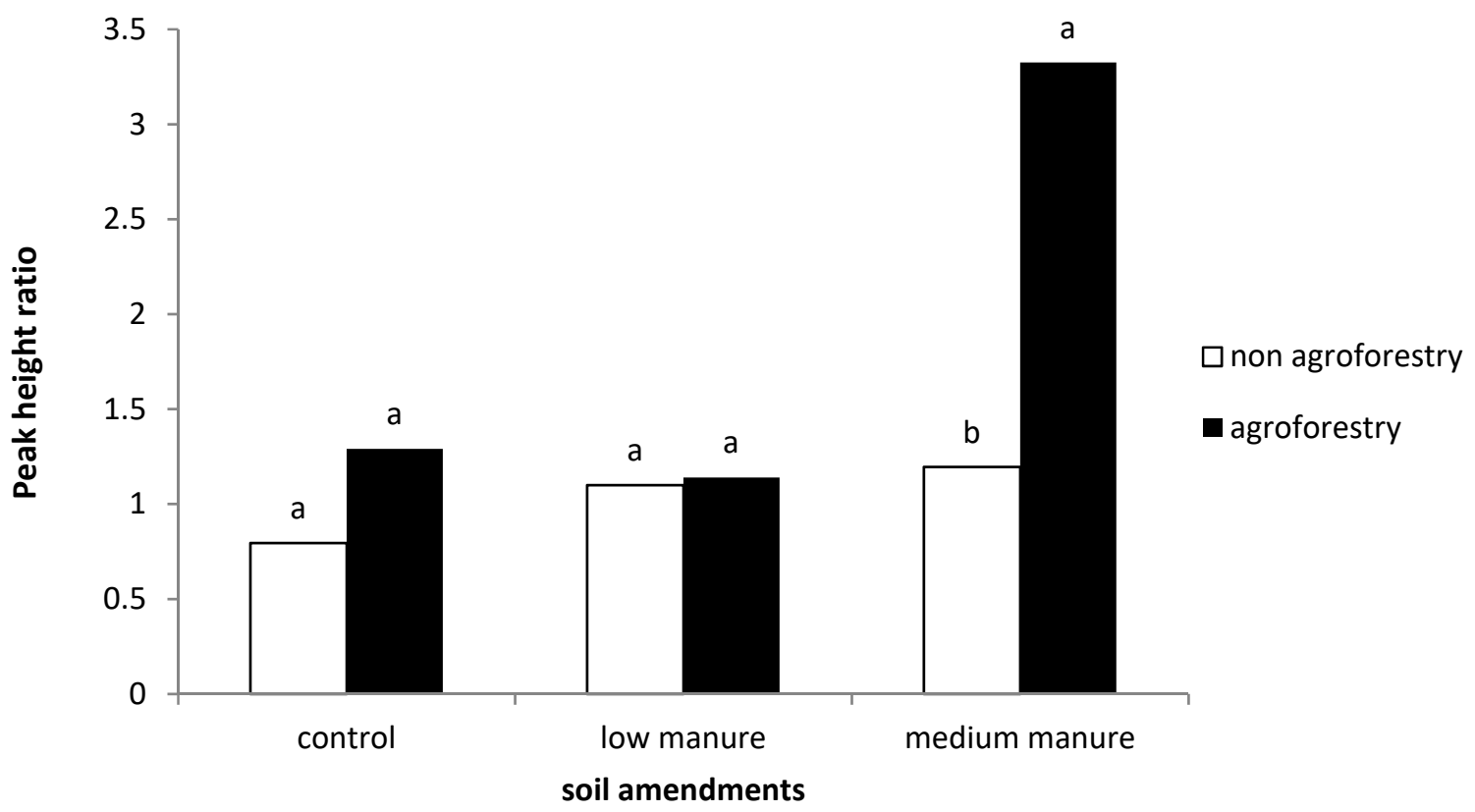

Figure 4.9. Comparing ratio of peak heights intensity $(\mathrm{O} / \mathrm{R})$ of HA under agroforestry, and non-agroforestry systems and different manure amendments in Location \#3 (Indonesia). Comparing within a soil amendment treatment, bars with the same letter are not significantly different based on the $\mathrm{LSD}_{0.05}$ value. 


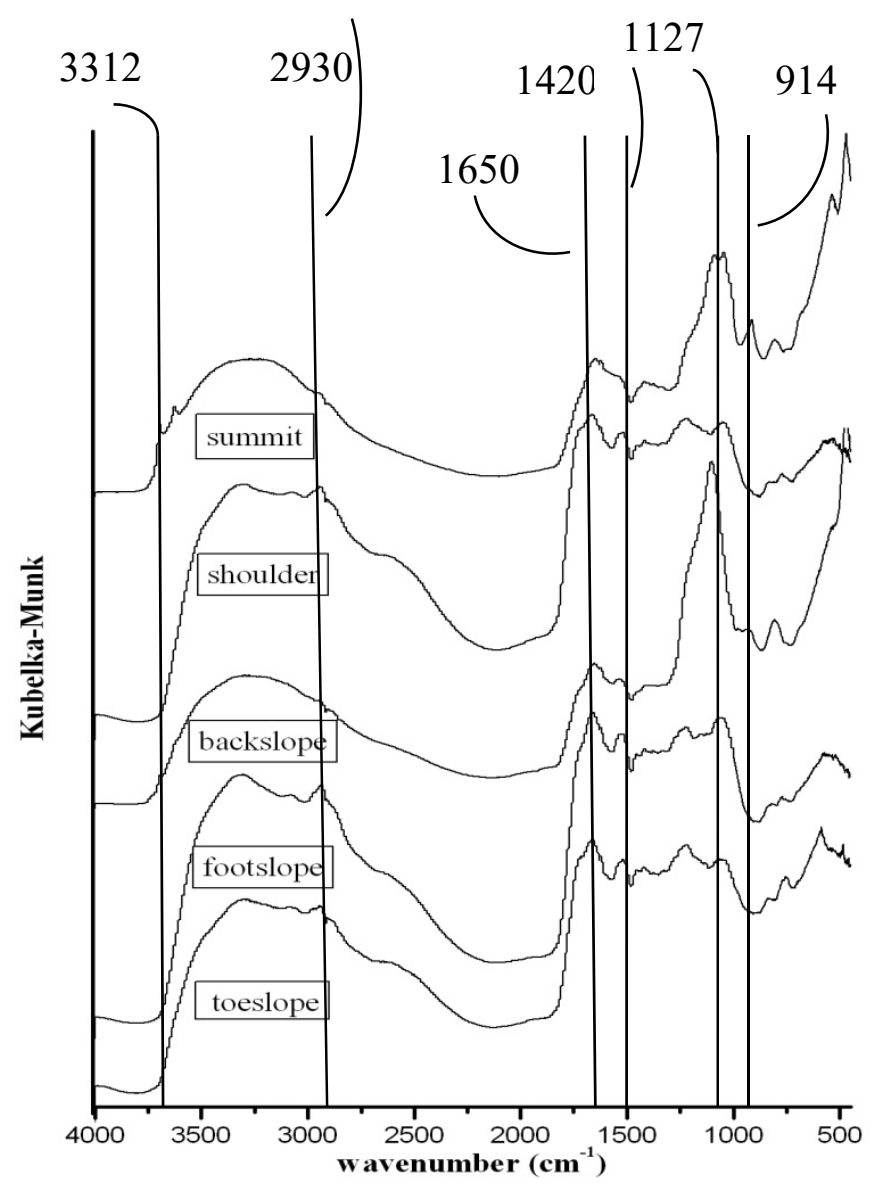

Cultivated area

Figure 4.10. Diffuse Reflectance Fourier Transform Infrared spectra of humic acids in cultivated area at different landscape positions in Location \#4 (Philippines). 


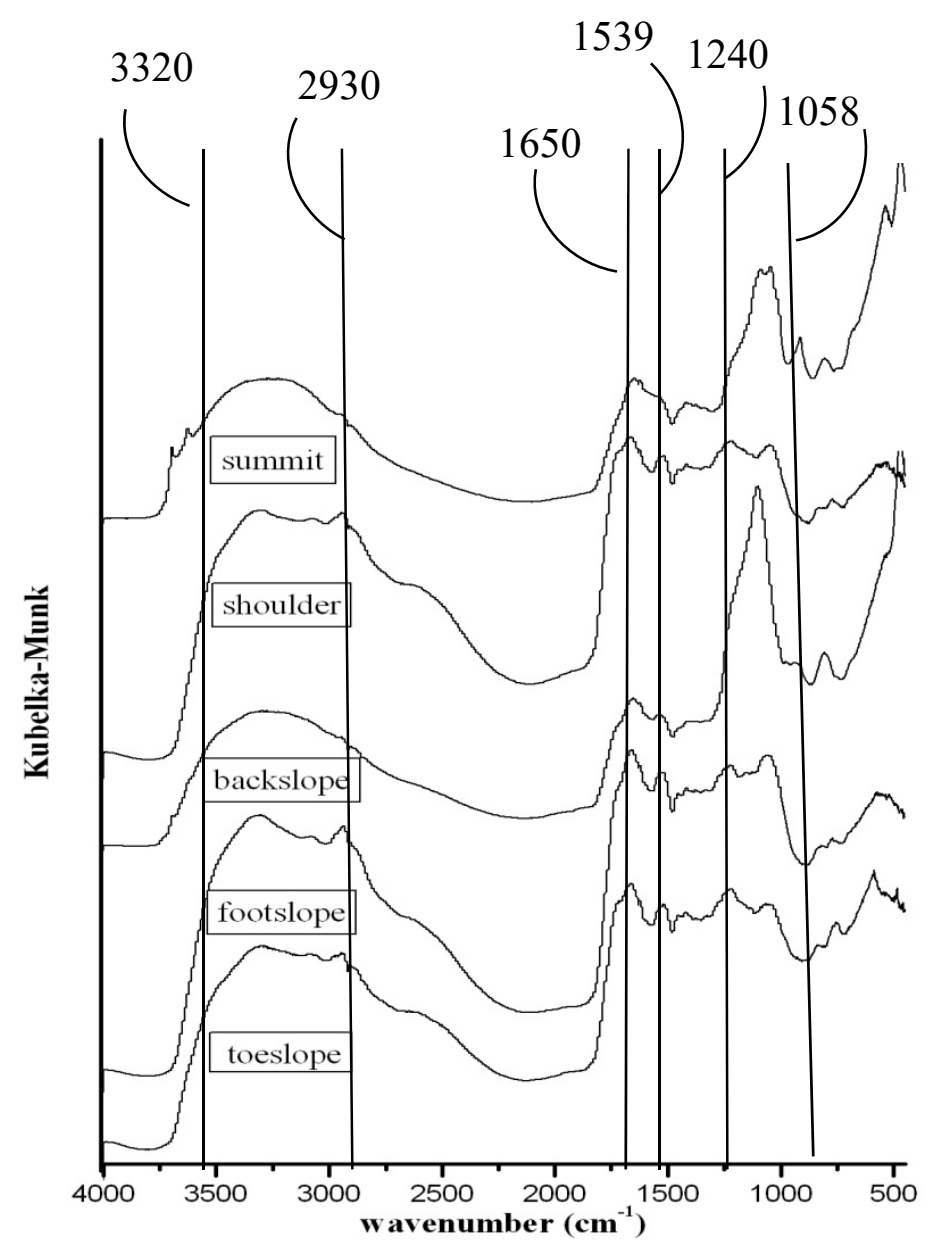

\section{Non-cultivated area}

Figure 4.11. Diffuse Reflectance Fourier Transform Infrared spectra of humic acids in non-cultivated area at different landscape positions in Location \#4 (Philippines). 


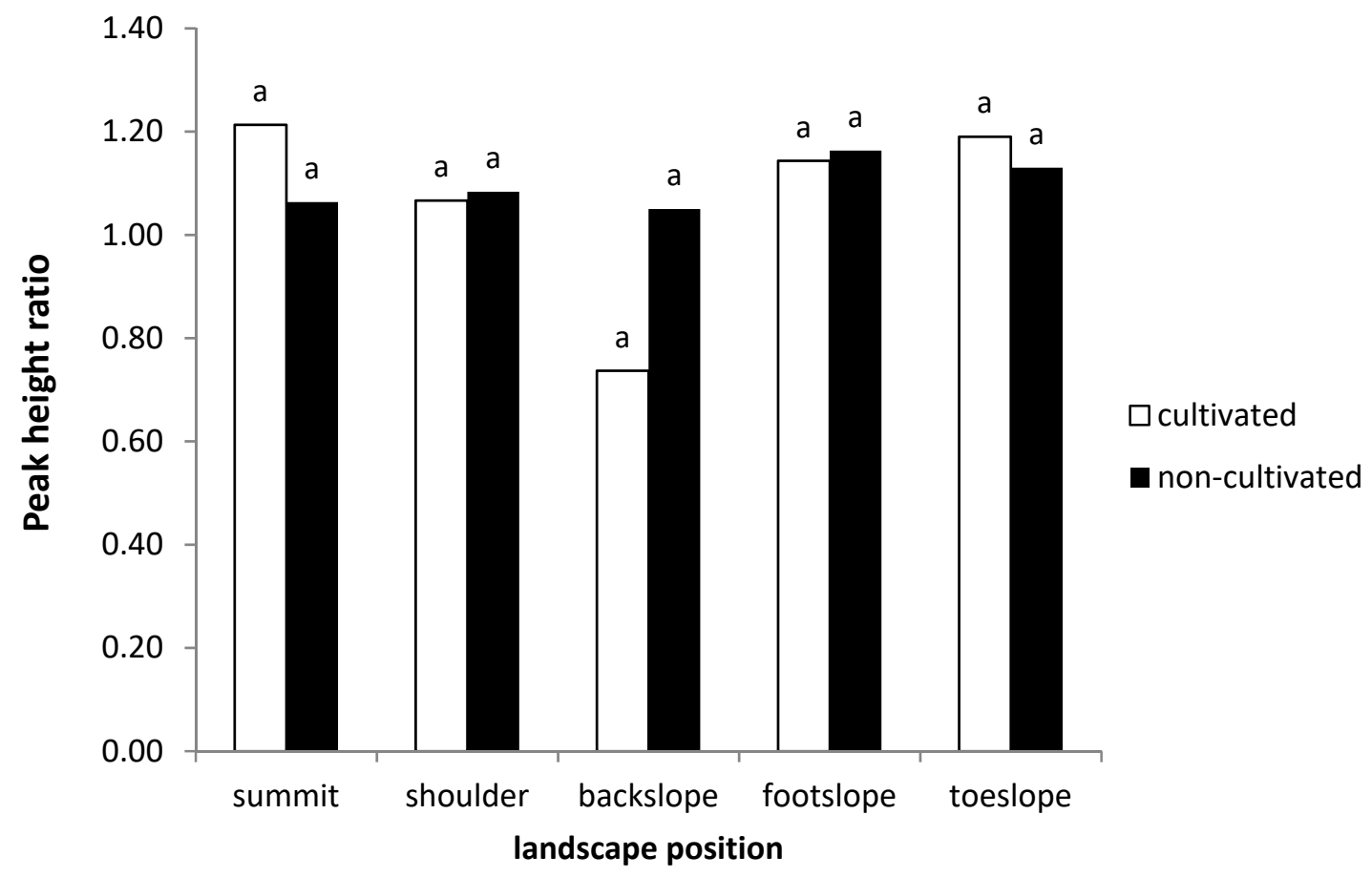

Figure 4.12. Comparing ratio of peak heights intensity $(\mathrm{O} / \mathrm{R})$ of humic acid with different landscape positions in cultivated, and non-cultivated areas in Location \#4 (Philippines). Comparing within a landscape position, bars with the same letter are not significantly different based on the $\mathrm{LSD}_{0.05}$ value. 


\section{CHAPTER 5 \\ GENERAL CONCLUSIONS}

The results of this research suggest that the soil $\mathrm{MnOxC}$ test can determine changes in soil $\mathrm{C}$ among a wide range of environmental conditions, cropping systems and soil management practices among tropical hillslope agroecosystems. It also showed that the $\mathrm{MnOxC}$ test is a sensitive indicator to assess changes in active $\mathrm{C}$ due to the effects of crop and soil management. Based on observation and survey results not discussed in this dissertation, this method has several advantages for adoption in the tropical hillslope regions, such as its ease of use, the availability of a modified $\mathrm{MnOxC}$ test adapted for field use, the relative low cost and availability of the reagents, especially if a color chart is substituted for the spectrophotometer. However, there were some disadvantages for this method including the necessity to store chemical reagents in rural areas, the effect of strong solar radiation on degradation of the color reagent, and the inconvenience of using chemical reagents in a field setting.

This research also provided an opportunity to evaluate the potential use of VNIR spectroscopy as a method for evaluating SOC and selected organic $\mathrm{C}$ fractions across a range of soil environments and management conditions in these tropical hillslope agroecosytems. Several potential advantages of use of VNIR compared to conventional soil testing methods in developing countries are that it may allow for simultaneous evaluation of several soil properties and it can be done rapidly and possibly in the field. However, the need for extensive calibration often with difficult statistical techniques and the relative high cost of current NIR instruments has prevented the widespread use of this method. 
Diffuse Reflectance Fourier Transform Infrared Spectroscopy (DRIFT) is considered to be one of the most sensitive infrared techniques for analyzing the structural composition of soil organic matter. The benefit of the DRIFT technique is the ability to characterize the functional group composition of heterogeneous materials with minimal sample preparation. Results showed that the different agricultural practices and cropping systems affected the HA peak height ratio or $\mathrm{O} / \mathrm{R}$ ratio. Therefore, using the DRIFT technique and the $\mathrm{O} / \mathrm{R}$ ratio related to changes in soil quality among these diverse soils and farming practices. The mid-infrared (MIR) region may provide a more accurate method to assess soil quality since it directly measures changes in functional groups of soil organic matter. However, some possible restrictions for increased use of this technique including the high cost for purchasing and maintaining the MIR instrument, the need for extensive training, lengthy sample preparation time, and possible interferences caused by minerals and water contained in the soil.

Visible, near-infrared, and mid-infrared spectroscopy methods are cost and time effective and environmentally friendly techniques that could be alternatives to conventional soil analysis methods. Results of this study indicate that spectroscopic methods can help in developing better land management in different land use and landscape position. In order to assess the potential of spectroscopic methods for use in organic systems, more research is needed with comparisons of these methods with traditional soil measures across a range of organic management practices. 


\section{APPENDICES - COMMUNITY SURVEY RESULTS}

\section{Cochabamba, Bolivia}

Appendix Table 1. Information on age, livelihood, and schooling level.

\begin{tabular}{|l|c|c|c|c|c|c|c|c|c|c|c|c|c|}
\hline & \multicolumn{3}{|c|}{ Age } & \multicolumn{9}{c|}{ Schooling level } & Total \\
\hline Gender & Min & Max & Average & $\begin{array}{c}\text { Do not } \\
\text { study }\end{array}$ & 1 & 2 & 3 & 4 & 5 & 6 & 7 & 8 & Survey \\
\hline Men & 20 & 70 & 43.3 & & & 2 & 2 & 7 & 10 & 3 & 3 & 2 & 29 \\
\hline Women & 18 & 64 & 36.2 & 2 & 1 & 2 & & 3 & 2 & 1 & & & 11 \\
\hline
\end{tabular}

Appendix Table 2. Number of head of livestock.

\begin{tabular}{lccc}
\hline & Bovine & Sheep & Pig \\
\hline Total & 127 & 376 & 38 \\
Average & 4.2 & 12.7 & 2.4 \\
Maximum & 11 & 40 & 22 \\
Minimum & 1 & 2 & 1 \\
\hline
\end{tabular}

Appendix Table 3. Parameters of soil quality by farmers.

\begin{tabular}{|c|c|c|c|c|c|}
\hline Parameters & Toralapa Baja & Sancayani Alto & Waylla Pujru & $\begin{array}{c}\text { Nearby } \\
\text { communities }\end{array}$ & Average $\%$ \\
\hline Black color & 27.8 & 15 & 17.9 & 15.8 & 19.1 \\
\hline Organic matter & 27.8 & 25 & 14.3 & 10.5 & 19.4 \\
\hline Depth & 22.2 & 10 & 14.3 & 5.3 & 12.9 \\
\hline Yield & 16.7 & 30 & 10.7 & 15.8 & 18.3 \\
\hline Texture & 5.6 & 10 & 14.3 & 5.3 & 8.8 \\
\hline Humidity & - & 10 & 14.3 & - & 6.1 \\
\hline Fertility & - & - & 14.3 & 42.1 & 14.1 \\
\hline Its use & - & - & - & 5.3 & 1.3 \\
\hline Percentage & 100 & 100 & 100 & 100 & 100 \\
\hline
\end{tabular}

Appendix Table 4. Characteristics of "good soil" in the different localities.

\begin{tabular}{lccccc}
\hline Parameter & $\begin{array}{c}\text { Toralapa } \\
\text { Baja }\end{array}$ & $\begin{array}{c}\text { Sancayani } \\
\text { Alto }\end{array}$ & $\begin{array}{c}\text { Waylla } \\
\text { Pujru }\end{array}$ & $\begin{array}{c}\text { Nearby } \\
\text { Communities }\end{array}$ & Average $(\%)$ \\
\hline Black color & 25.8 & 18 & 12.2 & 13.6 & 17.4 \\
Organic matter & 19.4 & 14 & 12.2 & 9.1 & 13.7 \\
Depth & 19.4 & 14 & 12.2 & 18.2 & 15.9 \\
Texture & 29.0 & 14 & 21.9 & 18.2 & 20.8 \\
Good yield & 6.5 & 12 & 4.9 & - & 5.8 \\
Puruma /virgin soil/fertility & - & 8 & 14.6 & 20.5 & 10.8 \\
Humidity & - & 16 & 17.1 & 9.1 & 10.5 \\
No pests & - & 4 & - & 2.3 & 1.6 \\
Good drain/infiltration & - & - & 4.9 & 6.8 & 2.3 \\
No frost & - & - & 100 & 100 & 0.6 \\
\hline Percentage & 100 & 100 & & 100 \\
\hline
\end{tabular}


Appendix Table 5. Characteristics of "bad soil" in the different communities.

\begin{tabular}{lcccc}
\hline \multicolumn{1}{c}{ Parameters } & Toralapa Baja & Sancayani Alto & Waylla Pujru & $\begin{array}{c}\text { Nearby } \\
\text { communities }\end{array}$ \\
\hline Yellow/white color & 12.9 & 16.3 & 9.1 & 17.9 \\
Low fertility/Without M.O. & 9.7 & 13.9 & 15.9 & 15.4 \\
Shallow soil & 9.7 & 11.4 & 9.1 & 15.4 \\
Tired/Low yields & 12.9 & 9.3 & 4.5 & 2.6 \\
Hard & 16.1 & 6.9 & 9.1 & \\
Rocky & 16.1 & 11.6 & 15.9 & 17.9 \\
White clay/Silt & 16.1 & 9.3 & 9.1 & 5.1 \\
Clods & 3.2 & - & - & - \\
Low humidity & - & 6.9 & 4.5 & 2.6 \\
No water infiltration/ Bad drain & - & 9.3 & 15.9 & 12.8 \\
With pests/diseases & - & 4.6 & - & 2.6 \\
Steep slope & - & - & 2.3 & - \\
Erosion & - & - & - & 2.6 \\
Frost & - & - & - & 2.6 \\
Weeds & 3.2 & - & 4.5 & 2.6 \\
\hline Total & 100 & 100 & 100 & 100 \\
\hline
\end{tabular}

Appendix Table 6. Practices that "improve" the soil quality.

\begin{tabular}{lccccc}
\hline & $\begin{array}{c}\text { Toralapa } \\
\text { Baja }\end{array}$ & $\begin{array}{c}\text { Sancayani } \\
\text { Alto }\end{array}$ & $\begin{array}{c}\text { Waylla } \\
\text { Pujru }\end{array}$ & $\begin{array}{c}\text { Nearby } \\
\text { communities }\end{array}$ & Average (\%) \\
\hline Fertilized & 50.0 & 40.0 & 41.7 & 35.3 & 41.7 \\
Plow with animal traction & 25.0 & 10.0 & - & 11.8 & 11.7 \\
Plow with tractor & 18.8 & 10.0 & - & - & 7.2 \\
Crop rotation & 6.3 & 10.0 & 8.3 & 29.4 & 13.5 \\
Irrigation channel & - & 10.0 & 25 & 5.9 & 10.3 \\
Living barriers & - & 20.0 & 8.3 & 11.8 & 10.0 \\
Reservoirs & - & - & 8.3 & - & 2.1 \\
Good farm work & - & - & 8.3 & - & 2.1 \\
Terraces & - & - & - & 5.8 & 1.5 \\
\hline
\end{tabular}


Appendix Table 7. Practices that "reduce" the soil quality.

\begin{tabular}{|c|c|c|c|c|c|}
\hline & $\begin{array}{c}\text { Toralapa } \\
\text { Baja }\end{array}$ & $\begin{array}{l}\text { Sancayani } \\
\text { Alto }\end{array}$ & $\begin{array}{c}\text { Waylla } \\
\text { Pujru }\end{array}$ & $\begin{array}{c}\text { Nearby } \\
\text { communities }\end{array}$ & Average $(\%)$ \\
\hline Plow in the slope/hills & - & 28.6 & 37.5 & 23.2 & 22.3 \\
\hline Tractor (plow equipment) & 44.2 & 14.3 & 25 & 30.8 & 28.6 \\
\hline Tractor disc plow & - & 42.9 & - & - & 10.7 \\
\hline $\begin{array}{l}\text { Bad irrigation use/ inefficient } \\
\text { distribution of secondary channels }\end{array}$ & 22.2 & - & 12.5 & - & 8.7 \\
\hline Pesticides & 11.2 & - & - & 7.7 & 4.7 \\
\hline Monoculture & 11.2 & 14.3 & - & 7.7 & 8.3 \\
\hline Others & 11.2 & - & - & - & 2.8 \\
\hline Lack of fertilizer & - & - & 25 & - & 6.3 \\
\hline No fertilizer & - & - & - & 15.4 & 3.8 \\
\hline No rest period & - & - & - & 7.7 & 1.9 \\
\hline Planting in the slope/hills & - & - & - & 7.7 & 1.9 \\
\hline
\end{tabular}

Appendix Table 8. The soil in the area of study improved or got worse in the last 10 years.

\begin{tabular}{lccccc}
\hline Improved/got worse & $\begin{array}{c}\text { Toralapa } \\
\text { Baja }\end{array}$ & $\begin{array}{c}\text { Sancayani } \\
\text { Alto }\end{array}$ & $\begin{array}{c}\text { Waylla } \\
\text { Pujru }\end{array}$ & $\begin{array}{c}\text { Nearby } \\
\text { communities }\end{array}$ & Average (\%) \\
\hline Improved & 30 & & & & 7.5 \\
Got worse & 60 & 90 & 100 & 100 & 87.5 \\
The same & 10 & 10 & & & 5.0 \\
\hline Why it is improved? & & & & & 67.0 \\
Fertilized & 67 & & & & \\
Rotation & 33 & & & & \\
\hline Why it is got worse? & & & & 21.1 & 28.6 \\
Lack of fertilizer & 37.5 & 35.7 & 13.3 & 26.3 & 17.9 \\
No resting soil & 25 & 7.2 & 6.7 & 5.3 & 7.9 \\
Monoculture & 12.5 & 7.2 & 20 & 10.5 & 16.1 \\
Low yield & 12.5 & 21.4 & 20 & & 11.7 \\
Weather change & 12.5 & 14.3 & & 15.8 & 7.5 \\
Fertilizers & & 14.3 & & & 1.7 \\
Low fertility & & & 6.7 & & 1.7 \\
Soil management & & 6.7 & & 1.7 \\
Excessive plow & & & & 5.7 & 2.6 \\
Farm tractor & & & 5.3 & 1.3 \\
Bad farm practices & & & & & 1.3 \\
Use of manure & & & & & \\
\hline
\end{tabular}

Appendix Table 9. The reasons why using a portable equipment to measure soil quality.

\begin{tabular}{lccccc}
\hline Why would you use it? & $\begin{array}{c}\text { Toralapa } \\
\text { Baja }\end{array}$ & $\begin{array}{c}\text { Sancayani } \\
\text { Alto }\end{array}$ & $\begin{array}{c}\text { Waylla } \\
\text { Pujru }\end{array}$ & $\begin{array}{c}\text { Nearby } \\
\text { communities }\end{array}$ & Average (\%) \\
\hline To know how is my soil & 80 & 70 & & & \\
To know if it is fertilized & 20 & 30 & 20 & 60 & 67.5 \\
\hline
\end{tabular}


Appendix Table 10. Characteristics of soil testing instruments desired by farmers.

\begin{tabular}{|c|c|c|c|c|c|}
\hline Characteristics of the instruments & \multicolumn{2}{|c|}{ frequency } & \multicolumn{3}{|c|}{ frequency $\%$} \\
\hline a)You can use it in your plots & 28 & 70 & $\begin{array}{l}\text { Only agronomists or professionals } \\
\text { working in the communities can } \\
\text { use it }\end{array}$ & 12 & 30 \\
\hline $\begin{array}{l}\text { b) Portable technique or equipment and easy-to- } \\
\text { use (light and small) }\end{array}$ & 32 & 80 & $\begin{array}{l}\text { Neither size or weight matter, if } \\
\text { works }\end{array}$ & 8 & 20 \\
\hline c) Not expensive & 32 & 80 & Price does not matter, if works & 8 & 20 \\
\hline d) You can understand and interpret the results & 37 & $\begin{array}{l}92 . \\
5\end{array}$ & $\begin{array}{l}\text { Results needs to be interpreted by } \\
\text { a professional }\end{array}$ & 7 & 17.5 \\
\hline e) Quick results & 29 & $\begin{array}{l}72 . \\
5\end{array}$ & $\begin{array}{l}\text { It is not important if results take } \\
\text { longer time }\end{array}$ & 11 & 27.5 \\
\hline f) Beside results, also provide recommendations & 39 & $\begin{array}{l}97 . \\
5\end{array}$ & $\begin{array}{l}\text { Results only indicate if soil is } \\
\text { degraded or not }\end{array}$ & 1 & 2.5 \\
\hline g) Provide training on how to use the method & 39 & $\begin{array}{l}97 . \\
5\end{array}$ & $\begin{array}{l}\text { No training needed, only } \\
\text { explanation }\end{array}$ & 1 & 2.5 \\
\hline h) Method explanation in native language & 31 & $\begin{array}{l}77 . \\
5\end{array}$ & Language does not matter & 9 & 22.5 \\
\hline
\end{tabular}

Appendix Table 11. Summary of the main problems related to agricultural soils identified by agricultural professionals.

\begin{tabular}{lcc}
\hline \multicolumn{1}{c}{ Main problems } & $\begin{array}{c}\text { Relative } \\
\text { frequency }\end{array}$ & Percentage (\%) \\
\hline Degradation/ Soil erosion & 16 & 28 \\
Low fertility & 12 & 21 \\
Contamination & 5 & 9 \\
Bad practices on soil management & 4 & 7 \\
Monoculture & 4 & 7 \\
Pests & 4 & 7 \\
Land plotting & 3 & 5 \\
Weather change & 2 & 3 \\
Compression & 2 & 3 \\
Salinization & 1 & 2 \\
Lack of conservation practices & 1 & 2 \\
Clay soils & 1 & 2 \\
Overgrazing & 1 & 2 \\
Deforestation & 1 & 2 \\
Land habilitation & 1 & 2 \\
\hline Total & 58 & 100 \\
\hline
\end{tabular}

Appendix Table 12. Parameters to define soil quality as identified by agricultural professionals.

\begin{tabular}{lcc}
\hline Criteria of soil quality & Relative frequency & Percentage (\%) \\
\hline Good yield & 11 & 38 \\
Good texture & 6 & 21 \\
Color and organic matter & 5 & 17 \\
Physical, chemical and biological structure & 4 & 14 \\
Good structure & 2 & 7 \\
Microorganisms & 1 & 3 \\
\hline Total & 29 & 100 \\
\hline
\end{tabular}


Appendix Table 13. Criteria or parameters to determine good or bad soils as identified by agricultural professionals.

\begin{tabular}{|c|c|c|c|c|c|}
\hline Good soil & Frequency & $\%$ & Bad soil & Frequency & $\%$ \\
\hline Black color & 20 & 28 & Low fertility & 16 & 23.5 \\
\hline Good texture & 15 & 21 & Clay soils & 10 & 10 \\
\hline Good fertility and yield & 13 & 18 & Low organic matter & 8 & 8 \\
\hline Flat and deep & 12 & 17 & Shallow soils & 8 & 11.8 \\
\hline Good drain & 4 & 6 & Rocky soils & 4 & 5.9 \\
\hline Health/Microorganisms & 3 & 4 & Compressed & 3 & 4.4 \\
\hline Good structure & 2 & 3 & Bad drain & 3 & 4.4 \\
\hline Agricultural practices & 1 & 1 & Saline & 3 & 4.4 \\
\hline \multirow[t]{8}{*}{ Coverage } & 1 & 1 & Steep slope & 3 & 4.4 \\
\hline & & & Low yield & 3 & 4.4 \\
\hline & & & Eroded soils & 2 & 2.9 \\
\hline & & & Without coverage & 1 & 1.5 \\
\hline & & & Bad management & 1 & 1.5 \\
\hline & & & Monoculture & 1 & 1.5 \\
\hline & & & Acid soils & 1 & 1.5 \\
\hline & & & Absence of Microorganisms & 1 & 1.5 \\
\hline Total & 71 & 100 & & 68 & 100 \\
\hline
\end{tabular}

Appendix Table 14. Parameters of soil quality as identified by agricultural professionals.

\begin{tabular}{|c|c|c|}
\hline Parameters & Frequency & Percentage \\
\hline Good yield & 11 & 58 \\
\hline Soil with organic matter & 2 & 10.5 \\
\hline Black soil & 2 & 10.5 \\
\hline Loose (texture)/easy for cultivation & 2 & 10.5 \\
\hline Rotation (it is not tired) & 2 & 10.5 \\
\hline Total & 19 & 100 \\
\hline
\end{tabular}

Appendix Table 15. Agriculture management practices that "improve" soil quality as identified by agricultural professionals.

\begin{tabular}{lcc}
\hline \multicolumn{1}{c}{ Practices } & Frequency & Percentage \\
\hline Chemical fertilizers and "natural” fertilizers & 15 & 36 \\
Soil and crop rotation & 10 & 24 \\
Soil conservation practices & 9 & 21 \\
Irrigation & 2 & 5 \\
Water reservoirs & 1 & 2 \\
Pest control & 1 & 2 \\
Drainage & 1 & 2 \\
Bio-consumables & 1 & 2 \\
Nutrient recycling & 1 & 2 \\
Fertility amendment practices & 1 & 2 \\
\hline Total & 42 & 100 \\
\hline
\end{tabular}


Appendix Table 16. Agricultural management practices that "reduce" soil quality as identified by agricultural professionals.

\begin{tabular}{|c|c|c|}
\hline Practices & Frequency & Percentage \\
\hline Plowing along the slope & 8 & 29 \\
\hline Monoculture & 7 & 25 \\
\hline Erosion & 6 & 21 \\
\hline No conservation practices & 3 & 11 \\
\hline Compression & 2 & 7 \\
\hline Use of agrochemical fertilizers & 2 & 7 \\
\hline
\end{tabular}

Appendix Table 17. Characteristic of the soil test and its evaluation based on its importance as identified by agricultural professionals.

\begin{tabular}{|l|c|c|c|c|c|}
\multicolumn{2}{l}{ * Rankect or characteristic of the test } & 1 & 2 & 3 & 4 \\
\hline & & & & & \\
1. Test is not expensive & 0 & 0 & 6 & 3 & 7 \\
\hline 2. Test is portable and can be used in the field & 0 & 0 & 1 & 4 & 11 \\
\hline 3. Test reagents are easy available & 0 & 1 & 2 & 6 & 7 \\
\hline 4. Test produce quick results & 0 & 0 & 1 & 4 & 11 \\
\hline 5. Results are easy to interpret & 0 & 0 & 0 & 5 & 11 \\
\hline 6. Results provide recommendations & 0 & 0 & 1 & 6 & 8 \\
\hline 7. Receive training on use and maintenance of the test & 0 & 0 & 1 & 6 & 9 \\
\hline 8. Instructions and training in native language & 0 & 3 & 4 & 4 & 5 \\
\hline
\end{tabular}

Note * 1 least important, 5 most important

\section{INDONESIA}

Appendix Table 18. Number of farmers surveyed in each town.

\begin{tabular}{|l|c|c|}
\hline \multicolumn{1}{|c|}{ Location } & Number (n) & Percentage (\%) \\
\hline Bantarkaret & 1 & 2.2 \\
Curugbitung & 5 & 11.1 \\
Hambaro & 5 & 11.1 \\
Kalong L & 1 & 2.2 \\
Malasari & 15 & 33.3 \\
Nanggung & 7 & 15.6 \\
Pangkaljaya & 2 & 4.4 \\
Parakan Muncang & 3 & 6.7 \\
Sukaluyu & 6 & 13.3 \\
\hline
\end{tabular}


Appendix Table 19. General information on age, livelihood and schooling level of surveyed farmers.

\begin{tabular}{|c|c|c|c|c|c|c|c|}
\hline & \multicolumn{3}{|c|}{ Age } & \multicolumn{4}{c|}{ Schooling level } \\
\hline Gender & Min & Max & Average & $\begin{array}{c}\text { Basic } \\
\text { school }\end{array}$ & $\begin{array}{c}\text { Middle } \\
\text { school }\end{array}$ & $\begin{array}{c}\text { High } \\
\text { school }\end{array}$ & Bachelor \\
\hline Men & 32 & 66 & 50.2 & 27 & 5 & 2 & 1 \\
\hline Women & 37 & 56 & 47.4 & 10 & - & - & - \\
\hline & & & & $\begin{array}{c}37 \\
(82.2 \%)\end{array}$ & $\begin{array}{c}5 \\
(11.1 \%)\end{array}$ & $\begin{array}{c}2 \\
(4.4 \%)\end{array}$ & $\begin{array}{c}1 \\
(2.2 \%)\end{array}$ \\
\hline
\end{tabular}

Appendix Table 20. Average area of land owned and land farmed of surveyed farmers.

\begin{tabular}{|c|c|}
\hline Type & Mean \\
\hline Area of Land Owned $\left(\mathrm{m}^{2}\right)$ & 3,580 \\
\hline Area of Land Farmed $\left(\mathrm{m}^{2}\right)$ & 2,580 \\
\hline
\end{tabular}

Appendix Table 21. Percentage of land rainfed and land irrigated of surveyed farmers.

\begin{tabular}{|c|c|c|}
\hline Type & Number (n) & Percentage \\
\hline \% of Land Rainfed & 1 & $2.2 \%$ \\
$0 \%$ & 7 & $15.6 \%$ \\
$10 \%$ & 37 & $82.2 \%$ \\
$100 \%$ & 37 & \\
\hline$\%$ of Land Irrigated & 7 & $82.2 \%$ \\
$90 \%$ & 1 & $15.6 \%$ \\
$100 \%$ & $2.2 \%$ \\
\hline
\end{tabular}

Appendix Table 22. Frequency and proportion of surveyed farmers with types of livestock and crops.

\begin{tabular}{lccccc|ccc}
\hline & \multicolumn{5}{c|}{ Livestock } & \multicolumn{3}{c}{ Crops } \\
\hline & Chicken & Goat & Rabbit & None & Total & Rice & Vegetable & Total \\
Number (n) & 1 & 10 & 3 & 31 & 45 & 3 & 42 & 45 \\
Percentage & 2.2 & 22.2 & 6.7 & 68.9 & 100 & 6.7 & 93.3 & 100 \\
\hline
\end{tabular}


Appendix Table 23. Parameters of soil quality identified by surveyed farmers.

\begin{tabular}{|c|c|c|c|c|c|c|c|c|c|c|}
\hline & $\begin{array}{l}\text { Bantar } \\
\text { karet }\end{array}$ & $\begin{array}{l}\text { Curug } \\
\text { bitung }\end{array}$ & Hambaro & Kalong & $\begin{array}{l}\text { Mala } \\
\text { sari }\end{array}$ & $\begin{array}{l}\text { Nang } \\
\text { gung }\end{array}$ & $\begin{array}{l}\text { Pangka } \\
\text { ljaya }\end{array}$ & $\begin{array}{l}\text { Parakan } \\
\text { Muncang }\end{array}$ & $\begin{array}{l}\text { Suka } \\
\text { luyu }\end{array}$ & total \\
\hline $\begin{array}{l}\text { Soil } \\
\text { color }\end{array}$ & $\begin{array}{c}1 \\
(100 \%)\end{array}$ & $\begin{array}{c}5 \\
(100 \%)\end{array}$ & $\begin{array}{c}5 \\
(100 \%)\end{array}$ & $\begin{array}{c}1 \\
(100 \%)\end{array}$ & $\begin{array}{c}15 \\
(100 \%)\end{array}$ & $\begin{array}{c}7 \\
(100 \%)\end{array}$ & $\begin{array}{c}2 \\
(100 \%)\end{array}$ & $\begin{array}{c}3 \\
(100 \%)\end{array}$ & $\begin{array}{c}6 \\
(100 \%)\end{array}$ & $\begin{array}{c}45 \\
(100 \%)\end{array}$ \\
\hline $\begin{array}{l}\text { Crop } \\
\text { yield }\end{array}$ & $\begin{array}{c}1 \\
(100 \%)\end{array}$ & $\begin{array}{c}1 \\
(20 \%)\end{array}$ & $\begin{array}{c}0 \\
(0 \%)\end{array}$ & $\begin{array}{c}0 \\
(0 \%)\end{array}$ & $\begin{array}{c}0 \\
(0 \%)\end{array}$ & $\begin{array}{c}0 \\
(0 \%)\end{array}$ & $\begin{array}{c}0 \\
(0 \%)\end{array}$ & $\begin{array}{c}0 \\
(0 \%)\end{array}$ & $\begin{array}{c}6 \\
(100 \%)\end{array}$ & $\begin{array}{c}8 \\
(17.8 \%)\end{array}$ \\
\hline Erosion & $\begin{array}{c}0 \\
(0 \%)\end{array}$ & $\begin{array}{c}1 \\
(20 \%)\end{array}$ & $\begin{array}{c}0 \\
(0 \%)\end{array}$ & $\begin{array}{c}0 \\
(0 \%)\end{array}$ & $\begin{array}{c}0 \\
(0 \%)\end{array}$ & $\begin{array}{c}0 \\
(0 \%)\end{array}$ & $\begin{array}{c}0 \\
(0 \%)\end{array}$ & $\begin{array}{c}0 \\
(0 \%)\end{array}$ & $\begin{array}{c}0 \\
(0 \%)\end{array}$ & $\begin{array}{c}1 \\
(2.22 \%)\end{array}$ \\
\hline $\begin{array}{l}\text { Preserva } \\
\text { tion }\end{array}$ & $\begin{array}{c}0 \\
(0 \%)\end{array}$ & $\begin{array}{c}1 \\
(20 \%)\end{array}$ & $\begin{array}{c}0 \\
(0 \%)\end{array}$ & $\begin{array}{c}0 \\
(0 \%)\end{array}$ & $\begin{array}{c}0 \\
(0 \%)\end{array}$ & $\begin{array}{c}0 \\
(0 \%)\end{array}$ & $\begin{array}{c}0 \\
(0 \%)\end{array}$ & $\begin{array}{c}0 \\
(0 \%)\end{array}$ & $\begin{array}{c}0 \\
(0 \%)\end{array}$ & $\begin{array}{c}1 \\
(2.22 \%)\end{array}$ \\
\hline
\end{tabular}


Appendix Table 24. Characteristics of soils in each location as identified by surveyed farmers.

\begin{tabular}{|c|c|c|c|c|c|c|c|c|c|c|}
\hline 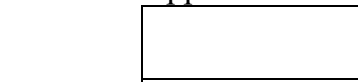 & Bantarkaret & Curugbitung & Hambaro & Kalong L & Malasari & Nanggung & Pangkaljaya & $\begin{array}{l}\text { Parakan } \\
\text { Muncang }\end{array}$ & Sukaluyu & Total \\
\hline $\begin{array}{c}\text { Color } \\
\text { Brown } \\
\text { Dark brown } \\
\text { Total }\end{array}$ & $\begin{array}{c}1(100 \%) \\
0(0 \%) \\
1(100 \%)\end{array}$ & $\begin{array}{c}4(80 \%) \\
1(20 \%) \\
5(100 \%)\end{array}$ & $\begin{array}{c}4(80 \%) \\
1(20 \%) \\
5(100 \%)\end{array}$ & $\begin{array}{c}1(100 \%) \\
0(0 \%) \\
1(100 \%)\end{array}$ & $\begin{array}{c}1(6.7 \%) \\
14(93.3 \%) \\
15(100 \%)\end{array}$ & $\begin{array}{l}5(71.4 \%) \\
2(28.6 \%) \\
7(100 \%)\end{array}$ & $\begin{array}{c}1(50 \%) \\
1(50 \%) \\
2(100 \%)\end{array}$ & $\begin{array}{l}2(66.7 \%) \\
1(33.3 \%) \\
3(100 \%)\end{array}$ & $\begin{array}{c}4(66.7 \%) \\
2(33.3 \%) \\
6(100 \%)\end{array}$ & $\begin{array}{l}23(51.1 \%) \\
22(48.9 \%) \\
45(100 \%)\end{array}$ \\
\hline $\begin{array}{c}\text { Texture } \\
\text { Loam } \\
\text { Sandy Loam } \\
\text { total } \\
\end{array}$ & $\begin{array}{c}1(100 \%) \\
0(0 \%) \\
1(100 \%)\end{array}$ & $\begin{array}{c}0(0 \%) \\
5(100 \%) \\
5(100 \%) \\
\end{array}$ & $\begin{array}{c}5(100 \%) \\
0(0 \%) \\
5(100 \%) \\
\end{array}$ & $\begin{array}{c}1(100 \%) \\
0(0 \%) \\
1(100 \%)\end{array}$ & $\begin{array}{c}1(6.7 \%) \\
14(93.3 \%) \\
15(100 \%) \\
\end{array}$ & $\begin{array}{c}7(100 \%) \\
0(0 \%) \\
7(100 \%) \\
\end{array}$ & $\begin{array}{c}2(100 \%) \\
0(0 \% \\
2(100 \%) \\
\end{array}$ & $\begin{array}{c}3(100 \%) \\
0(0 \%) \\
3(100 \%)\end{array}$ & $\begin{array}{c}6(100 \%) \\
0(0 \%) \\
6(100 \%) \\
\end{array}$ & $\begin{array}{l}26(57.8 \%) \\
19(42.2 \%) \\
45(100 \%) \\
\end{array}$ \\
\hline $\begin{array}{c}\text { Drainage } \\
\text { Good } \\
\text { total } \\
\end{array}$ & $\begin{array}{l}1(100 \%) \\
1(100 \%) \\
\end{array}$ & $\begin{array}{l}5(100 \%) \\
5(100 \%) \\
\end{array}$ & $\begin{array}{l}5(100 \%) \\
5(100 \%) \\
\end{array}$ & $\begin{array}{l}1(100 \%) \\
1(100 \%) \\
\end{array}$ & $\begin{array}{l}15(100 \%) \\
15(100 \%) \\
\end{array}$ & $\begin{array}{l}7(100 \%) \\
7(100 \%) \\
\end{array}$ & $\begin{array}{l}2(100 \%) \\
2(100 \%) \\
\end{array}$ & $\begin{array}{l}3(100 \%) \\
3(100 \%) \\
\end{array}$ & $\begin{array}{l}6(100 \%) \\
6(100 \%) \\
\end{array}$ & $\begin{array}{l}45(100 \%) \\
45(100 \%) \\
\end{array}$ \\
\hline $\begin{array}{l}\text { Fertility } \\
\text { Good } \\
\text { Medium } \\
\text { Poor } \\
\text { total }\end{array}$ & $\begin{array}{c}0(0 \%) \\
0(0 \%) \\
1(100 \%) \\
1(100 \%)\end{array}$ & $\begin{array}{c}0(0 \%) \\
1(20 \%) \\
4(80 \%) \\
5(100 \%)\end{array}$ & $\begin{array}{c}1(20 \%) \\
0(0 \%) \\
4(80 \%) \\
5(100 \%)\end{array}$ & $\begin{array}{c}0(0 \%) \\
0(0 \%) \\
1(100 \%) \\
1(100 \%)\end{array}$ & $\begin{array}{c}14(93.3 \%) \\
0(0 \%) \\
1(6.7 \%) \\
15(100 \%)\end{array}$ & $\begin{array}{c}0(0 \%) \\
2(28.6 \%) \\
5(71.4 \%) \\
7(100 \%)\end{array}$ & $\begin{array}{c}0(0 \%) \\
1(50 \%) \\
1(50 \%) \\
2(100 \%)\end{array}$ & $\begin{array}{c}0(0 \%) \\
1(33.3 \%) \\
2(66.7 \%) \\
3(100 \%)\end{array}$ & $\begin{array}{c}0(0 \%) \\
2(33.3 \%) \\
4(66.7 \%) \\
6(100 \%)\end{array}$ & $\begin{array}{c}15(33.3 \%) \\
7(15.5 \%) \\
23(51.1 \%) \\
45(100 \%)\end{array}$ \\
\hline $\begin{array}{c}\text { Crops suitable } \\
\text { Tree and } \\
\text { Vegetable } \\
\text { Rice } \\
\text { total }\end{array}$ & $\begin{array}{c}1(100 \%) \\
0(0 \%) \\
1(100 \%)\end{array}$ & $\begin{array}{c}5(100 \%) \\
0(0 \%) \\
5(100 \%)\end{array}$ & $\begin{array}{c}2(40 \%) \\
3(60 \%) \\
5(100 \%)\end{array}$ & $\begin{array}{c}1(100 \%) \\
0(0 \%) \\
1(100 \%)\end{array}$ & $\begin{array}{c}15(100 \%) \\
0(0 \%) \\
15(100 \%)\end{array}$ & $\begin{array}{c}7(100 \%) \\
0(0 \%) \\
7(100 \%)\end{array}$ & $\begin{array}{c}2(100 \%) \\
0(0 \%) \\
2(100 \%)\end{array}$ & $\begin{array}{c}3(100 \%) \\
0(0 \%) \\
3(100 \%)\end{array}$ & $\begin{array}{c}6(100 \%) \\
0(0 \%) \\
6(100 \%)\end{array}$ & $\begin{array}{c}42(93.3 \% \\
\\
3(6.7 \% \\
45(100 \%)\end{array}$ \\
\hline $\begin{array}{l}\text { Any changes } \\
\text { noticed over } \\
\text { last } 10 \text { yrs in } \\
\text { quality of } \\
\text { this soil } \\
\text { Yes } \\
\text { No } \\
\text { total }\end{array}$ & $\begin{array}{c}0(0 \%) \\
1(100 \%) \\
1(100 \%)\end{array}$ & $\begin{array}{c}0(0 \%) \\
5(100 \%) \\
5(100 \%)\end{array}$ & $\begin{array}{l}1(20 \%) \\
4(80 \%) \\
5(100 \%)\end{array}$ & $\begin{array}{c}0(0 \%) \\
1(100 \%) \\
1(100 \%)\end{array}$ & $\begin{array}{c}14(93.3 \%) \\
1(6.7 \%) \\
15(100 \%)\end{array}$ & $\begin{array}{c}0(0 \%) \\
7(100 \%) \\
7(100 \%)\end{array}$ & $\begin{array}{c}1(50 \%) \\
1(50 \%) \\
2(100 \%)\end{array}$ & $\begin{array}{l}1(33.3 \%) \\
2(66.7 \%) \\
3(100 \%)\end{array}$ & $\begin{array}{l}1(16.7 \%) \\
5(83.3 \%) \\
6(100 \%)\end{array}$ & $\begin{array}{c}18(40 \%) \\
27(60 \%) \\
45(100 \%)\end{array}$ \\
\hline
\end{tabular}


Appendix Table 25. Management practices that "improve" soil quality as identified by surveyed farmers.

\begin{tabular}{|c|c|c|c|c|c|c|c|c|c|c|}
\hline & $\begin{array}{l}\text { Bantar } \\
\text { karet }\end{array}$ & $\begin{array}{l}\text { Curug } \\
\text { bitung }\end{array}$ & Hambaro & Kalong & $\begin{array}{l}\text { Mala } \\
\text { sari }\end{array}$ & $\begin{array}{l}\text { Nang } \\
\text { gung }\end{array}$ & $\begin{array}{l}\text { Pangka } \\
\text { ljaya }\end{array}$ & $\begin{array}{l}\text { Parakan } \\
\text { Muncang }\end{array}$ & $\begin{array}{l}\text { Suka } \\
\text { luyu }\end{array}$ & Total \\
\hline $\begin{array}{c}\text { Adding } \\
\text { organic matter }\end{array}$ & $\begin{array}{c}1 \\
(100 \%)\end{array}$ & $\begin{array}{c}5 \\
(100 \%)\end{array}$ & $\begin{array}{c}5 \\
(100 \%)\end{array}$ & $\begin{array}{c}1 \\
(100 \%)\end{array}$ & $\begin{array}{c}15 \\
(100 \%)\end{array}$ & $\begin{array}{c}7 \\
(100 \%)\end{array}$ & $\begin{array}{c}2 \\
(100 \%)\end{array}$ & $\begin{array}{c}3 \\
(100 \%)\end{array}$ & $\begin{array}{c}6 \\
(100 \%)\end{array}$ & $\begin{array}{c}45 \\
(100 \%)\end{array}$ \\
\hline $\begin{array}{c}\text { Soil } \\
\text { conservation }\end{array}$ & $\begin{array}{c}1 \\
(100 \%)\end{array}$ & $\begin{array}{c}1 \\
(20 \%)\end{array}$ & $\begin{array}{c}0 \\
(0 \%)\end{array}$ & $\begin{array}{c}0 \\
(0 \%)\end{array}$ & $\begin{array}{c}0 \\
(0 \%)\end{array}$ & $\begin{array}{c}0 \\
(0 \%)\end{array}$ & $\begin{array}{c}0 \\
(0 \%)\end{array}$ & $\begin{array}{c}0 \\
(0 \%)\end{array}$ & $\begin{array}{c}0 \\
(0 \%)\end{array}$ & $\begin{array}{c}2 \\
(4.44 \%)\end{array}$ \\
\hline $\begin{array}{l}\text { Cover crop } \\
\text { management }\end{array}$ & $\begin{array}{c}0 \\
(0 \%)\end{array}$ & $\begin{array}{c}1 \\
(20 \%)\end{array}$ & $\begin{array}{c}0 \\
(0 \%)\end{array}$ & $\begin{array}{c}0 \\
(0 \%)\end{array}$ & $\begin{array}{c}0 \\
(0 \%)\end{array}$ & $\begin{array}{c}0 \\
(0 \%)\end{array}$ & $\begin{array}{c}0 \\
(0 \%)\end{array}$ & $\begin{array}{c}0 \\
(0 \%)\end{array}$ & $\begin{array}{c}0 \\
(0 \%)\end{array}$ & $\begin{array}{c}1 \\
(2.22 \%)\end{array}$ \\
\hline
\end{tabular}

Appendix Table 26. The soil in the area of study "improved" or "got worse" in the last 10 years as identified by surveyed farmers.

\begin{tabular}{|c|c|c|c|c|c|c|c|c|c|c|}
\hline & $\begin{array}{l}\text { Bantar } \\
\text { karet }\end{array}$ & $\begin{array}{l}\text { Curug } \\
\text { bitung }\end{array}$ & Hambaro & Kalong & $\begin{array}{l}\text { Mala } \\
\text { sari }\end{array}$ & $\begin{array}{l}\text { Nang } \\
\text { gung }\end{array}$ & $\begin{array}{l}\text { Pangkal } \\
\text { jaya }\end{array}$ & $\begin{array}{l}\text { Parakan } \\
\text { Muncang }\end{array}$ & $\begin{array}{l}\text { Suka } \\
\text { luyu }\end{array}$ & Total \\
\hline $\begin{array}{c}\text { Improved } \\
\text { Adding } \\
\text { organic } \\
\text { matter }\end{array}$ & 0 & $\begin{array}{c}1 \\
(20 \%)\end{array}$ & $\begin{array}{c}1 \\
(20 \%)\end{array}$ & 0 & $\begin{array}{c}14 \\
(93.3 \%)\end{array}$ & $\begin{array}{c}2 \\
(28.6 \%)\end{array}$ & $\begin{array}{c}1 \\
(50 \%)\end{array}$ & $\begin{array}{c}1 \\
(33.3 \%)\end{array}$ & $\begin{array}{c}2 \\
(33.3 \%)\end{array}$ & $\begin{array}{c}22 \\
(48.9 \%)\end{array}$ \\
\hline $\begin{array}{c}\text { Got worse } \\
\text { Lack or less } \\
\text { of adding } \\
\text { organic } \\
\text { matter }\end{array}$ & $\begin{array}{c}1 \\
(100 \%)\end{array}$ & $\begin{array}{c}4 \\
(80 \%)\end{array}$ & $\begin{array}{c}4 \\
(80 \%)\end{array}$ & $\begin{array}{c}1 \\
(100 \%)\end{array}$ & $\begin{array}{c}1 \\
(6.7 \%)\end{array}$ & $\begin{array}{c}5 \\
(71.4 \%)\end{array}$ & $\begin{array}{c}1 \\
(50 \%)\end{array}$ & $\begin{array}{c}2 \\
(66.7 \%)\end{array}$ & $\begin{array}{c}4 \\
(66.7 \%)\end{array}$ & $\begin{array}{c}23 \\
(51.1 \%)\end{array}$ \\
\hline
\end{tabular}


Appendix Table 27. Farmers' knowledge about the methods to measure soil quality.

\begin{tabular}{|c|c|c|c|c|c|c|c|c|c|c|}
\hline & $\begin{array}{c}\text { Bantar } \\
\text { karet }\end{array}$ & $\begin{array}{c}\text { Curug } \\
\text { bitung }\end{array}$ & Hambaro & Kalong & $\begin{array}{c}\text { Mala } \\
\text { sari }\end{array}$ & $\begin{array}{c}\text { Nang } \\
\text { gung }\end{array}$ & $\begin{array}{c}\text { Pangkal } \\
\text { jaya }\end{array}$ & $\begin{array}{c}\text { Parakan } \\
\text { Muncang }\end{array}$ & $\begin{array}{c}\text { Suka } \\
\text { luyu }\end{array}$ & $\begin{array}{c}\text { Total } \\
\text { No }\end{array}$ \\
\hline & 0 & 0 & 0 & 0 & 0 & 0 & 0 & 0 & 0 \\
& $(100 \%)$ & $(100 \%)$ & $(100 \%)$ & $(100 \%)$ & $(100 \%)$ & $(100 \%)$ & $(100 \%)$ & $(100 \%)$ & $(100 \%)$ & $(100 \%)$ \\
\end{tabular}

Appendix Table 28. Desired technical characteristics of soil test methods.

\begin{tabular}{|c|c|c|c|c|c|}
\hline Characteristics of the soil test methods & frequency & $\%$ & or & frequency & $\%$ \\
\hline a) You can use it in your plots & 45 & 100 & $\begin{array}{l}\text { Only agronomists or professionals } \\
\text { working in the communities can use it }\end{array}$ & 0 & 0 \\
\hline $\begin{array}{l}\text { b) Portable technique or equipment and } \\
\text { easy-to-use (light and small) }\end{array}$ & 45 & 100 & Neither size or weight matter, if works & 0 & 0 \\
\hline c) Not expensive & 45 & 100 & Prize does not matter, if works & 0 & 0 \\
\hline $\begin{array}{l}\text { d) You can understand and interpret the } \\
\text { results }\end{array}$ & 45 & 100 & $\begin{array}{l}\text { Results needs to be interpreted by a } \\
\text { professional }\end{array}$ & 0 & 0 \\
\hline e) Quick results & 45 & 100 & $\begin{array}{l}\text { It is not important if results take longer } \\
\text { time }\end{array}$ & 0 & 0 \\
\hline $\begin{array}{l}\text { f) Beside results, also provide } \\
\text { recommendations }\end{array}$ & 45 & 100 & $\begin{array}{l}\text { Results only indicate if soil is degraded } \\
\text { or not }\end{array}$ & 0 & 0 \\
\hline g) Provide training on how to use the method & 45 & 100 & No training needed, only explanation & 0 & 0 \\
\hline h) Method explanation in native language & 45 & 100 & Language does not matter & 0 & 0 \\
\hline $\begin{array}{l}\text { g) Both men and women should } \\
\text { be able to use the test }\end{array}$ & 45 & 100 & $\begin{array}{l}\text { Does not matter which gender uses the } \\
\text { test }\end{array}$ & 0 & 0 \\
\hline
\end{tabular}


Appendix Table 29. General information of the agricultural professionals surveyed.

\begin{tabular}{|c|c|c|c|c|c|c|}
\hline Gender & Number & \multicolumn{3}{|c|}{ Age (yrs) } & Schooling level & Experience in target \\
\cline { 3 - 6 } & $(\mathrm{N})$ & $\min$ & $\max$ & mean & Bachelor degree & 2 yrs \\
\hline Male & $3(100 \%)$ & 27 & 38 & $31 \pm 6.1$ & $3(100 \%)$ & - \\
Female & - & - & - & - & - & \\
& & & & & & community (yrs) \\
\hline
\end{tabular}

Appendix Table 30. Parameters to define soil quality as identified by agricultural professionals.

\begin{tabular}{lcc}
\hline Criteria of soil quality & Frequency & Percentage (\%) \\
\hline Can protect agricultural ecosystem & 1 & $33.3 \%$ \\
High plant yield & 1 & $33.3 \%$ \\
All of plant can grow well & 1 & $33.3 \%$
\end{tabular}

Appendix Table 31. Criteria or parameters to determine good or bad soils as identified by agricultural professionals.

\begin{tabular}{lcc} 
Characteristics of soil & Frequency & Percentage (\%) \\
\hline Plant yield & 3 & 100 \\
Soil color & 3 & 100 \\
Texture & 3 & 100 \\
\hline
\end{tabular}

Appendix Table 32. Agriculture management practices that "improve" and "reduce" soil quality as identified by agricultural professionals.

\begin{tabular}{lll}
\hline Agriculture management practices & Frequency & Percentage (\%) \\
\hline
\end{tabular}

Improve soil quality

All of management practice that can increase

3

100

plant yield, save the ecosystem, no erosion

Diminish soil quality

All of management practice that cause erosion,

decrease plant yield 
Appendix Table 33. Characteristics of the field test and its evaluation based on its importance as identified by agricultural professionals.

\begin{tabular}{|l|c|c|c|c|c|}
\hline \multicolumn{1}{|c|}{ Aspect or characteristic of the field test } & 1 & 2 & 3 & 5 \\
\hline Test is not expensive & 0 & 0 & 0 & 1 & 2 \\
\hline Test is portable and can be used in the field & 0 & 0 & 0 & 0 & 3 \\
\hline Test reagents are easy available & 0 & 0 & 0 & 1 & 2 \\
\hline Test produce quick results & 0 & 0 & 0 & 1 & 2 \\
\hline Results are easy to interpret & 0 & 0 & 0 & 2 & 1 \\
\hline Results provide management recommendations & 0 & 0 & 0 & 0 & 3 \\
\hline Management recommendations based on the test improve & 0 & 0 & 0 & 1 & 2 \\
\hline agricultural productivity & & & & & 3 \\
\hline Receive training on use and maintenance of the test & 0 & 0 & 0 & 0 & 3 \\
\hline Instructions and training in native language & 0 & 0 & 0 & 3 & 0 \\
\hline Both men and women can use the test & 0 & 0 & 0 & 0 & 3 \\
\hline
\end{tabular}

Note $* 1$ least important, 5 most important

\section{THE PHILIPPINES}

Appendix Table 34. General information on age and schooling level of surveyed farmers.

\begin{tabular}{|c|c|c|c|c|c|c|c|}
\hline & \multicolumn{3}{|c|}{ Age (yrs) } & \multicolumn{3}{|c|}{ School level (n) } & \multirow{2}{*}{$\begin{array}{c}\text { Total } \\
\text { Survey } \\
\text { (n) }\end{array}$} \\
\hline Gender & $\begin{array}{l}\text { Minimal } \\
(y r s)\end{array}$ & $\begin{array}{l}\text { Maximum } \\
(\mathrm{yrs})\end{array}$ & $\begin{array}{c}\text { Average } \\
\text { (yrs) }\end{array}$ & $\begin{array}{c}\text { Elementary } \\
\text { school }\end{array}$ & $\begin{array}{l}\text { High } \\
\text { school }\end{array}$ & College & \\
\hline Men & 20 & 65 & 38.9 & 17 & 2 & 3 & 22.7 \\
\hline Women & 24 & 57 & 39.4 & 10 & 1 & 2 & 13 \\
\hline Total & - & - & 39.1 & 27 & 3 & 5 & 35.7 \\
\hline
\end{tabular}

Appendix Table 35. Percentage of farming activity for surveyed farmers.

\begin{tabular}{|c|c|c|c|}
\hline Livelihood Activity & & $\mathrm{N}$ & Percent $(\%)$ \\
\hline 1. Farming & & 25 & 71.4 \\
\hline 2. Farming and related business & & 5 & 14.3 \\
\hline 3. Work for other farms (employee) & & 5 & 14.3 \\
\hline & Total & 35 & 100 \\
\hline
\end{tabular}


Appendix Table 37. Area of land owned and land farmed among surveyed farmers.

\begin{tabular}{l|cc|cc}
\hline \multirow{2}{*}{ Area (hectares) } & \multicolumn{2}{|c|}{ land owned } & \multicolumn{2}{c}{ land farmed } \\
\cline { 2 - 5 } & $\mathrm{N}$ & $\%$ & $\mathrm{~N}$ & $\%$ \\
\hline 1. Less than 1 hectare & 23 & 65.7 & 30 & 85.7 \\
2. 2-5 hectares & 11 & 31.4 & 4 & 11.4 \\
3. Greater than 5 hectares & 1 & 2.8 & 1 & 2.8 \\
\multicolumn{1}{c|}{ Total } & 35 & 100 & 35 & 100 \\
\hline
\end{tabular}

Appendix Table 38. Percentage livestock owned and crops planted among surveyed farmers.

\begin{tabular}{|c|c|c|c|c|c|}
\hline Livestock owned & $\mathrm{N}$ & $\%$ & Crops planted & $\mathrm{N}$ & $\%$ \\
\hline 1. Cow (1-2 no.) & 9 & 25.7 & Vegetables & 25 & 71.4 \\
\hline 2. Chicken (1-2 no.) & 6 & 17.1 & Fruit & 1 & 2.9 \\
\hline (4-5 no) & 2 & 5.7 & & & \\
\hline (10-20 no) & 2 & 5.7 & & & \\
\hline Total of chicken & 10 & 28.5 & & & \\
\hline 3. Carabao (1-2 no.) & 3 & 8.6 & $\begin{array}{l}\text { Vegetables, and } \\
\text { Fruit }\end{array}$ & 5 & 14.3 \\
\hline 4. Goats (1-2 no.) & 2 & 5.7 & Vegetables, and & 1 & 2.9 \\
\hline (10 no) & 1 & 2.9 & Flower & & \\
\hline Total of goats & 3 & 8.6 & & & \\
\hline 5. Horse (1-2 no.) & 2 & 5.7 & Vegetable, and tree & 1 & 2.9 \\
\hline 6. Pig (1-2 no.) & 2 & 5.7 & Tree, and fruit & 1 & 2.9 \\
\hline 7. Sheep & 1 & 2.9 & $\begin{array}{l}\text { Vegetable, tree, and } \\
\text { fruit }\end{array}$ & 1 & 2.9 \\
\hline 8. Geese & 1 & 2.9 & & & \\
\hline 9. None & 15 & 42.9 & & & \\
\hline
\end{tabular}


Appendix Table 39. Percent of types and characteristics of soil as identified by surveyed farmers.

\begin{tabular}{|c|c|c|c|c|c|c|c|}
\hline \multirow[b]{2}{*}{ Types of soils } & \multicolumn{5}{|c|}{ Characteristics of soil } & \multirow[b]{2}{*}{$\mathrm{N}$} & \multirow[b]{2}{*}{ Percent } \\
\hline & color & texture & drainage & fertility & weight & & \\
\hline Clay soil, loamy & $\begin{array}{l}\text { dark to } \\
\text { yellowish }\end{array}$ & $\begin{array}{l}\text { fine } \\
(\mathrm{n}=1)\end{array}$ & good & medium & heavy & 1 & 2.7 \\
\hline Clayey soil & reddish & $\begin{array}{l}\text { fine } \\
(n=1)\end{array}$ & moderate & low & heavy & 1 & 2.7 \\
\hline $\begin{array}{l}\text { Reddish soil } \\
\text { (unfertile soil) }\end{array}$ & reddish & $\begin{array}{l}\text { fine } \\
(\mathrm{n}=14) \\
\text { medium } \\
(\mathrm{n}=3) \\
\text { coarse } \\
(\mathrm{n}=3)\end{array}$ & $\begin{array}{l}\text { good } \\
(\mathrm{n}=3) \\
\text { moderate } \\
(\mathrm{n}=2) \\
\text { poor } \\
(\mathrm{n}=15)\end{array}$ & low & $\begin{array}{l}\text { light } \\
(n=3) \\
\text { heavy } \\
(n=17)\end{array}$ & 20 & 57.1 \\
\hline $\begin{array}{l}\text { Dark soil } \\
\text { (fertile soil) }\end{array}$ & black & $\begin{array}{l}\text { medium } \\
(n=6) \\
\text { coarse } \\
(n=1)\end{array}$ & good & high & $\begin{array}{l}\text { light } \\
(n=1) \\
\text { moderate } \\
\text { ly heavy } \\
(n=6)\end{array}$ & 7 & 20 \\
\hline $\begin{array}{l}\text { some reddish soil, } \\
\text { some dark soil }\end{array}$ & $\begin{array}{l}\text { some } \\
\text { reddish, } \\
\text { some dark }\end{array}$ & $\begin{array}{l}\text { fine } \\
(\mathrm{n}=1) \\
\text { fine } \\
\text { and } \\
\text { medium }(\mathrm{n}= \\
5)\end{array}$ & $\begin{array}{l}\text { good } \\
(n=1) \\
\text { good } \\
\text { and poor } \\
(n=5)\end{array}$ & $\begin{array}{l}\text { low } \\
(\mathrm{n}=1) \\
\text { low and } \\
\text { high } \\
(\mathrm{n}=5)\end{array}$ & $\begin{array}{l}\text { heavy } \\
(\mathrm{n}=1) \\
\text { moderate } \\
\text { ly heavy } \\
(\mathrm{n}=5)\end{array}$ & 6 & 17.1 \\
\hline
\end{tabular}

Appendix Table 40. Suitable crops for different types of soil as identified by farmers.

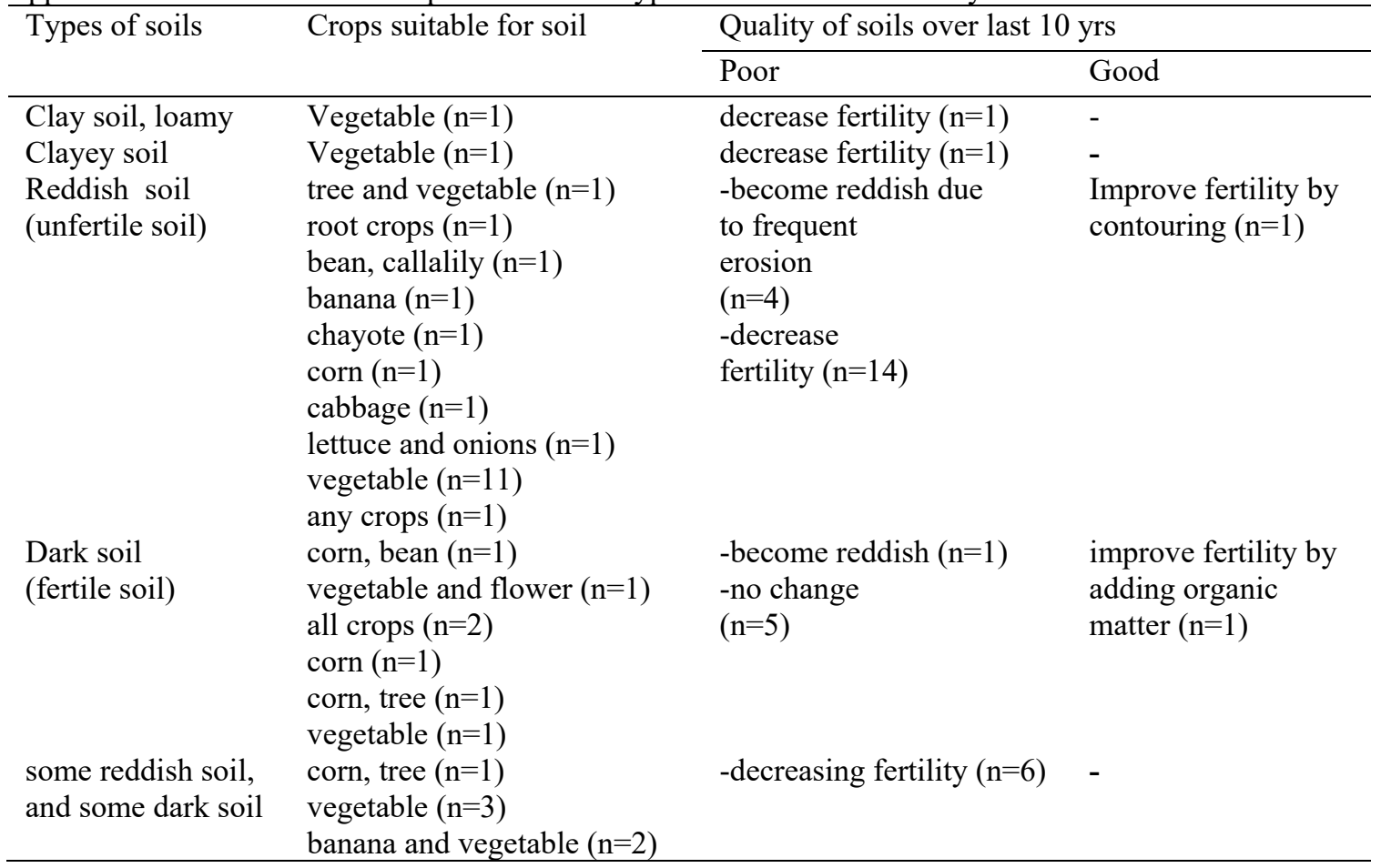


Appendix Table 41. Definition of soil quality and characteristic of soil quality "good or bad soils" as identified by farmers.

\begin{tabular}{|c|c|c|c|c|c|}
\hline Definition & weight point & Good & weight point & $\mathrm{Bad}$ & weight point \\
\hline $\begin{array}{l}\text { 1. good planted growth, } \\
\text { even though no } \\
\text { fertilizer are applied }\end{array}$ & 23 & $\begin{array}{l}\text { 1. good planted growth an } \\
\text { high yield }\end{array}$ & 61 & 1.poor plant growth & 47 \\
\hline \multirow[t]{5}{*}{$\begin{array}{l}\text { 2.black color, no need } \\
\text { fertilizer }\end{array}$} & \multirow[t]{5}{*}{12} & 2. dark in color & 59 & 2. reddish in color & 46 \\
\hline & & 3. not prone to erosion & 11 & 3. prone to erosion & 14 \\
\hline & & 4. well-drained & 9 & 4. need Frazer & 10 \\
\hline & & 5. organic matter content & 2 & 5. poor drain & 6 \\
\hline & & & & 6. wormgrass & 2 \\
\hline
\end{tabular}

Appendix Table 42. Management practices that "improve" and "reduce" soil quality as identified by surveyed farmers.

\begin{tabular}{lc|lc}
\hline \multicolumn{1}{c|}{ Improving soil quality } & \multicolumn{2}{c}{ Reducing soil quality } \\
\hline \multicolumn{1}{c|}{ Factor } & weight point & \multicolumn{1}{c}{ Factor } & weight point \\
\hline 1. Contour farming & 76 & 1. Continuous cultivation & 50 \\
2. Organic farming & 48 & 2. No contouring & 34 \\
3. Liming & 7 & 3.Continuous use of & 19 \\
& & inorganic fertilizer & \\
4. Fallows & 6 & 4. Frequent rainfall & 12 \\
5. Apply chicken dung & 5 & 5. Frequent soil erosion & 10 \\
6.Planting grass and crops to prevent & 4 & & \\
soil loose & & & \\
7. Soil conservation practices & 2 & & \\
\hline
\end{tabular}

Appendix Table 43. The reason of soil quality improving or reducing $(\mathrm{N}=35)$ as identified by surveyed farmers.

\begin{tabular}{lcc|lcr}
\hline \multicolumn{1}{c}{ Improving } & Frequency & $\%$ & \multicolumn{1}{c}{ Reducing } & Frequency & $\%$ \\
\hline 1. organic farming & 4 & 11.4 & $\begin{array}{l}\text { 1. continuous cultivation, and } \\
\text { became old soil } \\
\text { 2. continuous use inorganic } \\
\text { fertilizer }\end{array}$ & 2 & 11 \\
2. not always cultivating & 1 & 2.9 & $\begin{array}{l}\text { 3. decreasing fertility and soil } \\
\text { become acidic }\end{array}$ & 6 & 17.1 \\
3. contouring & 1 & 2.9 & $\begin{array}{l}\text { 4. flooding and soil erosion } \\
\text { 5. they don't know why I soil } \\
\text { quality is reduced }\end{array}$ & 5 & 11.4 \\
4. fallowing & 1 & 2.4 & 14.4 \\
\hline
\end{tabular}

* no change in soil quality 3 farmers 
Appendix Table 44. The reasons why farmers used a portable soil test to measure soil quality

\begin{tabular}{lcc}
\hline Farmer's reasons & Frequency & Percentage \\
\hline to bring back the soil to its original fertility & 7 & 20 \\
to determine exact application of nutrients & 1 & 2.85 \\
to determine the right fertilizer to be applied & 14 & 40 \\
to know the right practice to increase yield & 8 & 22.85 \\
to know whether the soil is acidic or not & 4 & 11.43 \\
to know what plants are suitable in the area & 1 & 2.85 \\
\hline
\end{tabular}

Appendix Table 45. Desirable characteristics of the soil test method.

\begin{tabular}{|c|c|c|c|c|c|}
\hline Characteristics of the test & Frequency & $\%$ & or & Frequency & $\%$ \\
\hline a)You can use it in your plots & 13 & 37.1 & $\begin{array}{l}\text { Only agronomists or } \\
\text { professionals working in the } \\
\text { communities can use it }\end{array}$ & 22 & 62.9 \\
\hline $\begin{array}{l}\text { b) Portable technique or equipment and easy-to- } \\
\text { use (light and small) }\end{array}$ & 13 & 37.1 & $\begin{array}{l}\text { Neither size or weight } \\
\text { matter, if works }\end{array}$ & 22 & 62.9 \\
\hline c) Not expensive & 23 & 65.1 & $\begin{array}{l}\text { Price does not matter, if } \\
\text { works }\end{array}$ & 12 & 34.3 \\
\hline d) You can understand and interpret the results & 4 & 11.4 & $\begin{array}{l}\text { Results needs to be interpret } \\
\text { by a professional }\end{array}$ & 31 & 88.8 \\
\hline e) Quick results & 3 & 8.57 & $\begin{array}{l}\text { It is not important if results } \\
\text { take longer time }\end{array}$ & 32 & 91.4 \\
\hline f) Beside results, also provide recommendations & 21 & 60 & $\begin{array}{l}\text { Results only indicate if soil } \\
\text { is degraded or not }\end{array}$ & 14 & 40 \\
\hline g) Provide training on how to use the method & 10 & 25.6 & $\begin{array}{l}\text { No training needed, only } \\
\text { explanation }\end{array}$ & 25 & 71.4 \\
\hline h) Method explanation in native lan & 15 & 42.8 & Language does not matter & 20 & 57.1 \\
\hline $\begin{array}{l}\text { g) Both men and women should be able to use the } \\
\text { test }\end{array}$ & 11 & 31.4 & $\begin{array}{l}\text { Does not matter which } \\
\text { gender uses the test }\end{array}$ & 24 & 68.6 \\
\hline
\end{tabular}

Appendix Table 46. Gender, age and schooling level of the agricultural professionals surveyed.

\begin{tabular}{cccccc}
\hline Gender & Number & \multicolumn{2}{c}{ Age (yrs) } \\
& $(\mathrm{N})$ & $\min$ & $\max$ & mean & Bachelor degree \\
\hline Male & 6 & 24 & 62 & 41.2 & $6(100 \%)$ \\
Female & 6 & 23 & 64 & 46.7 & $6(100 \%)$ \\
Total & 12 & 23 & 64 & 43.9 & $12(100 \%)$ \\
\hline
\end{tabular}


Appendix Table 47. Work experience of the surveyed agricultural professionals in present job and in target community.

\begin{tabular}{cc|cc}
\hline \multicolumn{5}{c}{ Work Experience } \\
\hline In presented job (yr) & $\mathrm{N}(\%)$ & In the community & $\mathrm{N}(\%)$ \\
$<5 \mathrm{yr}$ & $4(33.3 \%)$ & $<5 \mathrm{yr}$ & $4(33.3 \%)$ \\
$5-10 \mathrm{yr}$ & $1(8.3 \%)$ & $5-10 \mathrm{yr}$ & $3(25 \%)$ \\
$11-15 \mathrm{yr}$ & $2(16.7 \%)$ & $11-15 \mathrm{yr}$ & $1(8.3 \%)$ \\
$16-20 \mathrm{yr}$ & $1(8.3 \%)$ & $16-20 \mathrm{yr}$ & $1(8.3 \%)$ \\
$21-25 \mathrm{yr}$ & $2(16.7 \%)$ & $21-25 \mathrm{yr}$ & $1(8.3 \%)$ \\
$26-30 \mathrm{yr}$ & $2(16.7 \%)$ & $26-30 \mathrm{yr}$ & $2(16.7 \%)$ \\
\hline total & $12(100 \%)$ & total & $12(100 \%)$ \\
\hline
\end{tabular}

Appendix Table 48. Home places and places where the agricultural professionals were surveyed.

\begin{tabular}{|c|c|c|c|}
\hline \multicolumn{4}{|c|}{ Addresses } \\
\hline Home Places & frequency & Where grew up (city, town, farm etc) & frequency \\
\hline $\begin{array}{l}\text { Dalwangan, Malaybalay } \\
\text { City }\end{array}$ & $\begin{array}{c}2 \\
(16.7 \%)\end{array}$ & $\begin{array}{c}\text { Aglayan, Malaybalay City (Barangay) } \\
\text { Dalwangan, Malaybalay City } \\
\text { (barangay/village) }\end{array}$ & $\begin{array}{c}1 \\
(8.3 \%) \\
1 \\
(8.3 \%)\end{array}$ \\
\hline $\begin{array}{l}\text { Bantuanon, Lantapan, } \\
\text { Bukidnon }\end{array}$ & $\begin{array}{c}1 \\
(8.3 \%)\end{array}$ & $\begin{array}{c}\text { Poblacion, Lantapan, Bukidnon } \\
\text { (town) }\end{array}$ & $\begin{array}{c}1 \\
(8.3 \%)\end{array}$ \\
\hline $\begin{array}{l}\text { Alanib, Lantapan, } \\
\text { Bukidnon }\end{array}$ & $\begin{array}{c}1 \\
(8.3 \%)\end{array}$ & $\begin{array}{l}\text { Alanib, Lantapan, Bukidnon } \\
\text { (barangay/village) }\end{array}$ & $\begin{array}{c}1 \\
(8.3 \%)\end{array}$ \\
\hline Lantapan, Bukidnon & $\begin{array}{c}1 \\
(8.3 \%)\end{array}$ & $\begin{array}{r}\text { Magsaysay, Davao del Sur } \\
\text { (town) }\end{array}$ & $\begin{array}{c}1 \\
(8.3 \%)\end{array}$ \\
\hline Mailag, Valencia City & $\begin{array}{c}1 \\
(8.3 \%)\end{array}$ & $\begin{array}{l}\text { Mailag, Valencia City } \\
\text { (town) }\end{array}$ & $\begin{array}{c}1 \\
(8.3 \%)\end{array}$ \\
\hline Linabo, Malaybalay City & $\begin{array}{c}1 \\
(8.3 \%)\end{array}$ & $\begin{array}{l}\text { Linabo, Malaybalay City } \\
\text { (farm/village) }\end{array}$ & $\begin{array}{c}1 \\
(8.3 \%)\end{array}$ \\
\hline $\begin{array}{l}\text { Poblacion, lantapan, } \\
\text { Bukidnon }\end{array}$ & $\begin{array}{c}1 \\
(8.3 \%)\end{array}$ & $\begin{array}{c}\text { Lantapan, Bukidnon } \\
\text { (barangay/village) }\end{array}$ & $\begin{array}{c}1 \\
(8.3 \%)\end{array}$ \\
\hline $\begin{array}{l}\text { Balila, Lantapan, } \\
\text { Bukidnon }\end{array}$ & $\begin{array}{c}1 \\
(8.3 \%)\end{array}$ & $\begin{array}{l}\text { Linabo, Malaybalay City } \\
\text { (farm/village) }\end{array}$ & $\begin{array}{c}1 \\
(8.3 \%)\end{array}$ \\
\hline Malaybalay City & $\begin{array}{c}1 \\
(8.3 \%)\end{array}$ & $\begin{array}{l}\text { Malaybalay City } \\
\text { (city) }\end{array}$ & $\begin{array}{c}1 \\
(8.3 \%)\end{array}$ \\
\hline Valencia City & $\begin{array}{c}1 \\
(8.3 \%)\end{array}$ & $\begin{array}{l}\text { Lantapan, Bukidnon } \\
\text { (town) }\end{array}$ & $\begin{array}{c}1 \\
(8.3 \%)\end{array}$ \\
\hline $\begin{array}{l}\text { Kulasihan, Lantapan, } \\
\text { Bukidnon }\end{array}$ & $\begin{array}{c}1 \\
(8.3 \%)\end{array}$ & $\begin{array}{c}\text { Kulasihan, Lantapan, Bukidnon } \\
\text { (farm/village) }\end{array}$ & $\begin{array}{c}1 \\
(8.3 \%)\end{array}$ \\
\hline
\end{tabular}

Appendix Table 49. The level of speaking language of the agricultural professional as same as in the community.

\begin{tabular}{lc}
\hline \multicolumn{1}{c}{ The level of speaking language } & $\mathrm{N}(\%)$ \\
\hline None & $2(16.7 \%)$ \\
Yes & $9(75 \%)$ \\
Basic & $7(58.3 \%)$ \\
Intermediate & $1(8.3 \%)$ \\
Native & $1(8.3 \%)$ \\
Missing & $1(8.3 \%)$ \\
\hline total & $12(100 \%)$ \\
\hline
\end{tabular}


Appendix Table 50. Parameters to define soil quality as identified by agricultural professionals.

\begin{tabular}{lc}
\hline Criteria of soil quality & Frequency $(\%)$ \\
\hline soil that produces good harvest and good yield & $5(41.7 \%)$ \\
plants that grow vigorously and good yield & $2(16.7 \%)$ \\
good harvest without fertilizer application & $1(8.3 \%)$ \\
capable in supplying plants needs & $1(8.3 \%)$ \\
optimum yield with a lesser cost and low input & $2(16.7 \%)$ \\
no answer & $1(8.3 \%)$ \\
\hline Total & $12(100 \%)$ \\
\hline
\end{tabular}

Appendix Table 51. Criteria or parameters to determine good or bad soils as identified by agricultural professionals.

\begin{tabular}{lcc}
\hline \multicolumn{1}{c}{ Good soil } & Frequency & Percent \\
\hline Gives higher yield or good harvest & 8 & 66.7 \\
Higher organic matter content & 4 & 33.3 \\
High soil-water holding capacity & 3 & 25 \\
Dark or black color & 2 & 16.7 \\
Contain more nutrients & 2 & 16.7 \\
Well drained & 3 & 25 \\
Free from borne diseases & 2 & 16.7 \\
Good texture & 3 & 25 \\
Good structure & 2 & 16.7 \\
Good appearance & 1 & 8.3 \\
Favorable pH & 1 & 8.3 \\
\hline
\end{tabular}

Appendix Table 52. Agricultural management practices that "improve" soil quality as identified by agricultural professionals.

\begin{tabular}{lcc}
\hline Practices & Frequency & Percentage \\
\hline Chemical fertilizers and "natural" fertilizers & 9 & 75 \\
Contour farming & 6 & 50 \\
Crop rotation/ intercropping & 5 & 41.7 \\
Liming & 6 & 50 \\
Green manuring & 4 & 33.3 \\
Put permanent crop in slope land & 1 & 8.3 \\
Drainage & 1 & 8.3 \\
Grow the good uptake plant-nutrient & 1 & 8.3 \\
Fertility amendment & 1 & 8.3 \\
Soil conservation & 1 & 8.3 \\
\hline Total & 42 & 100 \\
\hline
\end{tabular}


Appendix Table 53. Agricultural management practices that "reduce" soil quality as identified by agricultural professionals.

\begin{tabular}{lcc}
\hline Practices & Frequency & Percentage \\
\hline Excessive use of inorganic fertilizer & 12 & 100 \\
No fallow periods & 3 & 25 \\
Continuous mono-cropping & 3 & 25 \\
No liming & 1 & 8.3 \\
Application of chemical & 3 & 25 \\
No soil conservation & 1 & 8.3 \\
Up and down plowing system & 1 & 8.3 \\
\hline
\end{tabular}

Appendix Table 54. The major constraints for soil testing as identified by agricultural professionals.

\begin{tabular}{llc} 
& \multicolumn{1}{c}{ Major constraints } & Weighting point \\
\hline 1. & Lack information or few soil test kits available & $7(58.3 \%)$ \\
2. & Soil testing is expensive & $6(50 \%)$ \\
3. & Lack of interest & $4(33.3 \%)$ \\
4. & Taking longer time & $2(16.7 \%)$ \\
5. & Laziness & $2(16.7 \%)$ \\
\hline
\end{tabular}

Appendix Table 55. Desirable characteristics of the soil test and its evaluation based on its importance as identified by agricultural professionals.

\begin{tabular}{|l|c|c|c|c|c|}
\hline \multicolumn{1}{|c|}{ Aspect or characteristic of the test Rank } & 1 & 2 & 3 & 4 & 5 \\
\hline Test is not expensive & 0 & 1 & 2 & 2 & 7 \\
\hline Test is portable and can be used in the field & 0 & 0 & 1 & 6 & 5 \\
\hline Test reagents are easy available & 0 & 0 & 2 & 5 & 5 \\
\hline Test produce quick results & 0 & 0 & 4 & 4 & 4 \\
\hline Results are easy to interpret & 0 & 0 & 3 & 2 & 7 \\
\hline Results provide management recommendations & 0 & 0 & 2 & 2 & 8 \\
\hline $\begin{array}{l}\text { Management recommendations based on the test } \\
\text { improve agricultural productivity }\end{array}$ & 0 & 0 & 2 & 4 & 6 \\
\hline Receive training on use and maintenance of the test & 1 & 0 & 3 & 1 & 7 \\
\hline Instructions and training in native language & 1 & 0 & 5 & 2 & 4 \\
\hline Both men and women can use the test & 0 & 0 & 1 & 2 & 9 \\
\hline
\end{tabular}

Note * 1 least important, 5 most important 


\section{VITA}

Bunjirtluk Jintaridth was born on May 6, 1963 in Bangkok, Thailand. She received a B.S. degree in Agriculture from Kasetsart University, Thailand in May, 1985. She also obtained an M.Sc.in Soil Science and Plant Nutrition from Wageningen Agricultural University, The Netherlands in July, 1996. After finishing her degree, she went back to work as a researcher in 1996 in the Department of Land Development, Thailand. Her work addresses acid sulfate soil management in Thailand. After that, in 2005, she had the opportunity to improve her academic education in the United States to pursue a Ph.D. degree in soil science at the University of Columbia-Missouri with a fellowship from the Royal Thai Government. In 2008, she received a research assistantship from the University of Missouri-Columbia as a part of an U.S. Agency for International Development-sponsored international research project in which she was involved. After continuous learning and enjoying the beauty of Columbia, Missouri, she is planning to graduate in December, 2017 and will return to Thailand to continue her agricultural research activities in the Department of Land Development, Ministry of Agricultural and Cooperatives, in Bangkok, Thailand. 